\title{
HEI TIKI: HE WHAKAMĀRAMA HŌU
}

By

DOUGAL REX AUSTIN

\begin{abstract}
A thesis
submitted to the Victoria University of Wellington

in fulfilment of the requirements for the degree of
\end{abstract}

Master of Arts in Māori Studies

Victoria University of Wellington

2014 


\section{Abstract}

This thesis addresses the problem that while hei tiki are the most culturally iconic of Māori adornments, there still remains much uncertainty concerning their origins, lineage of development and cultural use. A collections-based study investigates these areas of uncertainty in search of new mana-enhancing understandings.

A position developed in the review is that hei tiki were probably highly developed stylistically from the outset to conform to adze-shaped pieces of pounamu, with the common hei tiki style likely appearing and rising to prominence quickly. A case is argued for local conventions of style exerting an early and ongoing influence upon the stylistic diversity and development of hei tiki, with a close relationship with wood carving appearing likely. The mana of hei tiki derived from the agency of prolonged ancestral use is investigated in relation to the view that, while hei tiki making and use probably reached their height in the early $19^{\text {th }}$ century, a significant portion may have been made as European trade items. The manifestation of indigenous agency is a reoccurring theme investigated in this thesis and is argued to have implications for the mana of hei tiki.

Features of hei tiki belonging to the early contact period 1769-1777 and to a general sample of 50 hei tiki from the Te Papa collection were recorded and enabled shape, style, pounamu and wear analysis.

The results indicate that by 1769-1777 the adze shape was common amongst hei tiki, the most common style predominated, conventional proportions and most of the stylistic features apparently common to hei tiki in general had been established. Supporting evidence is found for a trend of increasing hei tiki size over time, and for hei tiki making and use having peaked in the early $19^{\text {th }}$ century. Shape-to-size analysis also indicates early origins and continuity for the adze-shaped hei tiki. Furthermore pounamu and wear analysis results indicate that hei tiki continued to be used primarily by Māori. Overall the results are interpreted as supporting or being consistent with the arguments developed in the literature review and they are held to be mana-enhancing for hei tiki. 


\section{Acknowledgements}

Firstly I thank my supervisor Associate Professor Peter Adds for his encouragement, sound guidance and enduring patience throughout the process of my researching and writing this thesis. I feel lucky to have had the benefit of such wise counsel. I acknowledge the significant support of Dame Claudia Orange, who enabled my research to be undertaken within the parameters of scholarship and mātauranga Māori at Te Papa Tongarewa. I acknowledge Arapata Hakiwai and Rhonda Paku for their support and advice and the support also of colleagues Matiu Baker, Awhina Tamarapa, and Puawai Cairns, who sometimes picked up work which I was unable to do due to thesis commitments. Special recognition is due to the awesome Martin Lewis from Te Aka Matua Library for locating many a book and article for my research. I acknowledge also the authorities Russell Beck, Ānaru Rondon, Janet Davidson and Atholl Anderson who kindly offered advice and significant insights.

Sincere gratitude is extended to the following international institutions and their staff who obligingly responded to my inquiries into the Cook voyage hei tiki held in their collections and who often waived reproduction charges for use of the images: The Royal Collection Trust, London, in particular Agata Rutkowska, The Pitt Rivers Museum, Oxford, in particular Jeremy Coote, The Field Museum, Chicago, in particular John Terrell and Christopher J. Philipp, and The Kunsthistorisches Museum, Vienna, in particular Gabriele Weiss and Ilse Jung.

Finally, as it is not always easy balancing commitments of whānau and study, I acknowledge my sons Manaia and Hāwea. Thank you for contributing in your own important way. 


\section{Table of Contents}

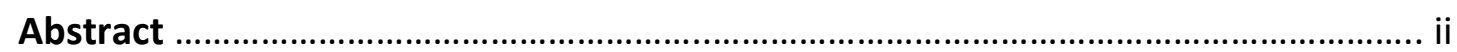

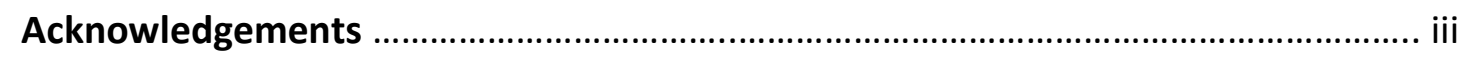

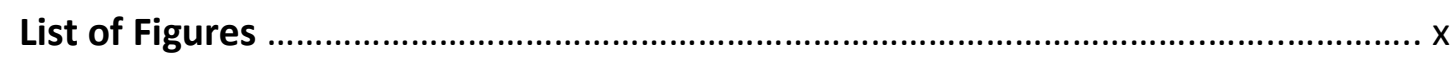

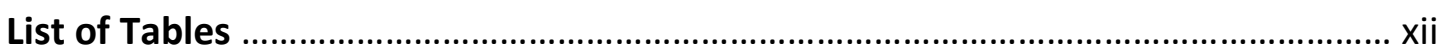

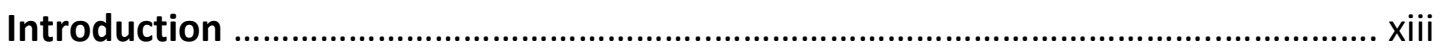

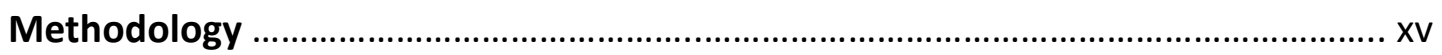

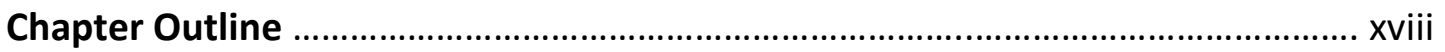

\section{Chapter One: Hei Tiki Origins}

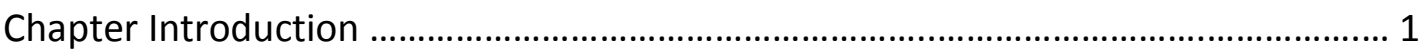

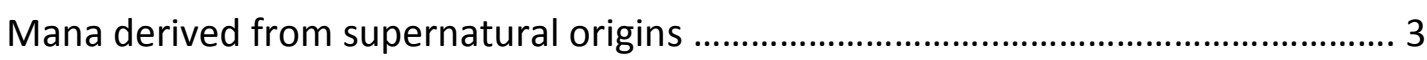

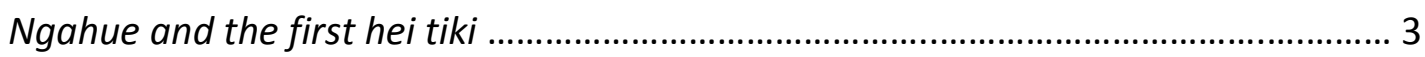

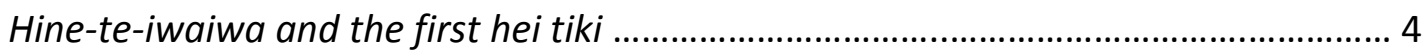

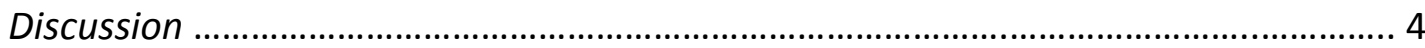

The lack of direct archaeological evidence ................................................................. 5

Whareakeake ('Murdering Beach'), Otago; Imperial site number S164/16 ............... 5

Oruarangi, Hauraki; Imperial site number N49/28 ................................................. 6

Pā Bay, Banks Peninsula, Canterbury; Imperial site number S85/23 ......................... 7

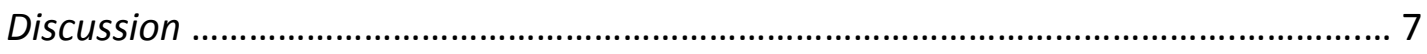

Evidence from the wider archaeologically supported picture .................................. 7 
Assessment of evidence for earlier hei tiki of softer and less durable materials ..... 10

Historical evidence for early hei tiki made from perishable materials ...................... 10

A bone tiki pendant from Kohika, Bay of Plenty ......................................................... 10

Skinner's hypothesised bone hei tiki ......................................................................... 10

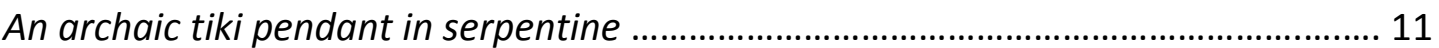

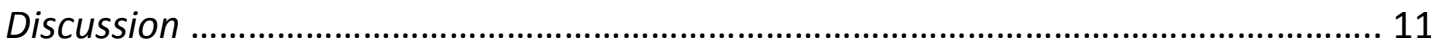

Arguments for the stylistic appearance of early hei tiki of pounamu ....................... 12

Assessing the argument for the influence of wood carving imagery ......................... 12

Developments in pounamu working and the origins of hei tiki ................................. 15

Argument for pounamu working methods favouring the common style

of hei tiki from an early date

Critical review of the proposed influence of European trade

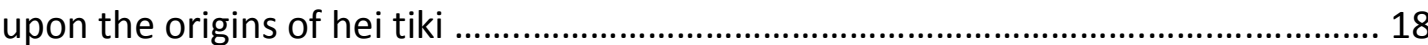

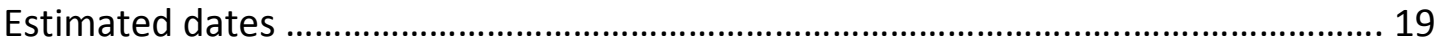

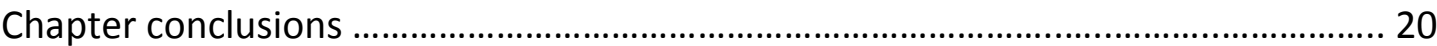

Chapter Two: The Development of Stylistic Variation in Hei Tiki

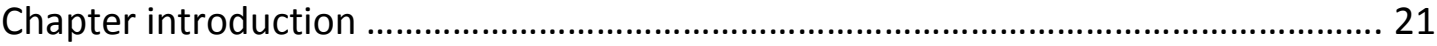

Influence of local artistic convention upon the stylisation of hei tiki ......................... 22

Probable influence of local conventions upon early diversity of styles ........................ 22

Indoctrination into the crafting of culturally acknowledged forms ............................. 22

The argument for a trend of increasing size of hei tiki ................................................... 23 
Evidence for the influence of regional wood carving

styles upon regional styles of hei tiki

Hei tiki making: - work requiring a high level of skill and dedication ...... 25

Moderating constraints imposed by the toughness of pounamu and the small size of hei tiki

Hei tiki style types 26

Two main style types 26

Other minor style types 27

Evidence for restricted regional distribution of the type II style 28

Chapter conclusions 29

Chapter Three: Māori Agency in the Popularity and Use of Hei Tiki

Chapter introduction 30

An investigation into the increasing supply of pounamu 31

Increase in pounamu supply from South Island sources 31

The transition to metal tools and the freeing up of pounamu adze blades 32 Increasing skill base for hei tiki making 33

The increasing demand for hei tiki; For traditional use, or as European trade items?

Indigenous agency in the making of hei tiki for trade to Europeans, but diminished ancestral status

An investigation into the mana of hei tiki derived from ancestral association 
He oha tupuna - ancestral heirloom 36

An argument for ancestral lineage sometimes extending from owners of adze blades

He tohu rangatira - symbol of chiefly rank

Focus for grief 37

Burial good status 38

Fertility and child birth talisman 38

Kaitiaki - protector against misfortune and witchcraft 38

Discussion

Chapter conclusions 39

Chapter Four: Hei tiki Research Project - Rational, Methods and Techniques

Chapter introduction 40

Selection methods and techniques 41

Identification of early contact period hei tiki in collections 41

Identification of drawings of additional early contact period hei tiki

Identification of the general selection of hei tiki

from the Te Papa collection 45

Recording methods and techniques 48

Recording on tables 48

Hei tiki shapes 49

Hei tiki style types 51

Dimensions 51 
Proportions

Body scan

Pounamu

Wear 54

Chapter Five: Hei Tiki Research Project - Analysis of Recorded Features

Chapter introduction 55

PART ONE - Hei tiki shape analysis 57

Group one 57

Group two 57

Discussion 57

PART TWO - comparative analysis of recorded stylistic features 58

Prevalence of style type I 59

List of shared stylistic features 59

List of unshared stylistic features 64

Discussion 64

PART THREE - investigating supporting evidence for

a trend of increasing hei tiki size over time 66

Interpretation of figure 16 67

PART FOUR - hei tiki shape categories and proportional numbers

of hei tiki assessed against a scale of increasing hei tiki size 68

Interpretation of figure 17 68

PART FIVE - assessing hei tiki use through pounamu and wear analysis 69 
Pounamu analysis 69

Interpretation of pounamu analysis findings 70

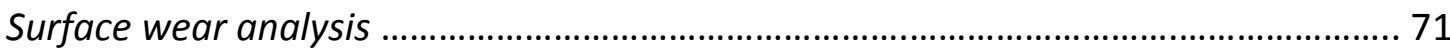

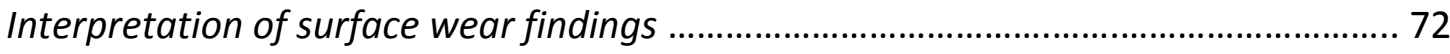

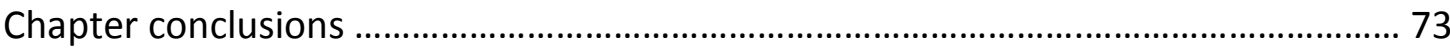

\section{Chapter Six: General Conclusions}

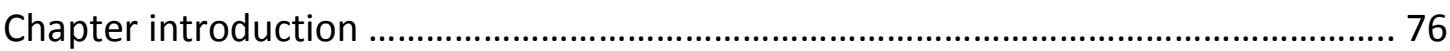

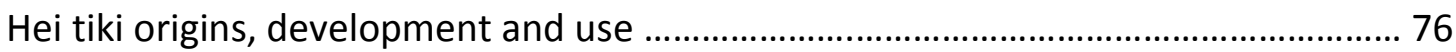

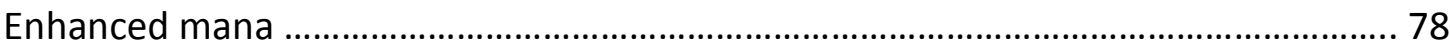

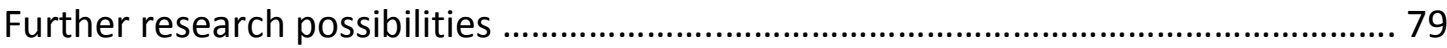

Appendix One: Hei Tiki Research Project - Recorded Features

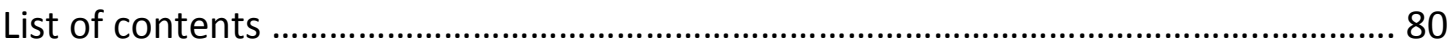

The Group One Assemblage - early contact period hei tiki .......................................... 81

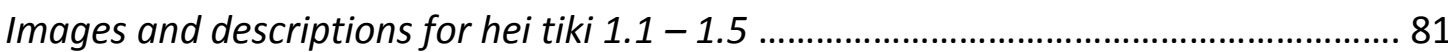

Drawings and descriptions of three hei tiki from

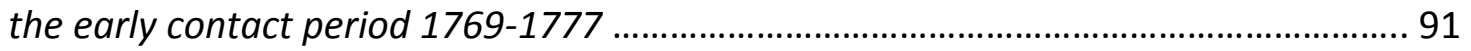

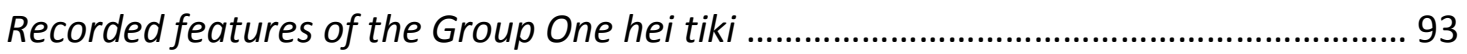

The Group Two Assemblage - general selection from the Te Papa collection ............ 95

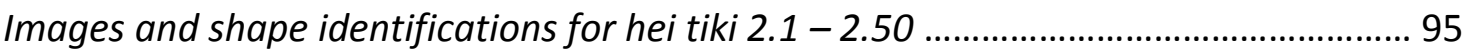

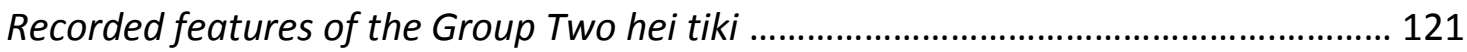

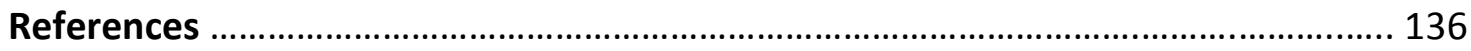




\section{List of Figures}

Figure 1 Tiki pendant from Waitati Valley, Otago ..................................................... 11

Figure 2 An 18th century poupou carving …......................................................... 13

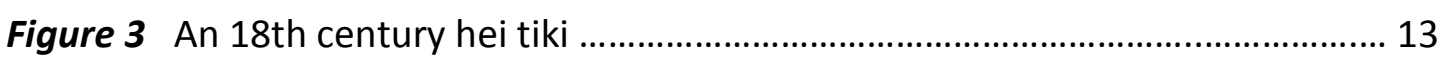

Figure 4 Variety B after Skinner (1932: Plate A, 207,208) ........................................ 18

Figure 5 Drawing of hei tiki from Doubtless Bay .................................................... 43

Figure 6 Drawing of hei tiki from Mahia Peninsula .................................................. 43

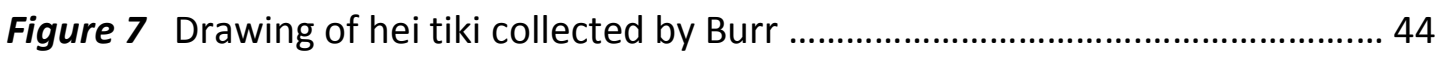

Figure 8 Examples of remnant saw scarves on back of heads to start holes ........... 46

Figure 9 Examples of remnant saw scarves on edges of hei tiki .............................. 46

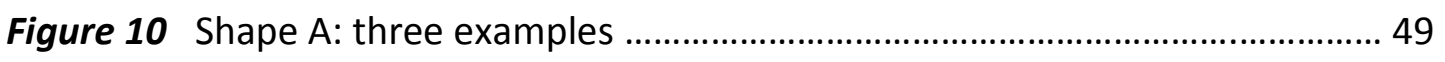

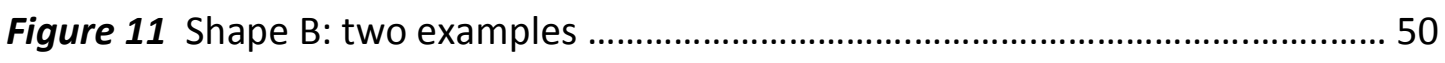

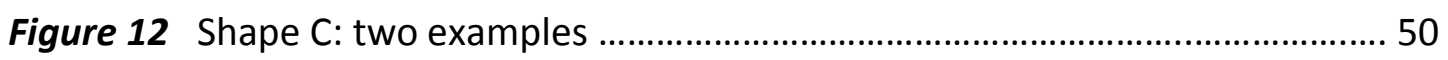

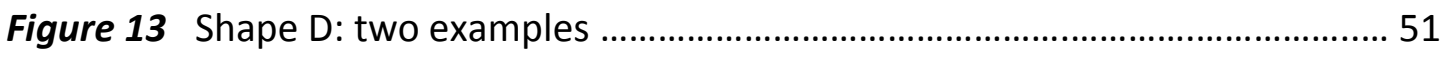

Figure 14 Technique for measuring head, body, and leg proportions ................... 52

Figure 15 Technique for measuring angle of head tilt ............................................ 53

Figure 16 Recorded mean wear in relation to size ranges ...................................... 67

Figure 17 Numbers of hei tiki belonging to different size ranges and

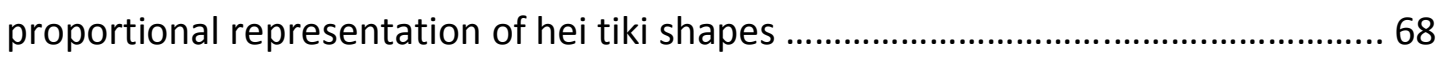

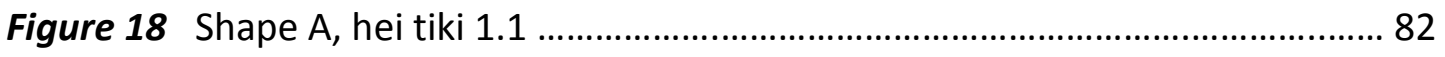

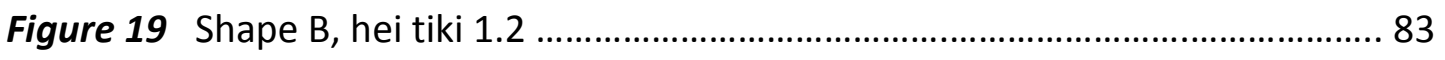


Figure 20 Shape C, hei tiki 1.3 85

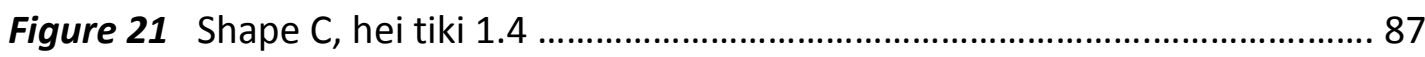

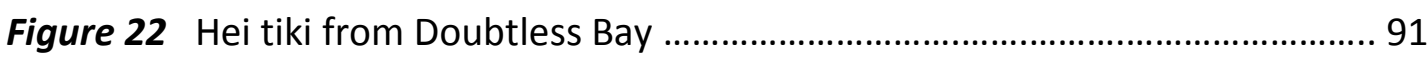

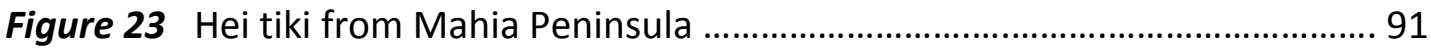

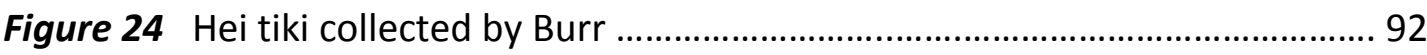




\section{List of Tables}

Table 1 - Numbers of hei tiki in group two belonging to

different recorded wear categories

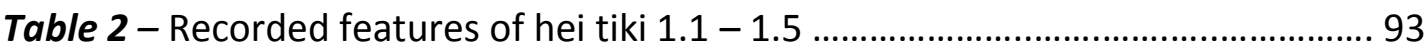

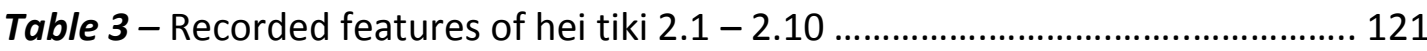

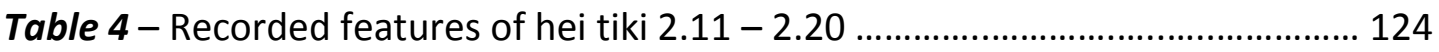

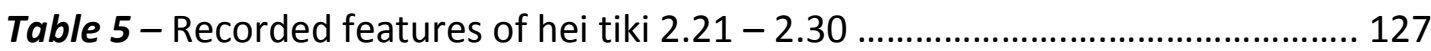

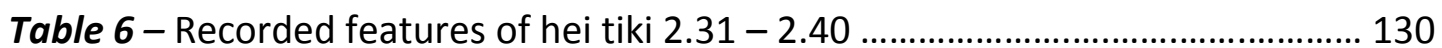

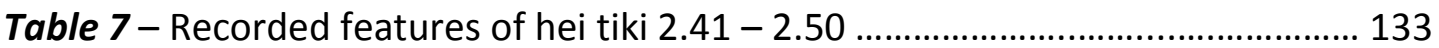




\section{Introduction}

Of all Māori personal adornments hei tiki are the most famous, highly prized and culturally iconic; yet as familiar as they are much uncertainty still surrounds the origins of hei tiki, their lineage of development and cultural use.

A new approach to the study of hei tiki is taken in this thesis, which investigates how the mana of hei tiki may be enhanced through a collections-based study into their origins, stylistic development and use. A comparative study is made, which is anchored on one end by a study group comprised of hei tiki in overseas collections, with known provenance to the early contact period 1769-1777. The recorded features of this group are compared with those of a larger general selection of hei tiki from the collection of the Museum of New Zealand Te Papa Tongarewa (Te Papa).

The investigation first seeks to reveal new understandings of the origins of hei tiki and their likely early stylisation. This investigation assesses the influence of 'pre-contact' tiki pendants, pounamu working methods and practices - including the importance of the adzeshape, - and the influence of wood carving traditions. Attaining such an understanding provides a point of reference against which to investigate later developments. Stylistic diversity amongst hei tiki is then explored, including an investigation into influences which saw styles maintained and progressively changed over time. Questions into the nature and extent of post-contact influences upon the popularity and stylistic development of hei tiki are explored. Developments in the early $19^{\text {th }}$ century receive particularly close attention as the majority of hei tiki are thought to date from this period and because the influences of European trade and collecting upon hei tiki are asserted in some of the literature to have been considerable (Groube 1964, 1967).

The role of indigenous agency in accounting for the origins, stylistic development, popularity and use of hei tiki, is a common theme throughout this thesis. The agency of Māori in the developmental lineage and use of hei tiki is seen as being closely aligned to the mana of hei tiki as an iconic taonga-tuku-iho 'treasured heirloom'. 
Three main theoretical perspectives are apparent in the literature review: The evolution of hei tiki in pendant form via a process of cultural diffusion from parallel forms evident in the early parent Polynesian homelands; stylistic development of the distinctive tiki imagery first in Māori wood carving, its subsequent transferral into pounamu pendant form and widespread adoption of hei tiki stylised according to local carving conventions; and the influence of proto-historic European trade in metal tools, resulting in the redundancy and freeing up of large numbers of pounamu adze blades for reworking into hei tiki, many potentially as European trade items, and with the common style of hei tiki asserted to have appeared at this time in association with the re-use of adze blades.

The position adopted in this study acknowledges that there were early Polynesian influences upon the appearance of hei tiki but it also places considerable emphasis upon local development following initial settlement, with a range of classic Māori motifs developing primarily in the wood carving arts. The lack of hei tiki from archaeologically dated contexts appears to have contributed greatly to the plethora of opinion evident within the literature. The wider archaeologically and historically constructed picture however points clearly to hei tiki being a "classic Māori" taonga, one of several complex single pendant pounamu adornments which made their somewhat 'sudden' appearance during the classic phase of Māori culture. 


\section{Methodology}

The philosophical position from which this thesis is developed is that this study will be mana- enhancing for hei tiki and culturally reaffirming for Māori. This approach may be termed kaupapa Māori, a culturally empowering research position advanced by Smith (1999), Barnes (2000) and others. The approach also aligns with the current trend of American Indian Studies research methodologies by being positioned within academia and aiming to engage with both academic and indigenous audiences (Innes 2004, The Graduate School website; Kidwell and Velie 2005).

The thesis recognises the value of the scientific approach to uncover important new understandings. But it employs a key concept of Māori culture, that of mana 'power, prestige, authority, reputation', by which to frame the research, so that its outcomes may more likely be of significance to Māori, as well as of wider significance. The approach seems particularly justified given the high status of hei tiki as a cultural treasure to Māori.

Four sources of mana are explored in relation to hei tiki:

- Mana of hei tiki derived from spiritual origins with Māori deities.

- Mana of hei tiki derived from the artistic excellence of hei tiki makers.

- Mana of hei tiki derived from association with revered ancestors.

- The mana of the hei tiki used in this study which possess the potential to effect significant new understandings.

A common theme of the thesis is indigenous agency. This concept is explored in relation to the origins, making and use of hei tiki to re-confirm and to an extent restore the cultural standing and potency of hei tiki; and hence it is a means by which mana is enhanced. Cultural agency is seen as taking place on a collective as well as on an individual level, as understood by Gell (1998) and Ratner (2000). Investigating the changing social relationships of agency is also a means by which the pre and post contact history of hei tiki can be better understood.

A premise upon which this thesis is founded is that hei tiki themselves still have something to tell us, that important new understandings may be revealed by close analysis of hei tiki 
and of the pounamu 'New Zealand jade' they are crafted from. The investigation is based upon this premise to explore how the mana of hei tiki may be enhanced by revealing new understandings of their origins, development and use, post $A D 1500$ through to the late nineteenth century.

The study approach compares several hei tiki known to have been collected or recorded during the early contact period, 1769-1777, with a general selection of 50 un-localised hei tiki in the collections of Te Papa. In the general absence of archaeologically dated hei tiki the 1769-1777 hei tiki are the earliest known examples by which to make interpretive comparisons with other hei tiki in collections. Some further understandings are also revealed by closer analysis of the larger assemblage of hei tiki from the Te Papa collection.

The investigation uses evidence gained through analysis of recorded hei tiki shapes and stylistic features to uncover insights into the origins of hei tiki and their stylistic development. It also draws upon evidence revealed from analysis of recorded wear patterns and pounamu characteristics to form an opinion on the extent to which Māori influences continued and European influences added to the increasing popularity of hei tiki during the early $19^{\text {th }}$ century, when the making of hei tiki is thought to have peaked (Groube 1967). An assessment is made of the extent to which hei tiki exhibit characteristics indicative of prolonged traditional use or characteristics indicative of European trade item status.

The selection of a representative sample of 50 hei tiki with which to characterise the features of hei tiki in general required a problematic narrowing down process from a larger pool of eligible hei tiki. While a random selection may have been one solution an alternative approach was taken. This approach involved identifying four outline shape characteristics applying to all hei tiki within the larger and presumably more representative original group and maintaining the relative proportions of those characteristics in the narrowing down process.

The creation of four shape categories has provided another tool for gaining an understanding of hei tiki, with the outline shapes of finished hei tiki to varying degrees often appearing to retain the shapes of the original pieces of pounamu they were worked from. Existing style categories were found to be inconsistent as an indicator of original outline shape. 
Considerable care has been taken in the identification of hei tiki for inclusion in the research assemblages in order to maintain integrity of results. The importance of doing this in order to avoid misleading self-referencing circular evidence is highlighted by Day (2001:9) and Brown (2003:23) in their respective studies of Māori carvings. Only hei tiki clearly displaying characteristics indicative of pre-1900 Māori workmanship are included. Details on the selection process are given in the outline of methods and techniques in chapter four.

The term traditional is used in this thesis even though, for some, it may contain connotations of Māori practice and belief today somehow being less traditional and culturally authentic than in the past. Implications of the use of this word have been explored by Mallon (2010). Its use in this thesis has most often been employed to indicate pre- $20^{\text {th }}$ century Māori beliefs and practice in relation to those of Pākehā. 


\section{Chapter Outline}

1. Chapter one explores the origins of hei tiki beginning with an outline and analysis of the mana of hei tiki which has its original source attributed to supernatural origins with atua 'deities' in the spiritual realm of Hawaiki. It surveys the limited archaeological evidence available for gaining an understanding of the appearance of hei tiki, before developing an argument for their origins based partly upon the wider archaeological picture. While the earlier existence of tiki pendants made from perishable materials is considered probable, it is proposed that the stylistic origins of hei tiki are probably more closely related to the need to work the tiki form in accordance with the constraints imposed by the tough new material, pounamu, and the shapes to which it was cut. An argument for the probable adaptation of prerefined wood carving imagery is presented. It is further argued that the working of pounamu was carried out largely in line with the need for adze blades. An argument is made for an early relationship between the origins of hei tiki and pieces of pounamu of adze-shape and thickness which probably favoured early dominance of the deeply modelled type I style of hei tiki.

2. Chapter two explores probable influences which may account for both the development of stylistic variation in hei tiki, - regionally and over time, - and the maintenance of stylistic coherence. It places emphasis upon the mana which is imbued into hei tiki by the artistic excellence of their makers, capable of the faithful representation of culturally acknowledged styles, while progressively extending those styles. It argues that there may have been a close ongoing relationship between wood carving and the making of hei tiki. Limitations imposed upon the rendering of stylistic detail by the extreme toughness of pounamu and the small size of hei tiki, are also discussed. It is suggested that ongoing innovative developments may have occurred first in wood carving before being adopted for use in simplified form in pounamu. 
3. The third chapter investigates the mana of hei tiki which is derived from prolonged ancestral use. The investigation is carried out within a wider exploration into the question of Māori agency in the rise in the popularity of hei tiki, particularly during the early $19^{\text {th }}$ century when hei tiki making and use is thought to have reached their highest point. Three components are identified in order to account for the growing popularity of hei tiki: increasing supply of pounamu, growing availability of skilled craftsmen to fashion hei tiki, and increasing demand for hei tiki. The implications of European trade item status are examined in relation to the mana of hei tiki which is derived from prolonged use by the ancestors. The chapter explores some of the main aspects of the traditional use and significance of hei tiki in order to highlight what is at stake through a lack of such ancestral association.

4. Chapter four outlines the research methods and techniques of the collections-based research project, including the selection criteria for inclusion in the two study groups. The first group is comprised of 5 known early contact period hei tiki held in various overseas collections, and it is supplemented by 3 drawings of hei tiki recorded 1769-1777. The second group is comprised of 50 hei tiki from the Taonga Māori collection of Te Papa. The chapter discusses the potential for the mana of hei tiki used in this study to enable significant new understandings of hei tiki in general.

5. Chapter five actualises the mana or empowering potential of the study group hei tiki by providing an analysis of the research findings. The results indicate the prevalence of the adze-shaped hei tiki and the level of stylistic development of hei tiki during the early contact period; they uncover new understandings of how hei tiki appear to have continued to develop over time. The analysis also finds supporting evidence for the view of a trend of increasing size of hei tiki over time and supporting evidence also for the view that there was an early $19^{\text {th }}$ century peak in hei tiki making. It assesses evidence indicative of the relative extent to which hei tiki appear to have been used traditionally or to have been produced specifically as European trade items. 
6. Chapter six is the general conclusion. It considers the research findings in relation to the arguments developed in the literature review and their impact upon the mana of hei tiki.

7. Appendix one. This presents a photographic record of the two assemblages of hei tiki and it lists details of their systematically recorded features.

8. References 


\section{Chapter One: Hei Tiki Origins}

\section{Chapter introduction}

In this chapter probable influences are explored in order to identify key elements which may have determined the origins of hei tiki and the style in which the early hei tiki were made. Developments in pounamu working methods and the wood carving arts are identified as two probable important influences, as is the toughness of pounamu and the need for hei tiki to conform somewhat to the shapes which could be cut. An argument is made for the most common style of hei tiki, often conforming to the adze shape, probably having very early origins due to these influences.

The chapter begins with an acknowledgement of the mana of hei tiki credited to supernatural origins with atua 'deities' in the spiritual realm of Hawaiki. The physical origins of hei tiki are then explored. A survey of the limited archaeological evidence for hei tiki recovered from sites is made, highlighting the scarcity of such data for gaining an understanding of hei tiki origins and development. The wider archaeological picture is investigated showing marked differences between the range of earlier archaic adornments and the curvaceous single-pendant pounamu adornments of classic Māori culture, which seem to have appeared on the scene somewhat 'suddenly' without apparent prototypes in pendant form.

The seemingly incompatible nature of this understanding, with that of Skinner's model for an unbroken lineage of hei tiki evolution in pendant form, extending from ancient Pacific tiki pendants, is outlined. The reliability of Skinner's morphological comparative methodology is critiqued. The accepted archaeological view of an uneven transition from archaic to classic phase throughout Aotearoa, when hei tiki likely came into being, is viewed as casting doubt upon the reliability of Skinner's model, in which the common style of hei tiki is identified as the most recent.

Evidence for the existence of hei tiki 'prototypes' in relatively soft and perishable materials is assessed, as being of a perishable nature it is possible they may have disappeared from the archaeological record, giving a false impression of a 'sudden' appearance of hei tiki 
made from pounamu. It is concluded that the wearing of tiki imagery in perishable materials and in less perishable although also relatively soft materials such as serpentine, may have been longstanding - if infrequent - extending from the early settlement period. The styles of two known early examples are assessed, and considered to be very different from that of pounamu hei tiki. This observation together with the understanding that the use of the new incredibly tough material, pounamu, probably required a new kind of stylisation to conform to cut shapes, leads to the view that early tiki pendants may not have been prototypes for hei tiki in a stylistic sense.

Archey's argument for the refinement of a number of classic Māori motifs first in wood carving prior to their adoption for use in the pounamu pendants hei tiki, pekapeka, marakihau, and manaia is assessed. The argument is considered to offer a good explanation for the 'sudden' appearance of such imagery in pounamu.

The development of pounamu working methods is explored and considered to have probably been closely associated with enabling the making of the classic style of pounamu adze blade. The cutting up of pounamu boulders is considered to have probably focused upon sawing off wedge and rectangular shapes of pounamu of suitable thickness, which could then be used for adze blades, mere, or potentially also for hei tiki. The origins of hei tiki are considered to have probably been closely linked to the use of adze shaped pieces of pounamu, either as recently cut blanks or as the re-working of old pounamu adze blades.

It is argued that at some point in time, probably post AD 1500, developments in wood carving imagery and pounamu working ability converged and hei tiki came into being. The making of hei tiki from either adze blades or blanks of pounamu of adze-like outline shape and adze-like thickness is argued to have favoured the common more deeply modelled type I style of hei tiki, which often retains traces of an original adze-like outline shape.

The development of the proto-historic argument put forward by Groube $(1967,1969)$ is traced and critiqued in light of the viewpoint which has been developed in the literature review. It is agreed that the origins of the most common style of hei tiki are probably closely associated with the use of adze-shaped pieces of pounamu, including the re-use of pounamu adze blades. But this relationship is argued to probably have existed from much earlier, potentially at or near to the pre-contact origins of hei tiki, rather than being 
something which only became of importance in the early $19^{\text {th }}$ century, when Groube argued the common style of hei tiki came into being.

\section{Mana derived from supernatural origins}

Two creation narratives show that according to traditional systems of belief the original source of mana of hei tiki can be credited to the atua 'Māori deities', Ngahue and Hine-teiwaiwa. The creation narratives are set in Hawaiki, the original tropical Polynesian homelands of Māori.

\section{Ngahue and the first hei tiki}

A pakiwaitara 'traditional story' tells of how the ancestor-like god Ngahue fled from Hawaiki with his coveted pounamu fish Poutini. They were chased from their homeland by Hine-tua-hoanga and her abrasive cutting-stone Whaiapu. After a long journey Ngahue and Poutini made landfall at Tuhua 'Mayor Island' in the Bay of Plenty, but they soon sensed the arrival of their foe and continued onwards, arriving at length at the remote Arahura River on the South Island's West Coast. Here Ngahue deposited Poutini making this an eternal resting place for his precious stone. He then returned to Hawaiki with a portion of pounamu taken from the side of his fish. Back in Hawaiki Ngahue told the people of the richness of the large land he had discovered. He worked upon the pounamu to fashion the first hei tiki adornments, making also kuru-pounamu 'ear pendants' and famous toki 'adzes'. The adzes were used to construct ocean voyaging canoes and voyages of settlement commenced resulting in the arrival of the people and their pounamu treasures in Aotearoa.

This story was originally published in Te Reo Māori by Sir George Grey in 1854 (68-69) and again the following year in English (1855b:82-84). While the English translation refers to "images for neck pendants" the original 1854 version is more specific with regards to the hei tiki made by Ngahue in Hawaiki: “...i te hei-tiki etahi..." (1854:68). The narrative has been attributed primarily to Te Rangikaheke, a principal chief of Ngāti Rangiwewehi, Te Arawa (Simmons 1966a:179). 


\section{Hine-te-iwaiwa and the first hei tiki}

Another hei tiki creation narrative involves Hine-te-iwaiwa and is also set in tropical Polynesia. Hine-te-iwaiwa was a goddess of exceptional beauty who acquired the first hei tiki as a gift from her father (Best 1914:131, Grey 1855a:50). The god Tāne is usually although not always - acknowledged as the father of Hine-te-iwaiwa (Orbell 1995:64).

Another name by which Hine-te-iwaiwa is known is Hinauri. Hinauri was married to Irawaru, however, a dispute arose in which Irawaru was transformed into a dog by Hinauri's brother, Māui (Grey 1855a:50-52). One account says Hinauri threw herself into the sea in grief for her husband and she came ashore eventually at the island home of Tinirau (Grey 1855a:54,81). Other versions say that Hinauri had heard of Tinirau, who was highly regarded as the most handsome man of his time, and she made her way to his island by either swimming or by sailing upon a shellfish (Reed 2004: 148-149). After arriving on the island Hine-te-iwaiwa/Hinauri and Tinirau slept together and this angered Tinirau's other two wives, Makai-atua-uriuri and Makai-atua-haehae. A fight took place in which Hine-te-iwaiwa killed these two co-wives. One account says that Hine-te-iwaiwa killed the women by intoning a powerful karakia 'incantation' and by throwing stones at them. The stones burst open as they struck the women letting forth a mass of greenstone, and it was by this means that pounamu had its origins (Reed 2004:150).

\section{Discussion}

The expression: "Ehara i te mea poka hōu mai: nō Hawaiki mai anō" ["It is not a new thing done without proper cause: it has come to us all the way from Hawaiki" - Royal's translation], is used by Te Ahukaramū Charles Royal (2012:1, Te Ara website) to support the view that with the passage of time Hawaiki became "...a mythical template for everything that is good, powerful and benevolent in the traditional Māori world view." The Hawaiki origin attributions for hei tiki and for the coveted pounamu stone from which they are made fit with this analysis and are to be expected of such highly regarded cultural treasures. These stories can be interpreted as supporting the fact that in hei tiki a material of unparalleled value was used to fashion an adornment of unparalleled cultural value. 
Jahnke (2006:96) refers to the two-world system in which the Māori spiritual world interpenetrates the material world. According to this understanding the supernatural origins of hei tiki would not have been something regarded traditionally as distant and remote in time, for the spiritual world was regarded as constant and immanently present within the physical world of Te Ao Mārama. This view is supported by that of Hakiwai (1996:53) who refers to the Mãori perception of the past as lying before the people, forming an 'everpresent now'.

An inquiry into the physical origins of hei tiki follows. In accounting for the physical origins of hei tiki this thesis develops an argument which places the origins of the most common style of hei tiki and the stylistic origins of hei tiki in general, within the pre-contact world of the ancestors. The inquiry begins with a discussion on the lack of hei tiki retrieved from archaeological contexts.

\section{The lack of direct archaeological evidence}

A survey is made of the few sites from which hei tiki have been recovered. It shows that while a number of pounamu hei tiki have been recovered from a few archaeological sites, their discovery unfortunately predated the use of controlled excavation techniques and they consequently lack valuable contextual data which otherwise could have been retrieved. The sites in order of importance include: Whareakeake / Murdering Beach (over 20 hei tiki), Oruarangi (3 hei tiki), and Pā Bay (1 hei tiki).

Whareakeake ('Murdering Beach'), Otago; site number 144/20 (metric)

Whareakeake on the northern side of Otago Peninsular provides a singular example of a site where a large number of hei tiki has been found. H.D. Skinner (1932:207) states that "no less than twenty three" hei tiki have been dug up from the locality. In subsequent publications the figure is indicated as being more than 20 (Skinner 1966:10) or at least 22 from the top layer (Skinner 1974:50).

The total quantity of pounamu retrieved from Whareakeake by 1900 was estimated by Augustus Hamilton at some 350 hundredweight (Skinner 1959:223). This figure converts to almost 18 tons of pounamu. The sheer quantity of pounamu, far from the nearest sources, in its raw, partially worked and finished states and the presence of some of the tools used to 
work it suggest that this village specialized in working pounamu (Neich 1997:8). Once called Small Bay by the sealers (Lockerbie 1959:91) and long known as Murdering Beach, this locality is now officially known by its original name, Whareakeake, the change arising as part of the Ngāi Tahu Treaty settlement with the Crown.

In 1817 the village of Whareakeake was entirely destroyed by a party of sealers who burnt it to the ground. The attack was led by Master James Kelly from the brig Sophia and can be placed within a context of escalating tension and violence since 1810 in the south between sealers and local Māori, as outlined by Anderson (1998:65-66). A rāhui or ritual prohibition is thought to have been placed upon Whareakeake following its destruction (Skinner, 1959:230). This is evidenced by the fact that despite the large quantity of valuable pounamu on site it remained untouched by Māori until at a later date fossicking was begun by Pākehā settlers (Lockerbie 1959:92). The bay was occupied by single Pākehā settler families from the 1840 s onwards with a number of surface finds of "curios" being made (Skinner 1959:221). Fossicking at the bay had become "a popular pastime" by 1862 . And during the 1880s and 1890s large scale digging for commercial gain took place following a pattern of systematic digging instigated by Alfred Reynolds (Lockerbie 1959:92, Skinner 1959:219). Reynolds focused on locating individual whare 'house' sites. He then excavated the floors concentrating on the line of the interior walls and around the fireplaces. Skinner (1959:221222) writes:

most of the pieces retrieved were found along the line of the walls, often in groups by the corner posts, suggesting that they had hung in small flax kits which fell to the floor when the whare was burnt. But finds were occasionally made by the fireplaces, as though cached below floor level there. Every house investigated by these early collectors had been destroyed by fire.

Skinner attributes dates for hei tiki collected from Whareakeake as "1817 or a few years earlier" (1966: front cover captions).

Oruarangi, Hauraki; site number T12/192 (metric)

Davidson (1984:249) and Furey (1996:27) record that the Hauraki swamp pā site of Oruarangi, including its northern extension Paterangi, is famous for the large number and 
the breadth of variety of artefacts typical of classic Māori culture which have been recovered from it. Material from the site includes a complete female hei tiki and the remains of two other hei tiki, - one identifiably female, the other un-diagnostic for this feature. The hei tiki are pictured by Furey (1996:50, Figs 90-92). All three examples are of the most common form of hei tiki with the head resting, - or apparently having rested, - directly upon the shoulders, and both arms positioned to rest on the thighs. The probable source of pounamu for all three hei tiki is identified as Arahura, Westland (1996:49-50). Oruarangi was excavated primarily by collectors in the early 1930s with little heed to archaeological technique. In addition the curio hunter's activities extended into the out-of-bounds urupā 'burial ground' section of the site from where the complete hei tiki was taken (1996:49).

Pā Bay, Banks Peninsula, Canterbury; site number N36/110 (metric)

Pā Bay is the site of an early nineteenth century Māori village on Banks Peninsula (Davidson 1984:87,253, Thacker 1960:11). A fragment of a single hei tiki was recovered from the site when it was excavated by Murray Thacker in 1960.

\section{Discussion}

Despite their extremely durable nature hei tiki are virtually absent from the archaeological record, a situation recorded by Davidson (1984:84) to be held in common with pounamu adornments in general. Davidson attributes the rarity of pounamu adornments in archaeological sites largely to the value in which they were held by their owners. An inference of this view is that these prized treasures were well looked after and handed on rather than being lost or discarded. The lack of archaeological evidence for hei tiki has seen less solid evidence used for the creation of developmental models.

\section{Evidence from the wider archaeologically supported picture}

Neich (1997:7) characterises the stylistic attributes of archaic adornments as angular and notched. Archaic adornments are characterised by an emphasis upon necklace units, reel, disc, twin-lobed, and whale's tooth pendant forms. Prickett (1999:6-8) records that the most common materials used for adornments from the archaic phase of Māori culture were bone, ivory, and serpentine. 
In comparison, classic adornments are characterised by Neich (1997:7) as emphasizing single pendants of curvaceous style, often of pounamu, which came into its own for use specifically as an adornment during the classic phase of Māori culture. Single pendants crafted from pounamu are a defining feature of the classic phase of Māori culture (Golson 1959). They include hei tiki, pekapeka, marakihau, and manaia (Neich 1997:18-28).

This range of pounamu pendants appear to belong to what Golson $(1959: 65,67)$ refers to as "some of the Classic Maori ornament forms typically rendered in greenstone which have other models than the Archaic types they replace." This understanding sits in apparent contradiction to Skinner's diffusionist model outlined next, which proposes a long lineage of hei tiki evolution in pendant form from the early settlement period and before.

\section{An examination of H.D. Skinner's evolutionary model}

Price (1994) writes "As a theoretical perspective diffusionism held its zenith in the early twentieth century ..." (cited in Wards 2009:37). Diffusionism accounts for cultural development in terms of influences spreading over time and through space from centres of cultural innovation to other cultures. It was the overarching theoretical position from which Skinner explored the origins of Māori culture, including hei tiki (Skinner 1974:13).

In a series of publications dating to 1916, 1932 and onwards, Skinner constructed an evolutionary sequence for hei tiki by making comparisons with tiki figures ranging in order of assumed stylistic antiquity from the human bone tiki pendants of the Marquesas Islands (Skinner 1932:207) and the wooden maoi miro figures from Rapanui 'Easter Island' (Skinner 1940:4,14-15), to the most common style of hei tiki. The lineage within Aotearoa extends from two painted rock art human figures from the South Island - one headless and one with an erect head - (Skinner 1916:311-312, Fig.1), to an archaic headless tiki pendant from Otago made of serpentine (1916:312, Fig.2, 313; Figure 1 below), to three pounamu anthropomorphic pendants from Otago with abbreviated limbs and all perforated with holes for suspension (1916:312 Fig.3, 313), to an attributed archaic style of pounamu hei tiki designated as variety $A$ with erect upright head, suspension hole, and possibly abbreviated legs (1932:207,210,Plate A No.5; Figs 2 and 3), and finally to the most common style of pounamu hei tiki designated as variety B with head inclined to one side (1932:Plate A,207,208, Figure 4 below). 
The morphological comparative technique employed by Skinner in constructing this sequence relied upon the identification of certain archaic features of style inherited from tropical Polynesia and the identification of some classic features resulting from local development within New Zealand. Archaic features include notching, abbreviated legs, forked tongue, the absence of a head, an upright head, and a hand positioned to the mouth. Classic features include the presence of holes for suspension, heads inclined to one side, and a general dissimilarity with anything archaic. Position within the sequence depended upon the extent to which these features were present. For example, the anthropomorphic pendants are positioned midway upon account of having abbreviated limbs (attributed archaic feature) and suspension holes (attributed classic feature).

Issue can be taken with Skinner's comparative method. In the absence of archaeologically determined dates for all of the tiki figures used in his sequence, Skinner attributed their antiquity based upon assumptions of style. The approach can be seen as particularly fraught when one considers that there appears to have been considerable unevenness throughout the various regions of New Zealand in the transition from the archaic to classic phase of Māori culture. For this reason Golson (1959) argues for use of the term phase to replace the term period when referring to the archaic and classic parts of New Zealand prehistory. Davidson (1984:223) and Furey (1996:179) also refer to the co-existence of both phases throughout the various regions and localities of New Zealand, during a prolonged period of transition. Furey cites the Coromandel Peninsula as one region in which some archaic elements of material culture, including archaic style personal adornments, appear not to have transitioned into the classic phase at all.

It is maintained that such was probably the situation when hei tiki came into being. Given this situation it may be expected that hei tiki of similar age but from different localities will possess some archaic features more so than others. The hei tiki with upright head, for example, may merely represent a style of hei tiki from localities in which archaic traits, or that particular trait, lingered longer in use than in other districts. Analysis of the relative presence of archaic and classic stylistic features in hei tiki therefore appears to be an unreliable method for determining a developmental sequence. While the developmental sequence proposed by Skinner is not necessarily wrong, its reliability appears doubtful, which in turn opens the way for other options to be considered. 


\section{Assessment of evidence for earlier tiki pendants of softer and less durable materials}

It is possible that the apparently 'sudden' appearance of hei tiki in the classic Māori phase of cultural development might be due to earlier prototypes not having survived in the archaeological record, because they were made from perishable materials. Four sources of evidence for the existence of such early tiki are outlined and a discussion assesses their significance.

\section{Historical evidence for early hei tiki made from perishable materials}

In 1772 Northland, Crozet observed the wearing of wooden tiki figures in addition to the wearing of pounamu hei tiki (Ling Roth 1891:45):

in the middle of every village there is a carved figure which appears to represent the tutelary god of the village. In their houses are to be found similar figures like little idols placed in positions of honour. Several savages carried similar figures carved in jade or in wood around their necks. These figures are simply hideous; they nearly all have an immoderately long tongue and have a fearful look

In 1920 some South Island Māori asserted that hei tiki were once made in a range of materials including wood, bone and pāua shell, although these assertions were disputed by others (Beattie 1994:57).

\section{A bone tiki pendant from Kohika, Bay of Plenty}

An unusual small hei tiki made from human bone was found at the late $17^{\text {th }}$ century swamp pā site of Kohika, when it was excavated during the second half of the 1970s (Irwin 2004:7682). The tiki is featured on the cover of Irwin's 2004 book and also on pages 160-162. Its appearance can be described as very unconventional.

\section{Skinner's hypothesised bone hei tiki}

In 1932 Skinner added a significant new component to his initial proposed evolutionary lineage by hypothesising the existence of an archaic bone hei tiki, from which he argued the earliest pounamu hei tiki likely evolved, as represented by variety A (Skinner 1932:207). The 
features of one variety A hei tiki in particular, an example from Ruapekapeka in Northland (Skinner 1940:4), were held to probably be close to that of the hypothetical bone hei tiki "in most respects". This hei tiki is notable for having an upright vertical head, possibly abbreviated legs, and both arms upraised with the hands resting upon the chest.

It is assumed that the reason Skinner hypothesised the existence of the bone hei tiki was to fill the void created by a lack of extant human form pendants with which to adequately demonstrate the evolution of hei tiki in pendant form, and adherence to the idea that a softer medium such as bone would have allowed the experimentation necessary for stylistic refinement of the form. In 1974 Skinner noted that his hypothesised bone hei tiki had yet to be found (Skinner 1974:487). Its existence remains unproven.

\section{An archaic tiki pendant in serpentine}

A rare archaic style tiki pendant, $72 \mathrm{~mm}$ in length, from Waitati, Otago, is recorded by Prickett (1999:29). The pendant is made from red serpentine, a relatively soft and easily worked stone, and a stone type typically used during the archaic. The pendant's style is angular and is identified by Trotter and McCulloch $(1971: 68,72)$ as similar to some of the rock art figures found in the South Island. The pendant is grooved along the top rather than perforated with a hole for suspension.

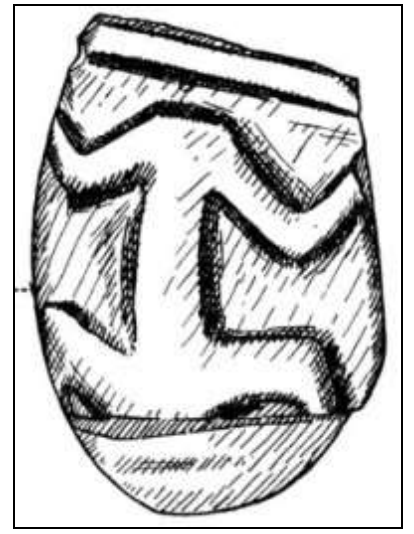

Figure 1 Tiki pendant from Waitati Valley, Otago. Drawing From Skinner 1916.

\section{Discussion}

Evidence for the post-contact use of alternative tiki pendants made from wood, bone, and shell hints at the possibility of a long-established practice extending from an earlier period, but other explanations could be made for their use originating as a classic Māori practice. 
The bone tiki pendant from the late $17^{\text {th }}$ century site of Kohika offers proof for pre-contact tiki pendants of bone, but its appearance is very different to that of hei tiki. Skinner's longproposed hypothetical bone tiki of a specified appearance remains hypothetical; - the existence of which may never be proven. The archaic rock art style serpentine tiki pendant from Waitati offers evidence of tiki pendants having been worn in the early settlement period.

Davidson (1984:91) indicates that single pendants may have formed a relatively minor component "at least" of archaic adornment prior to the classic Māori phase. This may in part account for the limited evidence for pre-classic tiki pendants, in addition to the generally perishable nature of the materials. Stylistically the appearance of these examples of tiki can be assessed as quite different to hei tiki. It will be argued that a particular stylisation of hei tiki, necessitated by the toughness of pounamu and the shapes to which it was cut, was probably a more significant influence. According to this understanding it appears to be misleading to think of the earlier tiki pendants as prototypes for the stylistic development of hei tiki. On the other hand the existence of earlier tiki pendants can be interpreted as important in accounting for the origins of hei tiki of pounamu, as it points to the wearing of hei tiki being a continuation of a long established practice of wearing human figure imagery.

\section{Arguments for the stylistic appearance of early hei tiki of pounamu}

A particular type of stylisation may have been required in order to render the human figure in the tough new medium of pounamu and according to the shapes in which it could be cut. This has long been argued for with regards to the common style of hei tiki; for example, Skinner (1916:311). According to this view something of a stylistic leap may have occurred with the transition to using pounamu for pendants. It seems that a good case can be made for refinement of stylised tiki imagery first in wood carving and its adaptation for use in pounamu, as a resemblance between a range of distinctive wood carving imagery and distinctive pounamu pendant forms has been observed.

\section{Assessing the argument for the influence of wood carving imagery}

A close relationship between pounamu hei tiki and carved wooden tiki has long been argued for; - notably by Archey $(1933,1936)$ and supported also by Golson (1959) and Phillips 
(1966:138-139). Archey (1936:51) proposed that hei tiki conforming in shape to rectangular or adze shaped pieces of stone are a pounamu counterpart to poupou 'wall post' house carvings in which the shape of the human figure is dictated by the shape of the slab of wood. His comparisons however were made with Māori carvings in general, instead of being restricted to early examples more indicative of the styles of carving which would likely have influenced the stylistic development of hei tiki. A comparison between an $18^{\text {th }}$ century poupou carving with stylised tiki figure and a hei tiki of comparable age (Figs 2 and 3) shows a high level of early stylisation in both mediums and points to the possibility of an early close relationship as suggested by Archey.

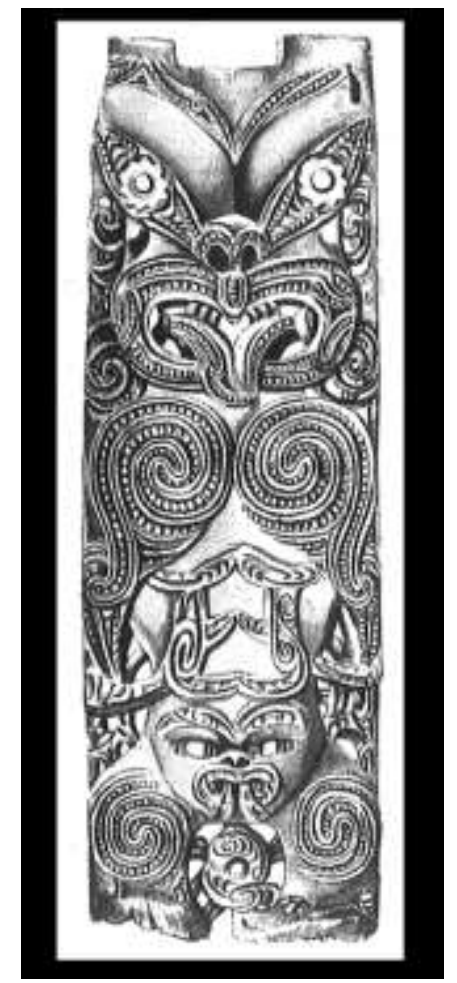

Figure 2

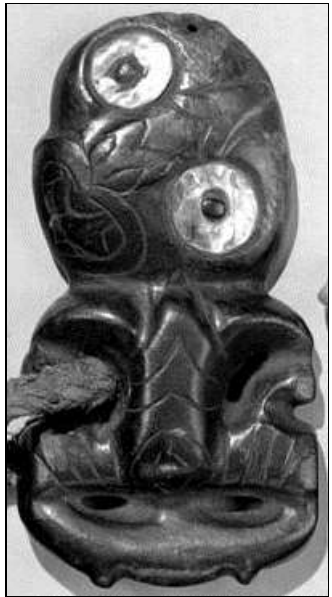

Figure 3 Image: Courtesy, The Field Museum, A97305

Fig.2 An 18th century poupou carving. Illustration of a poupou 'wall post' carving collected from Tolaga Bay in 1769 by Cook; 1771 engraving by John Frederich Miller. The carving has been discovered in the collection of Tuebingen University, Germany (Science in the News 1998, The Royal Society of New Zealand website). Plate 7.25 of Wood (2012) shows the poupou in pre-restored state with the top end cut off; recorded as $980 \mathrm{~mm}$ long by $330 \mathrm{~mm}$ wide. The original length can be estimated at about $1090 \mathrm{~mm}$ by comparing this plate with an image of the fully restored poupou (Schwabisches Tagblatt, 8. August 2013). The tiki 
features are stylised in typical poupou fashion to fit within a rectangular outline shape imposed by the block of wood.

Fig.3 An 18th century hei tiki. Hei tiki of the common Webster type I shape collected on one of Cook's voyages to New Zealand 1769-1777. 100mm long. From The Field Museum, Chicago; collection number 273856 . The features are stylised in typical hei tiki fashion to fit within a rectangular outline shape imposed by the piece of pounamu.

Hei tiki can be assumed to have originated before the 1769 poupou collected on Cook's first voyage was carved. However, this poupou carving arguably remains indicative of an early stylisation of the tiki figure in wood carving which had probably been in existence for some considerable time and which may have influenced other art forms including hei tiki.

Supporting evidence for the influence of wood carving upon the stylisation of hei tiki comes from the observation that the classic Māori manaia, marakihau and pekapeka pendants are also pounamu renditions of similar distinctive imagery found in wood carving (Archey 1936:49, Neich 1997:18-21). The fact that the imagery of several pounamu pendants appears to have its origins in wood carving appears to add significant weight to the plausibility of Archey's argument for the development of hei tiki.

Archey reasons that in Aotearoa two factors combined to influence the development of an elaborate Māori wood carving tradition to a higher level than achieved in the Polynesian homelands. These factors were an abundance of fine carving woods such as tōtara and kauri and the availability of superior stone for carving chisels, especially pounamu (Archey 1933:187, 1936:58). It appears that the Māori carving tradition with its elaborate and curvilinear forms of surface decoration gave rise to distinctive and refined classic Māori tiki imagery, and also the manaia, marakihau and pekapeka imagery.

A Polynesian-wide emphasis upon representing the human figure is identified by Archey (1933:185). Hei tiki can be seen as but one manifestation of this phenomenon, but the lineage of ancient influence from Polynesian homelands can be seen as having been of a dynamic nature, crossing over between different art-forms and developing stylistically in the process in accordance with the freedom allowed by the material. Wood can be identified as 
an ideal medium for the development over time of many distinctly classic Māori motifs, which may then have been worked in other materials.

This thesis adopts the position that hei tiki probably originated as a consequence of a convergence between refined tiki imagery from wood carving and refined pounamu working abilities, - which enabled the imagery of tiki to be rendered in the toughest of all natural materials known to Māori. This convergence is argued to have enabled the adaptation of refined imagery for use in pounamu.

\section{Developments in pounamu working and the origins of hei tiki}

A position taken in this study is that technological advances in pounamu working which contributed towards enabling the appearance of hei tiki, were probably driven largely by the practical survival need for high quality wood working tools. The East Polynesian ancestors of Māori arrived in Aotearoa bringing an ancient stone-working technology based upon the percussion method of flaking stone. This method involves use of hammer stones to skilfully strike off flakes of stone from the surface in order to render the required preform shape. Hammer dressing or repeatedly bruising the surface with a hammer stone was another method by which stone was shaped and rough surface texture achieved, often in order to provide grip for lashings (Beck with Mason 2010:148).

Fine grained argillite and basalt were commonly used for making a wide range of archaic stone adze forms, typically with a tang to facilitate lashing the blade to a wooden handle. Soon after initial settlement, pounamu was also sometimes used for making wood working tools. Beck with Mason (2010:148) refer to pounamu adze blades from early South Island sites which exhibit characteristics of having been hammered into shape, as evidence that this was the earliest means by which pounamu adzes were worked.

The pounamu tools replicated the archaic adze and chisel forms made from the other stone types, but they were fashioned with difficulty. While nephrite pounamu has an internal felted structure of tremolite crystals which gives the stone metal-like characteristics of toughness, this felted structure also causes pounamu to break in uncontrollable fashion when struck with a hammer stone risking destruction of the piece (Beck with Mason 2010:25,188). 
Over time more effective techniques were developed for working pounamu, in particular the use of mania 'abrasive stone saws' to cut through pieces of nephrite from each side and then, when the cuts were close enough together, snap the piece off with a sharp blow (Beck with Mason 2002:101-106, 2010:149, Chapman 1891:498,511-513). Grinding techniques are also thought to have improved significantly (Beck with Mason 2002:107-110, Neich 1997:69). Beck (2010:153) argues that the use of very large hoanga 'grindstones' at specialist pounamu workshops resulted in pounamu adze blades being more neatly quadrangular in section than adzes made from other stone types, which due to their more rounded quadrangular section, indicate the use of small hand-held grindstones in their making. Over time a standardized adze blade of quadrangular cross-section, without a tang, replaced the earlier diverse range of adze types and included pounamu adzes which became much more common.

Figure 02 of Beck with Mason (2010:156) illustrates how blanks for a range of pounamu taonga could be cut from a boulder of pounamu. It illustrates how cut wedge-shaped pieces of pounamu were ideal for making both adze blades and mere. This thesis asserts that wedge-shaped pounamu blanks were also ideal for making hei tiki. Russell Beck (Personal Correspondence 20 October 2013) comments that the proportions of hei tiki may have been dictated by the adze form, "but if one was going to make a tiki from scratch, one would saw the blank to roughly adze shape anyway, so which came first I am not sure."

Traditional stoneworker, Ānaru Rondon, is profiled by Tamarapa (2002:154-165). Ānaru observes that the proportions of many hei tiki are similar to toki 'adze blades' which are close to or at the end of their useful working lives (Personal Correspondence 20 September 2013). This observation suggests that newly cut blanks for hei tiki may have been relatively short adze-shapes.

Many of the finer features of hei tiki were worked using small hand held rasps called kani, and the pirori 'cord drill' was also used for making holes. The typically narrow inner leg and arm cavities of the thicker most common type of hei tiki appear to have been most often worked through using kani. It is noted by Beck with Mason (2010:157) that making kani appears to have been difficult and somewhat time consuming. It is argued that the initial shaping out work on hei tiki probably saw large grindstones used to reduce the lower and 
side edges in order to reduce the thickness for the arduous task of working through the leg and arm cavities, a position supported by stone worker Ānaru Rondon. This may have seen a bevel worked onto the lower edge which in partly finished examples could be mistaken for being the bevel of an adze blade. The portion of hei tiki identified as made from adze blades may have been over-estimated as a result. The recording by Heaphy in 1846 of newly made hei tiki receiving their final polish at the village of Taramakau, located at one of the main pounamu sources in Central Westland, provides further evidence for the view that not all hei tiki were made from redundant adze blades (Heaphy 1904:97, paperspast website).

\section{Argument for pounamu working methods favouring the common style of hei tiki from an}

\section{early date}

Beck (2010:115) asserts that in order to function effectively adze blades require a certain amount of thickness to give them the necessary weight to width-of-cutting-edge ratio for effective use. Traditional sawing of pounamu was largely focussed upon the making of adze blades, and pieces were accordingly cut of suitable thickness. A cut wedge-shaped length of pounamu may sometimes have been divided into two pieces - one piece for making an adze, and one piece for fashioning a hei tiki with deeply modelled features, as required by the thickness of the stone, namely Webster style type I. When an adze blade eventually wore too short for continued use it still retained its original thickness, which likewise lent itself to making the type I style of hei tiki.

It is maintained that a tendency for cutting relatively thick wedge-shaped pieces of pounamu probably existed very early on due a primary focus upon making adze blades and this together with re-cycling of old worn out adze blades probably ensured that the deeply modelled type I style of hei tiki [which is described in detail in chapter two] quickly became the most popular style, and apparently made in most districts of mainland New Zealand.

It appears that the origins of hei tiki may be closely associated with the pre-contact origins and importance of the common pounamu adze blade. This observation sits in opposition to the view proffered by Groube $(1967,1969)$ that the common adze-shape-derived hei tiki is proto-historic in origin. 


\section{Critical review of the proposed influence of European trade upon the origins of hei tiki}

A convergence of ideas can be credited with bringing about the notion that the common style of hei tiki may actually be of relatively recent proto-historic origin. These ideas include an observed high percentage of hei tiki considered to have originated as adze shapes, attributed late origins for the adze-shaped hei tiki style, and historical evidence for the widespread replacement of pounamu adze blades accompanied by the increasing popularity of hei tiki in the early $19^{\text {th }}$ century.

In 1915 Robley stated "When iron axes supplanted the native adzes many tiki and other ornaments were made out of discarded blades of greenstone." This statement is reinforced by pictures of what appear to be two pounamu adze blades partially re-worked into hei tiki (Robley 1915:66,72). The following year Skinner (1916:314-315) maintained that the majority of hei tiki, perhaps nine out of ten, have features determined by the adze shape. In Skinner's opinion this "orthodox" form of hei tiki is the most recent as it contains no archaic stylistic attributes linking it to early Polynesian forms of tiki. The orthodox hei tiki, designated by Skinner as variety B, is argued to be a product of local development in this land, an artistic development brought about by working the tiki image within an outline shape imposed by the adze blade or blank (Skinner 1916:311). In 1932 Skinner reconsidered his position on the prevalence of variety $B$ by noting that not all hei tiki are accounted for by varieties A and B (1932:208-209).

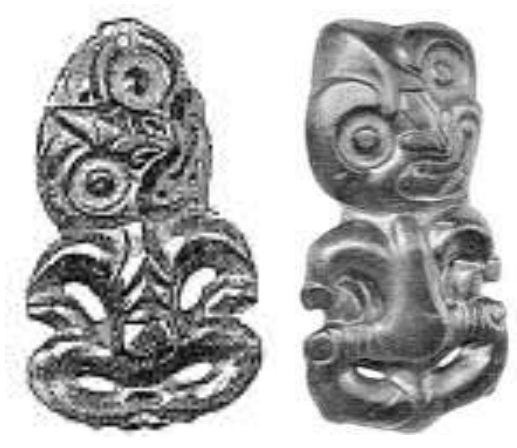

Figure 4 Variety B; after Skinner (1932:Plate A, 207,208).

In 1935 this position was confirmed by Skinner's proposal of "a loosely defined Variety C" representing a "good many" hei tiki previously unaccounted for (Skinner 1935:19). Hiroa (1950:292-294) then effectively re-extended Skinner's variety B with his "type B" 
represented by a wider range of hei tiki examples. A reason for this can be found in Hiroa's explanation that while the rectangular form may have been the most economic, the craftsmen were not averse to exerting more labour in order to achieve a look which pleased them.

Groube $(1967,1969)$ developed upon this common theme by proposing that while the rarer 'open form' style of hei tiki is archaic, the conventional 'closed form' style of hei tiki is postcontact in origin. According to Groube the conventional style of hei tiki arose in a protohistoric efflorescence of hei tiki making which resulted from large-scale reworking of pounamu adze blades in the early $19^{\text {th }}$ century, which were rendered obsolete by the postcontact acquisition of metal for carving tools. He asserted that this explanation needed to be made "... before sheer repetition makes the claim that the tiki is an "ancient form" an unassailable truth" (1967:458). This argument is an extension of Groube's larger thesis (1964) which was summarized by Orchiston (1972a:91) as the view that a great many socalled classic Māori artefacts were produced primarily as a result of European influence and should more correctly be identified as proto-historic.

This thesis agrees with the view that there appears to be a close relationship between the origins of the common style of hei tiki and the pounamu adze blade. But it argues for that relationship probably existing since the origins of hei tiki them-selves, long before contact with Europeans. While making of hei tiki may have peaked during the early $19^{\text {th }}$ century, the use of the term efflorescence for this occurrence may be considered inappropriate, as it appears to be intimately associated with the proto-historic argument for stylistic development.

\section{Estimated dates}

Davidson $(1984: 84,1996: 19)$ records evidence of the first pounamu adornments from sites on the east coast of the South Island dated to about A.D. 1500. Despite revision of archaeological dates in recent decades Davidson still believes the 1500 date holds true (Janet Davidson, Personal Correspondence 2013). While the original age of these early pounamu pendants may have been even earlier, when allowance for the development of pounamu working to its pinnacle is given - as evident in hei tiki - and allowance also for the 
refinement of tiki imagery in wood carving, a date of 1500 seems perhaps still too early for the first origins of hei tiki.

Based on this understanding the point in time at which hei tiki made their first appearance can be placed somewhere between and distanced from the chronological extremities of A.D. 1500 and A.D. 1769 when the first 'historical' sightings of hei tiki were made during the voyages of Cook and de Surville.

\section{Chapter conclusions}

While an important element of cultural diffusion from East Polynesian homelands is apparent in accounting for the origins of hei tiki, a gradual progression for the stylistic development of hei tiki in pendant form from archaic prototypes appears not to be supported. This understanding applies also to other classic curvaceous single-pendant pounamu adornments including the pekapeka, marakihau and manaia; - imagery of which is commonly found in wood carving. It appears that refinement of this classic Māori imagery probably occurred first in the softer medium of wood before being adopted for use in pounamu as pendants. The origins of hei tiki can be thought of as resulting from a convergence between pounamu working ability and the development of imagery in wood carving.

The origins of the common style of hei tiki appears to be closely associated with the use of adze-shaped pieces of pounamu, either in adze form or as newly cut blanks. Developments in pounamu working which enabled the fashioning of hei tiki probably focused upon the ability to cut wedge and rectangular shaped pieces of pounamu, of adze-like thickness, suitable for making into a range of classic Māori taonga including primarily adze blades, but also mere and hei tiki. Given these understandings it is concluded that many of the early hei tiki may have been adze shaped in outline, and of the highly stylised and relatively deeply modelled type I style. Agency for the origins of hei tiki in its common fully-realised form appears to be firmly embedded within traditional Māori culture. This culturally affirming view reflects the mana of the most familiar style of hei tiki as an iconic ancient treasure handed down from the early pre-contact realm of the ancestors. 


\section{Chapter Two: The Development of Stylistic Variation in Hei Tiki}

\section{Chapter introduction}

This chapter investigates cultural imperatives which appear likely to have influenced the creation of stylistic diversity amongst hei tiki and the progressive modification of hei tiki styles over time. The mana which is imbued into hei tiki by their makers in relation to the expectations of their community is explored. This form of mana is asserted to be an expression of correct stylistic coherence as achieved by the creative agency of hei tiki makers working in relation to - and in response to - the collective agency of their communities who define cultural norms. It is suggested that this tendency may have had an influence upon the relatively rapid development of stylistic diversity amongst hei tiki quite soon after their initial appearance, as the hei tiki fashion spread from a point of origin and was adapted stylistically in each locality to conform to pre-existing local conventions of style. It is further suggested that this tendency thereafter probably exerted a moderating influence upon stylistic development, so that while styles probably continued to change, change was probably gradual and continuous rather than abrupt. While hei tiki makers are viewed as having played a role in ensuring the continuity of styles, they are also seen as agents of restrained innovative change.

A position adopted in this study is that a close and continuing relationship between wood carving and the making of hei tiki may have existed throughout the era of traditional hei tiki making, from its beginning. This position is supported by the view that as wood is a softer and more easily worked material than pounamu, ongoing stylistic innovation - and changing convention - may have occurred first in wood carving before being adopted in simplified form for use in hei tiki. It is considered that as pounamu is such a valuable and difficult material to work, and as hei tiki are intricate and stylistically complex, tohunga whakairo 'expert carvers' probably carried out the challenging task of making hei tiki. It is asserted that tohunga whakairo may often have been proficient wood carvers as well as hei tiki makers, or at least highly proficient in the rendering of wood carving imagery in pounamu. 
The limited range of basic style types for hei tiki is outlined. It is maintained that most of the stylistic variation of hei tiki is a matter of detail with most hei tiki conforming to either of two configurations. The apparently restricted regional distribution of the less common type II style of hei tiki is investigated. It is considered that the full range of basic style types may not have been available for hei tiki makers in all districts and that this may have been another way in which adherence to local convention was made manifest.

\section{Influence of local artistic convention upon the stylisation of hei tiki}

\section{Probable influence of local conventions upon early diversity of styles}

A position adopted in this thesis is that once hei tiki had made their initial appearance - at a point of origin which may never be known - the fashion probably took hold and spread quite rapidly across many regions. It is suggested that much of the impetus for the hei tiki fashion taking hold and spreading quite quickly may have come from the intensely competitive hapu and tribal nature of Māori society. In such an environment the possession of such a prestigious new adornment was probably a matter of immanent concern, as the personal mana of rangatira was at stake.

It is argued that in the likely process of being quickly adopted throughout the many tribal regions of New Zealand, hei tiki probably took on a variety of stylistic appearances quickly to reflect existing local conventions, those of wood carving styles in particular. According to this view a relatively high degree of stylistic diversity probably came into being quite early on after the appearance of hei tiki.

It is argued that local conventions of style - reflected in the expectations of the community to whom the hei tiki maker belonged - were probably influential in seeing the appearance of a range of hei tiki styles which were maintained and slowly developed over time.

\section{Indoctrination into the crafting of culturally acknowledged forms}

Mead (2003:254-255,260-261) stresses the point that traditionally the place of the Māori artist was closely positioned within the community to whom they belonged. He records that creative talent or pūmanawa was believed to be primarily a genealogically inherited attribute, which, through much practice and appropriate training under a tohunga 'expert', 
could be developed to a high level of proficiency demanded by the people. The creative process was regarded as a tapu 'sacred' activity demanding adherence to tikanga 'protocol' as well as mastery over artistic form. A sub-standard piece of work may be rejected, and worse, regarded as a reflection of a breach of tapu with dire consequences to the artist and their family.

A conservative tendency to Māori artistic practice appears to be indicated by these views. They indicate that artists were trained according to a strict code of conduct and with high expectations placed upon them in the rendering of culturally acknowledged forms. This impression is reinforced by Mataira (1983:82) who asserts of Oceanic art in general "Subtle innovations might pass notice but attempts at radical change are likely to initiate strong disapproval." Gell (1998:158) provides a supporting view with his assertion that while "the expression of artistic individuality" is an important characteristic of Western art, this does not hold for non-Western cultures. He maintains that traditionally non-Western cultures have assessed the virtuosity of artists according to their ability to work within quite strictly defined cultural parameters to maintain the "stylistic coherence" of their art forms. Even so, Gell $(1998: 23,25,36-37)$ asserts that indigenous artists are primary agents, with the community sanctioned cultural "prototype" or template attributed as possessing secondary agency in this creative relationship.

\section{The argument for a trend of increasing size of hei tiki}

Skinner (1974:47) argues for a trend of increasing hei tiki size over time. As evidence for this trend he notes that about half a dozen hei tiki were collected on Cook's expeditions, "all are small in size", while one of the hei tiki retrieved from below the ash layer of the Murdering Beach village burnt to the ground in 1817 is $13 \mathrm{~cm}$ in length, and another Te Āti Awa hei tiki collected in 1844 and thought to date to about that time is $18 \mathrm{~cm}$ in length. The large Te Âti Awa hei tiki is shown by Beck with Mason (2010:130) who have summarised the argument: "The early hei tiki were quite small, usually less than $10 \mathrm{~cm}$ in length, but later giants of 18 cm and more in length were made." (2010:127,131). 


\section{Explanations for the trend}

Groube (1967:454) suggests that a trend towards increasing hei tiki size can be seen as part of a wider trend in which houses and all Māori art forms became larger and more elaborate as an assertion of Māoritanga in response to European colonisation. The trend of increasing size and elaboration of Māori wood carvings is also recorded by Simmons (1965:143-145). Regardless of the specific reasons it occurred, the trend of increasing hei tiki size serves as an example of ongoing innovation and the creative agency of hei tiki makers exerting their influence upon the appearance of hei tiki over time.

\section{Evidence for the influence of regional wood carving styles upon regional styles of hei tiki}

Archey (1933:186) states that "It is a well-known feature of all decorative art that difficult materials impose a simpleness of form and a restriction of ornament ... while easily-worked materials give scope for elaboration". This understanding suggests the possibility that as wood is a much softer more easily carved material than pounamu, ongoing innovation in tiki imagery may have occurred first in wood carving, establishing new stylistic conventions, to which hei tiki styles were then adapted in order to conform.

Neich (1997:25-26) asserts that hei tiki makers were evidently strongly influenced by their own regional wood carving traditions. He notes that while many hei tiki appear to adhere to generic configurations, much of the detailed stylistic variation to be found in many other examples appears to be a reflection of regional carving styles. Neich refers to the often-cited peaked head of hei tiki from the Taranaki district, the raised hand to the mouth of Te Arawa examples, and the upright head of hei tiki from North Auckland. From early on in his academic career Skinner (1916:314) credited the probable influence of wood carving upon the hollowed backs of some hei tiki, and later also attributed much of the regional variation of hei tiki to the influence of local wood carving styles. Skinner (1940:10) credits the variety of wood carving in the Auckland province as a possible reason for it being the region of greatest hei tiki variation.

The possibility that an ongoing dynamic relationship between wood carving and hei tiki making may have existed appears to be supported also by the view that hei tiki may have 
been made by tohunga whakairo 'expert carvers' proficient in both wood carving and pounamu working, or at least proficient in rendering wood carving imagery in pounamu.

\section{Hei tiki making: - work requiring a high level of skill and dedication}

In the $19^{\text {th }}$ century Henare Tawha told the Reverend J.W. Stack that only the most skilful craftsmen made hei tiki, their working being a much more difficult task than the making of simpler "ornaments", tools and weapons (Robley 1915:74).

Support for this view can be taken from an investigation into the time and effort required to make hei tiki. Barrow (1962:254) records an experiment conducted in 1955 by a Mr Hansson of Wellington in which a hei tiki was made using a variety of methods designed to approximate traditional techniques. It took some 350 hours to finish the hei tiki starting from a piece of pounamu pre-cut to approximate size. It was believed that the time taken could have been reduced considerably if a second example was attempted due to the experience he had gained. This estimate has been confirmed in recent years by the experience of a handful of skilled stone working practitioners, who, while they have been mostly practicing independently for many years, have recently (2013) formed an official group "Te Ao Kohatu". Group member Phil Belcher (Unpublished 2005:4) records at least 300 hours to fashion hei tiki by hand using traditional Māori techniques.

An approximation of 300 hours applies only to examples of hei tiki made from existing precut pieces of pounamu, such as adze blades. If such a piece of pounamu were not available then considerable additional work was required to saw a usable piece from a larger boulder. This laborious and time consuming task using abrasive mania cutters has been discussed in the previous chapter. And of course prior to the cutting phase of work, considerable time and effort was involved in finding pounamu in remote source areas and extracting it.

It is maintained that given the value and rarity of pounamu and the time, skill and difficulty involved in making hei tiki, this work was probably most often undertaken by tohunga whakairo 'expert carvers', who had been properly trained and who were highly familiar with local conventions of style. It is asserted that as tohunga whakairo hei tiki makers may also have been wood carvers or at least proficient in representing the conventions of wood carving tiki imagery in pounamu. 


\section{Moderating constraints imposed by the toughness of pounamu and the small size of hei} tiki

The extreme toughness of pounamu probably had an effect of minimising the stylistic design detail of hei tiki in relation to that of wood carving. The abrasive stone mania, kani and other pounamu working tools available to hei tiki makers may have been limited in their ability to depict the full range of stylistic detail as evident in wood carving figures. Furthermore it is suggested that even if such technical ability was at the hei tiki maker's disposal such an intricacy of design would have likely been lost upon the viewer given the relatively small size of hei tiki. With the exception of an overall increase in the size of carvings which could be reflected well in hei tiki, it is asserted that ongoing developments in wood carving could probably only be partially represented in hei tiki.

\section{Hei tiki style types}

The limited range of basic style types for hei tiki is outlined. It is argued that most of the stylistic variation of hei tiki is a matter of detail with almost all hei tiki conforming to the two basic configurations. The apparently restricted regional distribution of the less common type II style of hei tiki is investigated. It is concluded that the full range of style types may not have been available for hei tiki makers in all districts and that this is probably also a manifestation of adherence to local convention in the making of hei tiki.

\section{Two main style types}

It has long been observed that hei tiki pendants are of two general stylistic types, one being more common than the other. Robley (1915:63-64) designated the two hei tiki styles as type A and type B, with the more common being type A. Webster (1948) classified a large number of hei tiki in the Armytage Collection according to type I (hands on thighs) and type II (one hand on breast), these two types corresponding respectively to Robley's type A and type B.

Neich (1997:27) describes the most common form of hei tiki as typically “... made from a thick heavy piece of nephrite ..." which, "... allows the eyes to be large and deep, with similar deep moulding of the body and limbs." Both hands are typically positioned to the thighs. This style of hei tiki is also usually relatively wide at the neck. 
The rarer type of hei tiki, "appearing perhaps about once in every ten examples" is characterised by Neich as usually being made from a thin piece of nephrite, "with small shallow eyes" and body and limb features worked in low relief, and relatively narrow at the neck. An asymmetrical twist is typically given to this style of hei tiki by one hand being raised to the body or head, while the other hand is positioned down to the thigh.

Neich (1997) sometimes uses the terms symmetrical and asymmetrical as a convenient type of shorthand to signify the two stylistic types, although the 'symmetrical' common style of hei tiki with its head inclined to one side is really only symmetrical from the head down.

It should be noted that the evolutionary style categories employed by Skinner and Hiroa differ somewhat from the typological scheme outlined above. Skinner (1932:207) uses the designation of type $A$ for a restricted range only of the rarer shape of hei tiki and Hiroa (1950:293) includes both Webster type I and Webster type II hei tiki to exemplify the variation of his type $B$.

\section{Other minor style types}

Another hei tiki style configuration is a rare hybrid hei tiki-matau form incorporating both hei tiki and hei matau 'fish hook pendant' features. To date this type seems to be known by only two examples: a famous hei tiki in the British Museum which belonged to the Ngā Puhi chief Titore (Robley 1915:46-47, Skinner 1966:14) and a less well known example from the mouth of the Waikanae River, described by Barrow (1961). Given the depth of the body on each example Barrow concludes that it is unlikely the hei tiki form was worked on to existing hei matau, rather they appear to have been worked as hybrid hei tiki-matau from the outset.

The research project in this thesis employs an additional style category for hei tiki termed type I/II. Examples of type I/II contain stylistic elements of both of the type I and type II hei tiki as described above. 


\section{Evidence for restricted regional distribution of the type II style}

An investigation is made into evidence which suggests that the regional distribution of the type II style of hei tiki may have been more restricted than that of type I, or at least that it was much more common in some regions than others.

The type II shape of hei tiki has been associated with the Bay of Plenty region by Simmons (1966b:24-25). Simmons profiles an example of the type from Mokoia Island, Rotorua, but comments "There is some indication ... that this type of tiki is also well represented in the Whanganui Region."

A footnote in Ethnographical Album of the Pacific Islands (Edge-Partington 1996:182) comments:

Note: Mr Turnbull of Wellington, N.Z. considers that the more squareshaped tikis come from the north - Waikato, Thames, etc. Whereas those in which the neck is more defined are further south - Taranaki, Wanganui, etc.

The geographical distribution of the type II style of hei tiki could probably be extended through a fuller investigation, but such a task is beyond the scope of this thesis. Simmons (1966b:22-23) records the common type I hei tiki from both the Whanganui and Taranaki districts, so Edge-Partington's record of Turnbull's opinion on the regional distribution of this type should be considered in a less emphatic light. The restricted regional distribution or apparent preference for the type II hei tiki in some districts more so than others, can be interpreted as suggesting that local conventions of style also applied to the choice of basic hei tiki configuration. 


\section{Chapter conclusions}

Hei tiki makers imbued their work with mana by exercising their agency in the crafting of hei tiki in accordance with culturally acknowledged styles. Community sanctioned conventions of style were probably already well established, primarily in the wood carving arts, when the hei tiki fashion took hold and spread throughout the land. It is asserted that this probably exerted an early influence upon the creation of regional diversity amongst hei tiki styles. Thereafter it is probable that hei tiki styles continued to develop slowly over time in accordance with accepted convention resulting in continuity being a stronger feature of stylistic development than marked or abrupt change.

An enduring relationship between hei tiki and wood carving seems possible given the probability of early stylistic influence between the two art forms, regional similarities of style noted between hei tiki and wood carvings, the softer nature of wood making it a more ideal material for stylistic innovation, and the possibility that tohunga whakairo may have been accomplished in both wood carving and hei tiki making. The process of integrating some new innovative features from woodcarving into hei tiki may have been constrained by the extent to which features could be reproduced to effect in the much tougher material of pounamu and on a much smaller scale of size.

The argument for a trend of increasing hei tiki size over time may be tested by comparing mean size data for hei tiki provenanced to 1769-1777 with that recorded for the general assemblage; it may be tested also by comparing estimated use wear - indicative of age against hei tiki size to see if the features of smaller hei tiki appear to be worn to a greater extent than those of larger examples. If so then supporting evidence for the argument will have been found.

The degree to which the overall stylisation of hei tiki was probably established at an early date may be tested by analysing the recorded features of hei tiki known from the early contact period 1769-1777 and comparing these features with those of the larger general selection of hei tiki. 


\section{Chapter Three: Māori Agency in the Popularity and Use of Hei Tiki}

\section{Chapter introduction}

This chapter investigates the mana of hei tiki which is derived from prolonged ancestral use. The investigation is carried out within a wider exploration into the question of Māori agency in the rise in the popularity of hei tiki, particularly during the early $19^{\text {th }}$ century when hei tiki making is thought to have reached its highest point.

Three components are identified in order to account for the growing popularity of hei tiki: increasing supply of pounamu, growing availability of skilled craftsmen to fashion hei tiki, and increasing demand for hei tiki. An exploration is made into the influence of these three components. Growth in the supply of pounamu is argued to have probably resulted from a combination of an increase in the indigenous supply of pounamu from South Island sources and the freeing up of pounamu in adze form with the adoption of metal carving tools. Rising capacity for hei tiki making through an increasing skill base is suggested as having been associated with growth in the flourishing wood carving arts, bought about in part firstly by the increased availability of pounamu carving tools and secondly by the increased use of metal tools. Arguments for increasing demand for hei tiki are examined and found to be divided, with some maintaining demand continued to come primarily from Māori, and some arguing for greatly increased demand from Europeans eager to acquire hei tiki as trade items. A great deal of uncertainty is identified as existing in this area.

The implications of European trade item status are investigated. While Māori agency is maintained to exist in the making of hei tiki for trade to Europeans, it is asserted that such hei tiki may lack prolonged ancestral connections, which are important for traditional understandings of mana. An investigation is made into the mana of hei tiki which is derived from ancestral use. It is concluded that a considerable portion of the mana of hei tiki is derived from ancestral use, with the esteem in which hei tiki were held being closely related to their degree of antiquity. The extent to which hei tiki exhibit signs indicative of prolonged use or of a lack of such use is identified as being an important area of focus for the research project, with implications for the mana of hei tiki. 


\section{An investigation into the increasing supply of pounamu}

The notion that the adoption of metal for carving tools freed up large quantities of valuable pounamu in adze form for reworking into hei tiki and other taonga can appear quite persuasive; but it arguably tends to mask the contribution that a probable increase in the indigenous supply of pounamu made to the popularity of a range of classic and early $19^{\text {th }}$ century Māori taonga, including hei tiki.

\section{Increase in pounamu supply from South Island sources}

Anderson (1998:207-208) argues that while pounamu had been used from the early settlement period for tools, the pounamu industry had only existed on a relatively small scale until after the arrival of Ngāi Tahu in the South Island. Ngāi Tahu arrival and settlement in the Canterbury region has been tentatively placed to the early-mid $18^{\text {th }}$ century (Anderson 2008:29) with Ngāi Tahu exploitation of pounamu well established by the late $18^{\text {th }}$ century $(1998: 208)$. It is considered that from the second half of the $18^{\text {th }}$ century a thriving industry existed extracting nephrite pounamu from the central Westland source and the Wakatipu source and processing it in workshops located along the East Coast of the South Island to the north of Southland. The most notable of these pounamu workshops are identified as Kaiapoi in Canterbury and Whareakeake 'Murdering Beach' in Otago. It is argued that as pounamu became a major commodity of trade and a source of wealth to Ngāi Tahu, the boost in supply to all tribal areas fed the production of the range of pounamu tools, weapons and adornments, by which the classic phase of Māori culture is characterised (1998:146,207-208).

As evidence to support this argument Anderson points to the relative abundance of pounamu in late prehistoric era sites in areas which came under Ngāi Tahu control to the north of Southland, in relation to the relative scarcity of pounamu in Southland which remained under Ngāti Māmoe tribal control until considerably later $(1998: 167,207-208)$. Support for this argument can be found in Jacomb et al (2010:22) who adopt Anderson's position in their review of the archaeology of the Foveaux Strait region. They also refer to the relative wealth of pounamu in late precontact sites in the northeast South Island in comparison to a much lesser quantity of 
pounamu in Southland sites and interpret this as being indicative of the relatively late arrival of Ngāi Tahu in the far south.

Beck with Mason (2010:51) and Neich (1997:5) record that the primary and most accessible source area of pounamu is located in the rivers and tributaries between present day Greymouth and Hokitika. This is the central Westland source area, which Anderson (1998:22) notes had long been controlled by the Ngāti Wairangi tribe since their migration to the South Island via Taranaki in the late $15^{\text {th }}$ century. It is thought, however, that soon after settling in the South Island Ngāi Tahu managed to establish a degree of hegemony over Ngāti Wairangi so that a regular trade in pounamu was maintained across to Kaiapoi and other pounamu workshops on the eastern side of the island (Anderson 1998:39, 2008:37). Ngāi Tahu settlement in central Westland is considered to have only begun in about 1810 or a little later following a protracted period of raiding and warfare with Ngāti Wairangi (1998:39).

It is argued that the increase in the supply of pounamu achieved by Ngāi Tahu not only provided more of this precious material for making more hei tiki, it also provided more pounamu for making a greater number of adze blades, which by one means or another would eventually be rendered obsolete and re-worked into hei tiki and other items. It appears unlikely that such large numbers of pounamu adze blades would have been available for reworking into hei tiki in the early $19^{\text {th }}$ century had the supply of pounamu not increased dramatically beforehand.

\section{The transition to metal tools and the freeing up of pounamu adze blades}

Brown $(2003: 33-34,37)$ gives "the early 1800s" for the time at which Northland Māori had transitioned to using iron carving tools. She argues that the early transition was largely due to the high premium paid for pounamu in the far north located far from the South Island sources. Simmons (1965:144) states that the overall transition to steel tools, by Māori in general "was probably completed by about 1820 ". From these accounts it seems that the transition to metal tools was probably a gradual process, a phase which occurred unevenly throughout New Zealand during the late $18^{\text {th }}$ and early $19^{\text {th }}$ century and which saw pounamu adzes used alongside metal tools for a number of decades. 
The metal-like qualities of pounamu at holding a sharp cutting edge are acknowledged by Beck with Mason $(2010: 149,188)$. The value of the pounamu adze as a very effective wood working tool - close to metal tools in its efficiency - is well demonstrated in a film by master stone working revivalist Dante Bonica (2009, Te Papa Kura Pounamu exhibition website).

Given the effectiveness of pounamu adzes at wood working, it is probable that the gradual adoption of metal tools would have replaced adzes of less superior stone types first, and then perhaps many pounamu blades were not replaced with metal counterparts until they had worn out. This position appears to be supported by Simmons (1965:144-145) who argues that while metal carving tools have some advantages over those of pounamu, primarily in the making of holes and deeper relief carving, their adoption did not immediately transfer into a change in style, as carvers continued to execute their work for a period in the manner in which they had been trained. Given this understanding it appears that initially the continued use of adzes of pounamu would have had few if any disadvantages over those of metal.

Over time, however, it appears that the use of metal carving tools facilitated the carving of architectural components of growing size and elaboration. Hiroa (1950:196-197) argues that this trend was aided also by the transition over time from using iron carving adzes and chisels fashioned from iron spike nails and hoop iron, to the use of better quality blades of steel, such as the use of carpenter's plane blades for adzes.

It appears that eventually widespread adoption of metal for carving tools freed up pounamu adze blades for working into adornments, and arguably in greater proportions than ever before with the earlier practice of reworking old adze blades to make pounamu whao 'chisels' no longer competing for re-use of this precious commodity (Beck with Mason 2002:84). Continued supply of pounamu from the South Island probably added to available material and for a couple of decades hei tiki making probably reached its highest point.

\section{Increasing skill base for making hei tiki}

The second component identified in order to account for the growing popularity of hei tiki, is a probable growth in the skill base of those capable of making hei tiki. It is argued that a close relationship with the flourishing wood carving arts probably existed. It is maintained 
that growth in the number of pounamu wood working tools, - resulting largely from an increase in the supply of pounamu from the South Island, - underpinned the continued development of the wood carving arts, which in turn gave rise to more highly skilled craftsmen capable of working hei tiki. It is considered that this pre-existing trend was probably then enhanced to another level with the introduction of metal carving tools. Brown (2003:28-29) points to a growing proficiency in the wood carving arts using metal tools. She writes: "... it is very difficult to tell the difference between the best stone work and metal tool work. Indeed the 'classic' period appears to have reached its stylistic zenith with the adoption of metal tools." It is argued that again this probably led to a new level of increased capacity for hei tiki making with more proficient carvers able to carry out the demanding task of crafting hei tiki.

\section{The increasing demand for hei tiki; For traditional use, or as European trade items?}

Groube $(1967,1969)$ argued for an early $19^{\text {th }}$ century efflorescence of hei tiki making driven by increased demand from both Māori and Europeans. Commenting upon the trade with Europeans eager to acquire hei tiki as collectables, Groube (1967:453) asserted "The vast majority of collectors' pieces comes from these trade tiki."

In response to Groube's trade argument Skinner (1974:47-50) maintained that hei tiki were already increasing in numbers independent of European influences. He argued that this trend continued from pre-contact times to be "virtually in full flood" by 1817 when the pounamu working village of Whareakeake or 'Murdering Beach' was destroyed in Otago. In Skinner's opinion (1935b:219, 1974:48-49) the finding of large quantities of worked pounamu at Whareakeake, including some 22 hei tiki from the uppermost layer, is confirmation of a rapid increase in the internal demand for hei tiki from Māori to the north, and not due to European influence.

However, Neich (1997:8) arrived at an opposite conclusion, commenting that the village of Whareakeake "... apparently became a centre for a specialised jade industry, virtually massproducing the more elaborate types of ornaments that could be traded in answer to a growing European interest in jade artefacts." Beck adopts a compatible position to Neich when assessing evidence for an increase in the numbers of hei tiki from Cook's first sightings and growing trade in hei tiki with Europeans, in addition to continued use by Māori (Beck 
with Mason 2002:91, 2010:131,133). He comments "Obviously Maori appreciated the wants of the European and were quick to develop the market, for from this time on hei tiki were manufactured by Maori as trading commodities to exchange for metal tools and other articles that the visiting sealers and whalers could supply."

It seems that a significant level of uncertainty and debate exists over the relative extent to which hei tiki were made to meet Māori demand or European demand during the $19^{\text {th }}$ century.

Indigenous agency in the making of hei tiki for trade to Europeans, but diminished ancestral status

Wards (2009:15) states: "Indigenous agency is also evident in the reproduction of material culture for sale to collectors." He refers to the entrepreneurial nature of the encounter where the product is sometimes tailored - perhaps through "added ornamentation" - to appeal to collectors, and the production of items is set to a level commensurate with demand in order to maximise return. Indigenous agency certainly seems apparent in such entrepreneurial trade activity.

While at first glance it could be assumed that in the making of hei tiki as trade items, the cultural template for production (Gell 1998) became commandeered by the non-Māori tastes of the collector; such is argued to be only partially true. It is asserted that the makers of trade hei tiki were probably still significantly influenced by the social agency of their communities: conditioned through their training and years of practice, and possibly still accountable directly to their communities to some extent in the making of such culturally iconic adornments. The culturally defined trade item "proto-type" can accordingly be seen as a hybrid template representing both indigenous and non-indigenous agency.

Hei tiki of trade item status may still be primarily viewed as representations of creative indigenous agency. Yet it appears that the making of hei tiki as items specifically for relatively quick trade to collectors renders hei tiki devoid of prolonged use by the ancestors. It will be argued that it is through such ancestral association - the agency of indigenous use - that hei tiki derive a great deal of their cultural meaning and mana. 


\section{An investigation into the mana of hei tiki derived from ancestral association}

An investigation is made into ancestral use and beliefs associated with hei tiki. This is followed by a discussion assessing the extent to which the mana and cultural value of hei tiki appears to be derived from their ancestral associations.

\section{He oha tupuna - ancestral heirloom}

In 1882 the Ngāi Tahu elder and rangatira Hakopa-te-atu-o-tu asserted that hei tiki were primarily worn as an "oha tupuna", - mementos worn in fond remembrance of the revered ancestors who once possessed them (Robley 1915:74-75). Robley (1915:51) records that such an ancestral oha or heirloom would be treasured and not parted with easily. Te Awekotuku (1996:28) points to the accumulation of mana and associated tapu status of taonga through prolonged intimacy with their owners and notes that this increases with each generation of wearers. Mead (1984:21-22) refers to the cultural meaning applied to taonga through the kōrero or 'oral narratives' in which they are increasingly cloaked by the people with the passage of time. In 1838, following his 1831 to 1837 residency in Northland, the merchant J.S. Polack commented that hei tiki were "particularly cherished, from the circumstance of having belonged to relatives whose appearance will gladden their descendants no more. I have frequently desired to obtain some of these antiquities, but they were esteemed beyond any price" (Polack 1838:344). Edward Shortland's view of hei tiki was that "Their value greatly depends on their antiquity" (Chapman 1891:516). This view can be interpreted as a reference to value derived from prolonged ancestral use.

\section{An argument for ancestral lineage sometimes extending from owners of adze blades}

As many hei tiki appear to have been made from pounamu adze blades it should be emphasised that adzes of pounamu were highly valued possessions in their own right. This is evidenced from the observations of James Cook who on his first visit to New Zealand 17691770 recorded:

As they have no metal, their adzes and axes are made of a black stone, or of a green talc which is not only hard but tough ... Their axes they value above all that they possess, and never would part with one of them for anything that we could give. I once offered one of the best axes I had in the ship, 
besides a number of other things, for one of them, but the owner would not sell it; from which I conclude that good ones are scarce among them.

(Hawkesworth 1775:265)

It is apparent from this account that pounamu adzes were once highly valued and therefore were probably highly sought after possessions, the ownership of which would signify a substantial degree of mana. As such it seems likely that these adzes would sometimes have been passed on to descendants. When such an adze blade eventually wore too short for continued use as a tool or was replaced by a metal carving implement it may have been reworked into a hei tiki. Some newly fashioned hei tiki therefore probably already carried with them considerable mana derived from the whakapapa or ancestral lineage of those who had owned the pounamu adze blades that they were made from. The hei tiki fashioned from these adze blades would thereafter continue to accumulate additional mana as adornments owned by a succession of wearers.

\section{He tohu rangatira - symbol of chiefly rank}

An indication of chiefly status of hei tiki comes from Charles Wilkes' (1845:303) observations from the Bay of Islands in 1840. Wilkes records that: "Around the necks of the chiefs and their wives is hung the heitiki, made of a stone of a green colour, which is held very sacred ...". When ship's surgeon John Savage visited the Bay of Islands for two months in 1805 he observed that hei tiki were worn on all formal occasions, though they were also often worn at other times. In addition to full-sized hei tiki there were also "smaller ones, made to be worn by children." (Savage 1807:51). It seems clear from these historical accounts that hei tiki were regarded as prestigious heirlooms and their possession signified significant mana, the high social status and rank of leaders and their families.

\section{Focus for grief}

Another context of traditional use for hei tiki can be identified as a focus for remembrance and grief in the absence of the deceased. Chapman (1891:520) records the observations of the Reverend William Tate who resided in New Zealand from 1828 to 1835 . Tate observed that when whānau and friends met together a hei tiki might be placed on the ground resting 
upon a leaf or tuft of grass, wept over, caressed, and sung to, the hei tiki being addressed by the name of the deceased previous owner throughout the mourning process.

\section{Burial good status}

Chapman $(1891: 513,516)$ and Robley $(1915: 50)$ record that according to ancient hahunga burial practice, when a person of status died it was customary to deposit their hei tiki and other personal treasures with them and retrieve them at a later date, when the bones were shifted to their final resting place. Chapman (1891:516) records Edward Shortland's views concerning the value of hei tiki: "It is the practice to bury such and other valued articles with the dead. After a time they are removed, and then are specially valued." Shortland records also that a rangatira once declined to give him an ear pendant upon account of it being a "pirau-tupapaku-i.e., a thing with a dead taint". Considering these accounts it seems that having burial association intensified the tapu status of the taonga and placed even greater obligation upon the wearer to care for and retain it within extended whānau possession, and it added to the esteem in which the hei tiki was held.

\section{Fertility and child birth talisman}

Te Awekotuku $(1996: 43,45)$ refers to the practice of hei tiki being worn by women as talismans of fertility and easy childbirth. The use of hei tiki in this context appears to be closely associated with Hine-te-iwaiwa, the goddess often credited with owning the first hei tiki and who was the deity of childbirth and of all womanly tasks (Best 1914:130). Beattie (1994:57) records that if a high born woman was fortunate to possess a hei tiki to wear during pregnancy they would recite karakia to it "in the expectation that they would have an easy childbirth".

\section{Kaitiaki - protector against misfortune and witchcraft}

Another possibly allied protective use of hei tiki is recorded by Savage (1807:21) who writes: "It is worn round the neck of both sexes, particularly during times in which peril is apprehended". Support for this view is provided by Makereti (1986:13) who, in The old-time Maori, records that in addition to being a memorial to ancestors and conveying mana, a hei tiki was believed to possess the ability to avert witchcraft and accident. 


\section{Discussion}

In assessing the above accounts it appears obvious that a considerable portion of the mana and cultural significance of hei tiki is due to their ancestral use in a variety of ways and social contexts. A lack of such ancestral association through European trade item status would appear to impact negatively upon the mana of hei tiki. This conclusion is supported by Shortland's statement that 'their value greatly depends on their antiquity'.

\section{Chapter conclusions}

A continuum of considerable pre-contact and post-contact Māori agency can be discerned when identifying probable influences which saw hei tiki increase in popularity as the most highly prized Māori adornment.

Increased supply of pounamu in raw and in adze form appears to have resulted from indigenous agency which saw the southern pounamu industry developed to new heights from the second half of the $18^{\text {th }}$ century onwards. Large numbers of hei tiki may have been made in the early $19^{\text {th }}$ century from pounamu adze blades no longer used for wood carving because of the adoption of metal tools.

An argument for increased indigenous capacity for making increased numbers of hei tiki can be supported by the view that both pounamu and metal tools underpinned the flourishing wood carving arts, which probably saw the numbers of skilled craftsmen increase.

Māori agency is apparent in the production of hei tiki in order to satisfy European demand as well as in the meeting of continued Māori demand. It is concluded however that a lack of antiquity and ancestral association is implied by European trade item status and this lack of indigenous agency-of-use impacts negatively upon the mana of hei tiki.

The collections based research component to this thesis uncovers new evidence through surface wear and pounamu analysis which provides an indication of the relative extent to which hei tiki may have been made as European trade items or for traditional use. This chapter highlights the importance of ancestral connections for the establishing the mana of hei tiki and it shows that much hinges upon the outcome of the research findings in terms of the mana of hei tiki. 


\section{Chapter Four: Hei Tiki Research Project - Rationale, Methods and Techniques}

\section{Chapter introduction}

This chapter represents the first part of a collections-based study of hei tiki, which is based largely upon a comparison between the recorded features of two study groups: one a general selection of 50 hei tiki, the other a selection of 8 hei tiki and drawings of hei tiki with provenance to 1769-1777. A rationale is given for the way in which the study is structured, the method of hei tiki selection, and the recording methods and techniques. Images and recorded features of the selected study assemblages are to be found in appendix one.

The research project is based on the premise that the hei tiki used in this study, possess the mana, or latent potential, to bring about significant new understandings into hei tiki as a whole. The intention of the research project is to actualise this mana.

The research project is framed in its focus and scope by viewpoints developed in the literature review. These viewpoints include the position that the adze shape may be closely associated with the origins of hei tiki; that the most common type I style of hei tiki may have come to prominence very early on; that the stylistic complexity of hei tiki may have been highly developed from early on making use of pre-existing wood carving imagery; that a high level of stylistic diversity may possibly already be evident amongst early hei tiki; that a trend for increasing size of hei tiki over time may have occurred. The review also identified the importance of gaining a better understanding of the extent to which hei tiki exhibit characteristics indicative of prolonged Māori use, or characteristics consistent with having been European trade items.

The recording of hei tiki features has been structured to enable insight into the above viewpoints and to some extent test their validity. An emphasis is accordingly placed upon recording hei tiki shapes indicative or otherwise of the adze shape; recording hei tiki style types; systematically recording a full range of detailed stylistic features including their size and proportion measurements; recording the degree of apparent use-wear; and recording pounamu characteristics. Analysis of these recorded features is presented in chapter five. 
The group one hei tiki, with provenance to the period 1769-1777, when regular ongoing contact between Māori and Europeans was established, provides a point of comparison against which the recorded features of hei tiki in general may be analysed. The early contact assemblage is comprised of 5 hei tiki held in overseas collections with provenance to 17691777 , and is augmented by drawings of 3 hei tiki from the period. The general assemblage of hei tiki, referred to as group two, is comprised of 50 hei tiki selected from the collection of Te Papa.

\section{Selection methods and techniques}

\section{Identification of early contact period hei tiki in collections}

The five hei tiki selected as examples from the early contact period AD 1769-1777 are published as Cook voyage 'artificial curiosities' by Adrienne Kaeppler (1978:176-177). Three of the five hei tiki are also included in Kaeppler's book regarding the Leverian Museum (2011:157). Together, the five hei tiki may represent all currently known examples of hei tiki surviving from the early contact period. They are held in the collections of the Kunsthistorisches Museum, Vienna, the Royal Collection Trust, London, The Pitt Rivers Museum, Oxford, and The Field Museum, Chicago.

Kaeppler has spent much of her extensive career researching artefacts of Cook provenance and has applied rigorous research techniques to their identification. She notes that while Cook voyage provenance was often claimed it also often failed to be convincing when closely investigated (Kaeppler 1978:xiii).

Special mention is made of the non-inclusion in this early study group of three hei tiki, in order to ensure against the potential for claims that they should have been included, and because of their potential to mislead future investigations. One hei tiki from the Auckland Museum collection, registration number 3320, is referred to by Robley (1915:69) and later figured by Best (1924:216-217) who states that it was "... said to have been obtained by one of Cook's officers." However the same hei tiki is shown in the Te Maori exhibition catalogue (Mead et al 1984:231) and again by Salmond (1997:294) with the information that it was collected by a crew member of a different ship named the Endeavour; - this probably being 
the ship of that name abandoned as beyond repair in 1795 after arriving at Dusky Sound 'Tamatea' in Fiordland.

The other examples in question are two hei tiki returned to New Zealand in 1912 from the United Kingdom as a gift from a Lord St Oswald. They are part of the Te Papa collection, registration numbers ME002504 and ME002505. Collection documentation records that the hei tiki were part of a larger collection of taonga that Lord St Oswald inherited from his grandfather, Charles Winn, some of which can be traced to Cook voyages via the William Bullock Collection, but not these particular examples (Te Papa accession record: Acquisition - Donation; Lord St Oswald). Barrow (1964:28) published the first of these two hei tiki as having Cook voyage provenance. Kaeppler (1978:175) however refuted the validity of Barrow's stated provenance by asserting that its known history of ownership can only be traced back as far as 1819. Both hei tiki are included in the general study group (group two) listed as numbers 2.5 and 2.26. A conclusion of the analysis indicates that $1769-1777$ hei tiki possess a relatively high number of atypical features. Hei tiki 2.5 has a highly atypical mouth worked in profile, a stylistic feature consistent with it being from the early contact period, but this is considered insufficient reason for the inclusion of this example in the early study assemblage.

\section{Identification of drawings of additional early contact period hei tiki}

Because there are only 5 hei tiki in collections, with established provenance to $1769-1777$, the selection of hei tiki is augmented by drawings of another three hei tiki observed during the period. The drawings are considered to offer reliable evidence in a general sense to record some clearly evident features not greatly affected by the potential for minor artistic license. They thereby extend the number of early hei tiki from five to eight upon occasion for recording certain generally obvious features.

The inclusion of these images is based on the following evidence. The first hei tiki (figs 5 and 22) was recorded during a visit to Doubtless Bay in Northland in December 1769 by the French explorer Chevalier J.F.M. de Surville (Milligan 1958:187-188). Expedition member, L'Horme, figured a drawing of the hei tiki in his journal and this is reproduced as Plate 1 in Milligan (1958). 


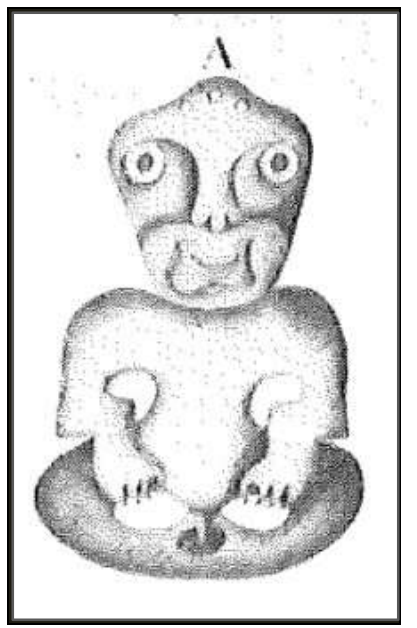

Figure 5 Drawing of hei tiki from Doubtless Bay.

The second hei tiki (figs 6 and 23) was drawn by naturalist Herman Sporing on the 18th of October 1769 when the Endeavour was anchored off Mahia Peninsula. It is thought to have been worn by one of two rangatira 'chiefs' who boarded the ship on that day (Salmond 1991:151-153). It is tentatively suggested by the British Museum that this may be one and the same hei tiki as the example from the Royal Collection: early contact study assemblage hei tiki 1.5 (The British Museum website, 'Tiki belonging to Captain Cook').

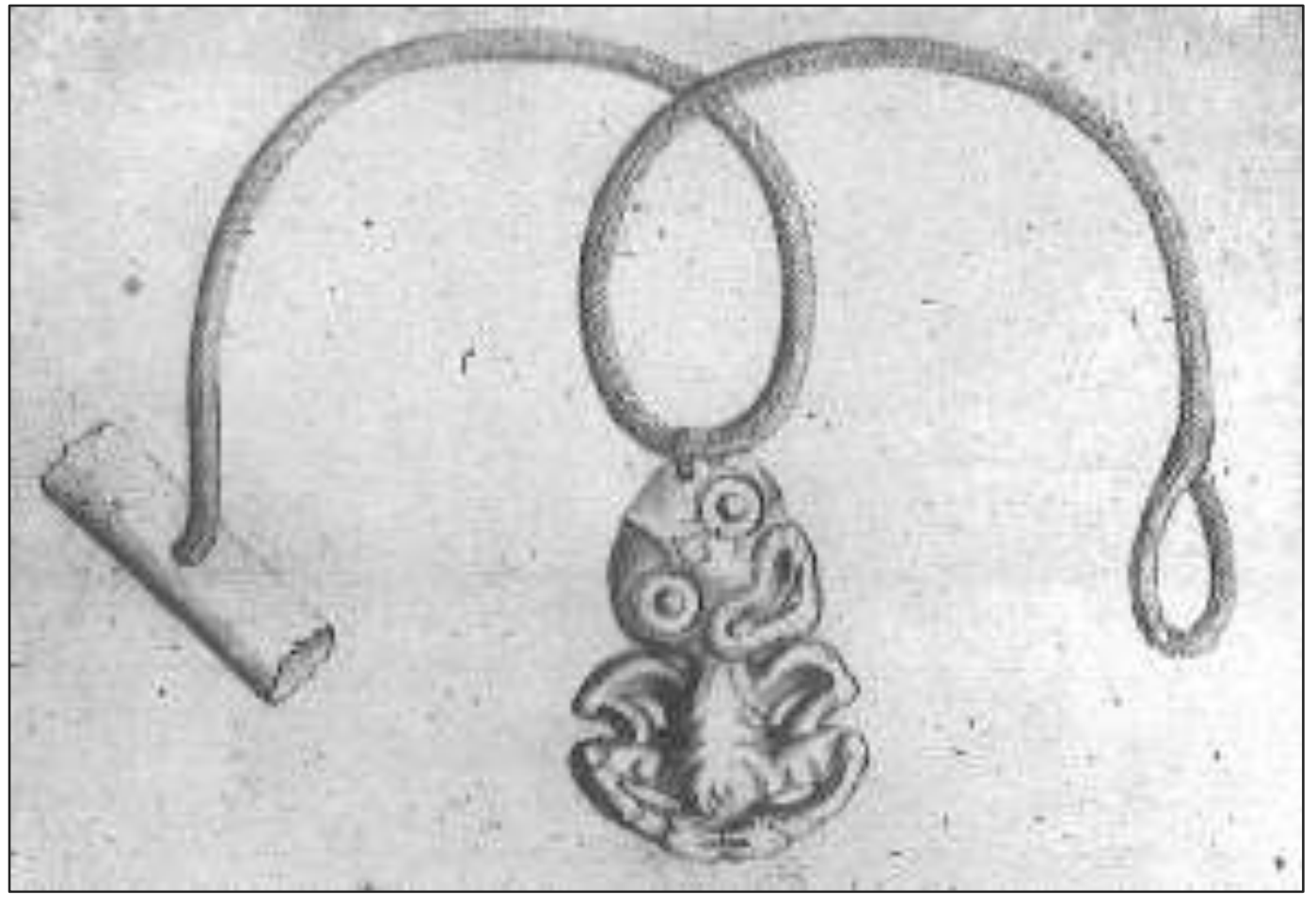

Figure 6 Drawing of hei tiki from Mahia Peninsula. 
A comparison between this drawing and hei tiki 1.5 (shown on page 89), however, shows the likeness to be superficial. The Sporing drawing (above) shows an identifiably female hei tiki with definite hands and feet, a single suspension hole, a very finely plaited suspension cord, and it is as wide at the knees as at the elbows. The thumbs of the hands rest across the lower abdomen in a manner typical of other known hei tiki [for example 23.23]; knobs are apparent at the knees and the indicative neck is worked in conventional manner. These are all notable differences demonstrating that this hei tiki and the Royal Collection example should be considered to be two Cook-voyage hei tiki rather than one and the same.

The third drawing (figs 7 and 24) comes from Robley (1915:60). It is of a hei tiki stated to have been collected by a midshipman Burr on Cook's third voyage to New Zealand. Reference to lists of crew on Cook's voyages failed to identify a midshipman Burr on the third voyage, but did identify a John Davall Burr who had sailed as a midshipman on vessels for several years directly prior to joining the Resolution on Cook's second voyage, where he served as a master's mate (Robson 2013, Captain Cook Society website). This evidence suggests that this is a Cook voyage hei tiki. The attribution appears to be further strengthened by the existence of a whalebone wahaika in the Te Papa collection with similar "Midshipman Burr" stated provenance to the third Cook Voyage. Collection number OL000061 (Oldman 2004:15-16, plate 48).

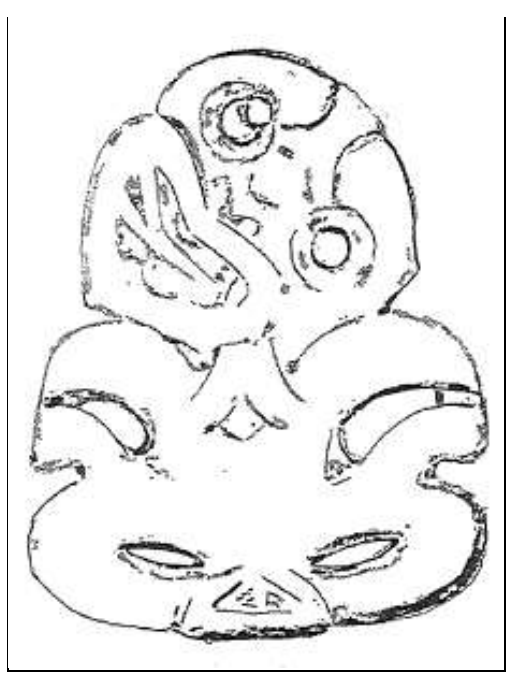

Figure 7 Drawing of hei tiki collected by Burr. 


\section{Identification of the general selection of hei tiki from the Te Papa collection}

The study assemblage of 50 hei tiki from the Te Papa collection was formed according to several selection criteria. The criteria included the need for hei tiki to be apparently finished and complete in order to maintain integrity of the observations. It was considered that little significance could be given to a feature being recorded as not present on an unfinished hei tiki, since the feature may potentially have been added had the hei tiki been finished. Including only fully complete hei tiki without broken off portions enabled a full range of features to be recorded for each hei tiki, apart from those features which were obscured by surface wear. It was decided not to discriminate against including any examples on the basis of wear, as surface wear is considered an important feature in its own right indicative of use and age. To exclude highly worn hei tiki may have excluded some of the oldest examples and resulted in a biased selection.

Importantly hei tiki also had to possess a range of features indicative of traditional Māori workmanship as many copies of hei tiki were produced by European lapidaries from the 1860s onwards, as outlined by Watt (1990:227-228). The cumulative presence of a number of indicators assisted the process of identification of traditional hei tiki of Māori make from those made by Europeans. Beck (2010:140-141) records how in comparison to most authentic Māori hei tiki European copies are often out of scale, too parallel, cut against the grain of the stone, and roughly made. European work is generally less accomplished and it sometimes contains unconventional elements. Traditional abrasive stone tools wear away themselves as they give shape to hei tiki resulting in smooth contours and grooves, features very difficult to replicate using European tools such as rotary grindstones and mandrills.

Suspension holes of traditional hei tiki are distinguished by their internal hour glass shape, with typically the largest cavity - representing most of the drilling - being on the back of the head hidden from view. The holes are drilled from each side meeting in the middle. Beck with Mason (2010:159) record how often the ends of shallow saw scarves can be seen extending from the edges of the holes. The intersection of these grooves was used to keep the tip of the stone drill bit in place while the hole was started. In contrast European tooled holes possess no starter grooves and were drilled straight through. 


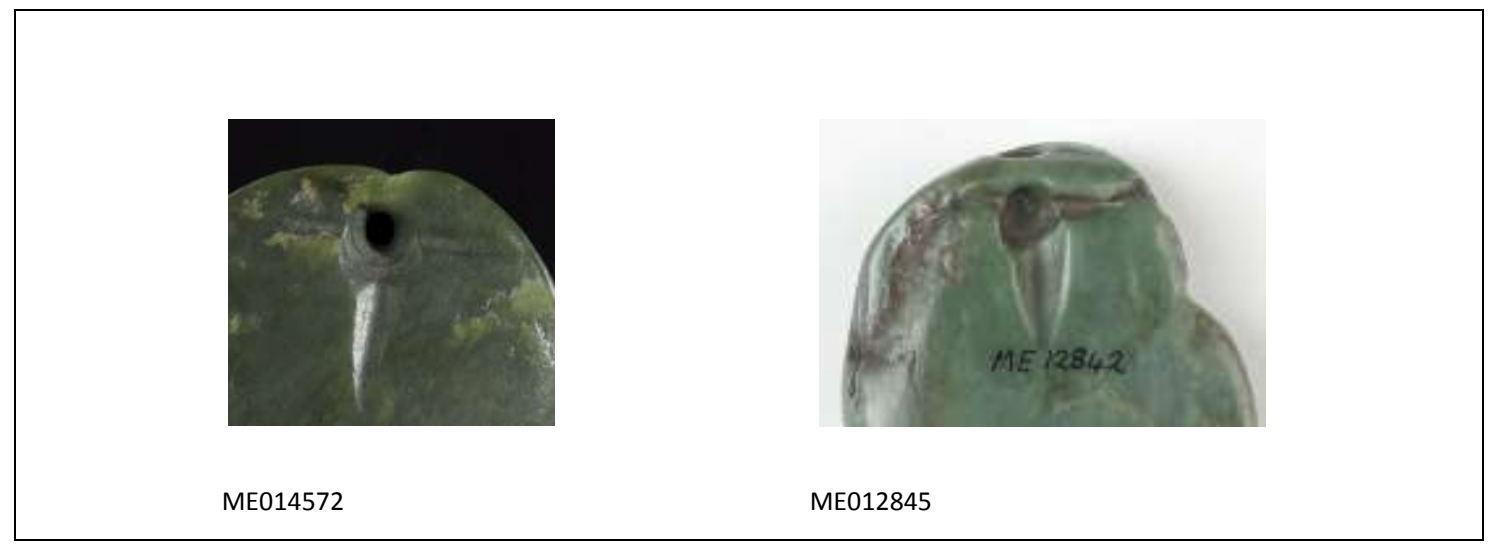

Figure 8 Examples of remnant saw scarves on back of heads to start holes.

The glossy jeweller's polish to the surface of $20^{\text {th }}$ century hei tiki is very different to the matt finish achieved by traditional means, or to the work of the early European lapidary.

Sometimes the remains of saw scarves can be seen formed when the pounamu was first cut.

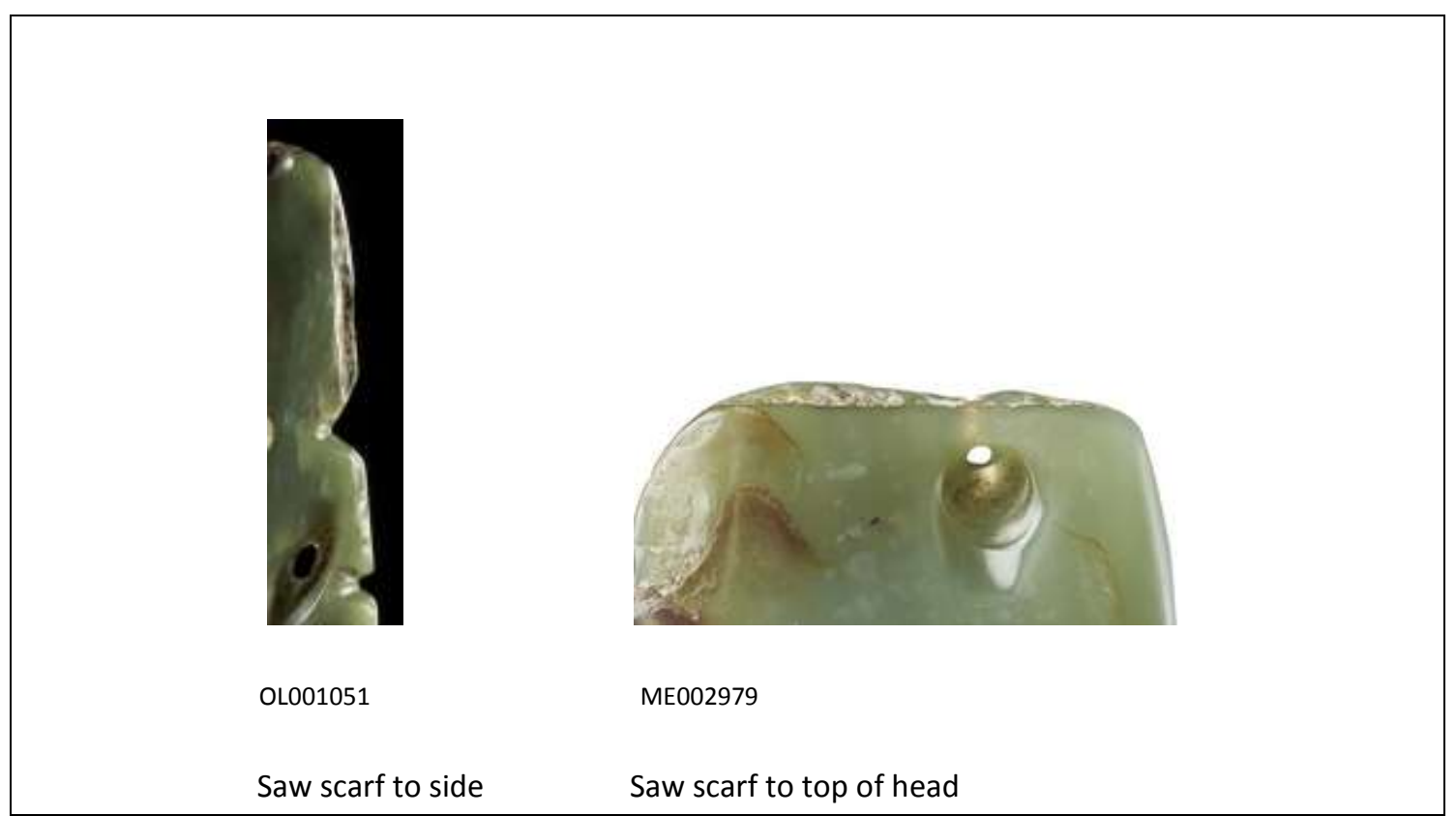

Figure 9 Examples of remnant saw scarves on edges of hei tiki.

It was considered that the presence of kōkōwai or red ochre could be interpreted as an indicator of traditional use, as could the presence of extensive wear. It was also considered that low temperature heat treatment - usually followed by regrinding the surface - was a traditional technique presumably unknown to non-Māori in New Zealand and could be taken as another indicator of what may be termed authenticity, in terms of established parameters of origin as discussed by Watt (1990:19). Another indicator of authenticity was 
considered to be the presence of original elaborately plaited suspension cords with bird wing bone toggles, as this appeared to be a feature unlikely to be found on hei tiki of European make. Similarly the presence of residue from traditional resin adhesive in the eyes was also considered to be indicative of early Māori work. It was considered that taken singly any one of these indicators would likely be insufficient to identify hei tiki for inclusion in the study group. However the cumulative presence in a hei tiki of a number of these indicators was considered to present fairly compelling evidence.

During the mid to late $19^{\text {th }}$ century Māori sometimes adopted introduced technology when making hei tiki, such as the sawing of pounamu with metal bed slats, as recorded by Skinner (1933:31) and drilling of holes using the non-traditional pump drill, as investigated by Best $(1912: 80,83-84,86,88,91)$. It was considered that although evidence of transitional sawing techniques could not be easily be identified if a hei tiki had been finished off by hand using abrasive stone tools, the possible inclusion of some hei tiki made by Māori craftsmen partly by using transitional technology could be viewed as legitimate in any case. However if European tool use was evident on the surface then they were not included. The approach taken to ruling out all such apparent European tooled examples, regardless of the possibility that some may have been made by Māori, was in accordance with that taken by Orchiston (1972b:164) in his study of straight pounamu pendants.

The selection of fifty hei tiki was deliberately made exclusively from the 'un-localised' portion of the collection for which information on localities of origin is scarce. The reasons for this included the fact that this is not a study which aims to identify hei tiki styles belonging to particular tribes and regions; locality of 'origin' was accordingly not deemed to be a criterion for inclusion. It was considered that this study presented an opportunity for un-localised hei tiki to make an important contribution to our understanding of hei tiki. The non-inclusion of localised hei tiki also alleviated the need for a multitude of iwi clearances prior to publication, a process which would have been time consuming and potentially may have resulted in a biased selection should clearance be denied for some examples.

The selection process started with making a wide initial selection of all eligible examples, which totalled 82 hei tiki. This selection was then narrowed down to a manageable 50 hei tiki, according to a plan of maintaining the relative numbers of hei tiki belonging to each of 
four shape categories [outlined below] as were evident in the larger initial pool. This process was achieved to within a one to two per cent variation for each of the shapes. Within these constraints priority for inclusion was given to hei tiki possessing good photographic and pounamu identification documentation.

\section{Recording methods and techniques}

Recorded features of group one early contact period hei tiki are presented first followed by those of the larger group two study assemblage from the Te Papa collection. The Cook voyage hei tiki are recorded photographically, by written descriptions, and in table form. They are supplemented by drawings of three other early contact period hei tiki accompanied by written descriptions. Features of hei tiki in group two are recorded photographically and in table form.

Photographs are shown in larger format for the Cook voyage hei tiki due to the significance of these particular examples and the space limitations for recording the larger group. Images are generally of consistent size with Te Papa collection examples showing both sides of each hei tiki. Smaller images showing overall views of hei tiki are also provided for those examples which have a cord attached.

\section{Recording on tables}

The sequence in which hei tiki are recorded on the tables follows the sequence in which they are presented photographically. Each hei tiki is allocated a study group number depending on their position within the sequence: $1.1-1.5$ for the first group, and $2.1-2.50$ for the second group. Collection numbers of each hei tiki are also given and then a large number of features are systematically recorded beginning with shapes. 


\section{Hei tiki shapes}

Four shape categories were created to reflect the possible original shapes of the pounamu pieces which were worked into hei tiki and the varying ways and extents to which hei tiki may have been worked away from those original shapes. The shape identification technique employed photographs of direct frontal views of each hei tiki. Straight lines were drawn along the outer margins of the images as part of the identification process. This system is derived from the observation that the sawing of pounamu results in cut pieces of stone with straight edges.

\section{Shape A}

Hei tiki belonging to shape $A$ are determined by straight lines touching the margins at three points on each side - at the outer head, body and legs. If a point is one millimetre or less from touching then it is deemed close enough to clearly belong to this category, which reflects closely an original wedge shape or a rectangular outline shape. If the gap is from one to three millimetres then an additional shape letter is added indicating a small degree of variation towards a secondary shape. For example, $A B$ indicates hei tiki primarily of shape A with a one to three millimetre variance towards shape $B$.
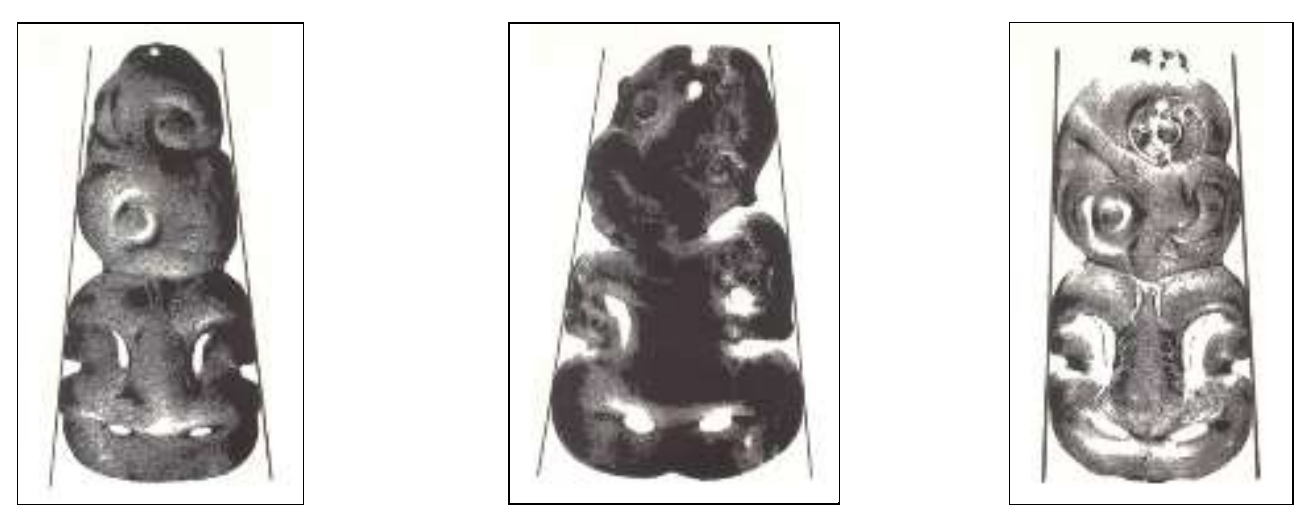

Figure 10 Shape A: three examples.

\section{Shape B}

Hei tiki of shape B are determined by straight lines touching at three points along one side and at only two points on the other side. For most examples the head may have been worked in on one side away from what may have been the outline of the original tab of stone. Alternatively the shape may result of one side being sawn straight and the other side 
reflecting the natural curve of the outer edge of a boulder. Like shape $A$, shape $B$ is also indicative of original wedge shapes which graduate towards rectangular outline shapes.
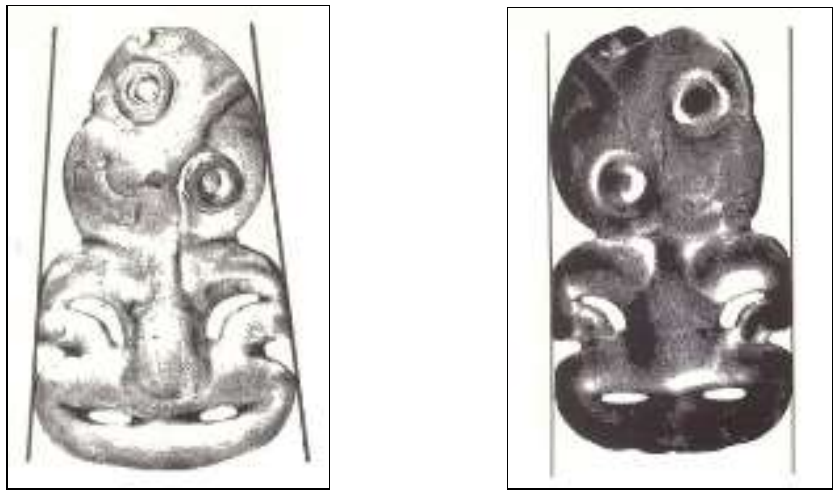

Figure 11 Shape B: two examples.

\section{Shape C}

Hei tiki of shape $C$ have straight lines touching neatly at two points only along each side. Typically the head appears to have been worked in from both sides. Shape $\mathrm{C}$ hei tiki graduate from shapes indicative of original tabs of wedge or rectangular outline towards shapes which may have originated as ovals.
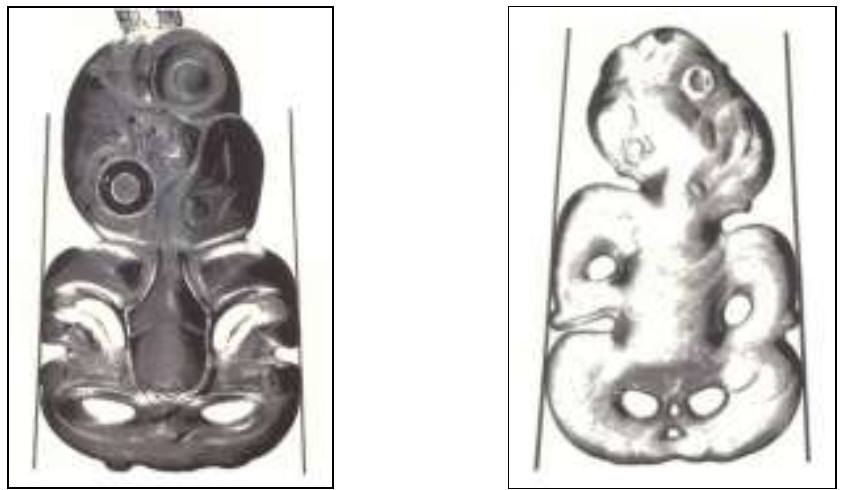

Figure 12 Shape C: two examples. 


\section{Shape D}

Hei tiki of shape D have oval-like outlines and are typically widest at the elbows.
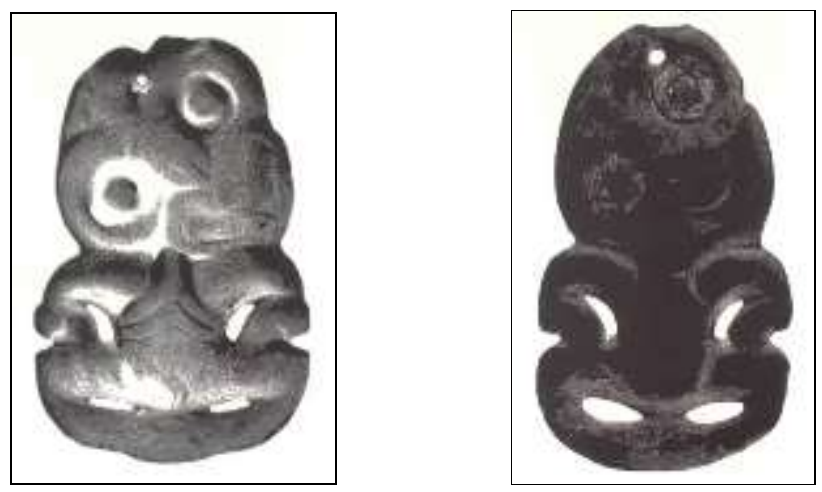

Figure 13 Shape D: two examples.

\section{Hei tiki style types}

This study also identifies hei tiki according to Webster's type I and type II classification system, and according to a third style, type I/II, where elements of both main types are displayed within a single hei tiki. The study contains no examples of the rare hybrid hei tikimatau style type. While Robley's type A and type B could alternatively have been used for recording the two main styles, Skinner and Hiroa's use of A and B for different sets of hei tiki types creates potential for confusion and so Webster's system was preferred.

\section{Dimensions}

Maximum length, width, and depth measurements were taken using digital callipers and rounded off to the nearest millimetre in most instances. If exactly half of a millimetre was measured then this is given up to 15 millimetres. Thereafter measurements of $0.5 \mathrm{~mm}$ and under are always rounded off downwards. Measurements provided by overseas institutions are relied upon for the five hei tiki in study group one. Hei tiki from the Te Papa collection were measured by me in 40 instances, with measurements by other staff relied upon for 10 others due to the realities of museum practice where significant portions of the collection were on loan to other institutions or on display at Te Papa behind glass. 


\section{Proportions}

Proportions were recorded using photographs of direct frontal views of each hei tiki. Firstly, the maximum length and width of the hei tiki image is measured. The width is then divided by the length and the decimal point moved two places to the right to determine the width to length ratio in terms of a percentage. Secondly, lines are drawn across the hei tiki to delineate the head, body and leg sections. Neck lines for most hei tiki neatly touch the top of each shoulder, but the neck line is angled for the less common necked type of hei tiki, which typically has one shoulder raised higher than the other. Measurement of the body and leg portions of hei tiki is complicated by there being a convergence zone where the lower body extends down to the lower thighs, or a little beyond. A line is drawn across the hei tiki from the tops of the thighs. A vertical line is then drawn down the centre of the hei tiki and measurements taken from where it intersects the two cross lines. Proportions are then determined as for the width to length ratio, and rounded off to percentages adding up to 100 per cent of the total length. Half percentages are rounded off downwards.
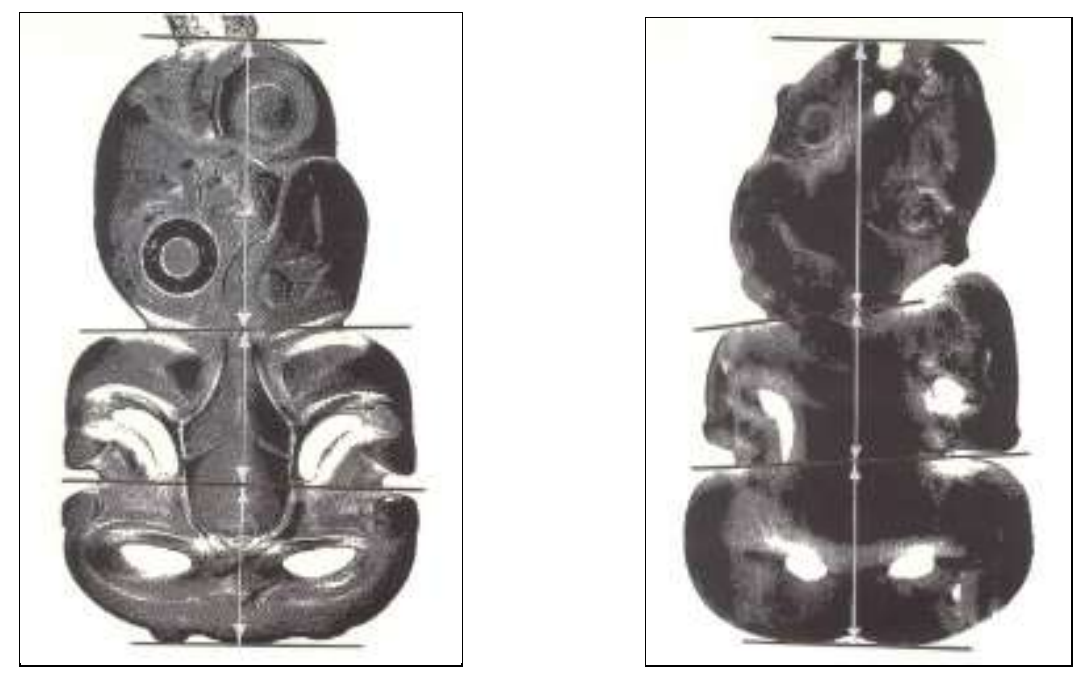

Figure 14 Technique for measuring head, body, and leg proportions.

\section{Body scan}

The next part of the tables systematically record features of hei tiki in body-scan fashion from head to toe, with evidence of many features recorded by "Y" (yes), "N" (no), or "?" (no data / inconclusive). A scale ranging from 0.0 to 10.0 is used to record the shape of the top of each head. Zero indicates a flat head, five a very rounded head, and ten a very pointed head. R (proper right) and L (proper left) are used to record direction of head tilt. Degree of 
head tilt is measured by drawing a straight line from the top of the head down the forehead ridge and nose bridge to the tip of the pointed lower lips and measuring the tilt of that line against a vertical line in 5 degree increments.

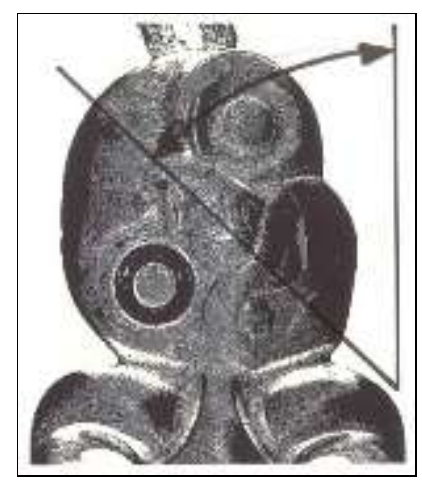

Figure 15 Technique for measuring angle of head tilt.

A zero to ten scale is also used for recording straightness of the thighs. Figures for thigh observations were generally polarised and enabled those measured in the 6.0 to 10.0 bracket to be identified as straight and those in the 0.0 to 4.0 bracket to be identified as rounded. The few examples recorded as 5.0 were treated as a separate in-between category. Knees were recorded as rounded, cornered, or in-between also using the 0.0 to 10.0 scale. Descriptions for hei tiki in the first study group are detailed in appendix one, and give a good account of the full range of features recorded in the body scan and how these have then been translated into table form; so it is not deemed necessary to go over all of the features here.

\section{Pounamu}

Pounamu identification records of researchers Russell Beck and Maika Mason were accessed at Te Papa to record pounamu varieties, source localities, evidence of low temperature heat treatment and surface regrinding for the hei tiki in study group two (KE Emu Collections Database). Pounamu varieties are abbreviated as KK (kawakawa), I (inanga), KR (kahurangi), T (tangiwai), and Inc. (inconclusive). Pounamu source identifications are abbreviated as CW (Central Westland); A, CW (Arahura source, Central Westland); W (Wakatipu); TK, W (Te Koroka source, Wakatipu); P (Piopiotahi / Milford Sound) and Inc. (inconclusive). Pounamu varieties, sources, and the heat treatment process have been well described in Beck with Mason (2002:15-20,25-75, 2010:34-43,50-87,159- 
161). Pounamu from SW (South Westland) was not recorded in this study. The Te Papa collection contains a hei tiki made from South Westland pounamu but it is incomplete and was not included on that basis. Evidence of heat treatment and surface regrinding is indicated by "Y" (yes), "N" (no), or "?" (no data / inconclusive).

No source identifications were available for hei tiki of group one. Tentative identifications of pounamu variety were made by me from images for 2 out of the 5 collection examples.

\section{Wear}

For each hei tiki an assessment is made of the extent of wear ranging from 0.0 to 10.0 , with 0.0 indicating no discernible wear at all and 10.0 an extreme degree of wear. Particular attention was paid to the suspension holes and to the features of the central face and body when determining wear. Fortunately hei tiki typically exhibit many detailed frontal features against which to assess wear. The featureless backs of hei tiki provide little detail against which to make such an assessment. The importance of the photographic record is emphasized as subjectivity was inevitably involved in this part of the recording process. Others may make their own judgments from the images to compare with those made in this study. Considerably higher resolution images of 33 examples of the hei tiki may be accessed on the Te Papa Kura Pounamu exhibition website (2009), with ability to zoom in for very close viewing. 


\section{Chapter Five: Hei Tiki Research Project - Analysis of Recorded Features}

\section{Chapter introduction}

This chapter provides a five-part analysis of the hei tiki features recorded according to the methods and techniques outlined in chapter four, and presented in appendix one. The first half of the analysis compares the recorded features of the early contact period hei tiki in group one with those of the general selection of hei tiki in group two. The second half relies more heavily upon a compositional analysis of the recorded features of the hei tiki in group two.

The mana of the hei tiki used in this study manifests in this chapter. The analysis actualises their potential to reveal new insights into the origins, development and use of the iconic cultural treasure, hei tiki.

The recording of features as mathematical values enabled statistical analysis of the large quantity of data collected and some general observations to be made. The data was analysed primarily according to percentages, mean averages and ranges. Whenever data was unavailable or inconclusive for a particular feature - perhaps due to wear - the total number of hei tiki against which calculations were made was reduced accordingly for that feature. Hei tiki against which calculations were made, are referred to as the valid examples.

A complicating factor in this comparative approach is that an unknown portion of the hei tiki in group two may be as early in origin as those in group one. However, assuming that the portion of hei tiki in group two of 1769-1777 and earlier antiquity is relatively small, the figures arrived at for the general assemblage are still considered to be reasonably indicative of later developments.

- Part one is the first phase of a shape analysis which compares the recorded shapes of hei tiki in group one with those of group two. The objective is to ascertain the extent to which observations may support the argument developed in the literature review for the early appearance and ongoing dominance of the adze shaped hei tiki. The second phase of shape analysis is carried out in part four. 
- Part two is a style analysis which compares the range of stylistic features recorded for the group one hei tiki with those recorded for group two. The analysis investigates the early prevalence of the type I style of hei tiki and it investigates the extent to which hei tiki of the early contact period were apparently already stylistically developed, in comparison to the range of stylistic features recorded as being characteristic of hei tiki in general. Differences are also revealed which suggest some ways in which the stylisation of hei tiki may have developed over time.

- Part three uses two avenues of investigation to look for evidence suggestive of a trend for increasing size of hei tiki over time. Firstly, it compares the recorded mean size data for hei tiki in each of the two study groups. Secondly, it compares recorded use wear of the 50 hei tiki in group two with their recorded lengths. Evidence is identified in both investigations supporting the argument for increasing hei tiki size over time. This finding suggested that hei tiki size might be a means by which hei tiki development could be further investigated.

- Part four draws upon the findings of part three to investigate the association of both recorded hei tiki shapes and proportionate numbers of hei tiki in group two in relation to their size. It assesses these two features in relation to a chronology of hei tiki development implied by a scale of increasing hei tiki size. This part of the analysis uncovers more evidence indicative of the early and prolonged existence of hei tiki made from portions of pounamu cut to approximate adze shape. A pronounced peak in the proportional number of hei tiki recorded in the $101-110 \mathrm{~mm}$ size bracket is interpreted as probably representing the occurrence of an early $19^{\text {th }}$ century peak in hei tiki making.

- Part five is an analysis of recorded surface wear and pounamu characteristics of the general selection of hei tiki in group two. It investigates evidence which informs an opinion on the extent to which Māori contexts of use appear evident in hei tiki in comparison to the proportion of hei tiki possessing characteristics compatible with European trade item status. 


\section{PART ONE - Hei tiki shape analysis}

Group One:

The full range of hei tiki shapes $-A, B, C$, and $D-$ is recorded for the five early-contact period hei tiki in group one and for the three supplementary drawings, with each shape represented evenly by two hei tiki, or $25 \%$ each. The outline shapes of hei tiki shapes $A$ and $B$, are most suggestive of straight-edged sawn blanks of pounamu or alternatively of adze blades having been used for their manufacture. Together these two recorded shapes represent $50 \%$ of the group one hei tiki. The two shape $C$ hei tiki -1.3 and 1.4 -are less conclusive to assess, while the two shape $D$ hei tiki are possibly made from oval, naturally shaped pieces of pounamu.

\section{Group Two:}

The full range of primary shapes $-A, B, C$, and $D$, as well as the secondary shapes $-A B, A C$, $B C$, and CD were recorded for hei tiki in group two. Secondary shape identification is outlined on page 49, chapter four. 23 (46\%) of the 50 hei tiki are of either shape A (16 examples), shape $A B$ ( 4 examples) or shape $A C$ ( 3 examples). Another $16 \%$ are of either shape $B$ (seven examples) or shape BC (one example). Together the $A$ and $B$ primary and secondary shapes constitute $62 \%$ of the hei tiki in group two. These 31 hei tiki are most indicative of adze shaped pieces of pounamu having been used in their making. In addition a less easily quantified proportion of the $30 \%$ of hei tiki of shape C (13 examples) and shape $C D$ (two examples) exhibit features consistent with this interpretation. Shape $D$ is represented by four examples or $8 \%$ of the total; their oval-like outline shapes are consistent with an interpretation that natural stones may have been used in their making.

\section{Discussion}

The shape analysis suggests that both the pre-sawing of pounamu into approximate adze shapes and possible re-use of adze blades was a common feature of hei tiki making during the early contact period, with at least half and probably most of the group one hei tiki made by this means. This feature appears evident also amongst at least $62 \%$ of the general sample. While not conclusive, these observations are suggestive of longstanding practice 
and are compatible with the view that development of the ability to saw pounamu was an important element in the origins of hei tiki.

It appears that the apparent use of naturally shaped oval-like pieces of pounamu for making hei tiki may have decreased significantly following the early contact period, while the use of adze shaped pieces of pounamu increased slightly. This is indicated by the recorded increase in representation of the $A$ and $B$ shapes from $50 \%$ in group one to $62 \%$ in group two, and the recorded decrease of shape $D$ hei tiki from $25 \%$ in group one to only $8 \%$ in group two. This may indicate that after the early contact period hei tiki of shape $D$ became rare and possibly ceased being made eventually.

Analysis of these two assemblages also illustrates the unreliability of style types to explore the origins and development of hei tiki through outline shape analysis, as there is no consistent correlation between style type and shape. While the type I style of hei tiki is often associated with adze shaped hei tiki, this is not always so. For example, both of the oval-outlined shape D hei tiki in group one, 1.5 and Fig.23, are type I in configuration; and the Doubtless Bay hei tiki with upright head, Fig.22, belongs to shape A, but has been designated as style type I/II. In group two most type II hei tiki possess the abstracted features of hunched shoulder, sharply bent elbow and elongated tilted head, which appear to result from working the figure to conform to the constraints of original cut pieces of pounamu, including those of adze shape.

\section{PART TWO - comparative analysis of recorded stylistic features}

A style analysis is made of the recorded stylistic features of the group one and two hei tiki, which are presented in the appendix one tables, - and also of various features clearly evident in the three supplementary images of hei tiki with provenance to the early contact period.

Firstly, evidence for the early and ongoing prevalence of the type I style of hei tiki is assessed. Secondly, an analysis of shared and non-shared features is made to gain insight into the extent to which hei tiki appear to have been stylistically developed by 1769-1777 and how hei tiki appear to have developed over time. A long list is compiled of stylistic features shared in common between the two study assemblages. In comparison another list 
for features which are not shared is relatively short. A discussion makes an overall assessment of the results.

\section{Prevalence of style type I}

Clear early and ongoing dominance of the type I style of hei tiki is indicated by seven out of eight or $87 \%$ recorded prevalence in group one and 38 out of 50 or $76 \%$ prevalence in group two.

\section{List of shared stylistic features:}

\section{Proportions}

Comparative analysis between proportion records for group one and group two hei tiki shows recorded mean width-to-length proportions of $62 \%$ and $59 \%$ respectively for each group, mean recorded head-to-length proportions of $47 \%$ and $46 \%$ respectively, mean recorded body-to-length proportions of $24 \%$ and $26 \%$ respectively, and mean recorded legto-length proportions of $28 \%$ for both groups. Based on these observations, the proportions which are characteristic of hei tiki in general appear to have been well established from early on and there appears to have been little change thereafter.

\section{Angle of head tilt}

Seven out of eight or $87 \%$ of group one hei tiki - including the three drawings and the five collection examples - are recorded as having their heads inclined to one side at an approximate 45 degree angle. In group two the recorded incidence of this feature is $66 \%$, or 33 out of the 50 examples. The common 45 degree angle of head tilt appears to have been well established by 1769-1777.

\section{Direction of head tilt}

Heads inclined to the right hand side are recorded for $50 \%$ of eight group one hei tiki, and for $80 \%$ of group two examples. Heads inclined to the left side are recorded for $37 \%$, or three of the eight group one hei tiki and $20 \%$ of the 50 group two examples. 


\section{Upper head shapes}

Shapes of the tops of the heads were measured on a scale from 0.0 (flat) to 5.0 (very rounded), to 10.0 (extremely pointed) and at intervals in between. The five group one hei tiki range from 3.0 to 8.0 in terms of their recorded upper head shapes, with a mean average of 4.8. Recorded upper head shapes for group two ranges from 1.0 to 9.5 , with a mean average of 5.9. It appears that on average upper head shapes may have changed from generally rounded in 1769-1777 to a little more-pointed later on.

\section{Eyes}

Pāua shell eye inlay without notches is recorded as present in $100 \%$ of the four valid group one collection hei tiki with inlay, but is recorded for only six (29\%) of the 21 valid group two hei tiki with inlay of one kind or another. Secondary eye rims are recorded on $40 \%$ of group one hei tiki and $20 \%$ of group two examples.

\section{Brows}

Brows above the eyes are recorded for $60 \%$ or three of five group one hei tiki compared to $96 \%$ (45 of 47 valid) group two examples.

\section{Forehead ridges}

Forehead ridges are recorded for all five of the hei tiki in group one, however, when the three drawings are included this figure is seven out of eight, or $87 \%$. Forehead ridges are recorded on $44(90 \%)$ of 49 valid hei tiki in group two.

\section{Forking of forehead ridges at the nose bridge}

Forking of the forehead ridge at the nose bridge is observed on four out of four valid group one hei tiki in collections. Including the three drawings a result of six out of seven, or $86 \%$ is observed. In group two this feature is recorded on 35 (87\%) of 40 valid hei tiki, a figure close to that recorded for group one.

\section{Arched nostrils}

Arched nostrils are recorded on four (80\%) of the five group one hei tiki. Only 26 of the 50 group two hei tiki were valid for recording nose features, surface wear apparently 
responsible for obscuring features on most of the remaining 24 examples. The arched nostril type is recorded as present on 22 (85\%) of the 26 valid examples.

\section{Alternative nose type}

In group one records for hei tiki 1.5 of oval-like outline provide a clear example of an alternative nose type. The nose treatment of this hei tiki is observed to fork upwards from the tip with flared nostrils either side and to possess a central ridge connecting the nose to the forehead ridge. In group two four of the 26 valid hei tiki, or 15\%, are recorded with similar nose types to hei tiki 1.5 .

Heart shaped mouths and presence of teeth

In group one heart shaped mouths are recorded for seven of the eight hei tiki, or $87 \%$. In group two the heart shaped mouth accounts for 47 (96\%) of the 49 valid hei tiki. Corner and upper and lower central teeth are a commonly recorded feature of hei tiki in both groups.

Unambiguous forked tongue, usually extended

Including the three drawings with the five hei tiki in group one the forked tongue is recorded on three (43\%) of the seven valid examples. In group two the forked tongue is recorded on only five (15\%) of the 34 valid hei tiki. This appears to be a feature which may have become less common over time.

\section{Head projections}

Head projections at the chin and ears are recorded for one (12.5\%) of the eight early contact hei tiki compared to 10 (20\%) of the 50 hei tiki in group two.

Indicative necks

Indicative necks formed by central ridges beneath the heads are recorded for four (80\%) out of five hei tiki in group one. In group two indicative necks are recorded for 39 (78\%) of the 50 hei tiki. 
Ribs

Forking of indicative necks on the lower end to form ribs is recorded on four (80\%) of the five hei tiki in group one, or six (75\%) of the eight examples including those represented by the three images. The number of ribs per side ranges from one to two. Ribs are recorded on $28(57 \%)$ of the 49 valid examples in group two, with the number of ribs per example ranging from one to four sets.

Single sets of ribs are recorded for two (25\%) of the eight group one hei tiki compared to 18 (37\%) of 49 group two hei tiki.

Multiple sets of ribs are recorded for $50 \%-60 \%$ of group one hei tiki (four out of eight or three out of five respectively) but only $20 \%$ (10 out of 49 valid) group two hei tiki.

\section{Patterns beneath ribs}

A pattern beneath the fork of the ribs - a diamond shape - is recorded for one group one example: hei tiki 1.5. For group two four hei tiki are recorded with diamond shapes beneath the ribs, also three with triangle shapes and one with a horizontal line.

\section{Arm configuration}

A consistent arm configuration is recorded for all (100\%) of group one hei tiki, including the three drawings. This configuration has both arms arranged in symmetrical fashion with the upper arms curving upwards and outwards and the lower arms curving inwards and downwards from pointed elbows to rest on the thighs. In comparison 41 (82\%) of the 50 hei tiki in group two are also of the common arm configuration.

\section{Hands}

Hands - all with three fingers - are recorded as worked on three (60\%) of the five group one collection hei tiki. It is observed that at least one hand and possibly a second are carved in raised relief: $20 \%$ and $40 \%$ respectively. Hands are recorded on 22 (45\%) of the 49 valid group two hei tiki, with raised relief a feature of several. Hands are recorded most commonly within the shape $C$ and $C D$ range: 11 (73\%) of the 15 examples. Hei tiki of shape $C$ 
are the most fully worked of all the shapes, the rendering of hands arguably in keeping with the apparent commitment towards fashioning a fully developed figure.

\section{Representation of female sex}

Female sex, as evidenced by the presence of a vagina, is identified on two (40\%) of the five collection hei tiki in group one. For group two, while vaginas are often prominent and clearly visible in the images, a closer physical examination identified this feature to be rendered in less prominent fashion on several other examples. All 50 group two hei tiki are considered diagnostic for this feature of which $18(36 \%)$ are identified as female, a percentage close to that of the early contact period examples.

\section{Straight thighs}

Straight thighs are recorded on four (80\%) of the five group one hei tiki and on 42 (84\%) of the 50 group two hei tiki.

\section{Leg knobs and projections}

Another close similarity is the recorded presence of leg knobs or projections on $60 \%$ of group one and $56 \%$ of group two examples.

\section{Shape of knees}

Knees are rounded on four (50\%) of the eight early contact hei tiki, compared to eight hei tiki (16\%) with rounded knees in group two. Cornered knees are recorded for three $(37 \%)$ of eight group one hei tiki and 37 (74\%) of the 50 group two examples. A trend toward more cornered knees over time appears to be evident.

\section{Feet}

In group one the presence of feet was recorded on two (40\%) of the five collection hei tiki. In group two feet were recorded on 31 (63\%) of the 49 valid hei tiki. 
Hei tiki shapes

Shapes A and B hei tiki are recorded for four (50\%) of the eight hei tiki in group one compared to 31 (62\%) of the 50 group two examples.

Shape D hei tiki, recorded for one (20\%) of five or two (25\%) of eight group one hei tiki, and recorded for four (8\%) of the 50 group two examples.

\section{List of unshared stylistic features:}

Group One:

Unshared stylistic features recorded exclusively for hei tiki in group one can be listed as: double suspension holes (hei tiki 1.5 and Fig.22); enlarged lower arms (hei tiki 1.3); pointed indicative neck (hei tiki 1.5); Upright vertical head (Fig.22); Exclusive use of un-notched pāua shell eye inlay; Alternative mouth shape (Doubtless Bay hei tiki). Hei tiki are exclusively $100 \mathrm{~mm}$ or less in length.

Group Two:

Unshared stylistic features recorded exclusively for hei tiki in group two can be listed as: the presence of the type II hei tiki (including the hunched shoulder, one asymmetrical raised arm, and the un-pointed elbow); Notched pāua shell inlay; Sealing wax eye inlay; Teardrop shaped mouths (hei tiki 2.8 and 2.13); A unique half heart shaped mouth rendered in profile (hei tiki 2.5); Hei tiki greater than $100 \mathrm{~mm}$ in length.

\section{Discussion}

Clear early and ongoing dominance of the type I style of hei tiki is indicated by $87 \%$ recorded prevalence in group one and $76 \%$ in group two. The hei tiki from Doubtless Bay (Figs 5 and 22) recorded in 1769 is primarily of type I configuration, but was classed as a type I/II hei tiki due to the possession of some less common type II features. Had a third category of style not been used then $100 \%$ of group one hei tiki would have been recorded as style type I. The results indicate that the type I style of hei tiki may have become slightly less common over time, and this can be attributed largely to the existence of the type II style amongst the general assemblage. 
It is observed that the quantity of stylistic attributes recorded as shared between the hei tiki of groups one and two far outweighs the prevalence of those attributes which are recorded as unshared in the second list. Clearly the iconography of hei tiki was well developed by 1769-1777 as most of the stylistic elements characteristic of hei tiki in general appear to have been in existence by then.

Continuity in the use of most of the early features appears to be implied by the high degree of shared commonality between the recorded features of both groups. Some features, such as adherence to conventions of proportion, and the incidence of the presence of indicative necks and of forehead ridges, appear to have changed little over time. However, for most of the shared features, variation is recorded where they appear to be either more or less common in the other group. This can be interpreted as implying change over time in the stylisation of hei tiki.

A notable aspect of the second list of unshared features is that the quantity of atypical features which were recorded from only eight early contact period hei tiki approaches that of the atypical features recorded for the 50 hei tiki in the general selection from the Te Papa collection. The possession of atypical stylistic features was recorded for three, of the eight, early contact period hei tiki. These observations can be interpreted as indicating that innovative practice may have been more prevalent amongst hei tiki makers in the earlier period than at a later date.

Considerable regional and tribal variation in styles was probably a factor in the ongoing stylistic diversity of hei tiki. However, the analysis points to the probability that localised variations at a later date were achieved mostly in terms of the selective use of a pool of longstanding pre-existing stylistic elements. It seems that stylistic features were probably drawn from this corpus of material to be used in various selections and combinations and rendered in new ways, rather than the creation of entirely new features playing a prominent part in the ongoing development of stylistic diversity. 
PART THREE - investigating supporting evidence for a trend of increasing hei tiki size over time

This part of the analysis uses two courses of investigation to search for evidence suggestive of a trend of increasing size of hei tiki over time. Firstly it compares the recorded mean size data for hei tiki in each of the two study groups. Secondly it compares recorded use wear of the 50 hei tiki in group two with their recorded lengths.

Lengths recorded for the five hei tiki in group one range from $65 \mathrm{~mm}$ to $100 \mathrm{~mm}$, with a mean average of $84 \mathrm{~mm}$. Widths recorded for these five hei tiki range from $40 \mathrm{~mm}$ to $63 \mathrm{~mm}$, with a mean average of $52 \mathrm{~mm}$. In comparison recorded lengths of the 50 hei tiki in group two ranges from $62 \mathrm{~mm}$ to $170 \mathrm{~mm}$ with a mean average of $105 \mathrm{~mm}$. Recorded group two widths range from $30 \mathrm{~mm}$ to $101 \mathrm{~mm}$ with a mean average of $62 \mathrm{~mm}$.

It is observed that the hei tiki in group two are on average recorded as $21 \mathrm{~mm}$ longer and $10 \mathrm{~mm}$ wider than hei tiki in group one. The general difference in hei tiki size observed between the two groups appears to support the view that there was a trend of increasing hei tiki size over time, as advanced by Skinner (1974:47).

The second part of the investigation draws upon the records of use wear and lengths of the general selection of hei tiki in group two to reveal an apparent relationship, which is also interpreted as supporting the argument for a trend of increasing size of hei tiki over time. Mean recorded wear data for hei tiki in group two belonging to different length brackets was plotted on a graph (Fig.16) and reveals a noticeable correlation: 


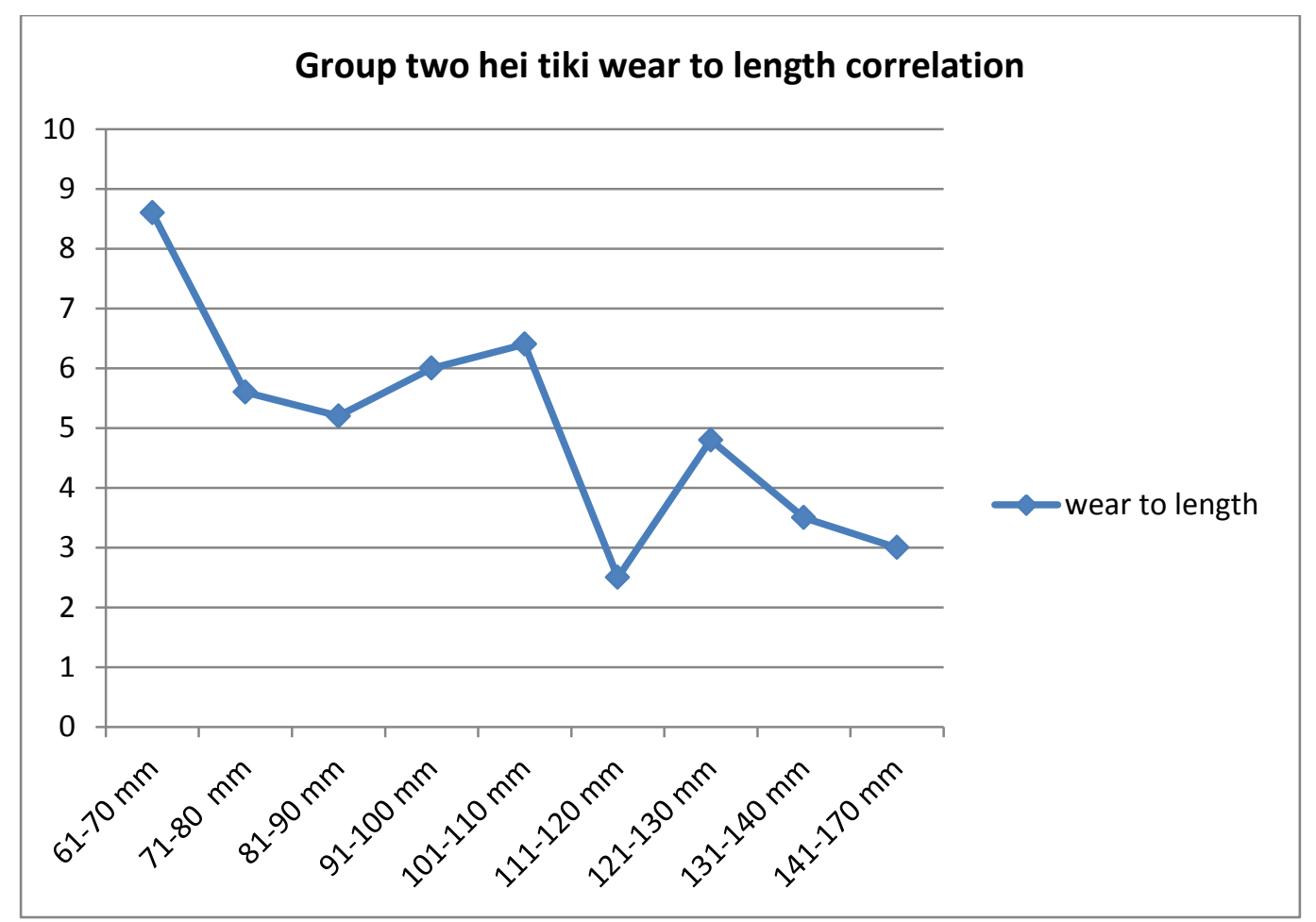

Figure 16 Recorded mean wear in relation to size ranges.

Note: wear records for the three hei tiki in the $141-170 \mathrm{~mm}$ length range are aggregated together.

\section{Interpretation of figure 16}

While there are a number of variables which contribute to the rate of surface wear on hei tiki (discussed in part four below), it is assumed to be a relatively slow process which takes place over time and in contexts of hei tiki use. Despite some large hei tiki exhibiting considerable wear and some small examples exhibiting little wear, the mean results shown in figure 16 indicate a trend towards decreasing surface wear with increasing hei tiki size; they indicate that the smaller hei tiki are generally of earlier apparent origin than the larger hei tiki. This provides supporting evidence for the argument for a trend of increasing hei tiki size over time. Furthermore this observation provides another means by which the recorded features of hei tiki may be analysed according to an indicative chronology of development, a means of analysis which is carried out next. 
PART FOUR - hei tiki shape categories and proportional numbers of hei tiki assessed against a scale of increasing hei tiki size

An indicative chronological sequence was arranged according to a scale of increasing recorded length brackets for the 50 hei tiki in group two. This scale was used to plot the proportional distribution of the numbers of hei tiki belonging to each bracket and the compositional make-up of each bracket in terms of recorded hei tiki shapes. The result is shown in figure 17:

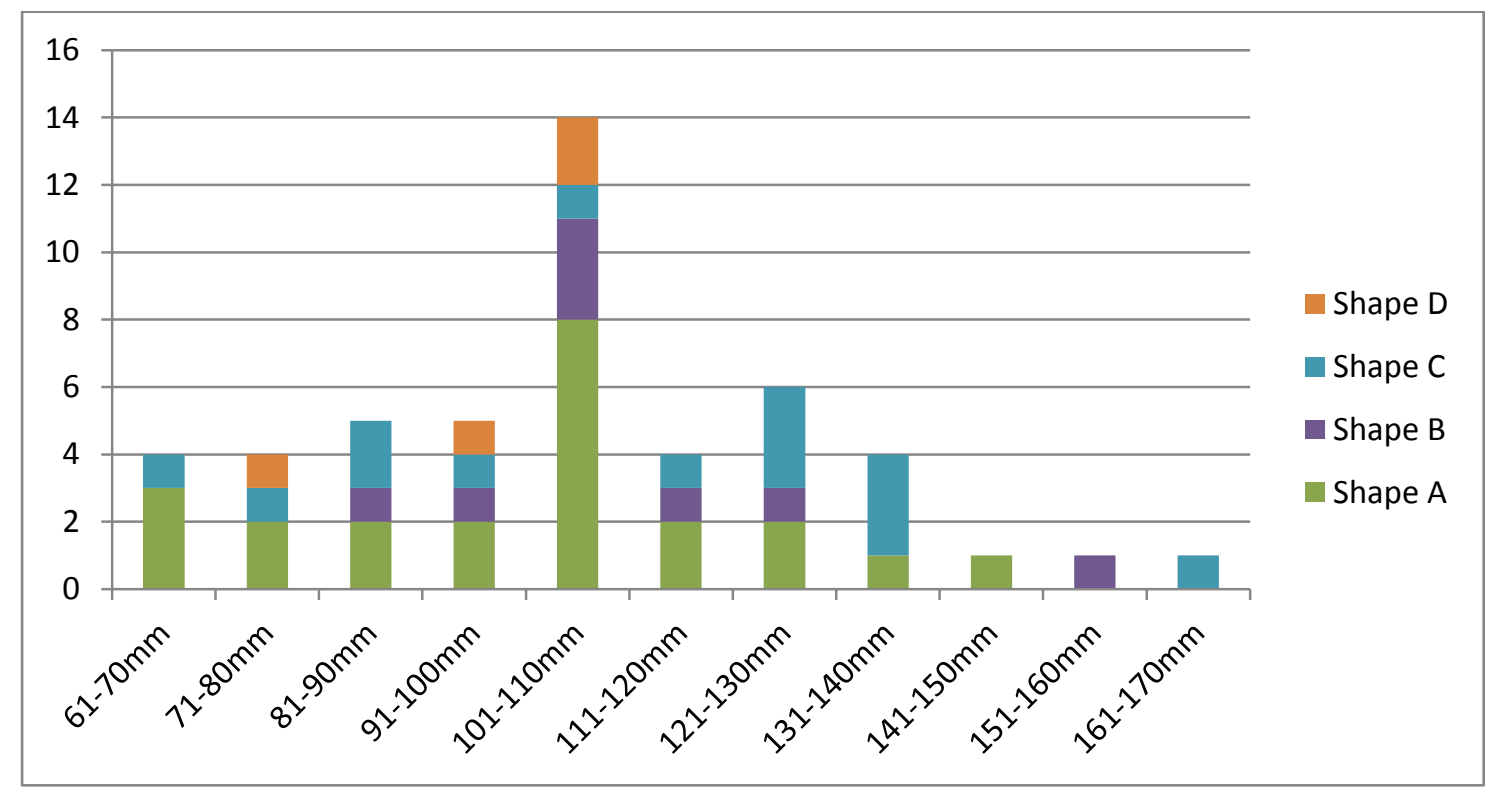

Figure 17 Numbers of hei tiki belonging to different size ranges and proportional representation of hei tiki shapes.

\section{Interpretation of figure 17}

Considering that all known early contact period hei tiki are recorded as no longer than $100 \mathrm{~mm}$ in length the peak in the chart can be considered to probably represent hei tiki mostly made at a later date. If Skinner's (1974:47) argument for the gradually increasing size of hei tiki over time is accepted, - and mean size comparisons between the hei tiki of groups one and two and also interpretation of Fig.16 provide supporting evidence for its acceptance; - then this high point which follows directly on from the 91-100mm bracket, can be interpreted as being consistent with the view that the making of hei tiki peaked in the early $19^{\text {th }}$ century, making use of pieces of pounamu belonging mostly to a particular sizerange. The bars to each side of the peak may also partially represent this phenomenon. 
The presence of shape A and shape B hei tiki along most parts of the group two size spectrum including the smaller size ranges, their recorded presence also within the group one hei tiki, and their only marginally increased proportional representation within the most common hei tiki size range of group two, suggests that the use of wedge or rectangular pieces of pounamu in hei tiki making was well established practice which continued in use for making hei tiki of a wide range of sizes. This observation supports the view that a post contact peak of hei tiki making may have had little qualitative influence upon the stylistic development of hei tiki due to the use of adze shaped pieces of stone. The use of adze shaped pieces of pounamu to make hei tiki appears to have had much earlier origins, a viewpoint supporting the hei tiki origin argument developed in chapter one.

The part one shape analysis for recorded shape $D$ hei tiki shows them to be relatively scarce in group two (8\%) compared to group one (20-25\%). An explanation for this variation is that the shape became less common over time. The recorded distribution of shape D in Fig.17 supports this view indicating that shape D perhaps did not survive or became quite rare beyond the early $19^{\text {th }}$ century.

Of the 50 hei tiki in group two 19 or $38 \%$ are recorded as being $100 \mathrm{~mm}$ or less in length. Taking size of hei tiki to be generally indicative of age then this observation may indicate that the proportion of early, - pre-peak, - hei tiki in collections may be reasonably high, perhaps about as high as a third.

\section{PART FIVE - assessing hei tiki use through pounamu and wear analysis}

\section{Pounamu analysis:}

\section{Sources}

There were no pounamu source identifications available for the five group one hei tiki. For group two 42 of the 50 hei tiki were considered valid for pounamu source identifications. The Central Westland pounamu source area is recorded for 37 (88\%) of these hei tiki, including 16 examples identified as made of pounamu from the Arahura River source. Wakatipu is recorded as the pounamu source area for four (9.5\%) of the hei tiki, including three identifications to the mountainous Te Koroka pounamu site. Piopiotahi (Milford Sound tangiwai source area) accounts for a single example. 


\section{Varieties}

For group one, pounamu varieties were recorded for only two out of five hei tiki: both identified as made from inanga.

For group two pounamu varieties were identified for 49 hei tiki. Inanga is recorded for 28 $(57 \%)$ of the valid hei tiki and it is present combined with other varieties in three more examples (6\%). Kawakawa variety is recorded for $13(27 \%)$ of the valid hei tiki and it is present combined with other varieties in another three examples (6\%). Kahurangi is recorded for three hei tiki (6\%) and is present combined with other varieties in two instances (4\%). Tangiwai is the rarest pounamu variety for early hei tiki and is recorded in one example only (2\%).

\section{Heat treatment}

Low temperature heat treatment is recorded as having been carried out on five (11\%) of the 47 valid group two hei tiki and regrinding of the surface is recorded for three of these heat treated examples.

\section{Interpretation of pounamu analysis findings}

Beck with Mason $(2010: 161,173,175)$ record that Europeans in the late $19^{\text {th }}$ century preferred pounamu of rich green kawakawa variety which could be cut from large boulders using mechanical saws. They argue that while pounamu of inanga variety was highly esteemed by Māori, Europeans considered it to be too pale. The traditional Māori heat treatment process is described as a deliberate procedure to change pounamu from a green colour to a silvery white induced inanga variety, in order to cater to Māori tastes.

The recorded preference for the pale coloured inanga variety of pounamu for group-two hei tiki supports an interpretation that Māori tastes were being primarily catered for in the making of hei tiki. This impression is strengthened by the recorded presence of $11 \%$ of hei tiki in group two as having been low temperature heat treated. While Europeans obtained their green coloured kawakawa from lapidary workshops in the late $19^{\text {th }}$ and early $20^{\text {th }}$ centuries, it is asserted that small naturally worn boulders of green kawakawa would have 
been relatively plentiful and could have been made more use of during the early part of the century had catering for European tastes been a major factor in the making of hei tiki.

In addition the pounamu analysis highlights the importance of Central Westland as the most significant source of pounamu used for making hei tiki. This observation supports the argument presented in chapter three that following their settlement in the South Island the Ngāi Tahu tribe developed the pounamu industry to a much higher level while drawing heavily upon pounamu extracted from this source.

\section{Surface wear analysis}

It is possible to identify many variables which will have influenced the extent of wear observed on hei tiki. These variables include the relative toughness or durability of the pounamu, the extent to which cords were allowed to become loose and more abrasive in holes before being replaced, the degree to which individual wearers formed a habit of rubbing their hei tiki, and the age at which hei tiki entered into collections after being made. Another variable is the recording technique itself which involves a certain amount of subjectivity. A benefit of recording wear characteristics for a relatively large number of hei tiki in a consistent manner, however, is that variations are averaged out and a more reliable general picture emerges.

Wear is assessed on a scale of 0.0 to 10.0 , with 0.0 indicating no discernible wear and 10.0 extremely high wear. Recorded wear to group one hei tiki ranges from 1.0 to 8.0 with a mean average of 3.6. Although the group one hei tiki were early in origin, with the exception of hei tiki 1.4 which is highly worn and apparently considerably older than the others, they appear to have been collected relatively soon after they were made in the $18^{\text {th }}$ century, hence the mean average of only 3.6 wear. It should be noted that excluding hei tiki 1.4 mean recorded wear for group one is only 2.5 . 
Recorded wear for group two hei tiki ranges from 0.0 to 9.5, with a mean average of 5.35. The details are collated on table 1.

Table 1-Numbers of hei tiki in group two belonging to different recorded wear categories

\begin{tabular}{|c|c|c|c|c|c|c|c|c|c|c|c|c|c|c|c|c|c|c|c|c|c|}
\hline 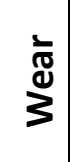 & 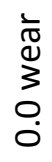 & 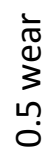 & 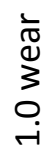 & 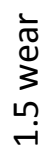 & 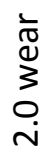 & 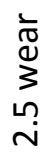 & 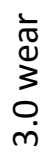 & 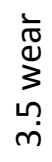 & 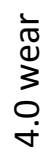 & 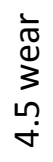 & 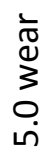 & 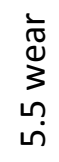 & $\begin{array}{l}\frac{1}{\pi} \\
\stackrel{0}{3} \\
0 \\
0\end{array}$ & $\begin{array}{l}\frac{1}{\pi} \\
\stackrel{d}{3} \\
\stackrel{1}{\omega}\end{array}$ & $\begin{array}{l}\frac{1}{\pi} \\
\stackrel{d}{3} \\
0 \\
0\end{array}$ & 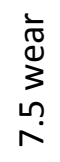 & $\begin{array}{l}\frac{1}{\pi} \\
\stackrel{d}{3} \\
0 \\
\infty \\
\infty\end{array}$ & $\begin{array}{l}\frac{1}{\pi} \\
\stackrel{\infty}{3} \\
10 \\
\infty\end{array}$ & $\begin{array}{l}\frac{1}{\pi} \\
\stackrel{0}{3} \\
0 \\
0 \\
0\end{array}$ & 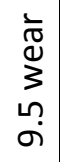 & 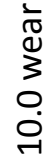 \\
\hline $\begin{array}{l}\dot{\bar{z}} \\
\bar{\Phi} \\
\dot{0} \\
\dot{0}\end{array}$ & 3 & 0 & 3 & 0 & 2 & 0 & 7 & 0 & 3 & 1 & 5 & 1 & 6 & 0 & 2 & 1 & 9 & 2 & 3 & 2 & 0 \\
\hline
\end{tabular}

It is possible that a higher number of hei tiki in overseas collections might be trade items than those which remained in New Zealand, and consequently exhibit less use wear. To test for this possibility, 23 hei tiki in group two - which had once been in the United Kingdom, were analysed. These examples are recorded in the appendix tables 3-7 with collection registration numbers beginning with the letters $\mathrm{OL}$ or $\mathrm{WE}$, which indicate that they come from the collections of William Oldman and K.A. Webster respectively. The overall mean recorded wear was 5.2, a mid-range result close to the 5.35 mean wear recorded for the group two assemblage as a whole, implying no significant difference in the prevalence of hei tiki of trade item status.

\section{Interpretation of surface wear findings}

Despite a number of variables the mean recorded wear assessments can generally be taken as indicative of traditional use over time before the hei tiki entered into collections, where little to no subsequent wear is assumed to have taken place. According to this understanding little wear is indicative of traditional use over a relatively short period of time before entering into a collection and high wear is indicative of traditional use over a relatively prolonged period of time.

Three (6\%) of the 50 group two hei tiki were recorded with 0.0 wear, strongly consistent with European trade item status. It appears to be significant that one of these three examples (hei tiki 2.44 ) is also the largest, a type II hei tiki at $170 \mathrm{~mm}$ long. Apart from no 
noticeable surface wear the inside of its suspension hole still contains drilling dust residue and is still sharp around the mid part of the hole, having never been rasped out for wearing. Simmons (1966b:29) suggests that very large hei tiki were probably made to satisfy European demand. He asserts that "Size is still a criterion of excellence for collectors. No doubt this was of importance when tikis were being produced for sale to the first Europeans."

A low point of 2.5 mean wear recorded in Fig. 16 for hei tiki in the $111 \mathrm{~mm}-120 \mathrm{~mm}$ size range suggests the possibility that this this size range may have been the most common for hei tiki of European trade item status. It is possible that a proportion of these hei tiki were made larger than average for the collector's market during the peak of early $19^{\text {th }}$ century hei tiki making due to the collector's criterion of size.

Overall the research results suggest, however, that the making of hei tiki specifically for trade to Europeans was a secondary activity of lesser significance than the making of hei tiki for traditional Māori use. If one takes 2.5 mean wear as a cut-off point only 8 (16\%) of the hei tiki are accounted for. If 3.5 mean wear is taken then this proportion rises to 15 (30\%). The evidence suggests that most hei tiki were not produced as European trade items and they consequently possess the full assortment of traditional meaning and enhanced mana derived from prolonged use by the ancestors.

\section{Chapter conclusions}

Shape analysis indicates that the adze shaped hei tiki probably had an early and ongoing presence in the developmental lineage of hei tiki. The adze shape is best represented by shapes A and B. These shapes are recorded as relatively common amongst the 1769-1777 examples and as relatively common amongst hei tiki in general, suggesting both early origins for the adze shaped hei tiki and continuity in its prevalence. Supporting evidence for this conclusion is provided by the shape-to-size analysis. Shapes A and B are recorded as well represented amongst most sizes of hei tiki, including the smaller size ranges, which on average are considered to be probably the earliest.

Early dominance in the popularity of the type I style of hei tiki is apparent, with seven out of eight early contact period hei tiki being recorded with this style and $100 \%$ had the Doubtless 
Bay hei tiki not been classed as type I/II. The type II style of hei tiki is conspicuous by its absence from the early contact period assemblage, although it was not necessarily absent from the period. It may be that early European explorers didn't visit those areas of New Zealand in which it was present.

The analysis of recorded stylistic features provides evidence suggesting that hei tiki were highly developed by the early contact period, with most of the stylistic features which are characteristic of hei tiki in general being well represented amongst the 1769-1777 examples.

While there were probably significant regional variations in the development of hei tiki styles the results enable some general observations to be made. Conventions of style appear to have been established early and maintained for the following: prevalence of the adze shape and type I style; proportions of width to length of about $60 \%$; head, body and leg proportions; heads usually inclined to one side at an approximate 45 degree angle; eyes both large or small in size but with large eyes much more prevalent; presence of brows and forehead ridges; forking of forehead ridges on the lower end at the nose bridge; arched nostrils; heart shaped mouths often with internal teeth; indicative necks formed by central ridges beneath the heads; forking of the lower ends of indicative necks to form ribs; symmetrical arm configuration with both arms positioned to the thighs, with the lower arms bending inwards and downwards from pointed elbows; female sex identifiable on $36 \%$ to $40 \%$ of hei tiki; preference for straight thighs in $80 \%$ to $84 \%$ of examples; and the presence of leg knobs or projections on $56 \%$ to $60 \%$ of examples.

Developments in style over time appear to be apparent in the variations of recorded features observed between the two groups. Over time it appears that double suspension holes may have ceased being made or became uncommon; hei tiki of shape $D$ became uncommon; multiple sets of ribs, the forked tongue, and secondary eye rims became less common; un-notched pāua shell eye inlay became less common in favour of notching; wax inlay made its appearance; knees became less rounded and more cornered; the fashioning of brows above the eyes became more common; the type II style of hei tiki 'made its appearance' or became more common; and hei tiki became larger. 
A feature of the early contact period hei tiki is the relatively high recorded presence of atypical elements of style. This may be interpreted as suggesting that innovative practice may have been more prevalent during the early contact period than later on.

Supporting evidence for the argument for a trend of increasing size of hei tiki over time is provided by the analysis of recorded dimensions, which show that on average the general assemblage hei tiki are $21 \mathrm{~mm}$ longer and $10 \mathrm{~mm}$ wider than the $1769-1777$ examples. Further evidence for the trend is provided by the wear-to-length correlation observed for the hei tiki in group two, with the small hei tiki appearing on average to be more highly worn than the larger hei tiki, indicating that they were made at an earlier date and received more use over time.

Supporting evidence for the occurrence of a high point of hei tiki making in the early $19^{\text {th }}$ century may be reflected in the pronounced peak in the numbers of hei tiki belonging to the $101 \mathrm{~mm}-110 \mathrm{~mm}$ size range of group two (Fig.17).

Pounamu analysis of hei tiki indicates a preference for using the pale coloured inanga variety favoured by Māori and conversely not favoured by Europeans during the $19^{\text {th }}$ century. Furthermore analysis of recorded use wear indicates prolonged use of the majority of hei tiki in the study. These findings suggest traditional status and ancestral use for most hei tiki in preference to European trade item status. 


\section{Chapter Six: General Conclusions}

\section{Chapter introduction}

This study has aimed to reveal mana-enhancing understandings of hei tiki through an investigation into their origins, ongoing development and use. In today's modern society Māori often walk in two worlds, acknowledging and practicing distinctively Māori systems of belief, while acculturated also to the ways and beliefs introduced by Pākehā New Zealanders and the wider world at large. The dual approach of this thesis reflects this reality. It sees legitimacy and benefit in understanding hei tiki according to both world views. Furthermore it adopts the position that empirical research findings may have an impact on how the taonga hei tiki is viewed according to Māori philosophical systems of belief.

\section{Hei tiki origins, development and use}

The line of reasoning developed and tested in this thesis suggests a reassessment of some understandings for the origins, development and use of hei tiki. While it may never be known for sure which style of hei tiki appeared first, it seems that good grounds exist for the view that the most common type I style of hei tiki probably made its appearance early on in the developmental lineage of hei tiki and quickly came to dominate as the most preferred basic style type.

During the early contact period 1769-1777 it appears that the adze-shaped hei tiki was common, the popular relatively deeply modelled type I style of hei tiki already predominated, and hei tiki by then already possessed most of the stylistic details of design which appear to be characteristic of hei tiki in general. It seems apparent that convention for these hei tiki characteristics was established early on - probably well before the early contact period - and there was considerable continuity over time.

Given this understanding it seems reasonable to think that the origins of hei tiki themselves may be closely associated with the ability to saw adze-shaped pieces of pounamu of adzelike thickness; that the common deeply modelled type I style of hei tiki may have existed from early on due to its suitable match with the shape and thickness of available pieces of 
sawn pounamu; and that stylised hei tiki imagery may have been adapted from pre-existing classic Māori wood carving motifs.

The high proportion of stylistic elements recorded amongst early contact period hei tiki, which appear to be characteristic of hei tiki in general, is also consistent with the view for a relatively early spread of the hei tiki fashion and adaptation in the stylistic appearance of hei tiki in different localities to conform to local conventions. It seems this provides a reasonable explanation for why by the early contact period hei tiki had collectively already taken on most of the stylistic attributes which remained characteristic of hei tiki in general. The relatively high number of features recorded as being unique amongst the early contact period hei tiki suggest that innovative practice may have been somewhat more common in the making of hei tiki during the early period than later on.

In assessing these conclusions it seems that a creative 'efflorescence' in the formation of hei tiki can be more rightly attributed to the pre-contact era than to post-contact developments. Ongoing later developments of style may have been on a less dramatic scale, however a number of stylistic developments appear to have occurred, including a chronological trend for increasing size of hei tiki.

The research project focused upon the comparative analysis of two groups of hei tiki and so it does not provide supporting evidence for an ongoing relationship between hei tiki making and wood carving. However the findings are compatible with the view that an ongoing dynamic relationship may have existed. With the making of hei tiki said to have required a high level of skill, it is possible that the hei tiki maker and the wood carver were often one and the same person. Innovations may have been made first in wood carving and then transferred in simplified form into the tougher material, pounamu.

The compositional analysis of the recorded features of the group two hei tiki found supporting evidence for the view that the making of hei tiki peaked during the early $19^{\text {th }}$ century. The analysis found no evidence for a significant change in the outline shapes of hei tiki during this period, which may have bought about the appearance of the common style of hei tiki, or other large changes in the appearance of hei tiki. The apparent high point in hei tiki making achieved during the early $19^{\text {th }}$ century can be attributed largely to an 
increase in the supply of pounamu, increased skill base for making hei tiki and increased demand. The early $19^{\text {th }}$ century likely saw increased supply of pounamu from the South Island augmented by the freeing up of pounamu in the form of adze blades, when they were replaced with metal carving tools. Analysis of recorded pounamu varieties and signs of use wear indicate that demand for hei tiki appears to have continued to come mostly from Māori, with trade in recently-made hei tiki to Europeans probably taking place on a lesser scale.

\section{Enhanced mana}

The findings of this thesis suggest that the origins of most aspects of the iconography of hei tiki can be firmly placed within the pre-contact realm of the ancestors, with considerable antiquity able to be attributed to the most common highly stylised and familiar style. That the stylistic origins of hei tiki can be attributed to early indigenous agency - as opposed to proto-historic influence - is deemed to be mana-enhancing for hei tiki. This understanding affirms traditional understandings of the mana of hei tiki as an ancient cultural treasure passed down from the world of the atua and ancestors.

Insight into the mana which has been imbued into hei tiki by the artistic agency and excellence of their makers has been gained in this study, through an examination of the importance of maintaining conventions of style, while also maintaining stylistic edge through subtle innovation. The stylistic complexity of hei tiki, the extreme toughness of the material, the estimation of 300 or more hours work required to make them, and the high community expectations placed upon hei tiki makers, are all factors which show the making of hei tiki to have been a significant achievement. It seems that the classic Māori iconography developed in wood carving would have been elevated to new heights by the ability of hei tiki makers to transfer that imagery into the most highly valued of all materials, pounamu.

The mana of hei tiki is closely associated with their ancestral connections, with the relative antiquity of hei tiki playing a large part in the esteem in which they are held, as mana accumulates with age and use over successive generations. The pale coloured inanga variety of pounamu has been indicated by this study to be the most common variety used for hei tiki, suggesting that hei tiki were made primarily for Māori cliental who valued this variety, 
rather than as trade items for Pākehā who preferred the deeper shades of green. Use wear analysis supports this conclusion by showing most hei tiki to have signs of wear indicative of prolonged ancestral use. It is concluded that most hei tiki carry the full assortment of cultural meaning and enhanced mana derived from the agency of prolonged ancestral use. That indigenous agency appears to be largely responsible for the increased post-contact popularity of hei tiki is deemed to be mana-enhancing for hei tiki and for Māori culture; - of which hei tiki is one iconic expression of cultural self-determination.

Mana can be thought of as the possessing the potential to effect significant change. The considerable mana of the study assemblage hei tiki has been revealed through their proven ability to reveal significant culturally affirming new understandings. This thesis has realised the mana-enhancing potential of the hei tiki used in this study to enhance the mana of hei tiki in general. It is satisfying that a selection of hei tiki predominantly without known backgrounds or localities of origin should help reconstruct the whakapapa of hei tiki in general.

\section{Further research possibilities}

The site of Whareakeake has been highlighted in this thesis as the only site from which a large number of hei tiki has been recovered. A number of the Whareakeake hei tiki are known of in collections today. The value of the Whareakeake hei tiki for research purposes is suggested by the ability to place them in time to 1817 when the village was destroyed and the ability also to place them to a particular locality, community and tribal context.

An important and large area of study which has only been touched upon lightly in this thesis is research into the identification of regional and tribal styles of hei tiki. Given the portable nature of hei tiki and the fact that many have probably travelled far from their points of origin, and the possibility that many diagnostic features of style may be quite subtle, this would be a difficult task, but some general observations may be possible. 


\section{Appendix One: Hei Tiki Research Project - Recorded Features}

\section{List of contents:}

Group One Assemblage - early contact period hei tiki

Images and descriptions for hei tiki $1.1-1.5$

Drawings and descriptions $\times 3$ : Figs $22-24$

Table 2-Recorded features of hei tiki 1.1-1.5

Group Two Assemblage - general selection from the Te Papa collection

Images* and shape identifications for hei tiki $2.1-2.50$

Table 3 - Recorded features of hei tiki $2.1-2.10$

Table 4-Recorded features of hei tiki $2.11-2.20$

Table 5 - Recorded features of hei tiki $2.21-2.30$

Table 6 - Recorded features of hei tiki $2.31-2.40$

Table 7-Recorded features of hei tiki $2.41-2.50$

*Note: copyright on all group two images is held by Te Papa 
Group One Assemblage - early contact period hei tiki

Images and descriptions for hei tiki 1.1-1.5

1.1

Kunsthistorisches Museum 23, Vienna

Ex Forster Collection; Second Cook voyage.
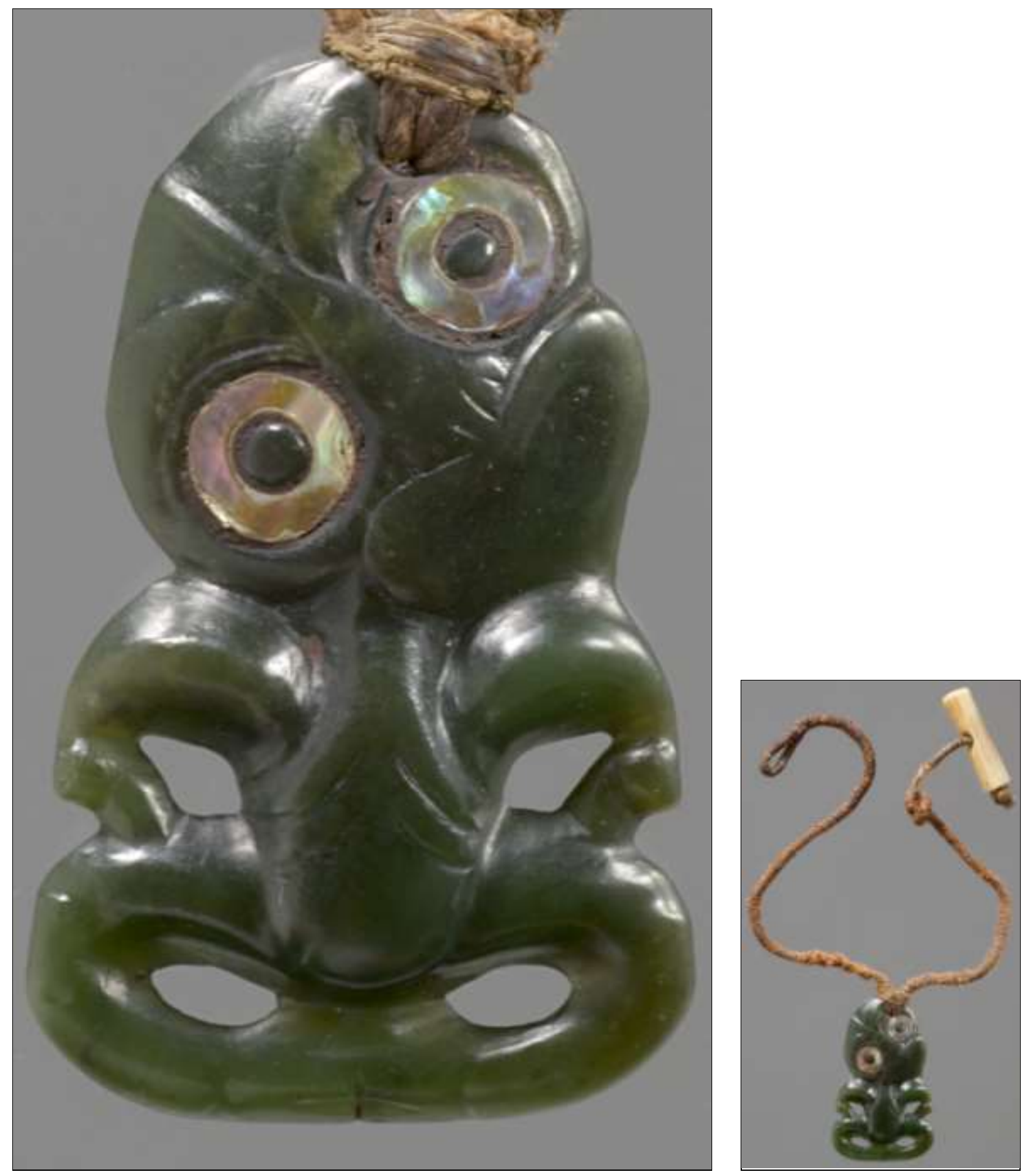

(c) Kunsthistorisches Museum 
Figure 18 Shape A, hei tiki 1.1

$65 \mathrm{~mm} \times 40 \mathrm{~mm}$; Wear assessed as 5 out of 10

A small hei tiki with stylised features conforming relatively closely to a wedge shaped outline. The head is marginally peaked on top and tilts to the right at an approximate 45 degree angle. A forehead ridge extends to the nose-bridge but details of the nose-bridge and nose appear to be mostly worn away. Part of an arched nostril can be seen. Large eyes have inlay of un-serrated pāua shell and secondary rims around the upper margins. Resin inlay adhesive is visible. Prominent brows are evident with a hole drilled straight through the upper brow above the left eye. The mouth is heart shaped with inner details apparently worn away. A central ridge beneath the head forms an indicative neck which forks on the lower end to form two sets of ribs. The arms rest on the thighs. Elbows are pointed and lugged. No hands. Smoothly worn knobs are visible at the knees and the ankles. Thighs and lower legs curve around in tapered fashion to meet at well-defined three toed feet. The finely plaited muka cord is of multiple strands and exhibits wear in places; bone toggle. 


\section{2 \\ The Field Museum 273856, Chicago}
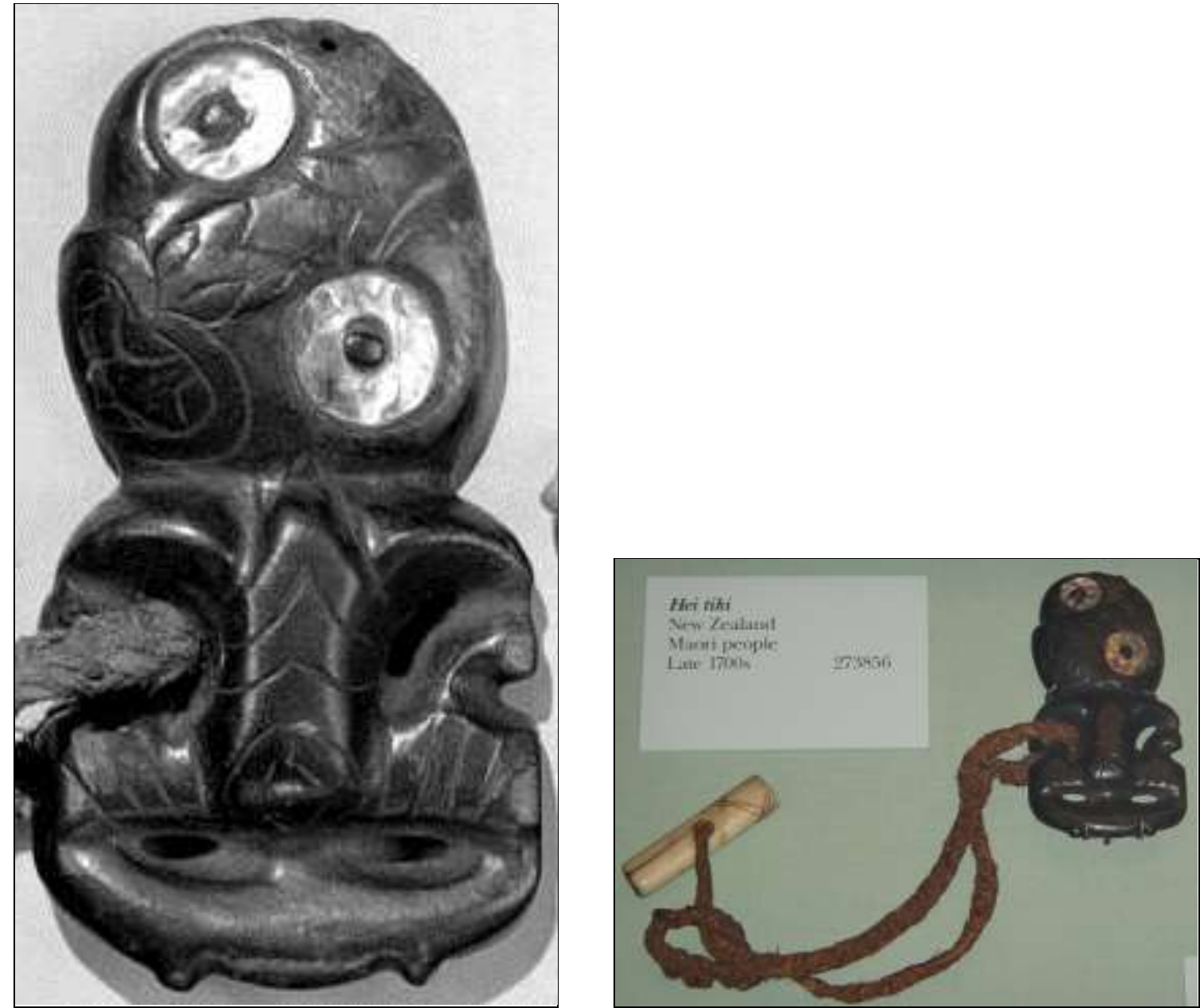

(c) Courtesy of The Field Museum

Installation image by Christopher J. Philipp, 2013. @ Courtesy of The Field Museum

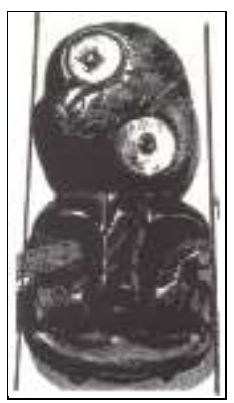

Figure 19 Shape B, hei tiki 1.2

$100 \mathrm{~mm}$ (length) x $52 \mathrm{~mm}$ (width); Wear assessed as 2 out of 10

The features of this hei tiki conform to a predominantly rectangular outline shape with a slight wedge aspect to it. The head is rounded marginally on top and tilts to the left at an approximate 45 degree angle, although the centre of the face does not align well with the 
lower pointed lip. Two large eyes have wide rings of un-notched pāua shell inlay. Brows are indistinct / absent. The forehead ridge forks at the nose-bridge. Well defined arched nostrils. A heart shaped mouth has four teeth with an internal tongue splayed against the left corner tooth. The direction of the tongue towards the inner part of the hei tiki is uncommon. An indicative neck forks on the lower end to form ribs: two per side. Grooves of the large diamond shaped vagina are of similar proportion to those of the ribs. Both arms are positioned downwards with three fingered hands rendered upon the thighs, possibly in raised relief. The thighs extend straight outwards to cornered knees. The lower legs have prominent ankle projections; no feet. Leg and arm cavities are worked through in economical fashion. A thick plaited cord is attached through the right arm cavity in apparent non-original fashion. Bird wing bone toggle has grooved diagonal patterns. The cord appears to be somewhat worn in places. The end of the suspension hole can be seen above the right eye. The small size of the hole indicates it has been drilled mostly from the back; although the top surface is rough indicating possible loss to the original surface and top part of the hole.

Ex A.W.F. Fuller Collection; Ex Leverian Museum, London (Kaeppler 1978:177) 


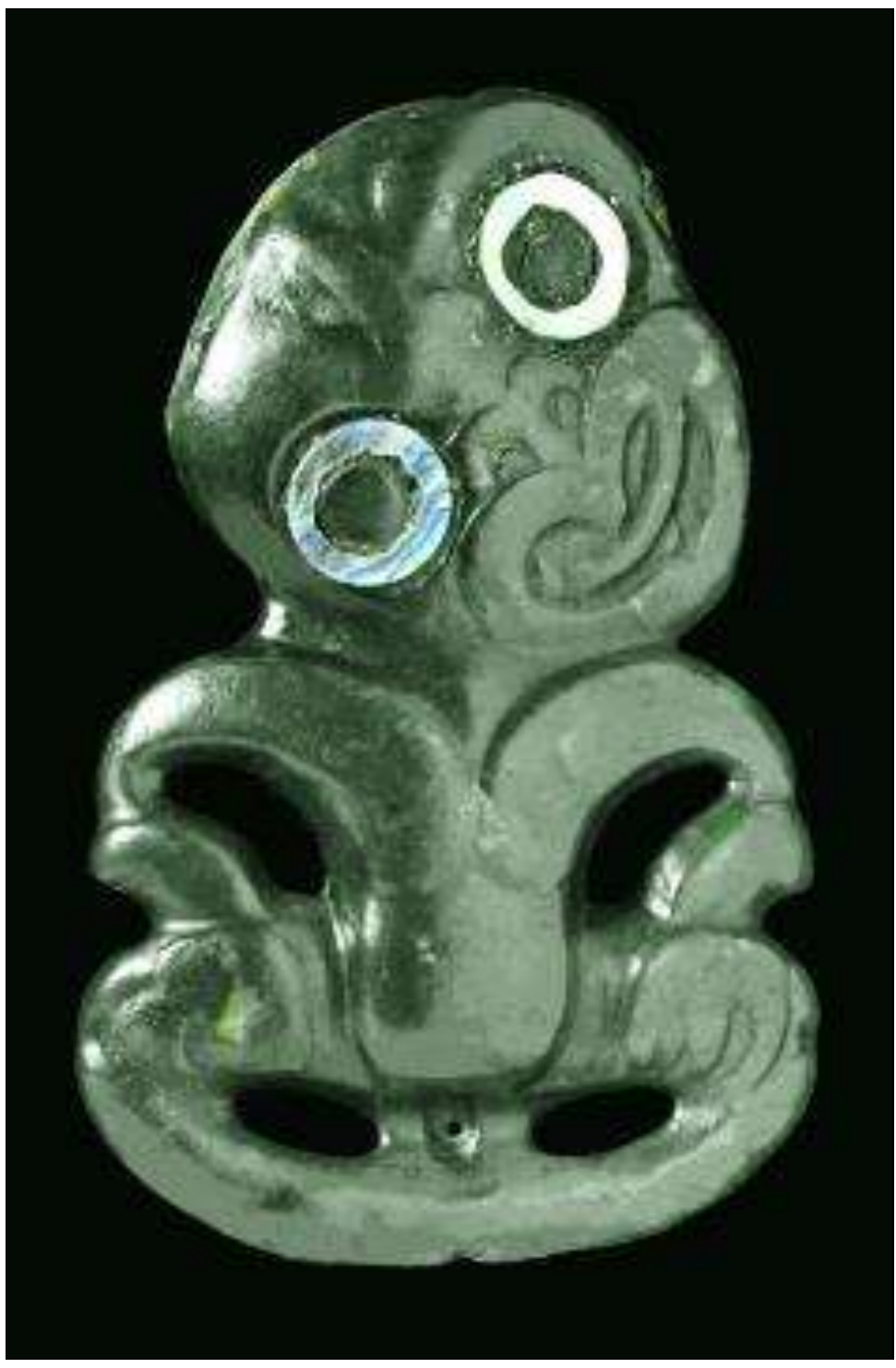

(C) Pitt Rivers Museum

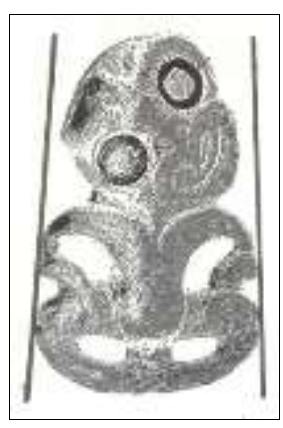

Figure 20 Shape C, hei tiki 1.3

$100 \mathrm{~mm}$ (length) x $63 \mathrm{~mm}$ (width); Wear assessed as 2 out of 10

The features of this hei tiki appear to have been worked substantially away from the confines of the original piece of pounamu, a characteristic also evident in the rendering of the extensive inner arm and leg cavities. The head is slightly rounded on top and tilts to the hei tiki's right at an approximate 45 degree angle. A worn forehead ridge forks at the nose bridge; prominent arched nostrils to the nose. The large eyes are inlaid with thin rings of un- 
notched pāua shell. A prominent brow is evident above the left eye. The heart-shaped mouth has small teeth in the right corner and at the bottom middle. A tongue extends to the left side of mouth, and possibly originally beyond, but details are not visible, possibly worn. A slightly extended neck is evident on the right hand side, but on the left side the head rests directly upon the shoulder. The upper arms are unusually narrow directly above the elbows and they join to the chest in distinctive fashion. No ribs. The lower arms are exceptionally wide. Also distinctive are the three fingered hands carved onto the thighs in raised relief. Thighs extend straight outwards to rounded knees. Lower legs taper together with feet delineated by a lower notch and a small hole drilled above. Worn knobs are visible at the knees. 
Ex Forster Collection; Second Cook voyage.

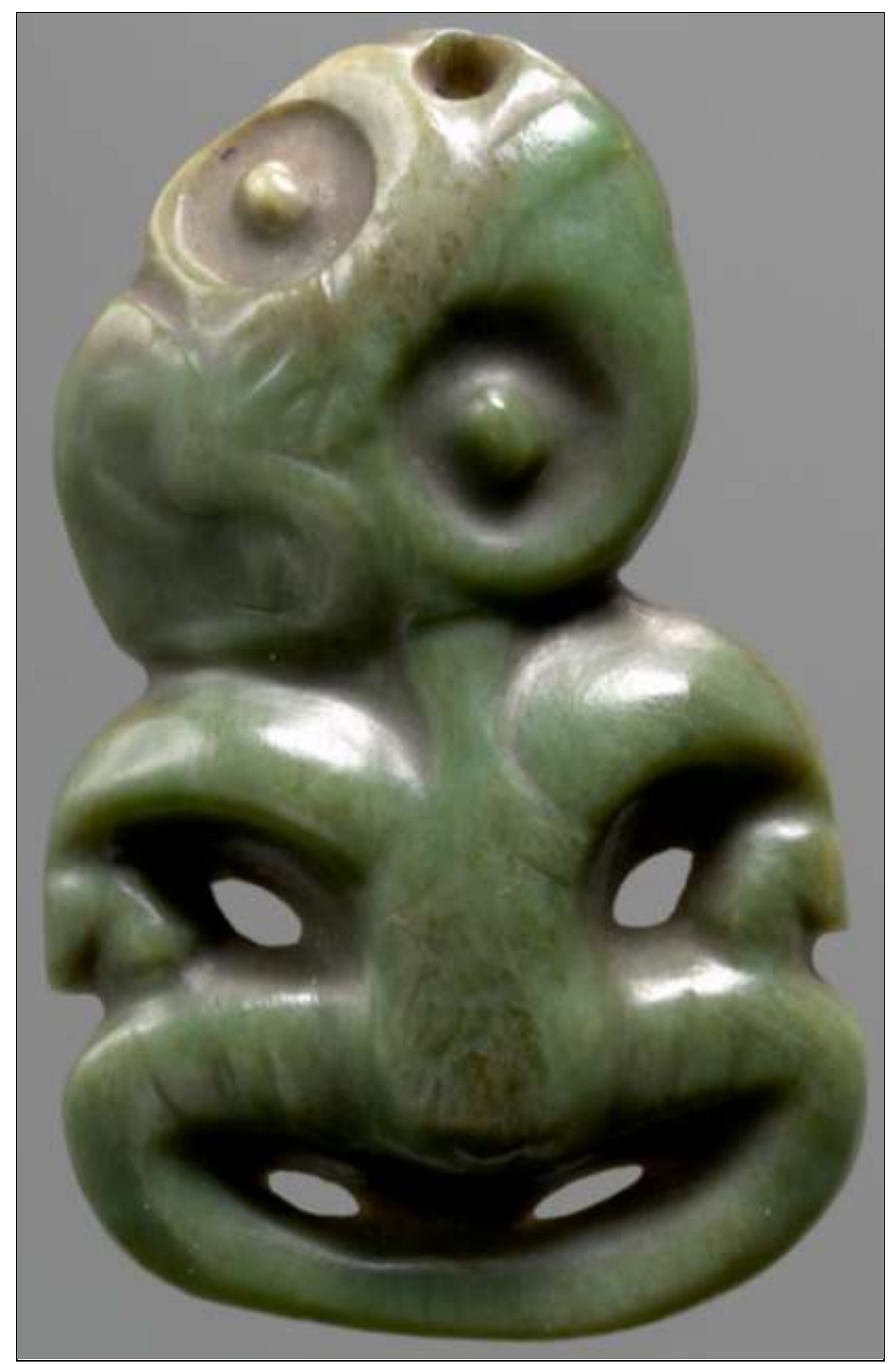

(c) Kunsthistorisches Museum

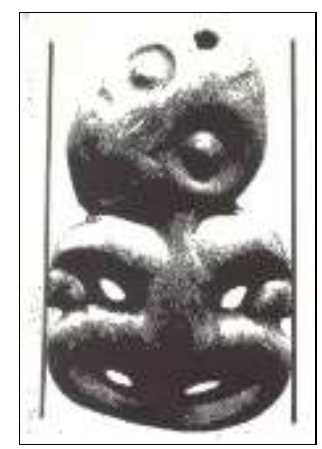

Figure 21 Shape C, hei tiki 1.4

$85 \mathrm{~mm} \times 55 \mathrm{~mm}$; Wear assessed as 8 out of 10

This Hei tiki has a slightly elongated head which tilts to the left at an approximate 45 degree angle. The fore head ridge forks at the nose-bridge; prominent arched nostrils; large, deeply grooved eyes without inlay; indistinct brows. Heart shaped mouth with worn teeth in 
corners. Indicative neck forks on the lower end to form ribs: one per side. Lower arms bend inwards at downturned sharply pointed elbows. Three fingered grooved hands on the thighs. Female sex indicated. Thighs extend outwards to rounded knees. Lower legs taper and join together. No feet. Work to the arm and leg cavities is relatively extensive, possibly due to deep thickness of hei tiki; wide thighs and upper arms. Pounamu is of pale inanga variety. The features are worn significantly possibly resulting in loss of original eye inlay. 


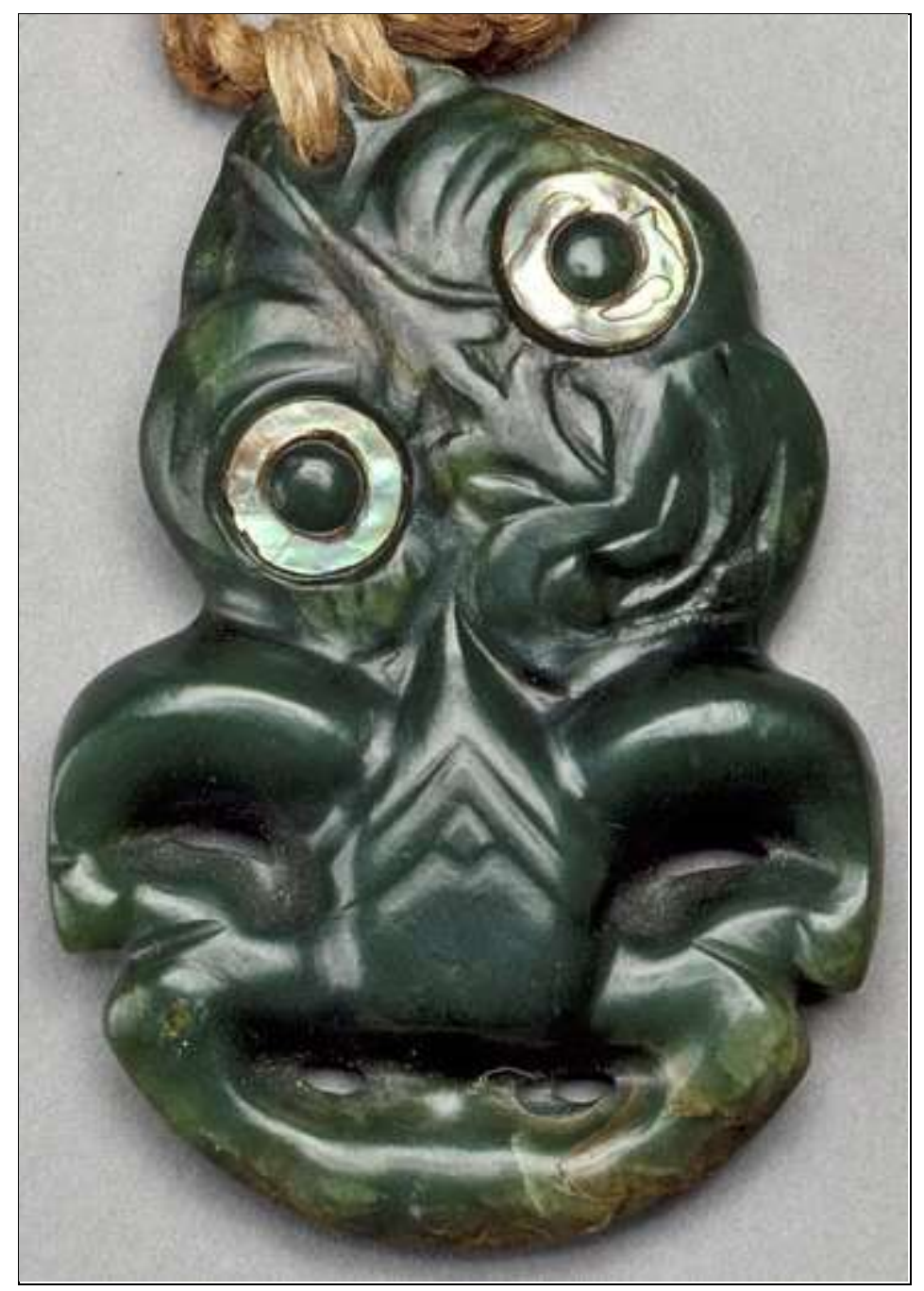

Royal Collection Trust/@ Her Majesty Queen Elizabeth II 2013

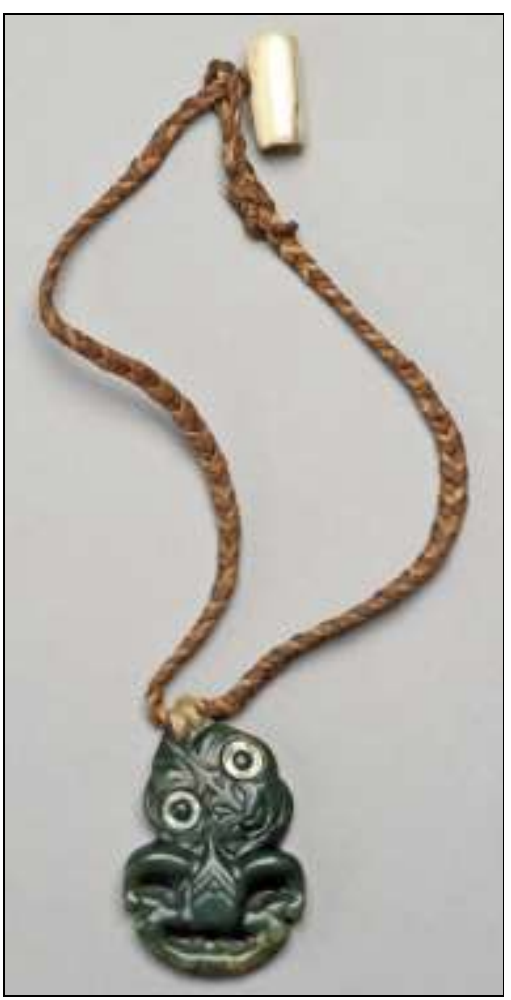

Shape D, hei tiki 1.5

$70 \mathrm{~mm}(\mathrm{I}) \times 50 \mathrm{~mm}(\mathrm{w}) \times 10 \mathrm{~mm}(\mathrm{~d})$; Wear assessed as 1 out of 10

Given to King George III by Captain James Cook

A relatively small hei tiki with features highly stylised to conform within an oval-like outline shape. Enlarged upper arms contrast with reduced legs. The top of the head is accentuated into a peak and is notable for having two suspension holes. The head tilts to the right at an approximate 45 degree angle. The forehead ridge forks at the nose bridge. The lower nose is flared in distinctive alternative fashion and joins with the nose bridge via a central ridge. The large eyes are inlaid with un-notched rings of pāua shell. Secondary eye rims and prominent 
brows are in evidence above the eyes. The heart shaped mouth has three teeth and an extended forked tongue, the details of which may have worn somewhat. Head rests directly upon the shoulders. A sharply pointed central ridge beneath the head forms an indicative neck which forks on the lower end to form ribs: two per side. A small diamond shape is worked beneath the fork of the ribs. Arms curve outwards and then inwards to rest on the thighs in conventional Webster type 1 fashion. Elbows are pointed. No hands or feet. Hei tiki is made from a pale coloured pounamu of inanga variety. Plaited cord with bone toggle on the end. Hei tiki is widest at the mid-point.

(Kaeppler 1978:177, Fig.332) 
Drawings and descriptions of three hei tiki from the early contact period 1769$\underline{1777}$

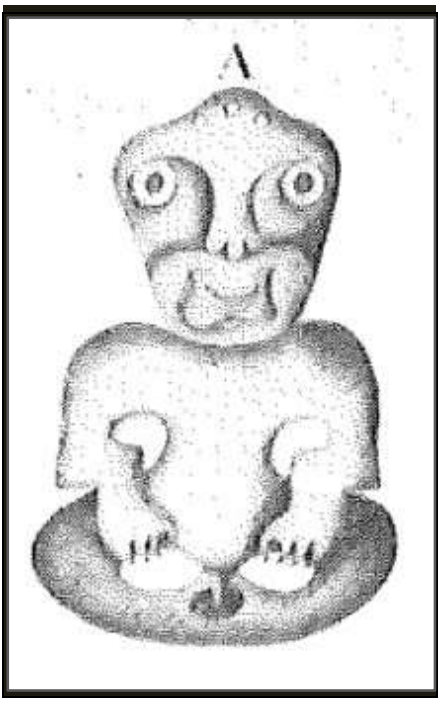

Figure 22

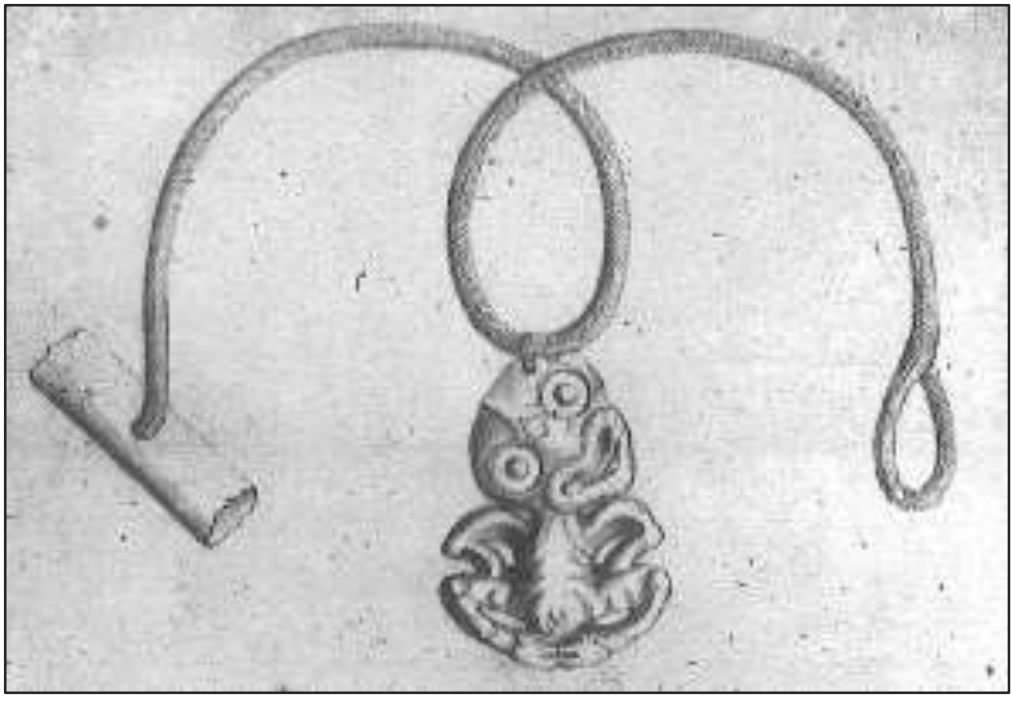

Figure 23

Fig.22 Hei tiki from Doubtless Bay. While essentially configured in symmetrical type I style, this hei tiki also contains some Webster type II elements of design in terms of its relatively narrow head, small eyes, absence of both a brow ridge and absence of an indicative neck. It is accordingly identified as type I/II. In addition to its upright head the hei tiki is notable for being fully symmetrical and apparently having two suspension holes. Outline shape is identified as shape $A$.

Fig.23 Hei tiki from Mahia Peninsula. Of style type I with large eyes, head resting directly upon the shoulders, and both arms positioned to the thighs. It also has a forked extended tongue and two sets of ribs; female sex. Outline shape is tentatively identified as shape D. 


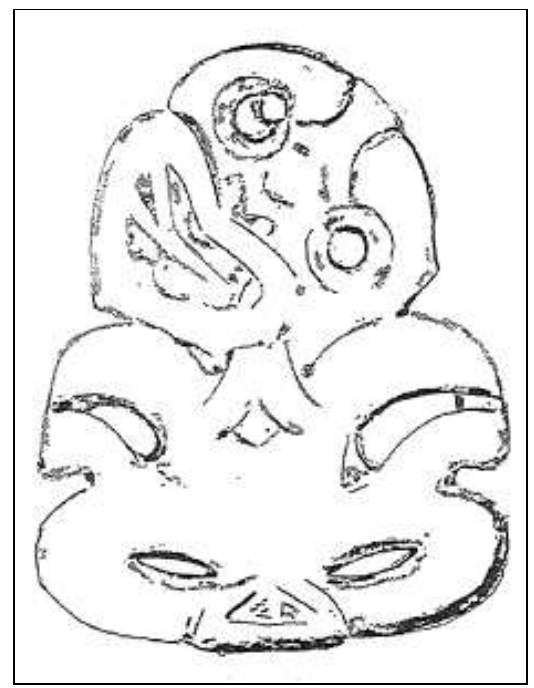

Figure 24 Hei tiki collected by Burr.

Fig.24 The Burr hei tiki is of type I. Features of note include the forked tongue, the diamond shape beneath a set of forked ribs, and the small head projections at the chin and at the left ear. The suspension hole is drilled through the upper eye. The outline most closely resembles shape $B$. 
Recorded features of the Group One hei tiki

Table 2 - Recorded features of hei tiki 1.1-1.5

\begin{tabular}{|c|c|c|c|c|c|}
\hline Study no. & 1.1 & 1.2 & 1.3 & 1.4 & 1.5 \\
\hline Collection number & 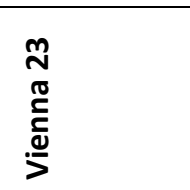 & 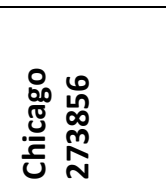 & 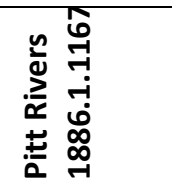 & 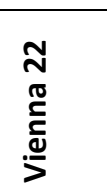 & 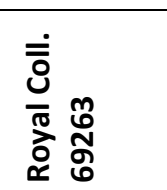 \\
\hline Outline shape & A & B & $\mathrm{C}$ & $\mathrm{C}$ & $\mathrm{D}$ \\
\hline $\begin{array}{l}\text { Type } \\
\text { (Webster) }\end{array}$ & I & I & I & 1 & I \\
\hline Length $\mathrm{mm}$ & 65 & 100 & 100 & 85 & 70 \\
\hline Width $\mathrm{mm}$ & 40 & 52 & 63 & 55 & 50 \\
\hline Depth mm & $?$ & $?$ & $?$ & $?$ & 10 \\
\hline Width \% of length & $62 \%$ & $53 \%$ & $66 \%$ & $62 \%$ & $69 \%$ \\
\hline Head \% of length & $49 \%$ & $49 \%$ & $47 \%$ & $45 \%$ & $47 \%$ \\
\hline Body \% of length & $22 \%$ & $22 \%$ & $22 \%$ & $28 \%$ & $28 \%$ \\
\hline Legs \% of length & $29 \%$ & $29 \%$ & $31 \%$ & $27 \%$ & $25 \%$ \\
\hline $\begin{array}{l}\text { Head tilt: } \\
\text { Left or Right? }\end{array}$ & $\mathrm{R}$ & $\mathrm{L}$ & $R$ & $\mathrm{~L}$ & $\mathrm{R}$ \\
\hline Degree of head tilt & 45 & 45 & 45 & 45 & 45 \\
\hline $\begin{array}{l}\text { Extent head pointed at } \\
\text { top: } 0-10\end{array}$ & 5 & 3 & 3 & 5 & 8 \\
\hline $\begin{array}{l}\text { Eyes large, medium or } \\
\text { small? }\end{array}$ & $\mathrm{L}$ & $\mathrm{L}$ & $\mathrm{L}$ & $\mathrm{L}$ & $\mathrm{L}$ \\
\hline Eye inlay? & $\begin{array}{l}\mathrm{Y} \\
\text { un-notched } \\
\text { pāua shell }\end{array}$ & $\begin{array}{l}Y \\
\text { un-notched } \\
\text { pāua shell }\end{array}$ & $\begin{array}{l}Y \\
\text { un-notched } \\
\text { pāua shell }\end{array}$ & $\mathrm{N}$ & $\begin{array}{l}\text { Y } \\
\text { un-notched } \\
\text { pāua shell }\end{array}$ \\
\hline Secondary eye rims? & $\mathrm{Y}$ & $\mathrm{N}$ & $\mathrm{N}$ & $\mathrm{N}$ & $\mathrm{Y}$ \\
\hline Brows? & $\mathrm{Y}$ & $\mathrm{N}$ & $\begin{array}{l} \\
1 \text { distinct }\end{array}$ & $\mathrm{N}$ & $\mathrm{Y}$ \\
\hline Forehead ridge? & $\mathrm{Y}$ & $Y$ & $\mathrm{Y}$ & $\mathrm{Y}$ & $\mathrm{Y}$ \\
\hline Forking at nose bridge? & $\begin{array}{l}\text { ? } \\
\text { worn }\end{array}$ & $\mathrm{Y}$ & $\begin{array}{l}Y \\
\text { worn }\end{array}$ & $\begin{array}{l}Y \\
\text { worn }\end{array}$ & $\mathrm{Y}$ \\
\hline Nostrils? & $\begin{array}{l}\mathrm{Y} ; \\
\text { arched; worn }\end{array}$ & $\begin{array}{l}\mathrm{Y} \\
\text { arched }\end{array}$ & $\begin{array}{l}\mathrm{Y} \\
\text { arched }\end{array}$ & $\begin{array}{l}\mathrm{Y} \\
\text { arched }\end{array}$ & $\begin{array}{l}\text { Y different } \\
\text { type }\end{array}$ \\
\hline $\begin{array}{l}\text { Ridge from nostrils to } \\
\text { nose bridge? }\end{array}$ & $\begin{array}{l}? \\
\text { worn }\end{array}$ & $\mathrm{N}$ & $\mathrm{N}$ & $\begin{array}{l}? \\
\text { worn }\end{array}$ & $\mathrm{Y}$ \\
\hline Heart shaped mouth? & $\mathrm{Y}$ & $Y$ & $\mathrm{Y}$ & $Y$ & $\mathrm{Y}$ \\
\hline
\end{tabular}




\begin{tabular}{|c|c|c|c|c|c|}
\hline Mid upper tooth? & $\begin{array}{l}\text { ? } \\
\text { worn }\end{array}$ & $\mathrm{Y}$ & $\mathrm{N}$ & $\mathrm{N}$ & $\mathrm{Y}$ \\
\hline Corner teeth? & $\begin{array}{l}? \\
\text { worn }\end{array}$ & $\mathrm{Y}$ & ? & $\begin{array}{l}\text { Y } \\
\text { worn }\end{array}$ & $\mathrm{Y}$ \\
\hline Internal Tongue? & $\begin{array}{l}? \\
\text { worn }\end{array}$ & $\begin{array}{l}? \\
\text { uncertain }\end{array}$ & $\begin{array}{l}? \\
\text { worn }\end{array}$ & $\begin{array}{l}? \\
\text { worn }\end{array}$ & $\mathrm{N}$ \\
\hline $\begin{array}{l}\text { Tongue against corner } \\
\text { tooth? }\end{array}$ & $\begin{array}{l}? \\
\text { worn }\end{array}$ & $\begin{array}{l}? \\
\text { uncertain }\end{array}$ & $\mathrm{N}$ & $\begin{array}{l}? \\
\text { worn }\end{array}$ & $\mathrm{N}$ \\
\hline Extended tongue? & $\mathrm{N}$ & $\mathrm{N}$ & $?$ & $\mathrm{~N}$ & $\mathrm{Y}$ \\
\hline Forked tongue? & $\begin{array}{l}\text { ? } \\
\text { worn }\end{array}$ & ? & ? & $\begin{array}{l}? \\
\text { worn }\end{array}$ & $\begin{array}{l}Y \\
\text { worn }\end{array}$ \\
\hline Head projections? & $\mathrm{N}$ & $\mathrm{N}$ & $\mathrm{N}$ & $\mathrm{N}$ & $\mathrm{N}$ \\
\hline Indicative neck? & $\mathrm{Y}$ & $\mathrm{Y}$ & $\mathrm{N}$ & $\mathrm{Y}$ & $\mathrm{Y}$ \\
\hline Extended neck? & $\mathrm{N}$ & $\mathrm{N}$ & $\mathrm{Y}$ & $\mathrm{N}$ & $\mathrm{N}$ \\
\hline Hunched shoulder? & $\mathrm{N}$ & $\mathrm{N}$ & $\mathrm{N}$ & $\mathrm{N}$ & $\mathrm{N}$ \\
\hline $\begin{array}{l}\text { Forked ribs? Y/N } \\
\text { Number per side: 1-? }\end{array}$ & $\begin{array}{l}\text { Y: } \\
2 \text { per side }\end{array}$ & $\begin{array}{l}\text { Y: } \\
2 \text { per side }\end{array}$ & $\mathrm{N}$ & $\begin{array}{l}\text { Y: } \\
1 \text { per side }\end{array}$ & $\begin{array}{l}\mathrm{Y}: \\
2 \text { per side }\end{array}$ \\
\hline Pattern beneath ribs? & $\mathrm{N}$ & $\mathrm{N}$ & $\mathrm{N}$ & $\mathrm{N}$ & Y: diamond \\
\hline Vagina? & $\mathrm{N}$ & $\mathrm{Y}$ & $\mathrm{N}$ & $\mathrm{Y}$ & $\mathrm{N}$ \\
\hline Arms curve out then in? & $Y$ & $Y$ & $Y$ & $Y$ & $Y$ \\
\hline Arms rest on thighs? & $Y$ & $Y$ & $Y$ & $Y$ & $\mathrm{Y}$ \\
\hline Hand to chest or mouth? & $\mathrm{N}$ & $\mathrm{N}$ & $\mathrm{N}$ & $\mathrm{N}$ & $\mathrm{N}$ \\
\hline Hands worked? & $\mathrm{N}$ & $Y$ & $Y$ & $Y$ & $\mathrm{~N}$ \\
\hline $\begin{array}{l}\text { Elbows pointed and /or } \\
\text { lugged? }\end{array}$ & $P ; L$ & $P ; L$ & $P ; L$ & $P ; L$ & $P ; L$ \\
\hline $\begin{array}{l}\text { Thighs: rounded (0-4), } \\
\text { straight }(6-10) \text {, or } \\
\text { in-between (5) }\end{array}$ & $\begin{array}{l}R \\
4.0\end{array}$ & $\begin{array}{l}S \\
9.5\end{array}$ & $\begin{array}{l}S \\
8.0\end{array}$ & $\begin{array}{l}S \\
7.0\end{array}$ & $\begin{array}{l}\mathrm{S} \\
8.5\end{array}$ \\
\hline $\begin{array}{l}\text { Knees: rounded }(0-4) \text {, } \\
\text { cornered }(6-10) \text {, or in- } \\
\text { between }(5)\end{array}$ & $\begin{array}{l}R \\
4.0\end{array}$ & $\begin{array}{l}C \\
9.0\end{array}$ & $\begin{array}{l}R \\
4.0\end{array}$ & $\begin{array}{l}1 \\
5.0\end{array}$ & $\begin{array}{l}C \\
8.0\end{array}$ \\
\hline Feet? & $Y$ & $\mathrm{~N}$ & $Y$ & $\mathrm{~N}$ & $\mathrm{~N}$ \\
\hline Leg projections? & $\mathrm{N}$ & Y: ankles & $\mathrm{N}$ & $\mathrm{N}$ & $\mathrm{N}$ \\
\hline Leg knobs? & $\begin{array}{l}\text { Y: knees, } \\
\text { ankles }\end{array}$ & $\mathrm{N}$ & Y: knees & $\mathrm{N}$ & $\mathrm{N}$ \\
\hline Pounamu variety? & $?$ & $?$ & $?$ & I & 1 \\
\hline Pounamu source? & $?$ & $?$ & $?$ & $?$ & $?$ \\
\hline Heat treatment? & $\mathrm{N}$ & $?$ & $\mathrm{~N}$ & $\mathrm{~N}$ & $?$ \\
\hline Surface reground? & $\mathrm{N}$ & $?$ & $\mathrm{~N}$ & $\mathrm{~N}$ & $?$ \\
\hline Wear: 0-10 & 5 & 2 & 2 & 8 & 1 \\
\hline
\end{tabular}


Group Two assemblage - general selection from the Te Papa collection

$\underline{\text { Images and shape identifications for hei tiki } 2.1-2.50}$

Shape category A (Including secondary shapes AB, AC)

where straight lines touch each side at three points

$2.1 \quad$ OL001051 [A]

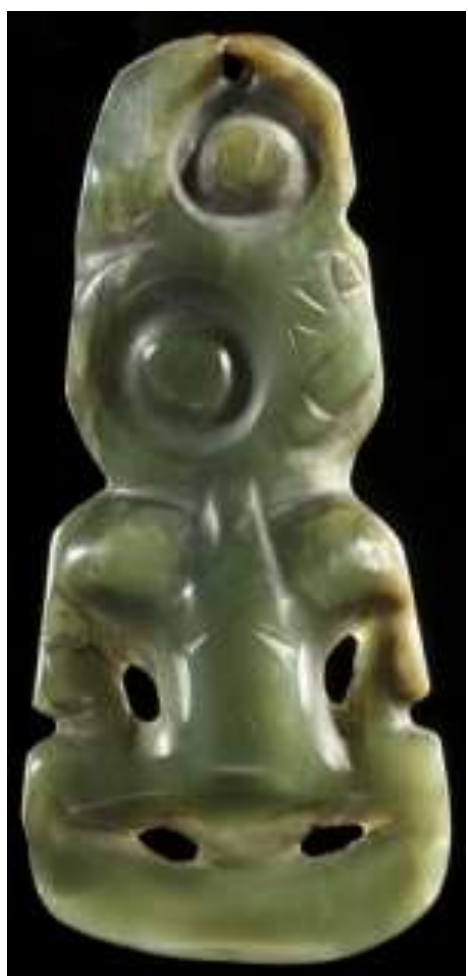

Front

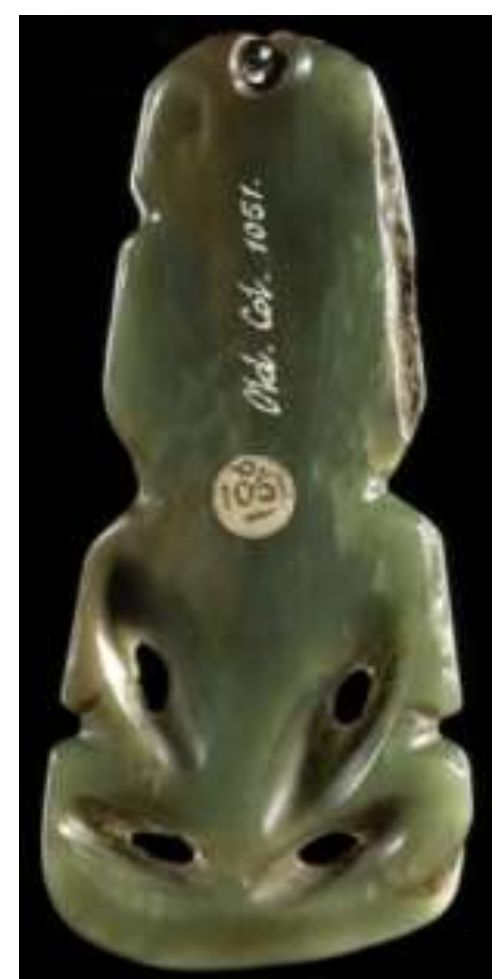

Back 
$2.2 \quad$ OL000495 [A]

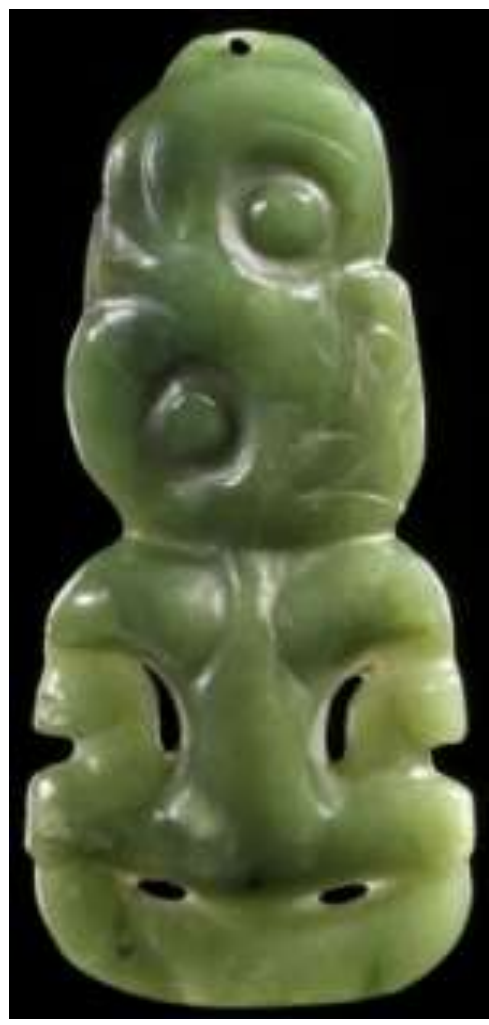

Front

2.3 ME001610 [A]

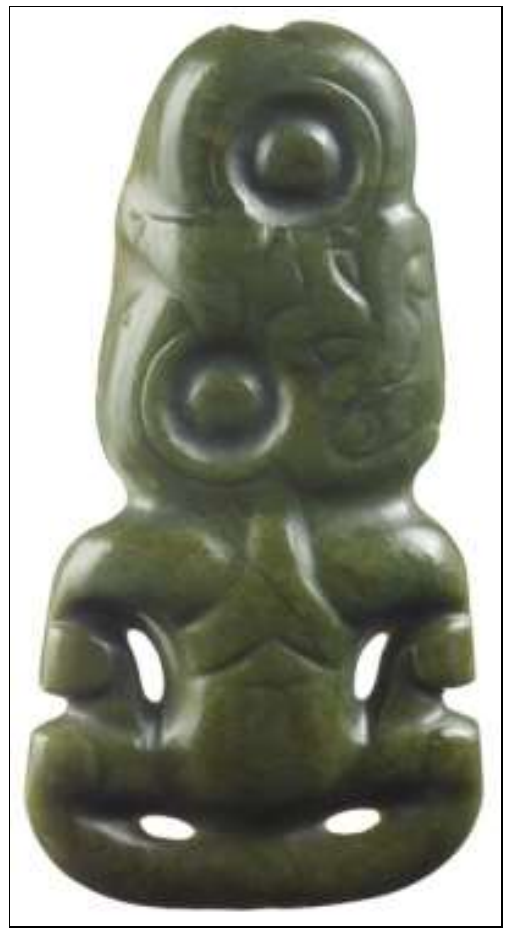

Front

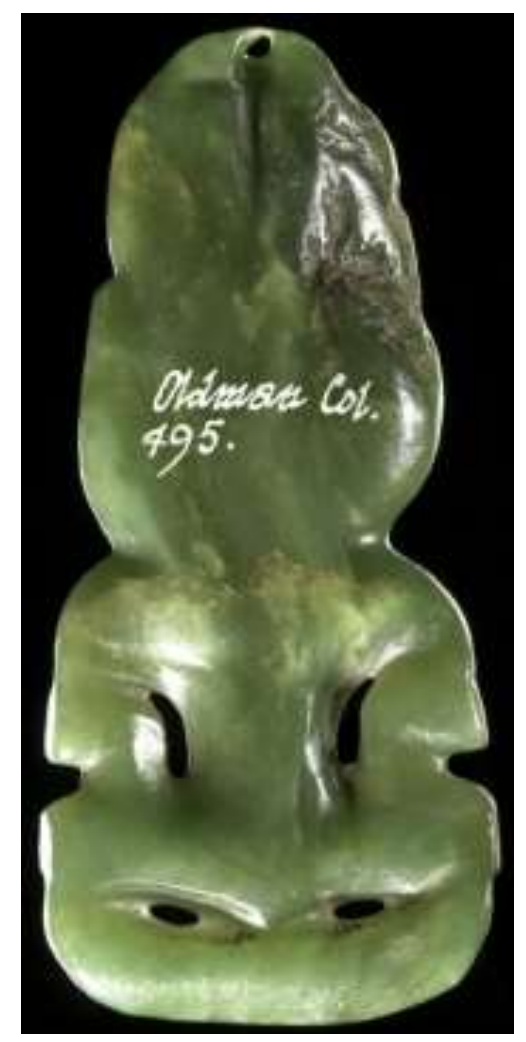

Back

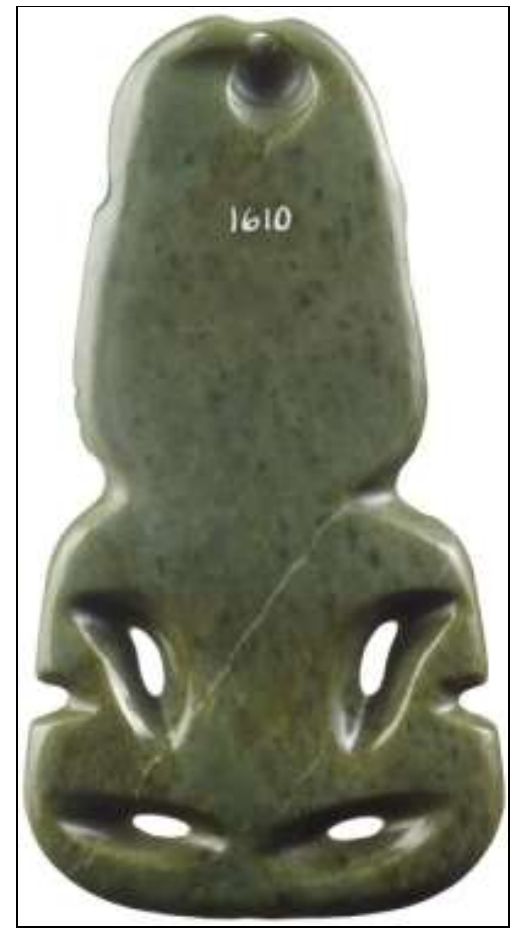

Back 
$2.4 \quad$ OL000486 [A]

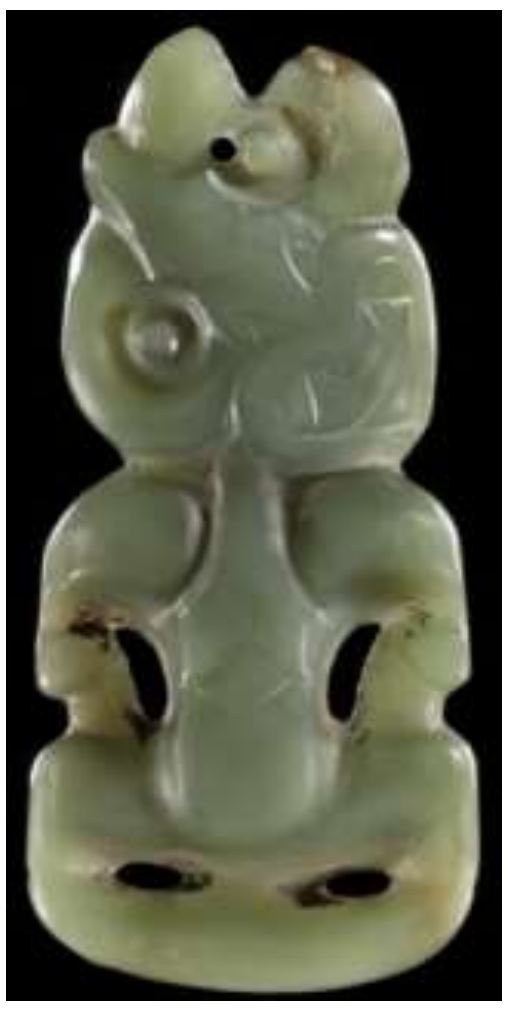

Front

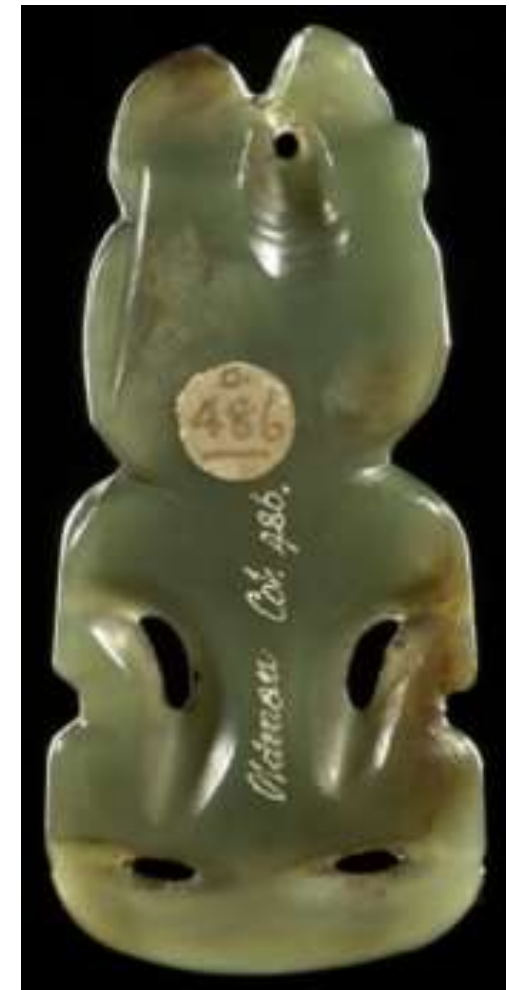

Back

$2.5 \quad$ ME002504 [A]

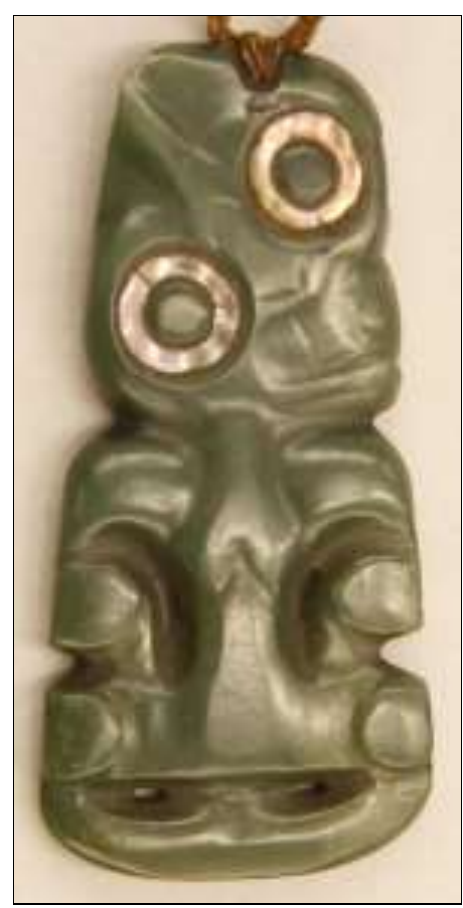

Front

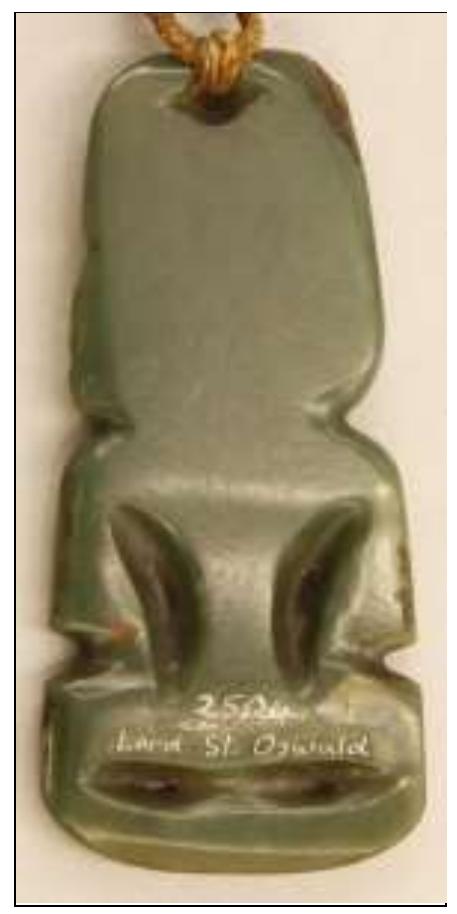

Back

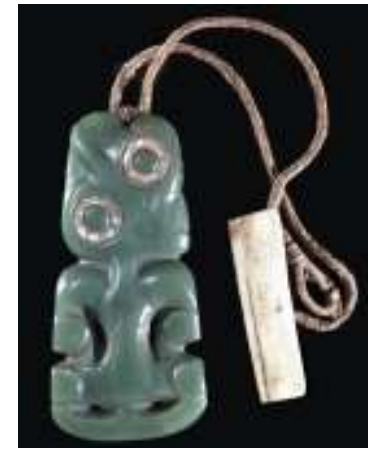

Overall 


\section{$2.6 \quad$ ME012898 [A]}

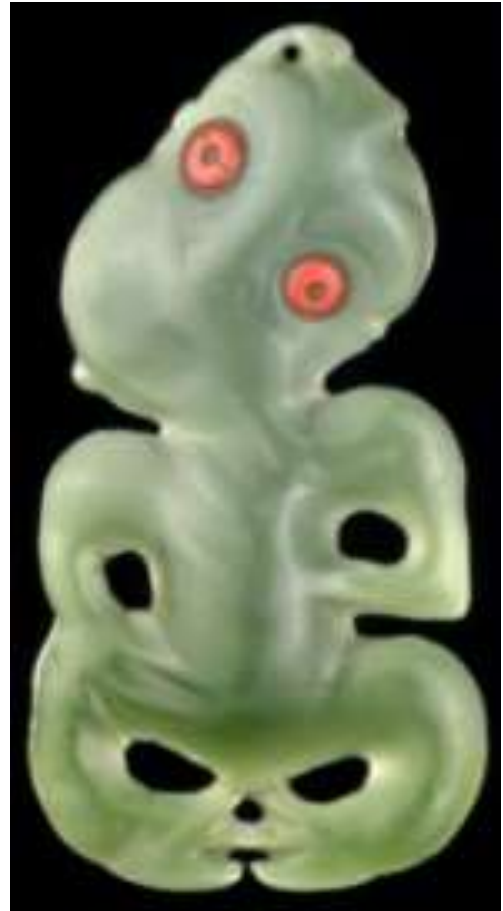

Front

$\begin{array}{lll}2.7 & \text { ME002518 [A] }\end{array}$

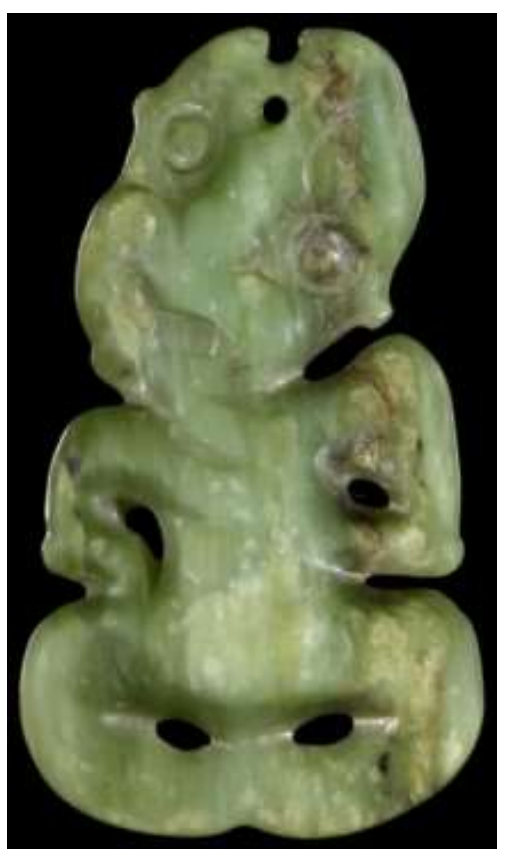

Front

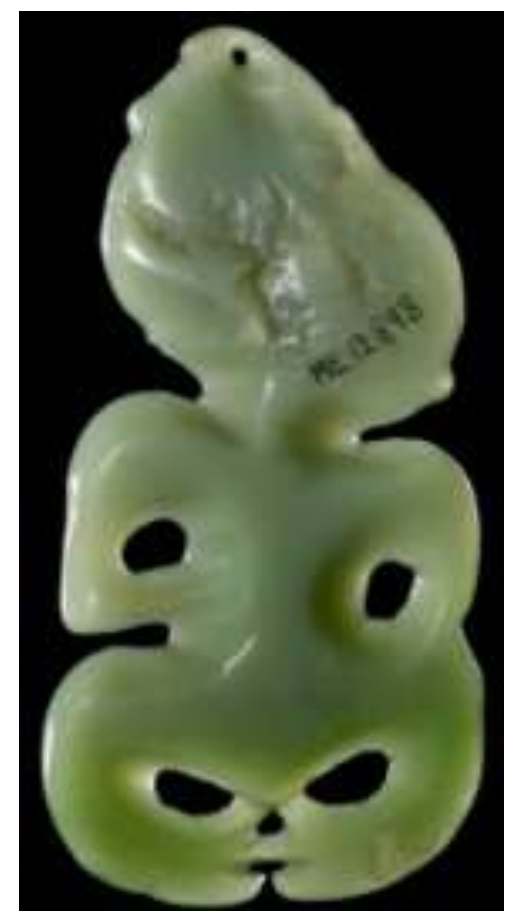

Back

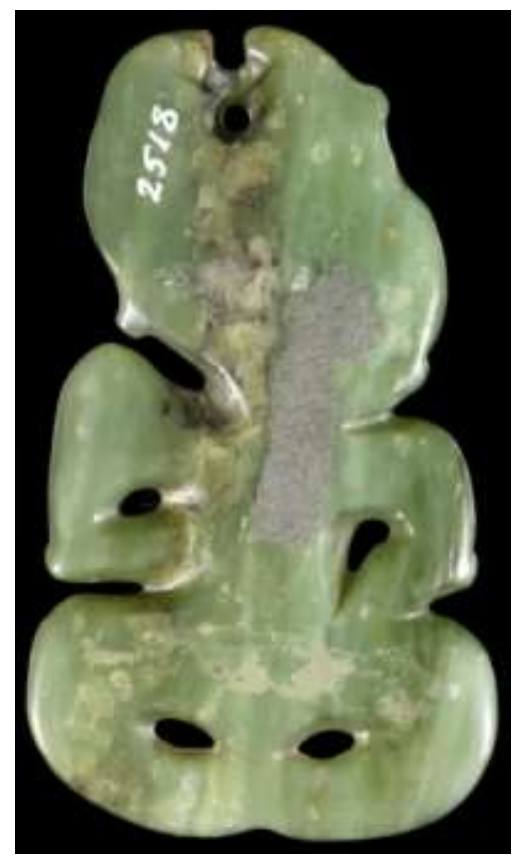

Back 


\section{$\begin{array}{lll}2.8 & \text { ME008701 [A] }\end{array}$}

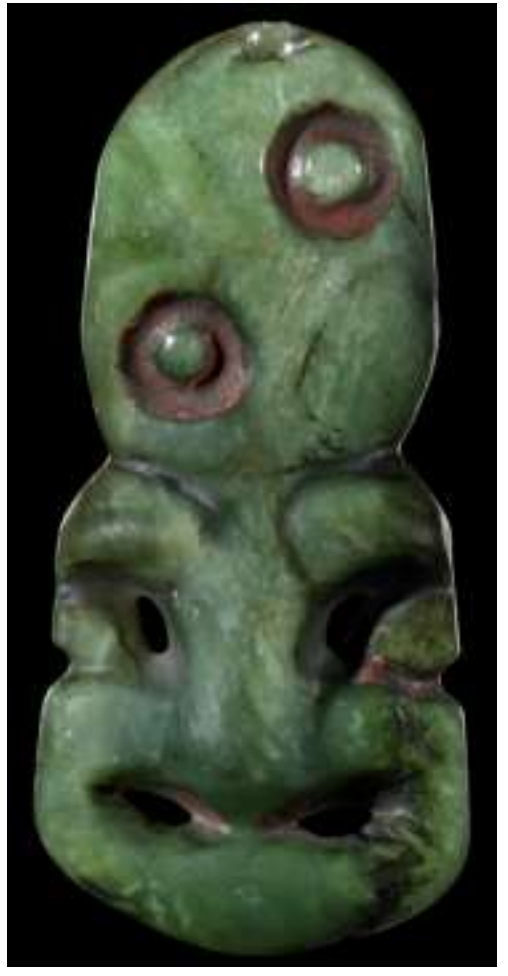

Front

\section{$2.9 \quad$ ME023985 [A]}

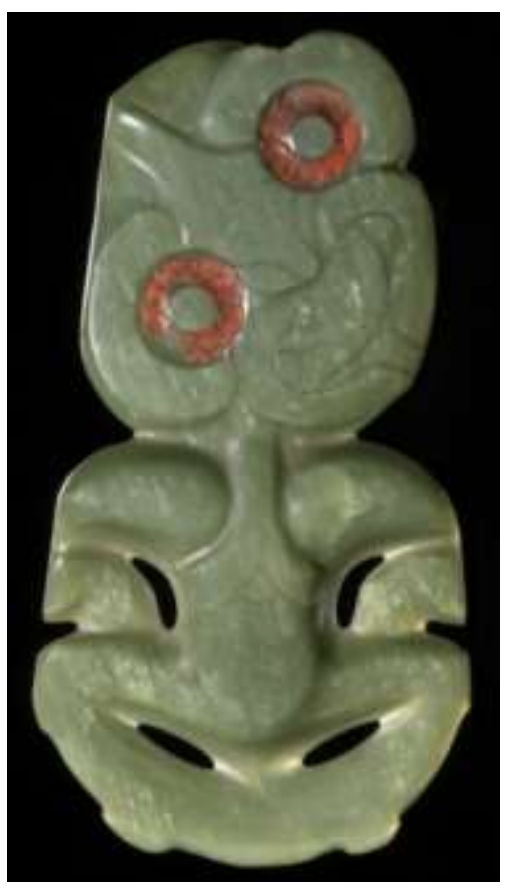

Front

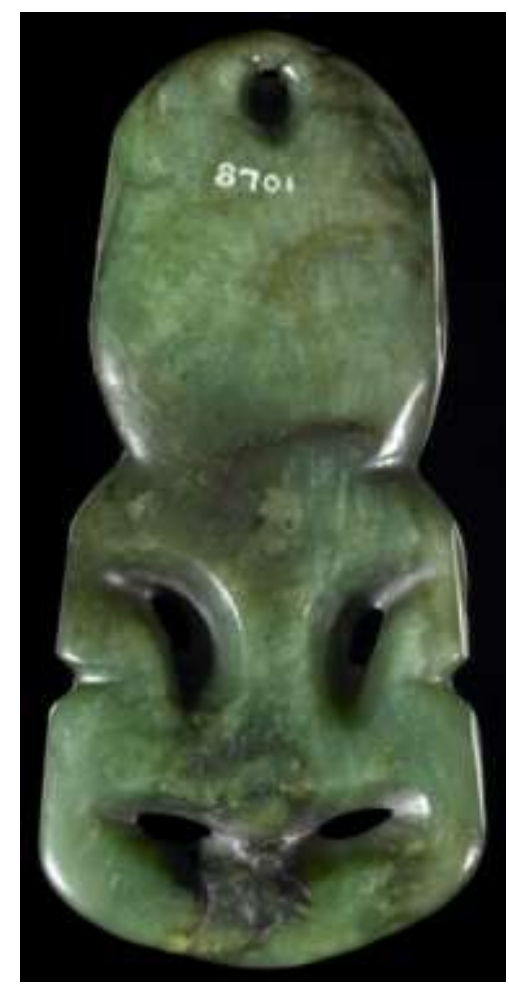

Back

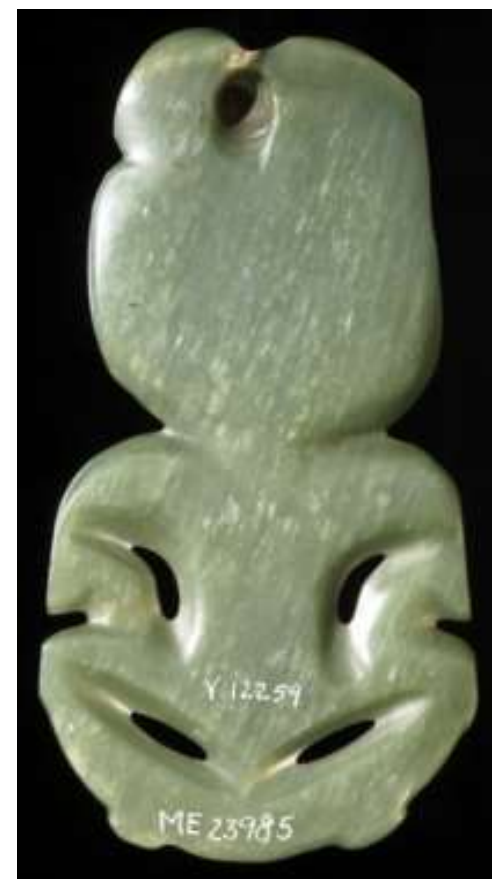

Back 
2.10 ME002979 [A]

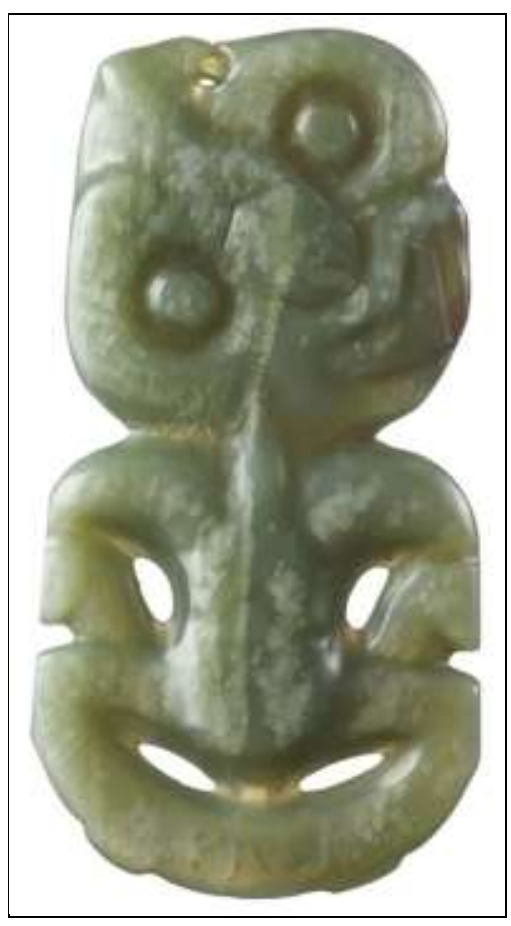

Front

$2.11 \quad$ OL000335

[A]

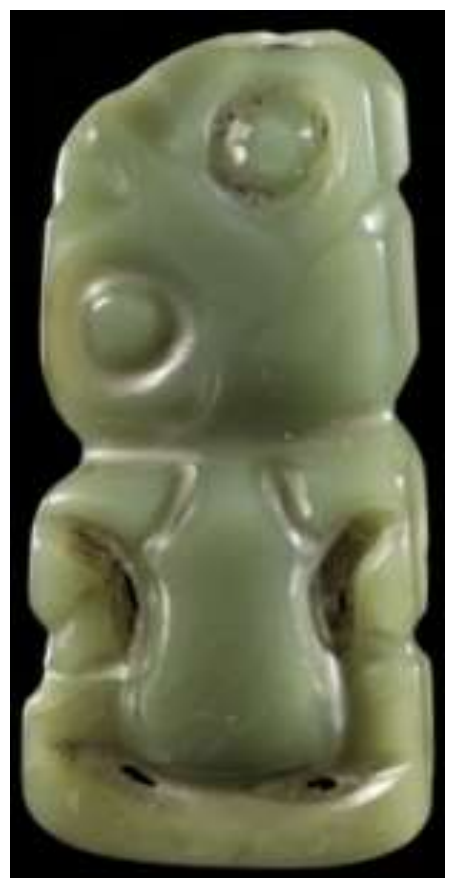

Front

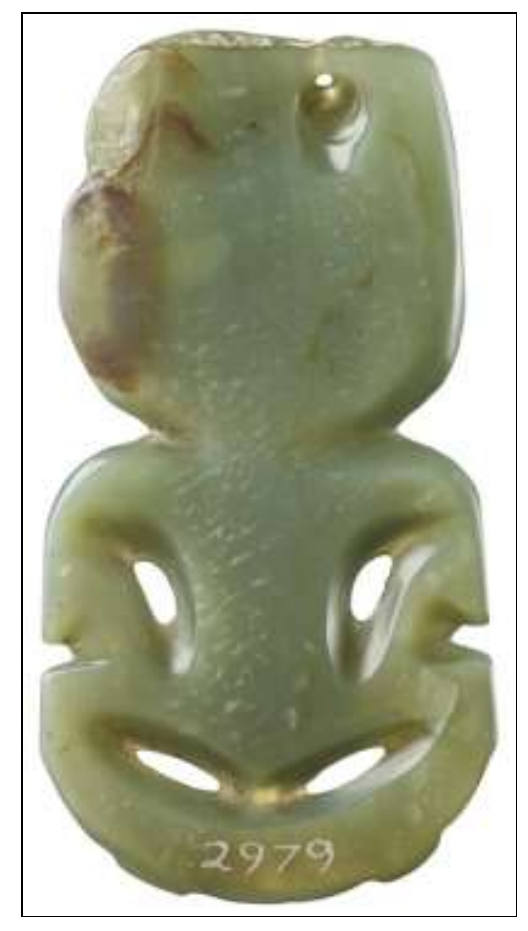

Back

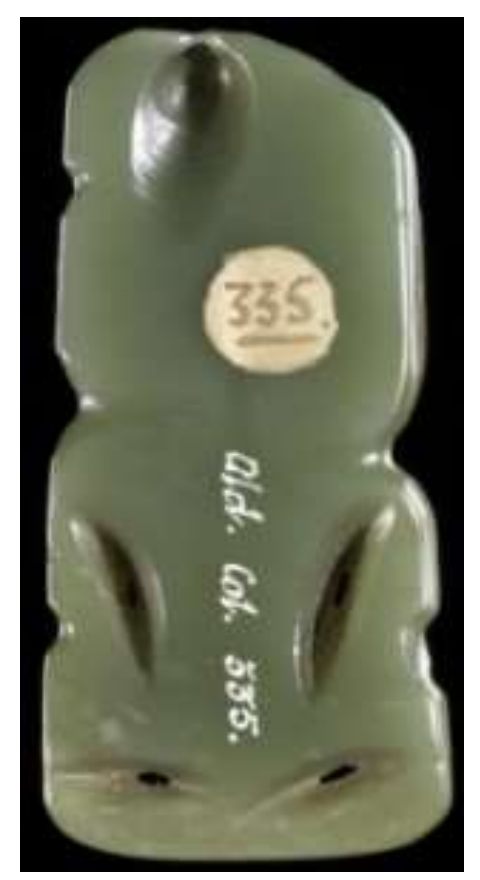

Back 


\subsection{ME004796 [A]}
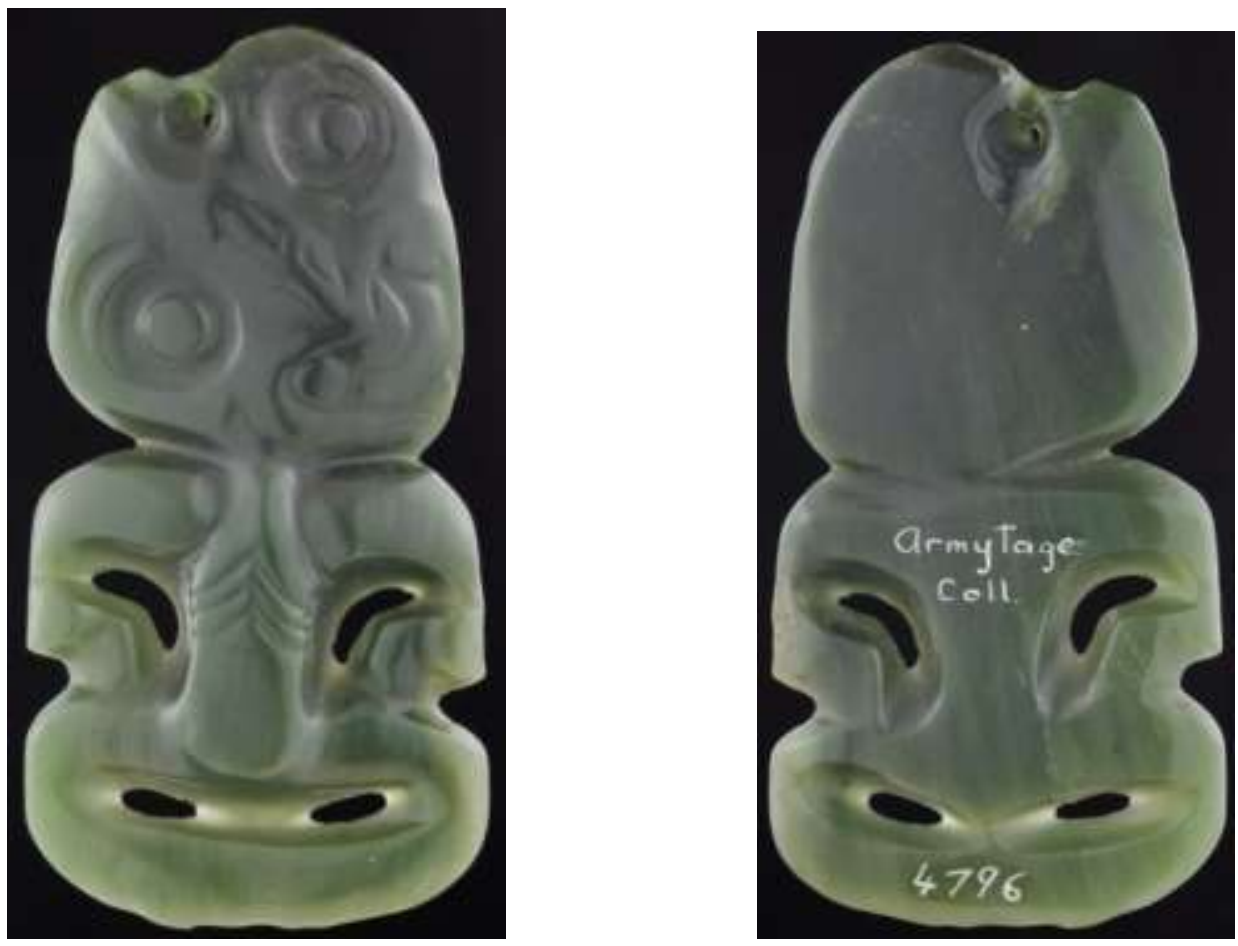

Front

Back

\subsection{WE00458 [A]}
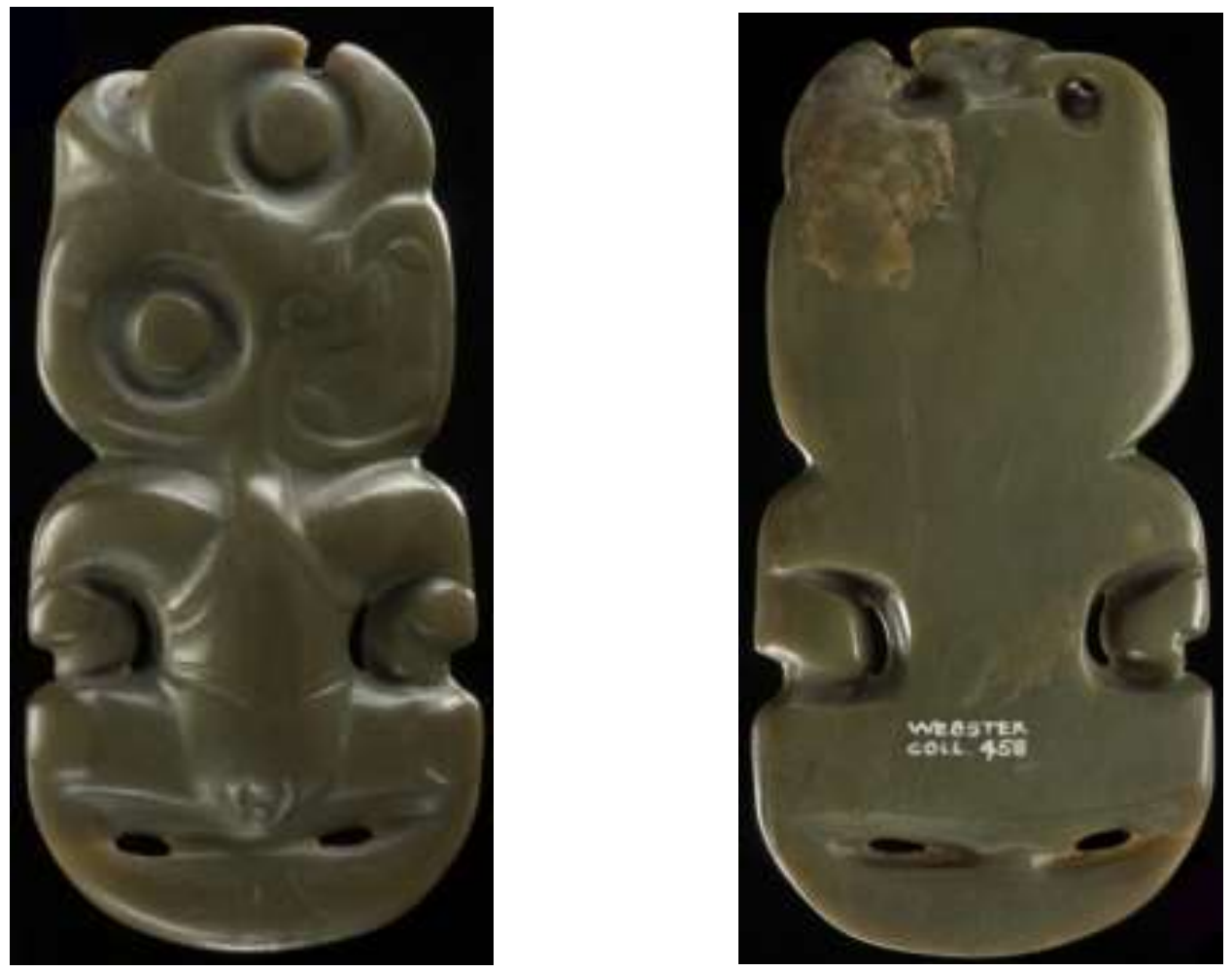

Front

Back 
$2.14 \quad$ OL000572 [A]

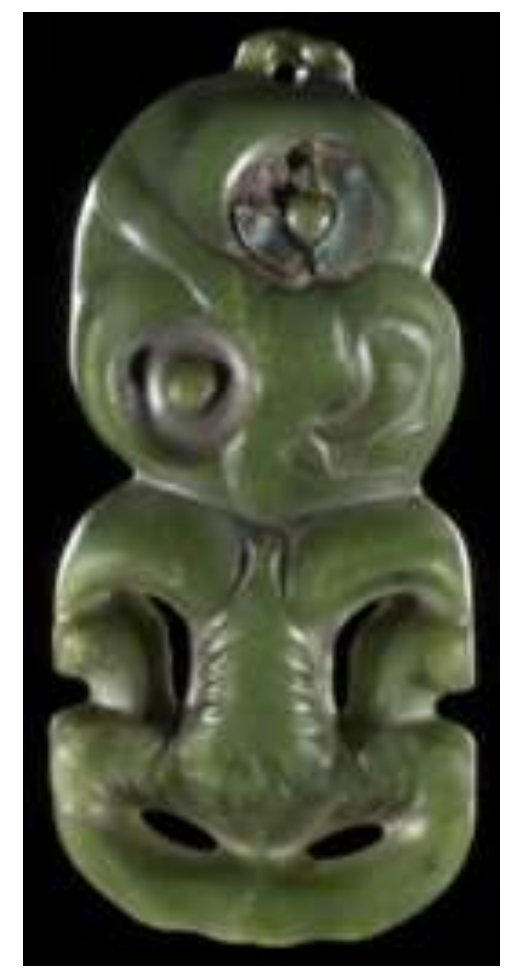

Front

\subsection{WE000451 [A]}

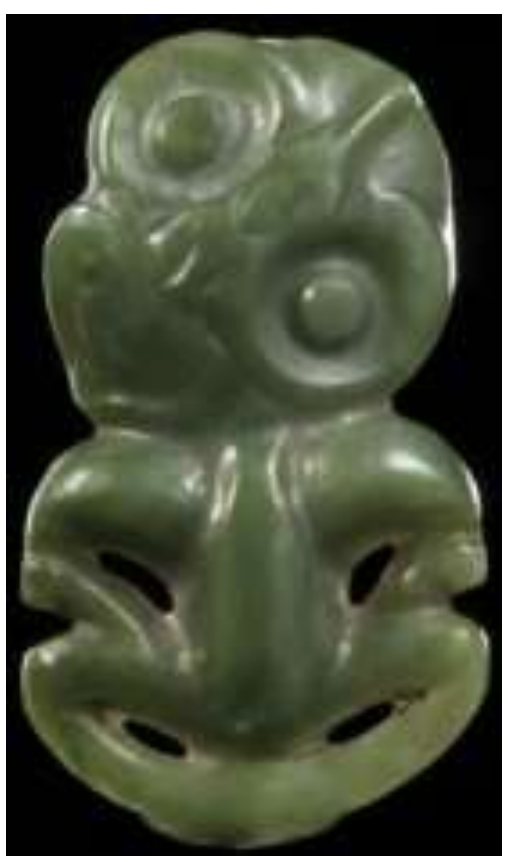

Front

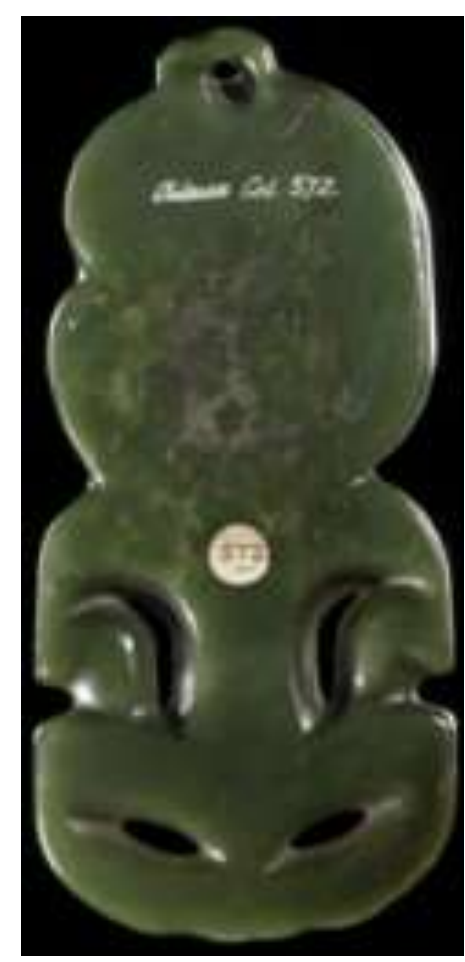

Back

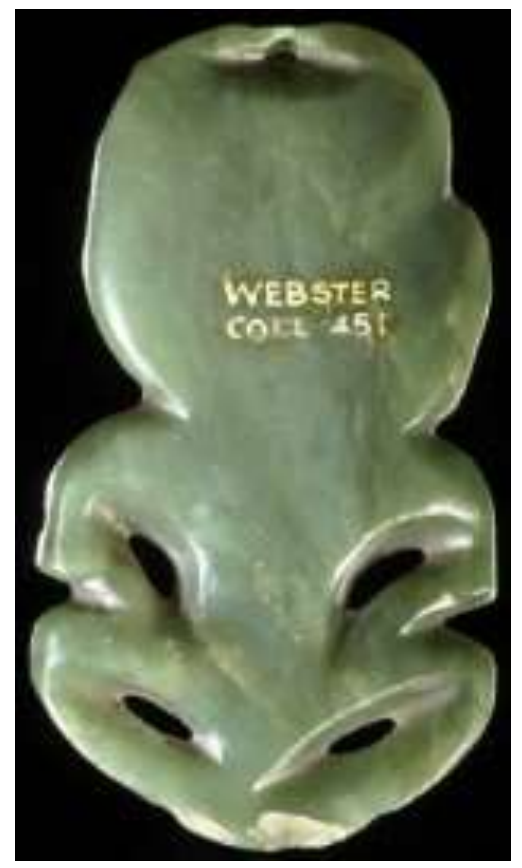

Back 


\section{$2.16 \quad$ OL000151 [A]}
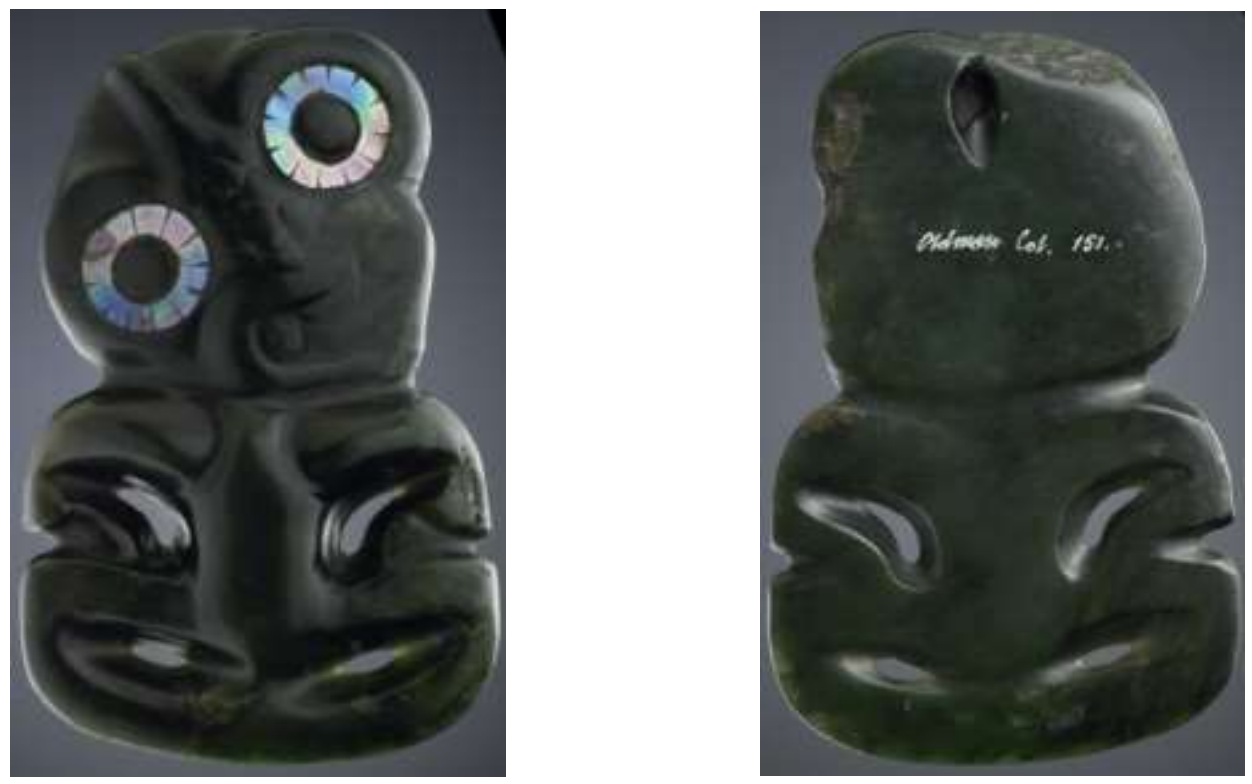

Front

Back

2.17 WE000231 [AB]

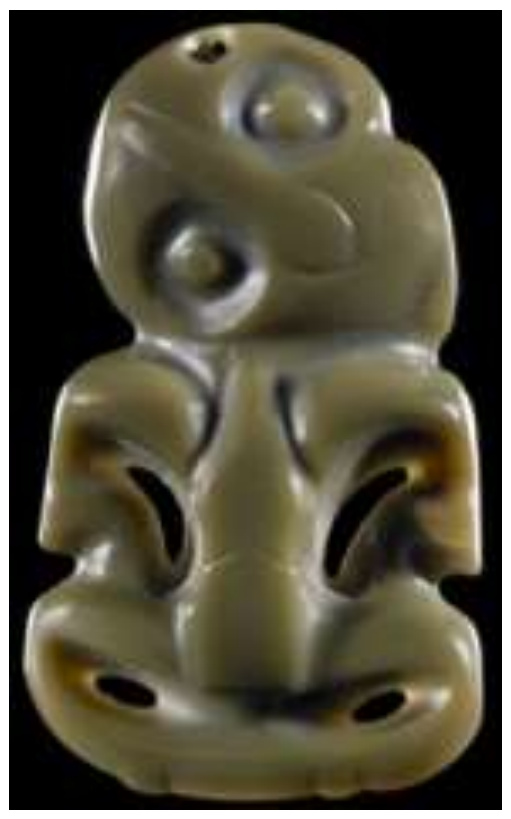

Front

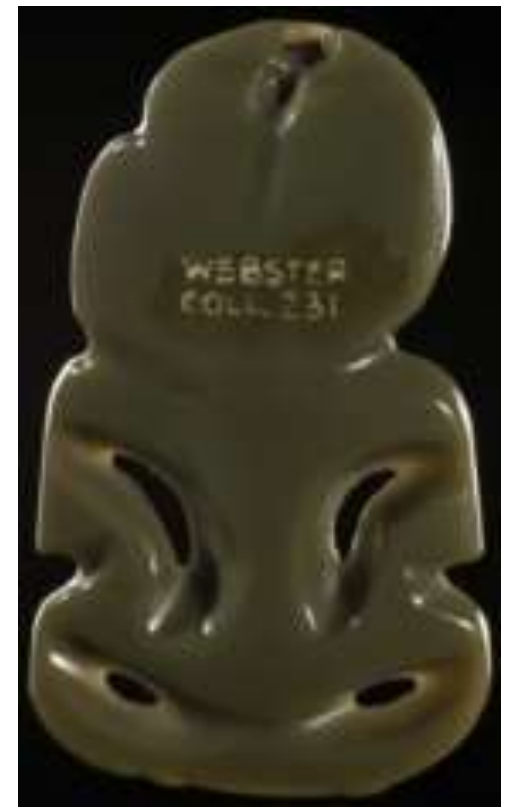

Back 
2.18 ME001615 [AB]

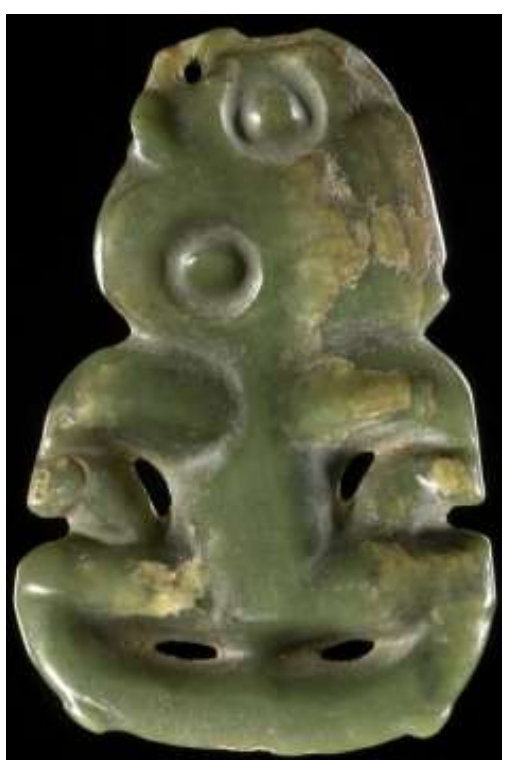

Front

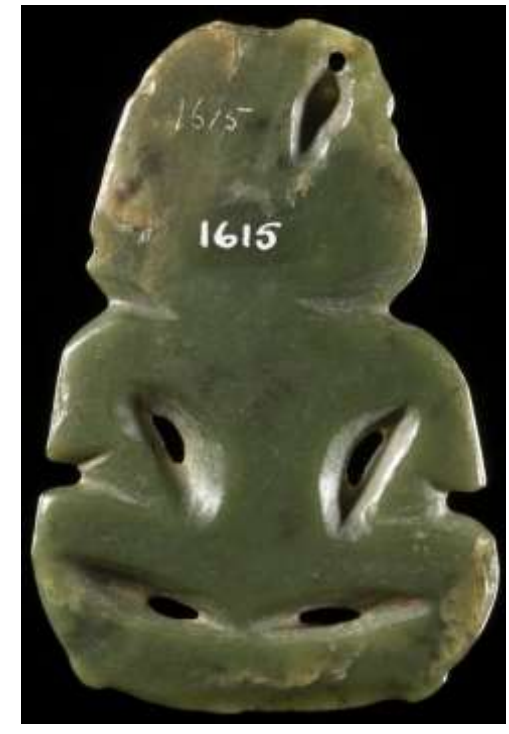

Back

\section{$2.19 \quad$ OL000099 $\quad[A B]$}

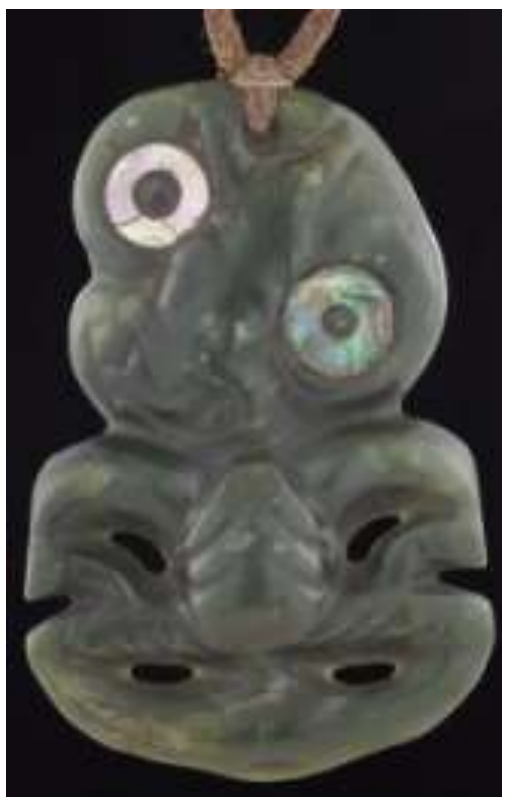

Front

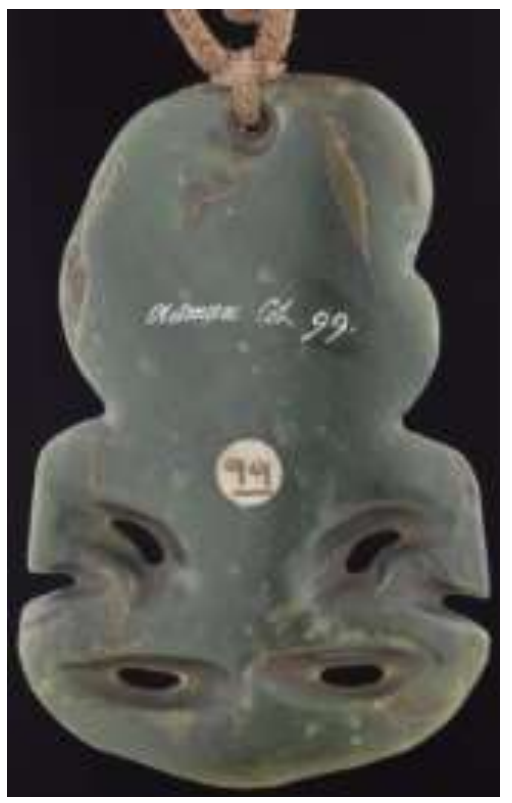

Back

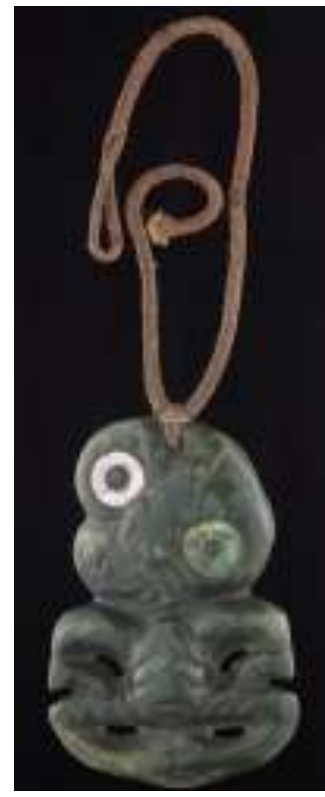

Overall 


\section{$2.20 \quad$ OL001044 [AB]}

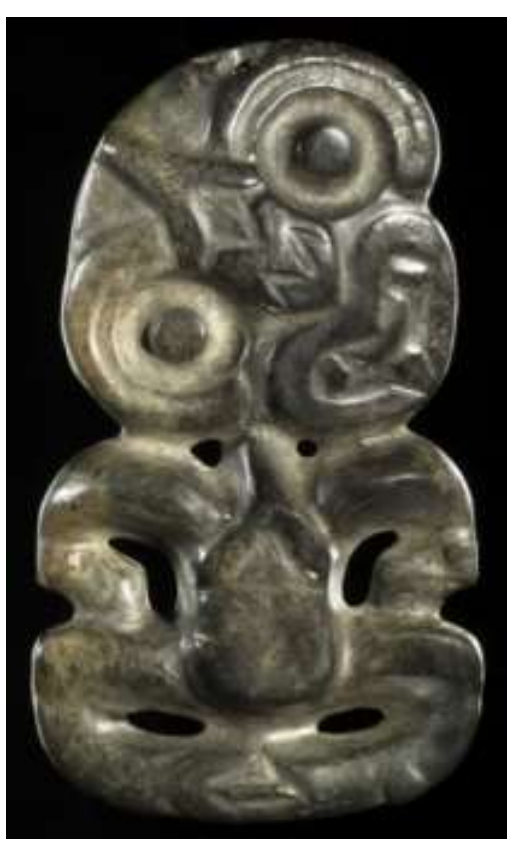

Front

\subsection{ME002101 [AC]}

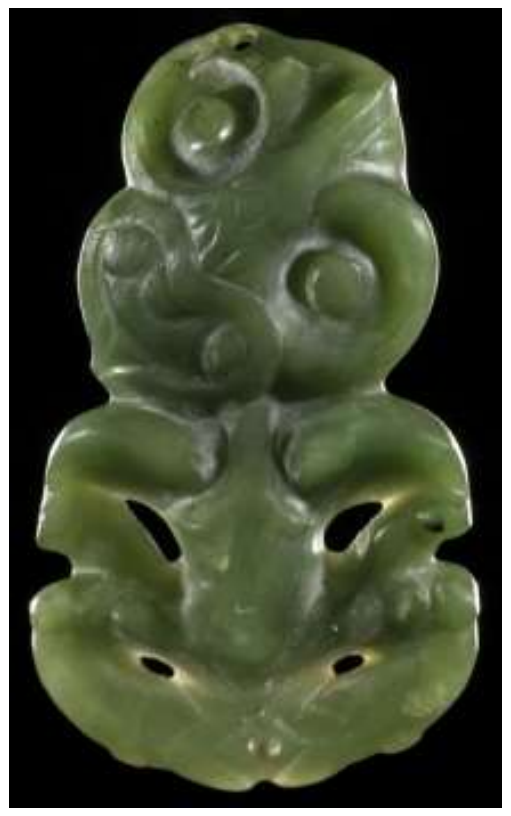

Front

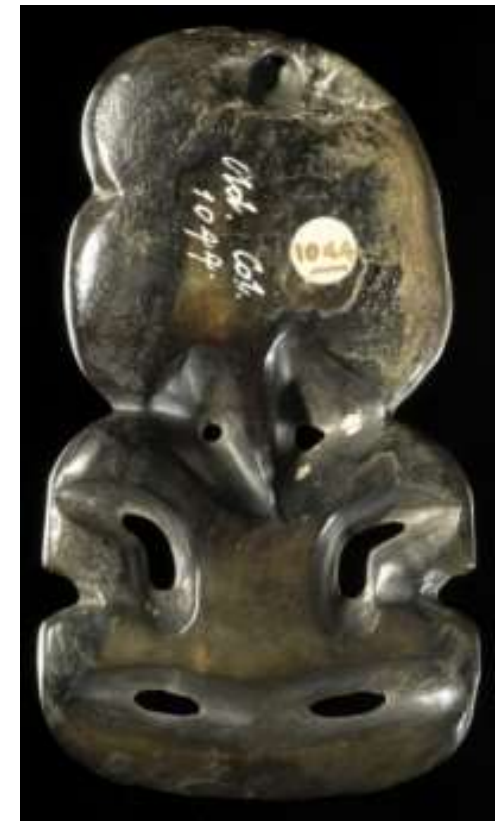

Back

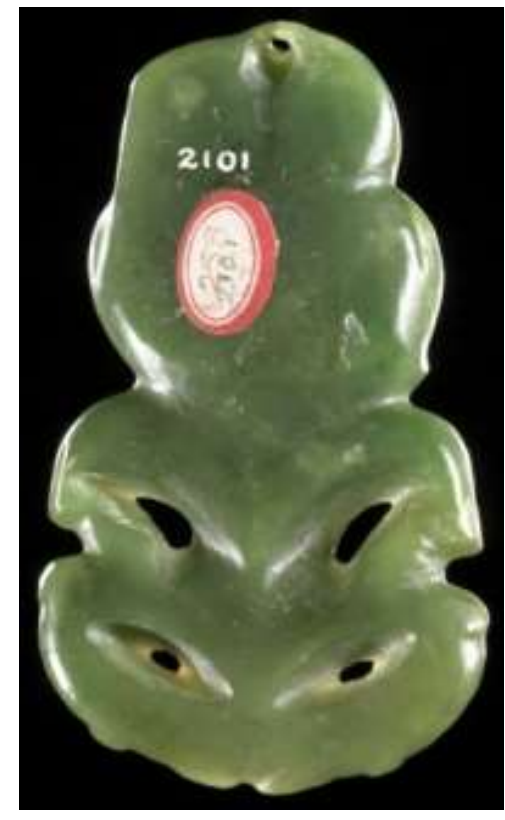

Back 


\section{$2.220 L 000110 / 3 \quad[A C]$}

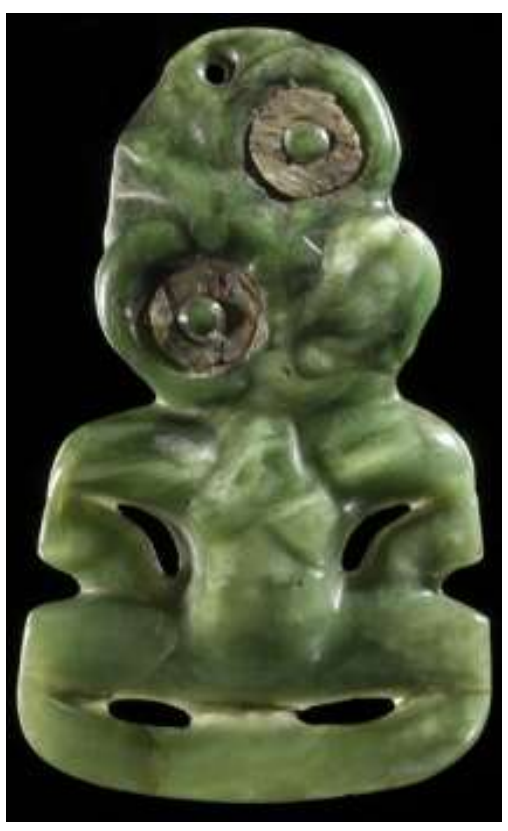

Front

\subsection{WE000394 [AC]}

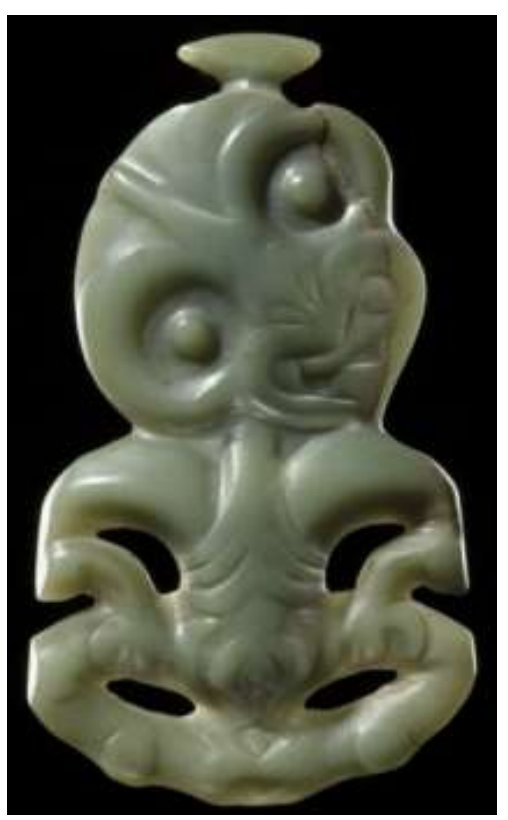

Front

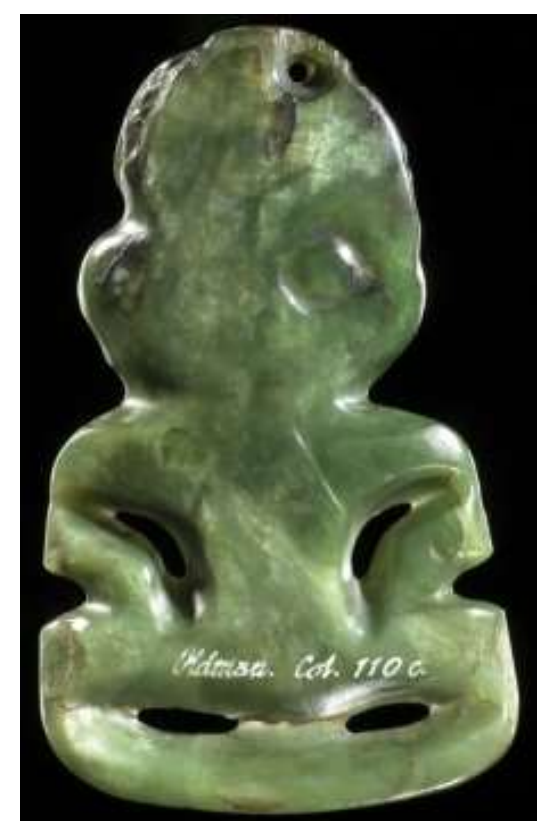

Back

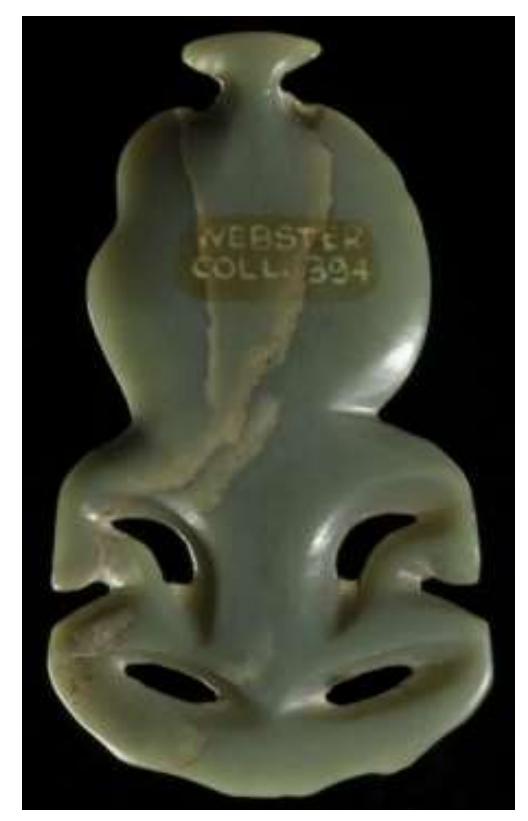

Back 


\subsubsection{Shape category B (Including secondary BC shape)}

Hei tiki with straight lines touching sides at three and two points

\subsection{4 \\ ME001617 \\ [B]}

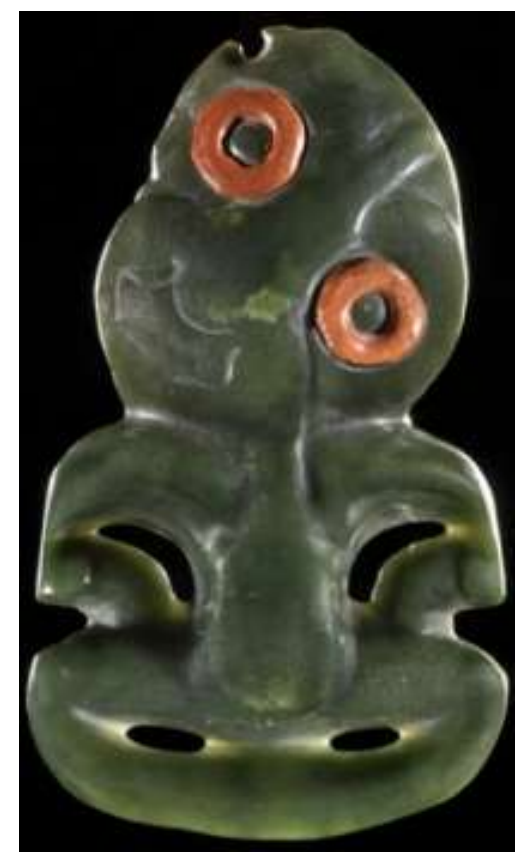

Front

\subsection{ME023772 [B]}

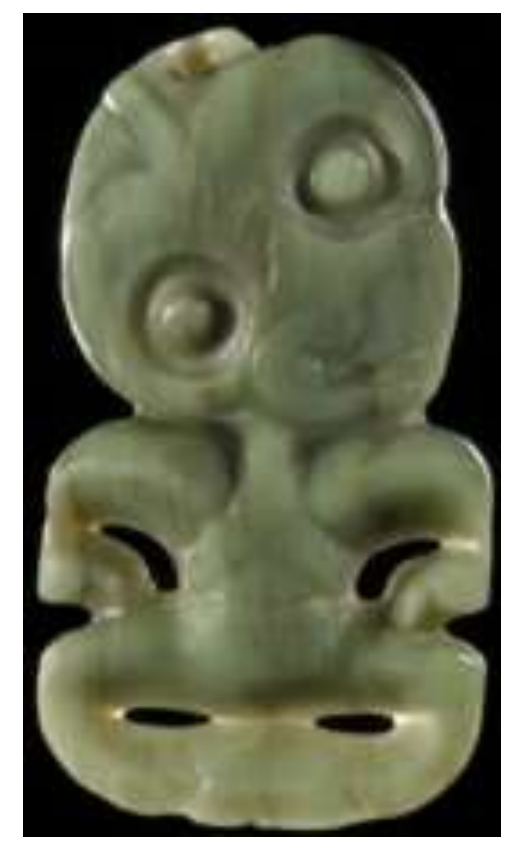

Front

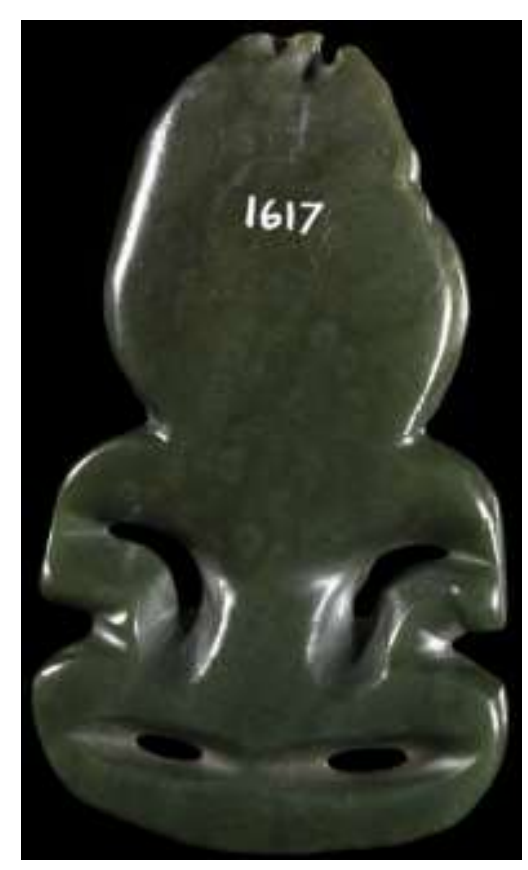

Back

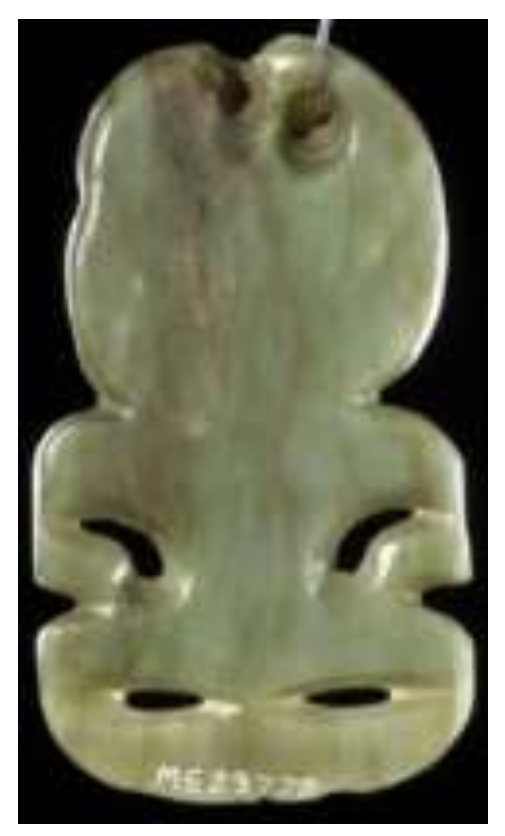

Back 
2.26 ME002505 [B]

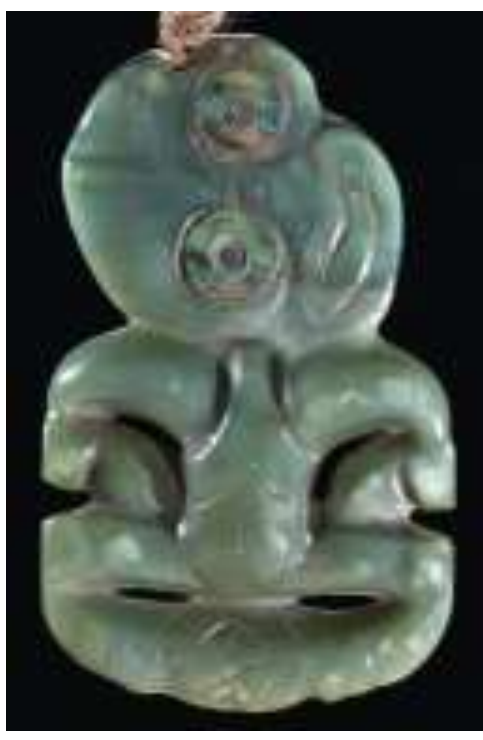

Front

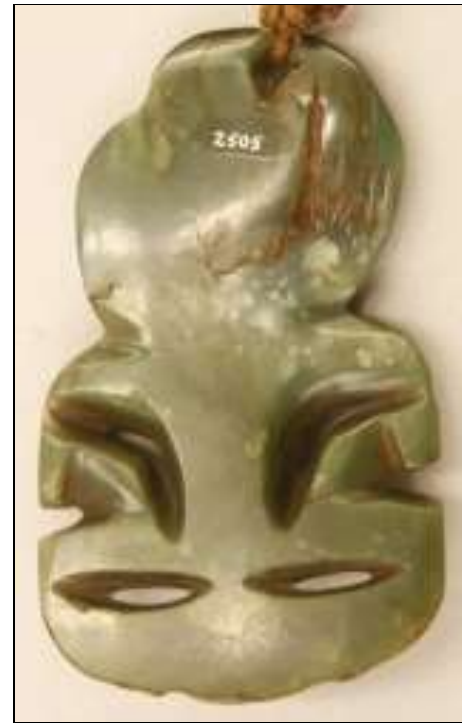

Back

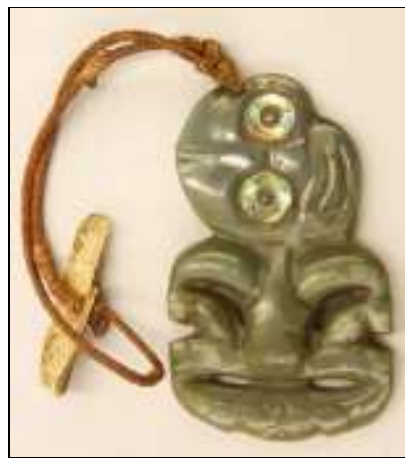

Overall

\subsection{ME005172/4 [B]}

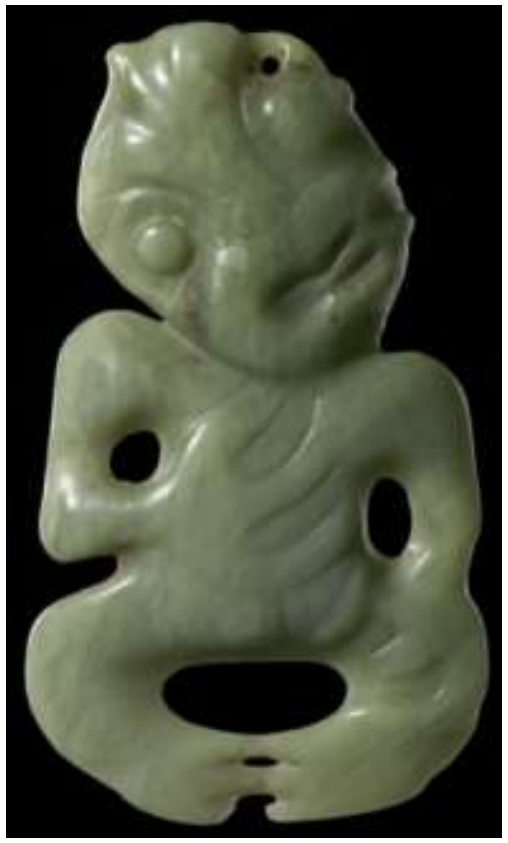

Front

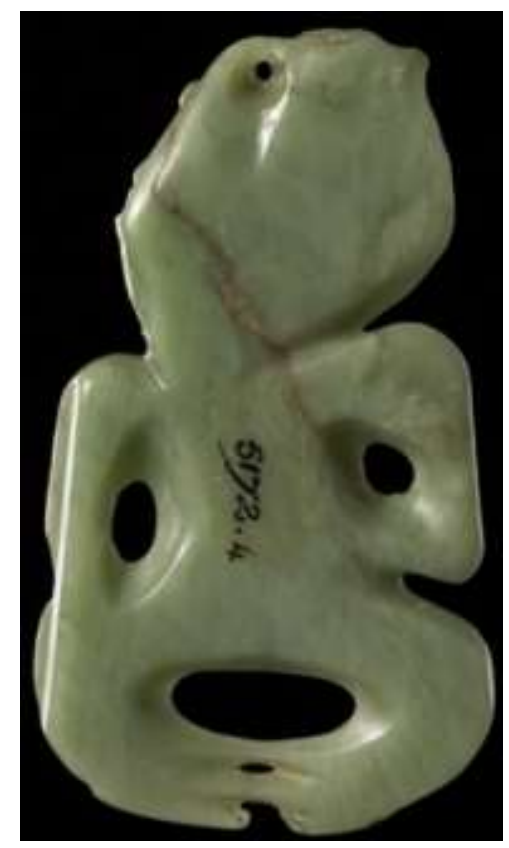

Back 


\subsection{ME023984 [B]}
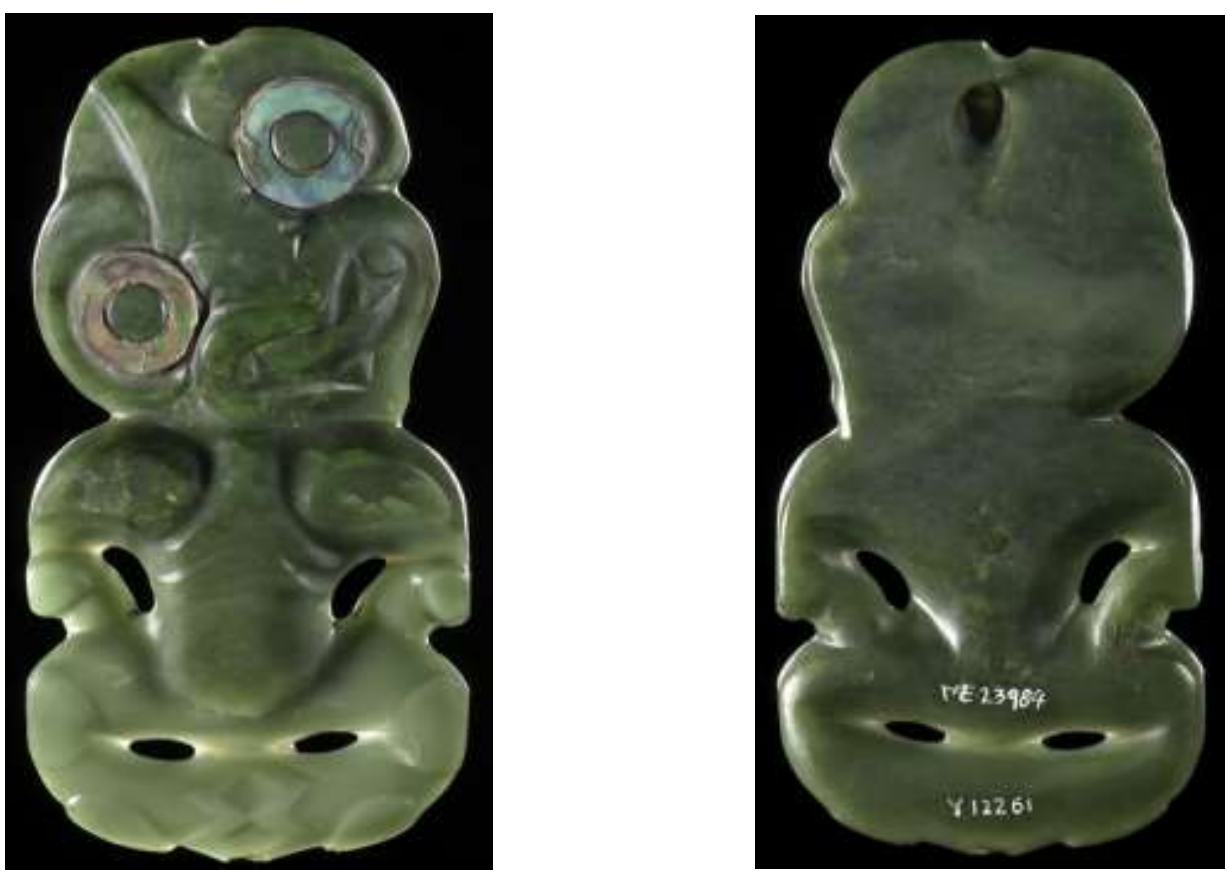

Front

Back

\subsection{ME012496 [B]}
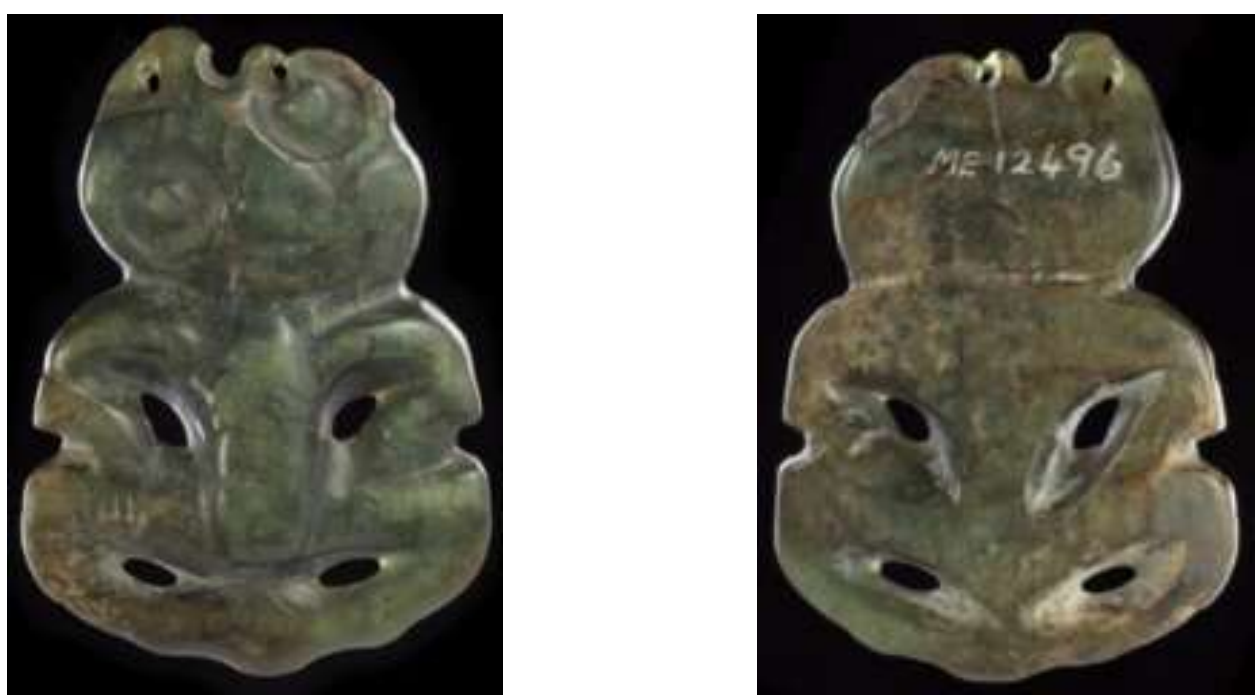

Front

Back 
$\begin{array}{lll}2.30 & \text { WE000378 [B] }\end{array}$

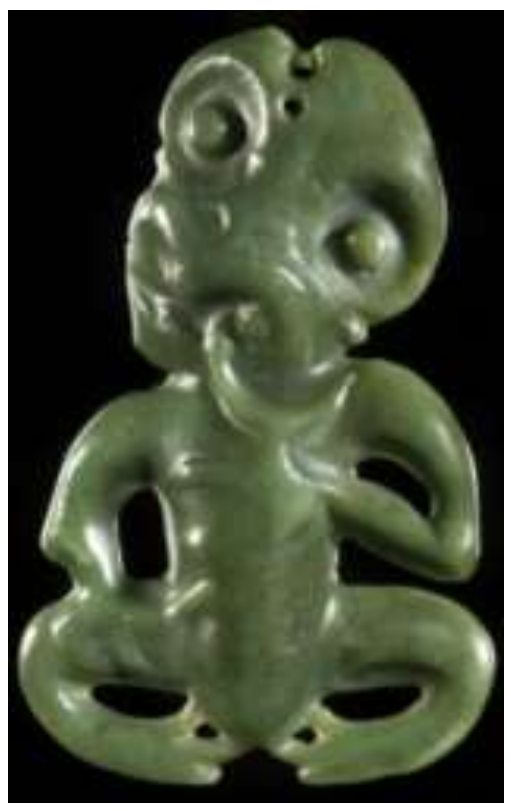

Front

2.31 ME016176 [BC]

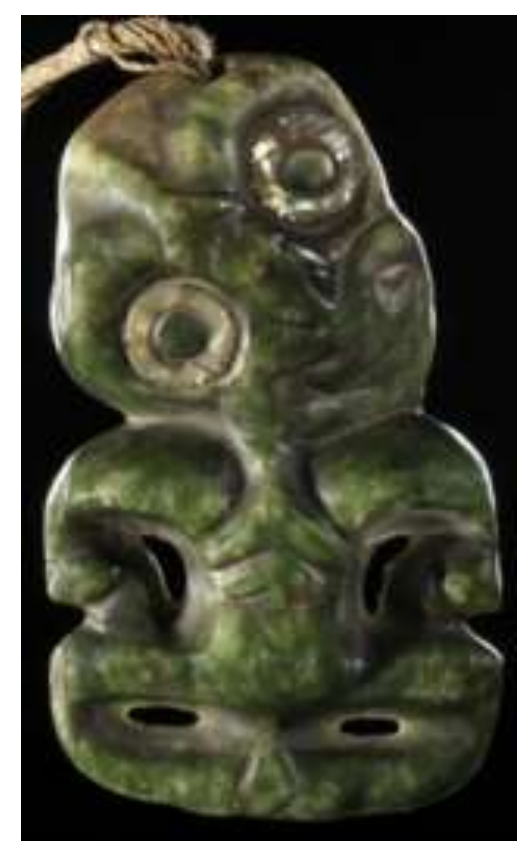

Front

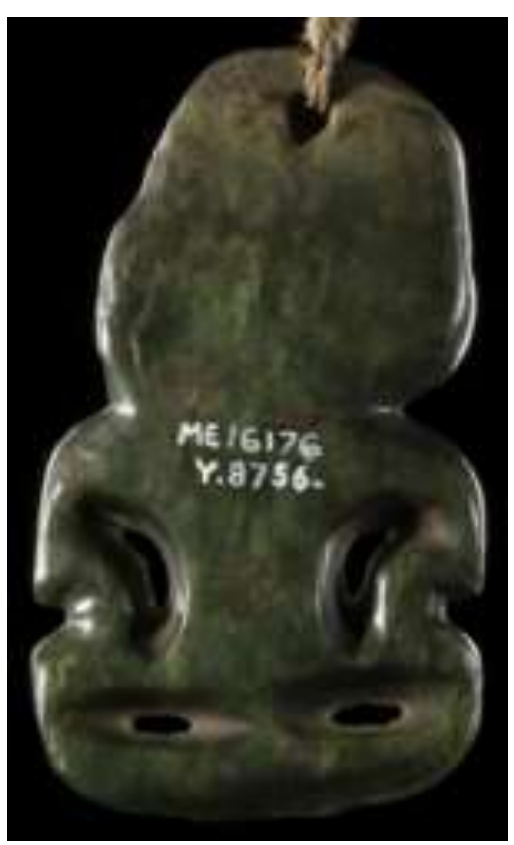

Back

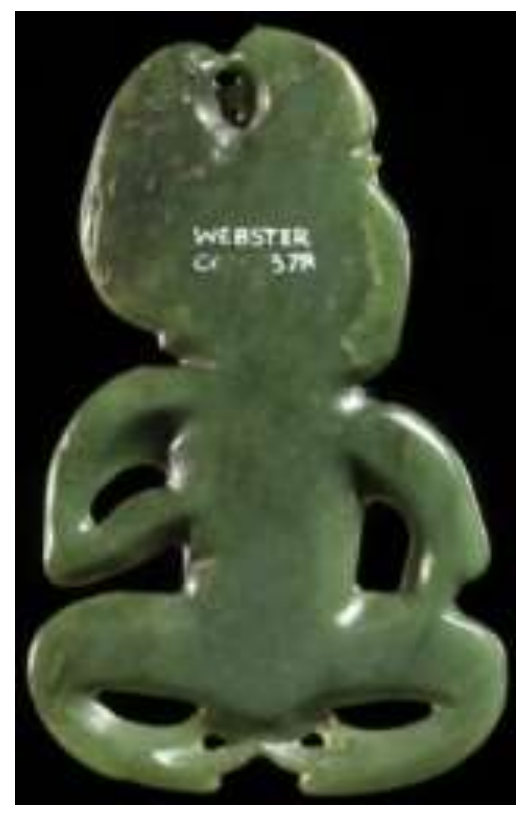

Back

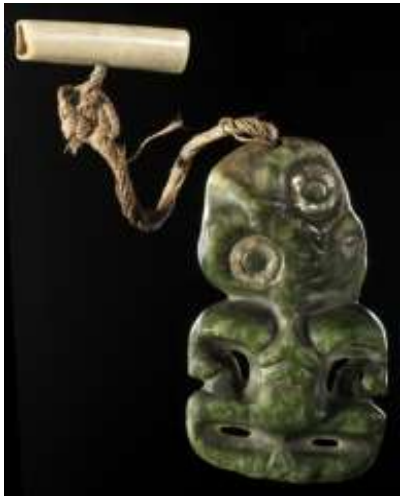

Overall 


\subsubsection{Shape category C (including secondary CD shape)}

Hei tiki with straight lines touching each side at two points

\section{$2.32 \quad 0 L 000685 \quad[C]$}

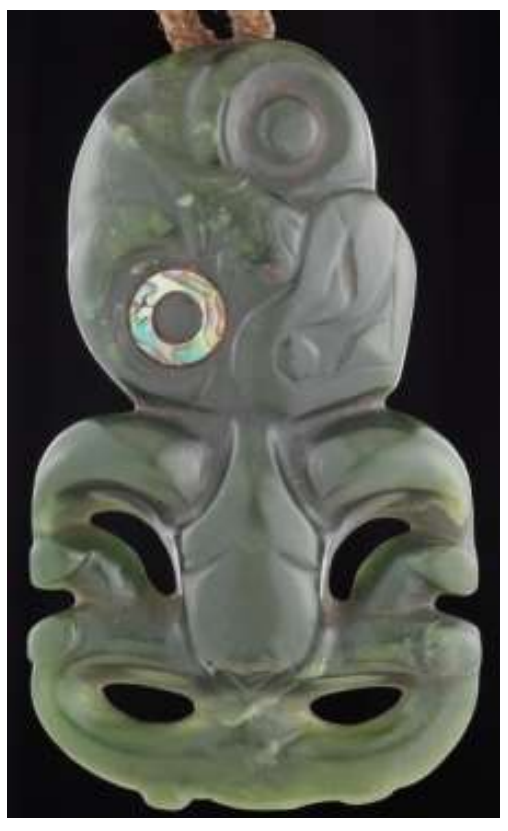

Front

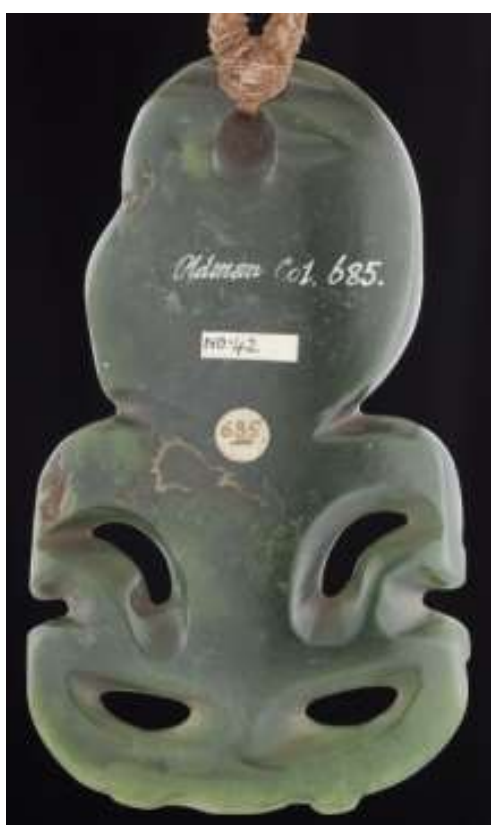

Back

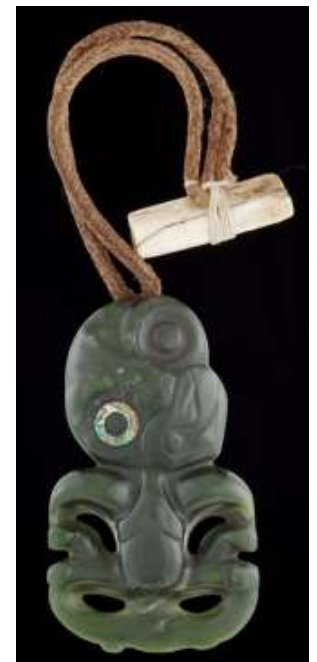

Overall

\section{$2.33 \quad$ OL001045 $\quad[C]$}

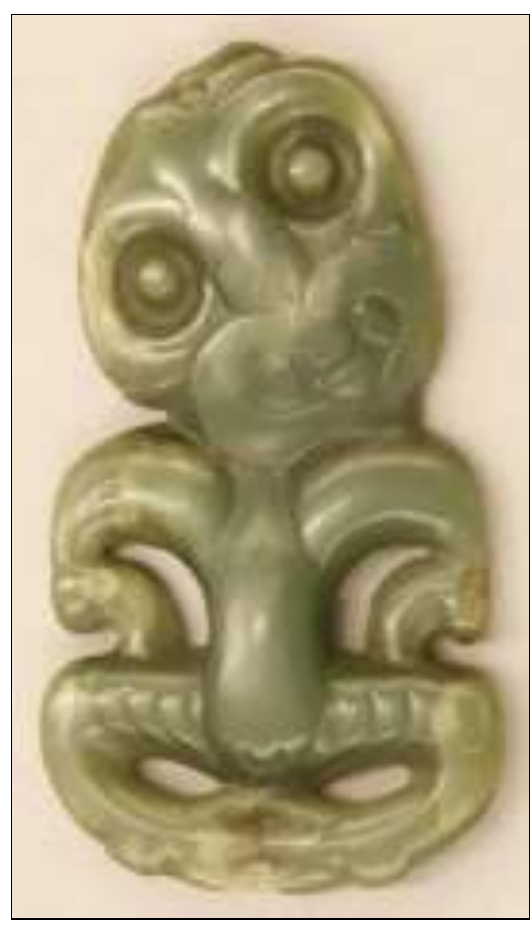

Front

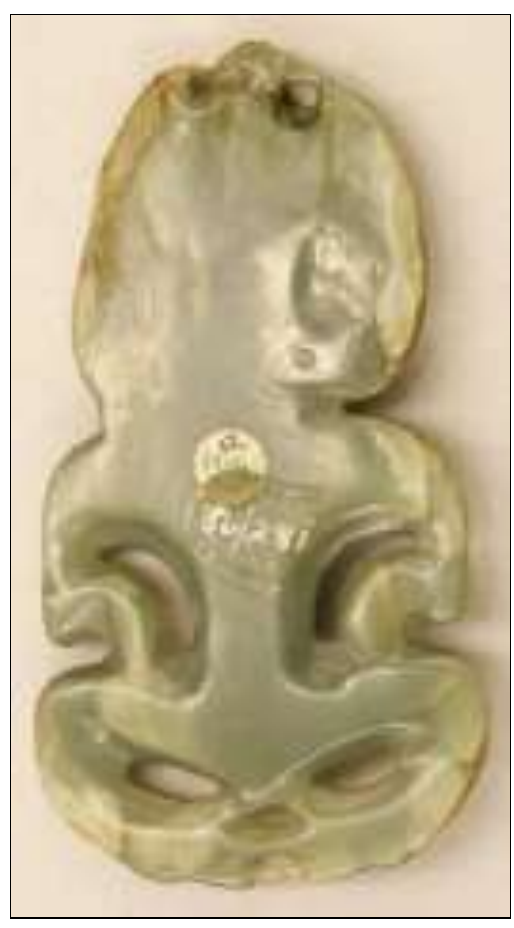

Back 
2.34 ME000312 [C]

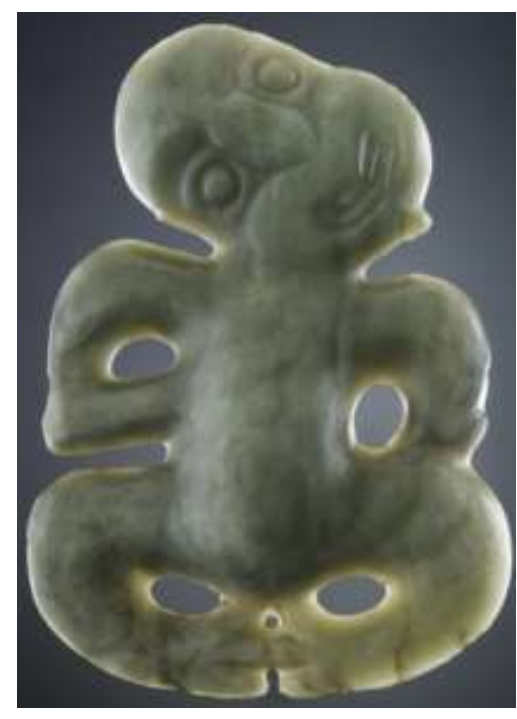

Front

\subsection{ME004969 [C]}

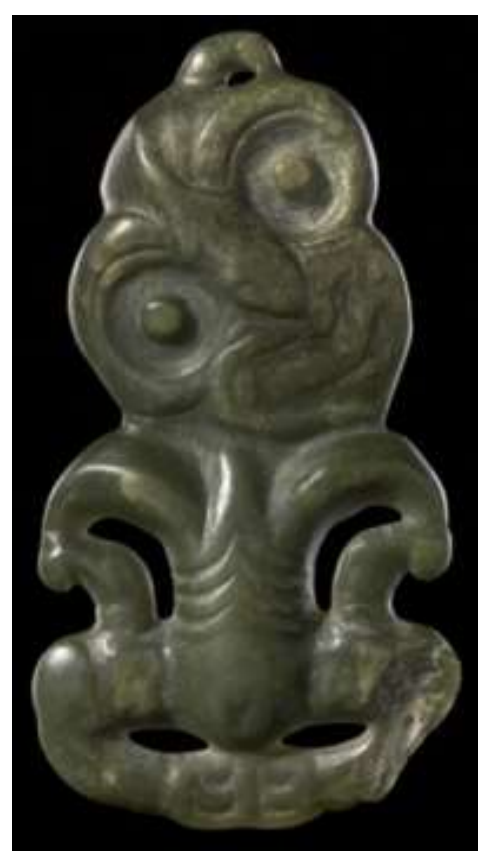

Front

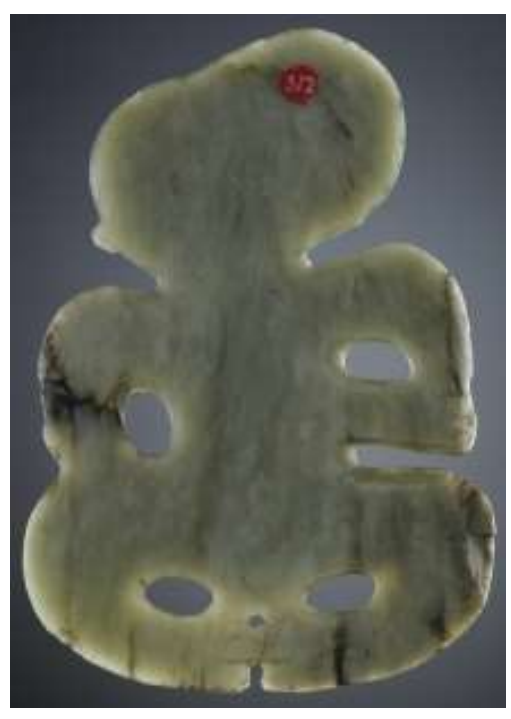

Back

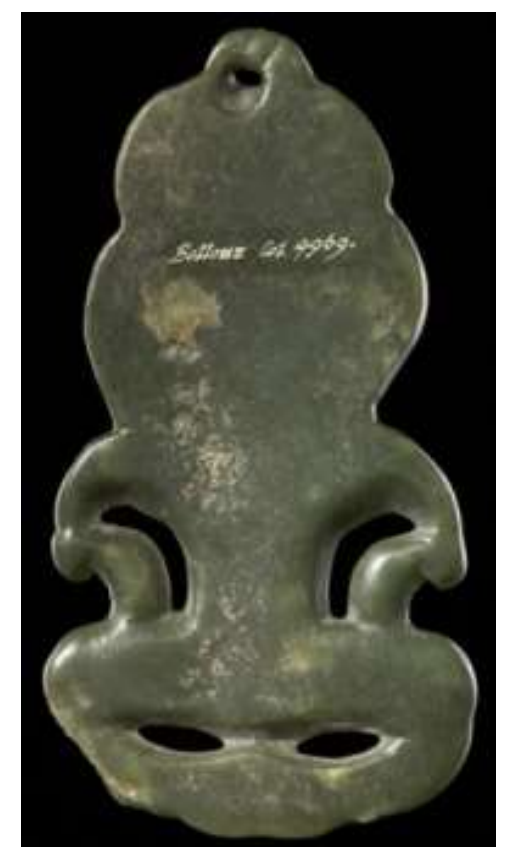

Back 
2.36 ME002973 [C]

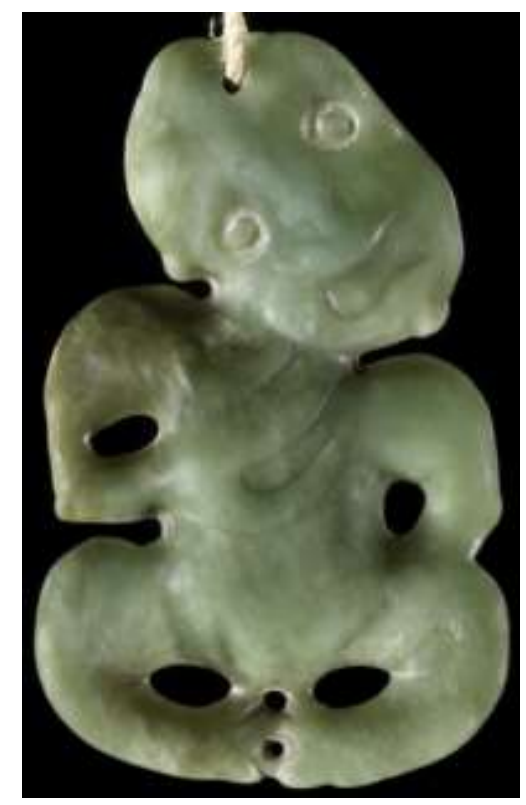

Front

$2.370 L 000130 / 2 \quad[C]$

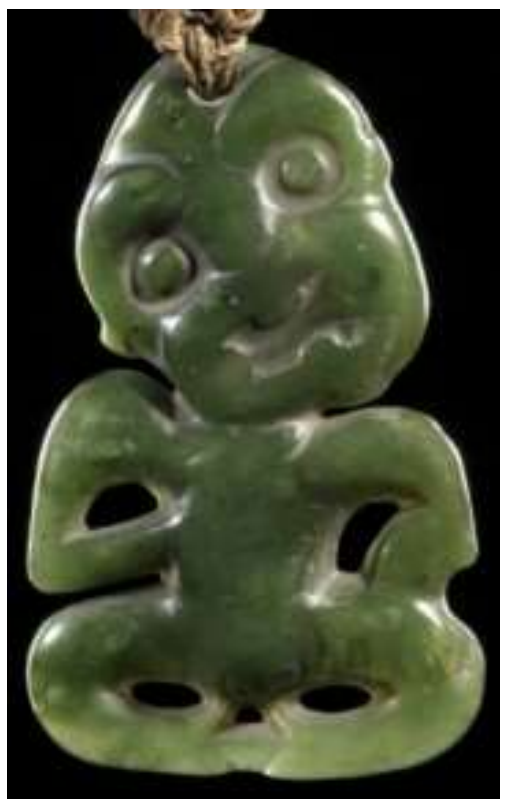

Front

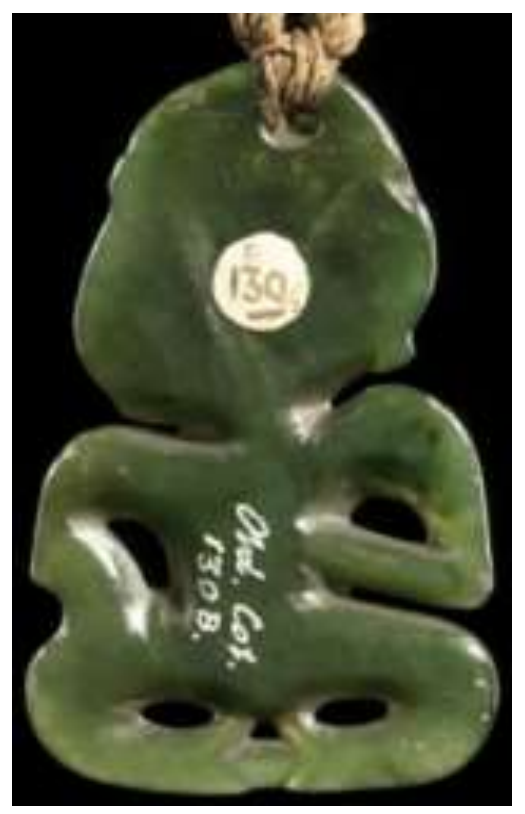

Back

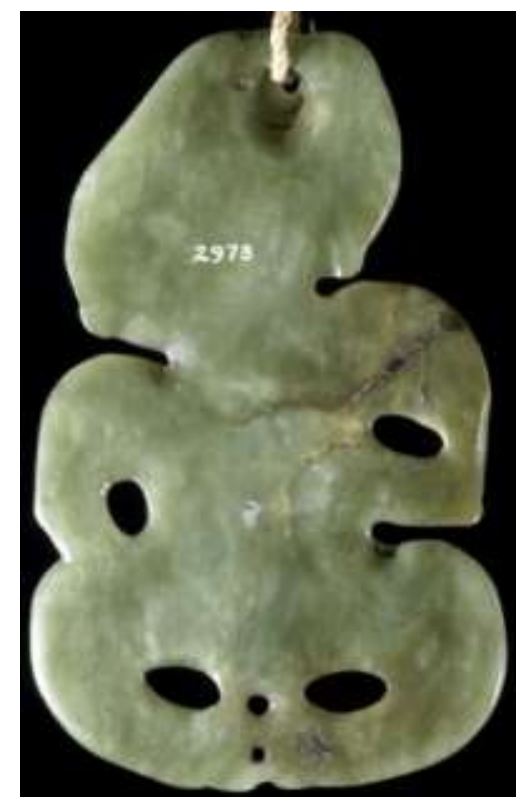

Back

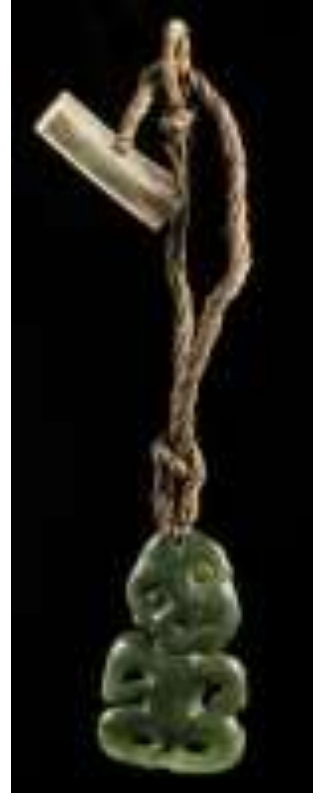

Overall 
$2.38 \quad$ OL001031 [C]

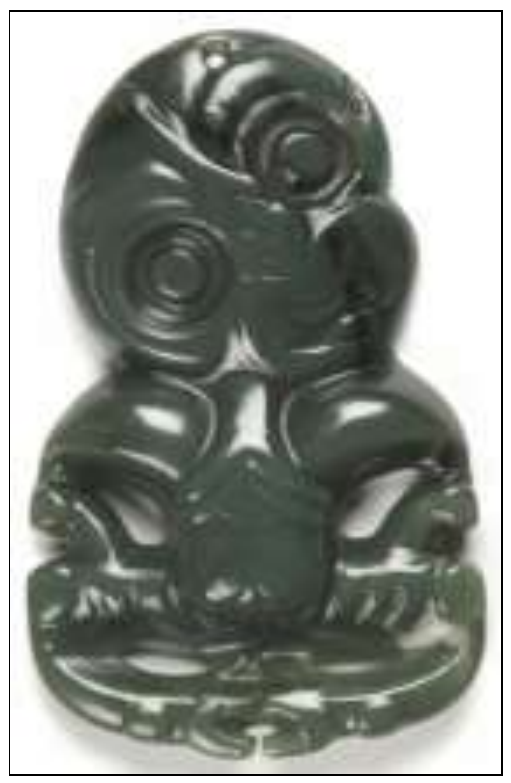

Front

$2.39 \quad 0 L 000084 \quad[C]$

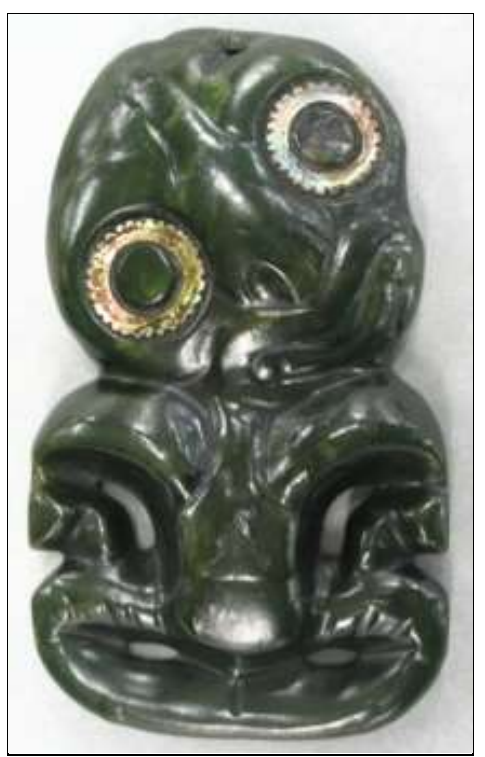

Front

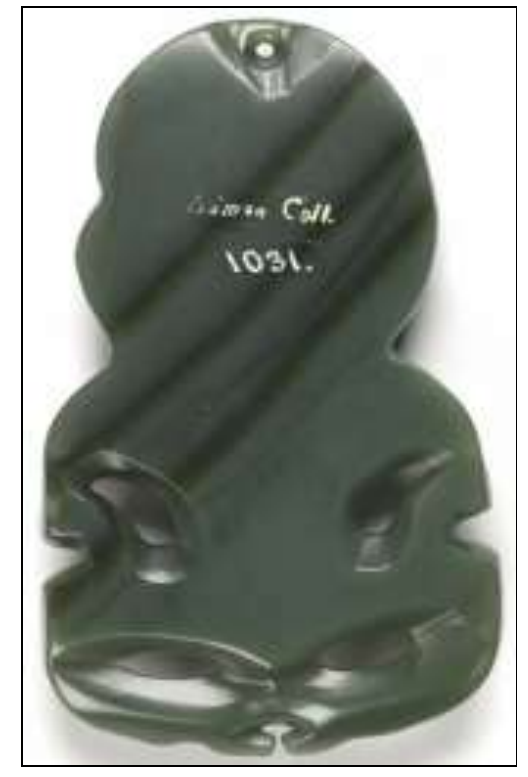

Back

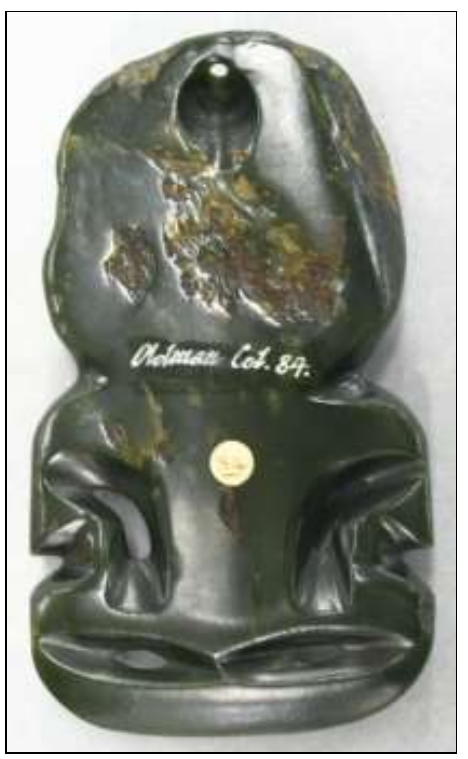

Back 
$2.40 \quad 0 L 000090 \quad[C]$

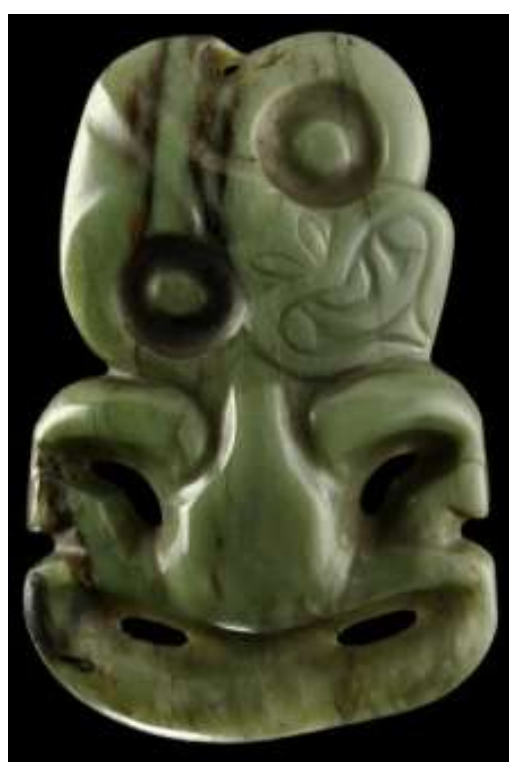

Front

\subsection{ME012842 [C]}

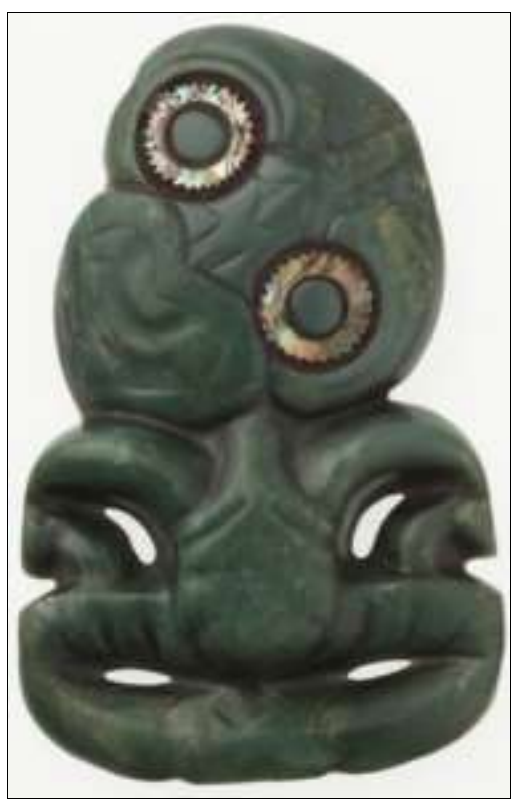

Front

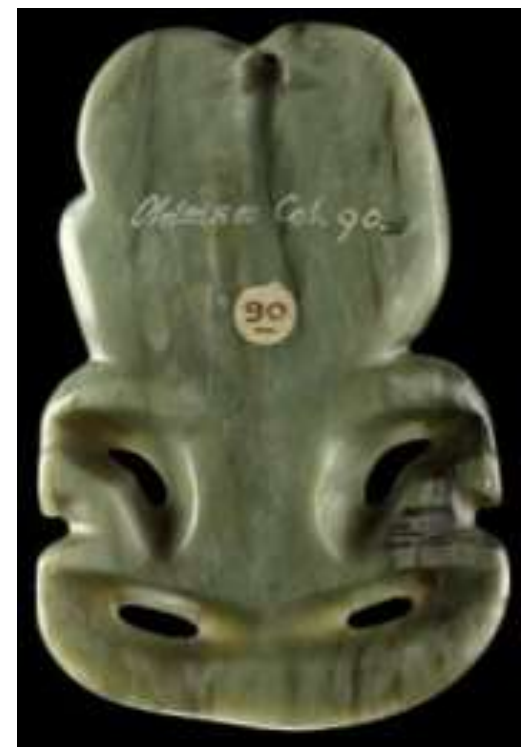

Back

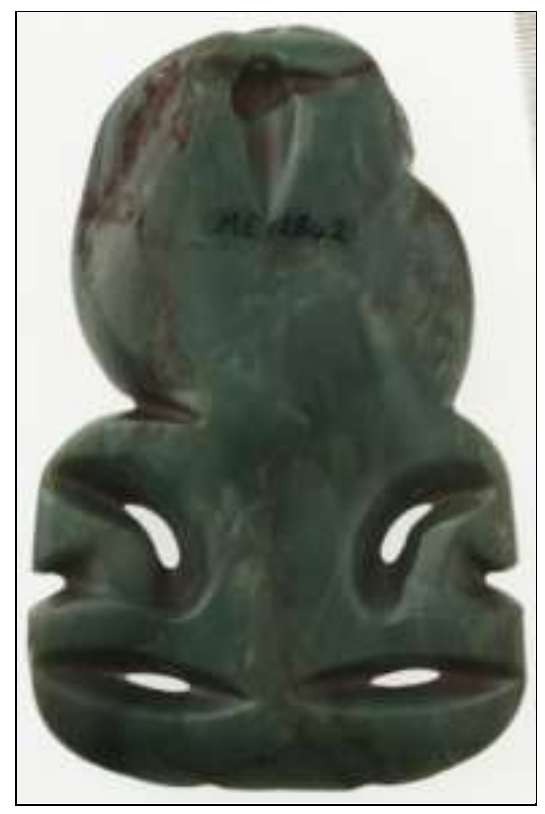

Back 
2.42 ME016813 [C]

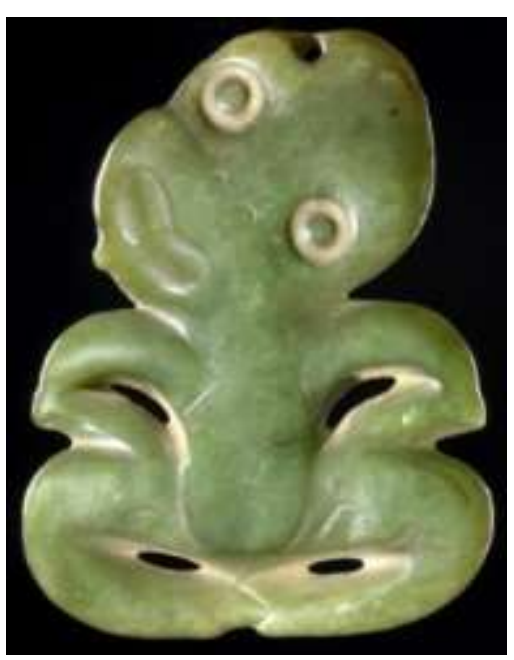

Front

\subsection{ME015639 [C]}

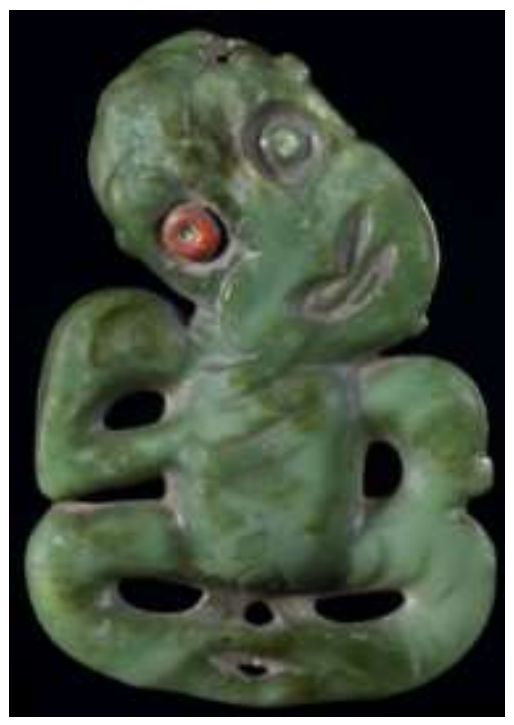

Front

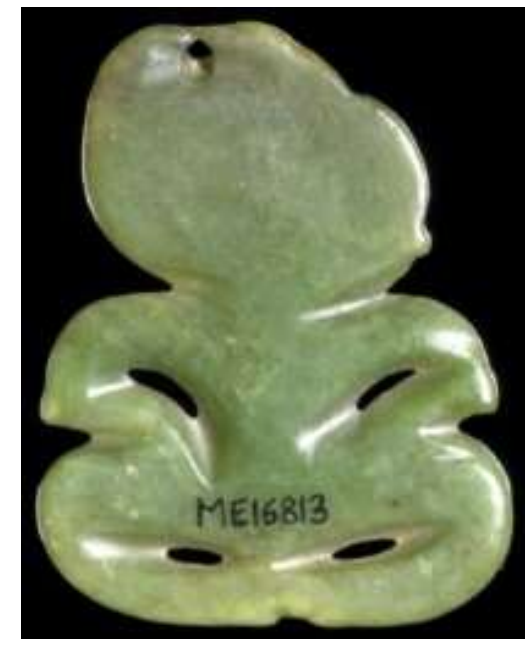

Back

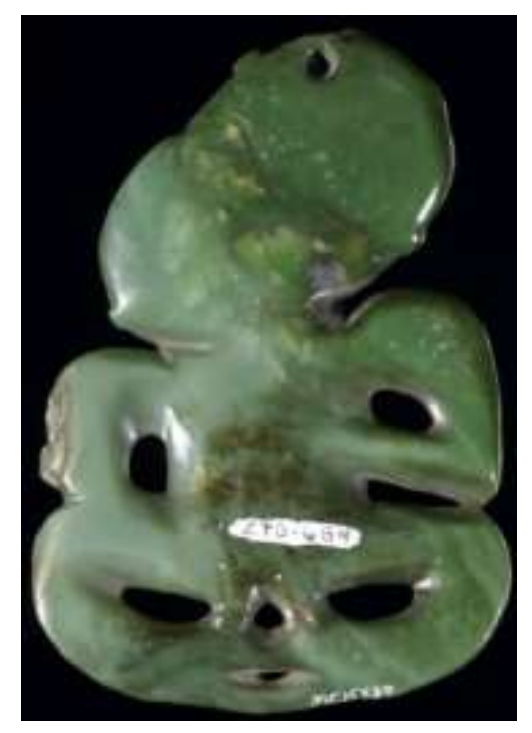

Back 
2.44 ME002971 [C]

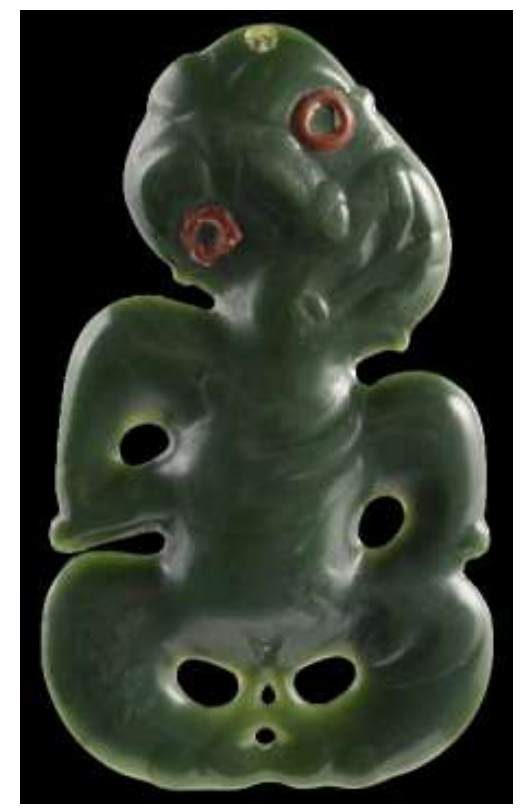

Front

\section{$\begin{array}{lll}2.45 & 0 L 000108 & {[C D}\end{array}$}

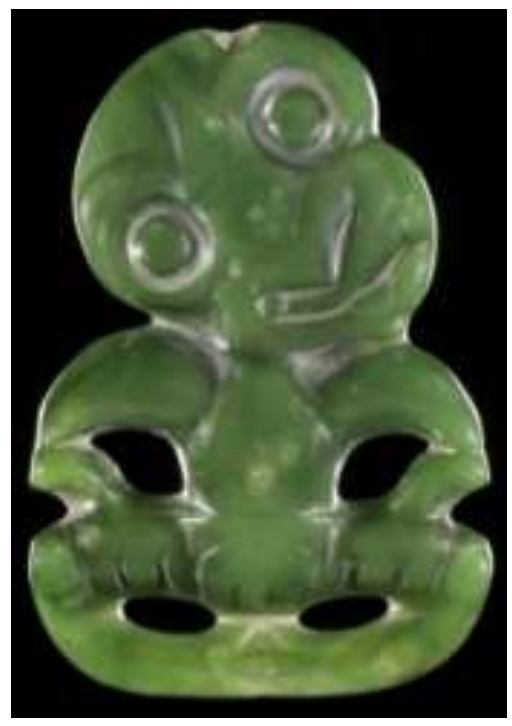

Front

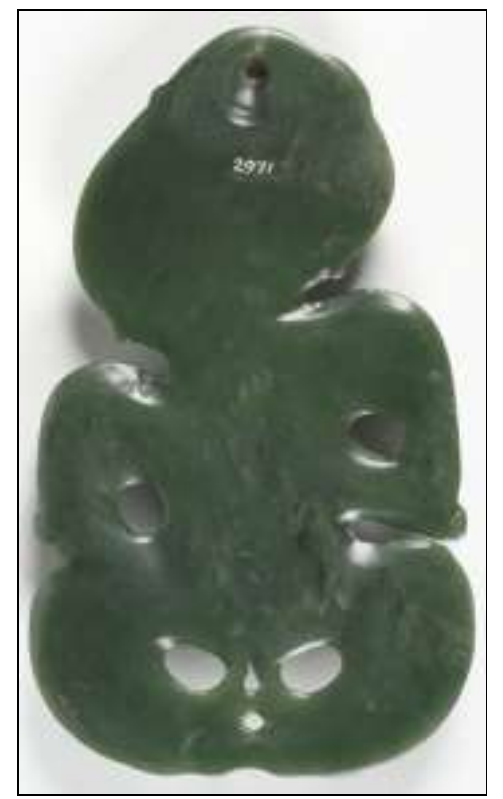

Back

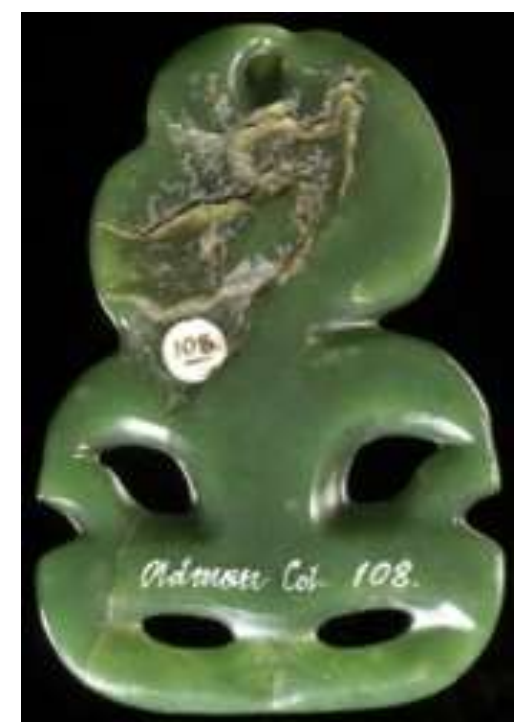

Back 
2.46 ME013442 [CD]

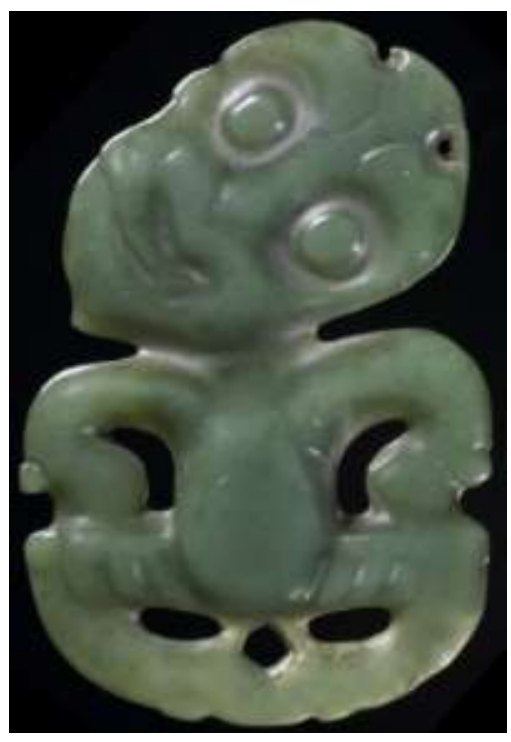

Front

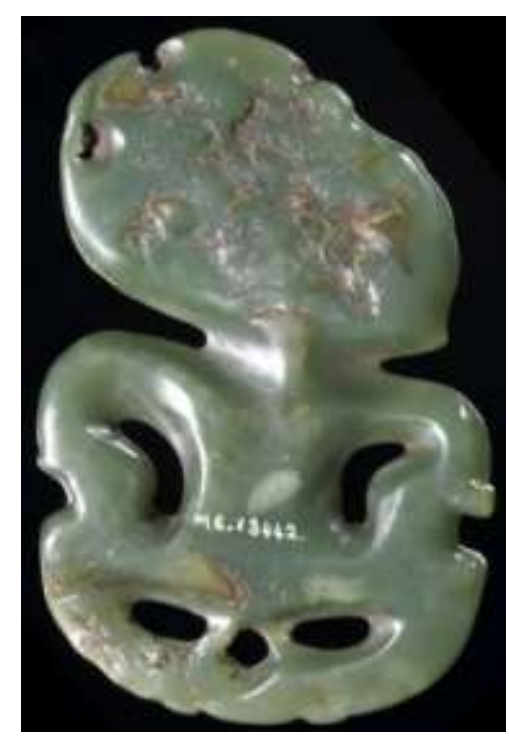

Back

\subsubsection{Shape category D}

Hei tiki of more oval outline shape

\subsection{ME014130 [D]}

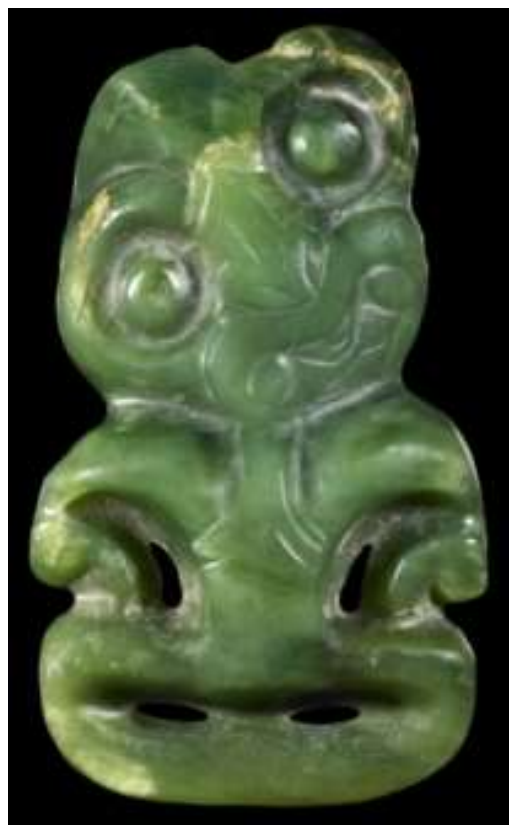

Front

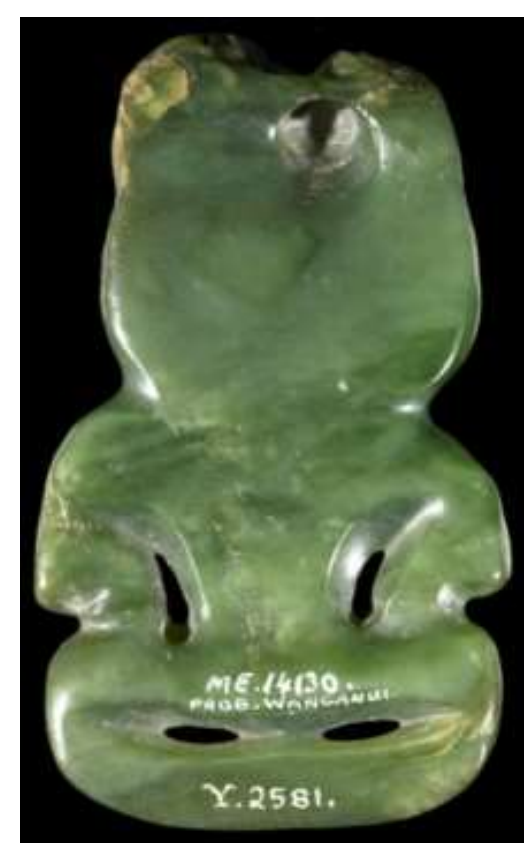

Back 
$\begin{array}{lll}2.48 & \text { OL000087 } & \text { [D] }\end{array}$

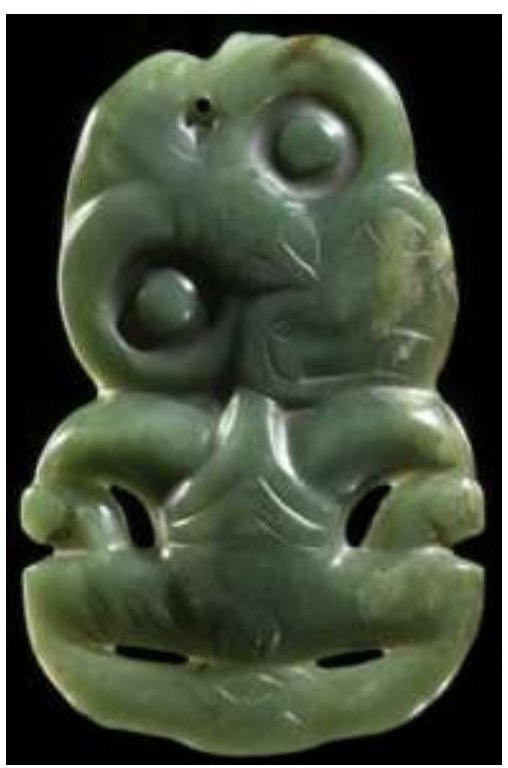

Front

\section{$\begin{array}{lll}2.49 & \text { OL000089 } & \text { [D] }\end{array}$}

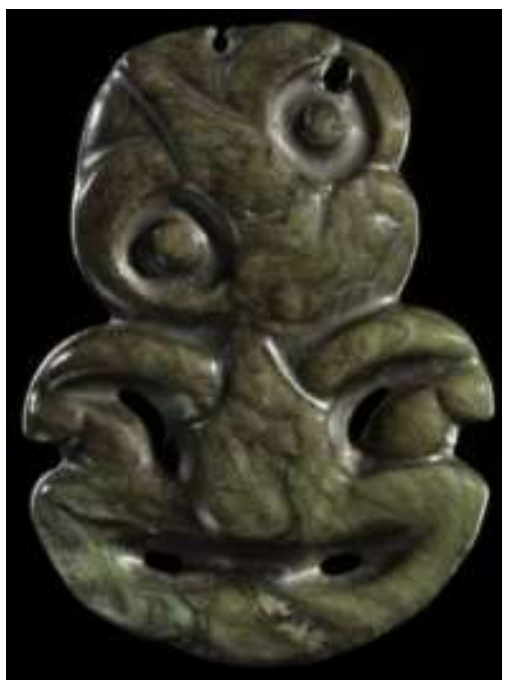

Front

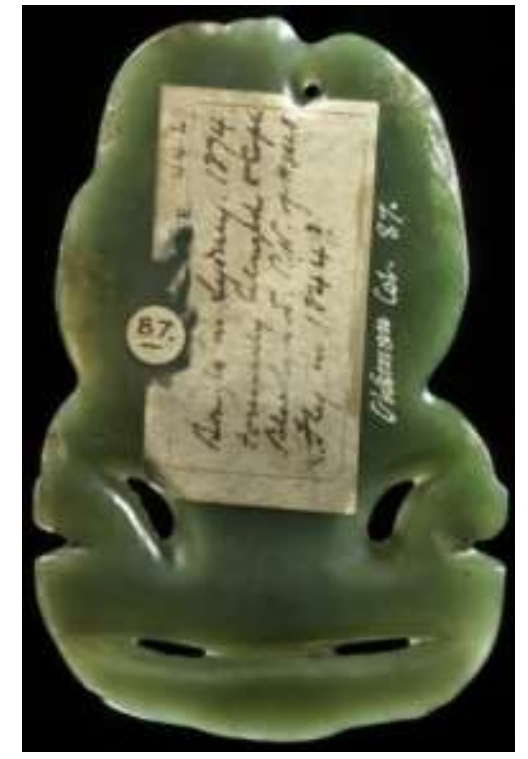

Back

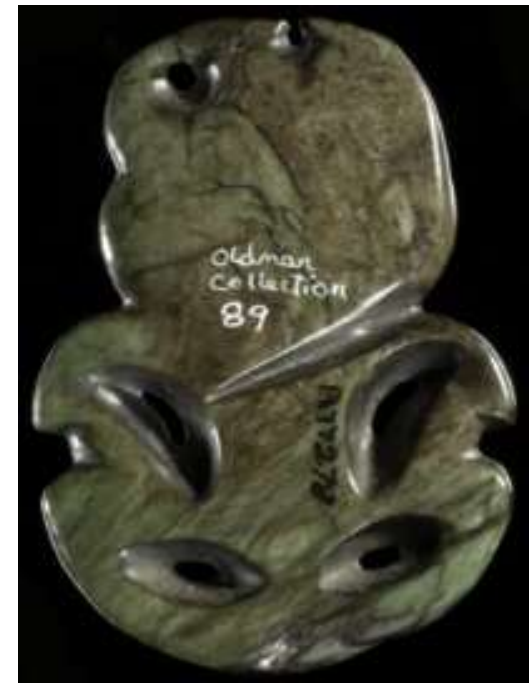

Back 
2.50 ME002978 [D]
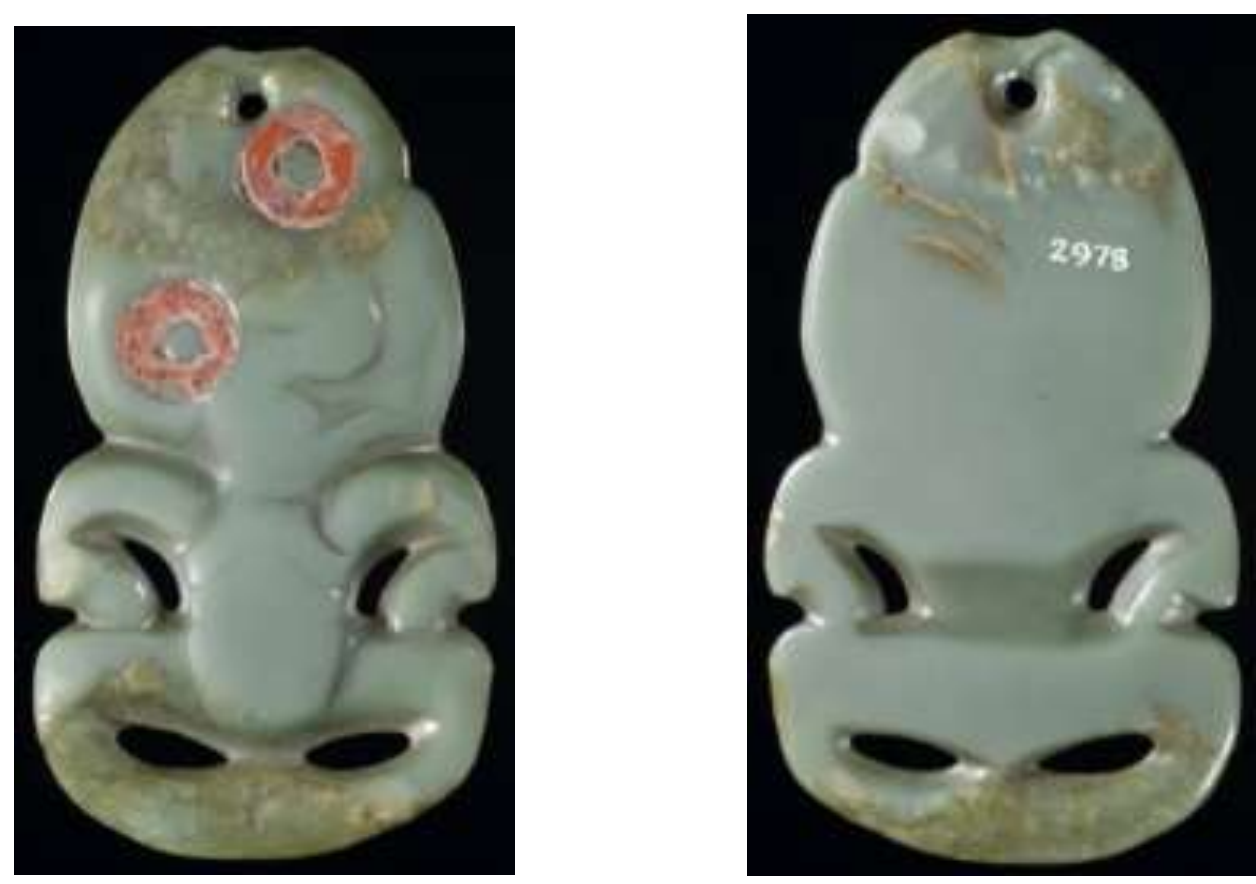

Front

Back 
Recorded features of the Group Two hei tiki

$\underline{\text { Table } 3 \text { - Recorded features of hei tiki } 2.1-2.10}$

(Group Two, 1 of 5)

\begin{tabular}{|c|c|c|c|c|c|c|c|c|c|c|}
\hline Study no. & 2.1 & 2.2 & 2.3 & 2.4 & 2.5 & 2.6 & 2.7 & 2.8 & 2.9 & 2.10 \\
\hline $\begin{array}{l}\text { Collection } \\
\text { number }\end{array}$ & $\begin{array}{l}\text { 동 } \\
\text { ờ } \\
\text { o }\end{array}$ & 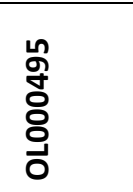 & 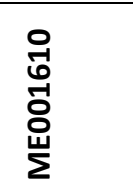 & $\begin{array}{l}0 \\
\infty \\
\delta \\
\delta \\
0\end{array}$ & 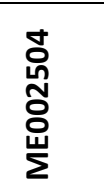 & 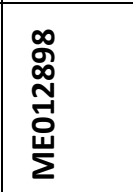 & 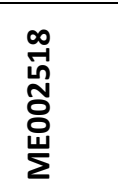 & 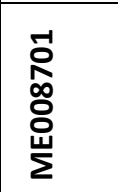 & 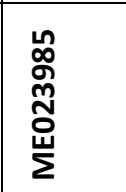 & 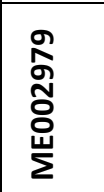 \\
\hline $\begin{array}{l}\text { Outline } \\
\text { shape }\end{array}$ & A & A & A & A & A & A & A & A & A & A \\
\hline $\begin{array}{l}\text { Type } \\
\text { (Webster) }\end{array}$ & 1 & 1 & 1 & 1 & 1 & 11 & II & 1 & 1 & 1 \\
\hline Length $\mathrm{mm}$ & 93 & 101 & 117 & 76 & 105 & 106 & 105 & 108 & 123 & 104 \\
\hline Width $\mathrm{mm}$ & 43 & 46 & 62 & 35 & 50 & 57 & 61 & 51 & 66 & 54 \\
\hline Depth $\mathrm{mm}$ & 12 & 14 & 16 & 10 & 10 & 10 & 10 & 15 & 11 & 8 \\
\hline $\begin{array}{l}\text { Width \% of } \\
\text { length }\end{array}$ & 46 & 46 & 52 & 46 & 47 & 52 & 58 & 46 & 53 & 51 \\
\hline $\begin{array}{l}\text { Head \% of } \\
\text { Length }\end{array}$ & 48 & 52 & 53 & 46 & 45 & 44 & 44 & 47 & 49 & 48 \\
\hline $\begin{array}{l}\text { Body \% of } \\
\text { length }\end{array}$ & 26 & 24 & 26 & 27 & 29 & 26 & 26 & 23 & 22 & 24 \\
\hline $\begin{array}{l}\text { Legs } \% \text { of } \\
\text { length }\end{array}$ & 26 & 24 & 21 & 27 & 26 & 30 & 30 & 30 & 29 & 28 \\
\hline $\begin{array}{l}\text { Head tilt: } \\
\text { Left or Right? }\end{array}$ & $R$ & $\mathrm{R}$ & $R$ & $R$ & $\mathrm{R}$ & L & $\mathrm{L}$ & $R$ & $\mathrm{R}$ & $R$ \\
\hline $\begin{array}{l}\text { Degree of } \\
\text { head tilt }\end{array}$ & 65 & 45 & 60 & 50 & 45 & 50 & 40 & 40 & 45 & 45 \\
\hline $\begin{array}{l}\text { Extent head } \\
\text { pointed at } \\
\text { top: } 0-10\end{array}$ & 2.0 & 1.0 & 1.0 & 2.0 & 9.5 & 3.0 & 6.5 & 6.0 & 9.0 & 9.0 \\
\hline $\begin{array}{l}\text { Eyes large, } \\
\text { medium or } \\
\text { small? }\end{array}$ & $\mathrm{L}$ & $\mathrm{L}$ & $\mathrm{L}$ & $\mathrm{L}$ & $\mathrm{L}$ & $\mathrm{s}$ & $\mathrm{S}$ & L & L & L \\
\hline $\begin{array}{l}\text { Inlay? } \\
\text { (pāua, } \\
\text { sealing } \\
\text { wax) }\end{array}$ & 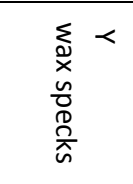 & $z$ & $z$ & 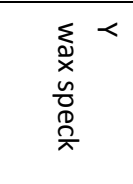 & 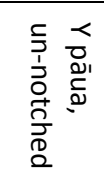 & 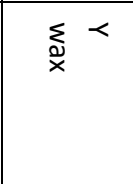 & $z$ & $\underset{\dot{X} \boldsymbol{x}}{\sum}<$ & $\underset{\dot{x}}{\sum_{x}}<$ & $z$ \\
\hline $\begin{array}{l}\text { Secondary } \\
\text { eye rims? }\end{array}$ & $\mathrm{N}$ & $Y$ & $\mathrm{Y}$ & $N$ & $\mathrm{~N}$ & $\mathrm{~N}$ & $Y(1)$ & $N$ & $\mathrm{~N}$ & $\mathrm{~N}$ \\
\hline Brows? & $Y(1)$ & $\mathrm{Y}$ & $Y$ & $Y$ & $Y$ & $\mathrm{Y}$ & $\begin{array}{l}\text { Y not } \\
\text { distinct }\end{array}$ & $Y$ worn & $\mathrm{Y}$ & $\mathrm{Y}$ \\
\hline $\begin{array}{l}\text { Forehead } \\
\text { ridge? }\end{array}$ & $\begin{array}{l}\text { Y not } \\
\text { distinct }\end{array}$ & $Y$ & $Y$ & $Y$ & $Y$ & $Y$ & $Y$ & $\begin{array}{l}\mathrm{Y} \\
\text { worn }\end{array}$ & $\mathrm{Y}$ & $\mathrm{Y}$ \\
\hline
\end{tabular}




\begin{tabular}{|c|c|c|c|c|c|c|c|c|c|c|}
\hline $\begin{array}{l}\text { Forking at } \\
\text { nose } \\
\text { bridge? }\end{array}$ & $\mathrm{N}$ & $\begin{array}{l}Y \\
\text { worn }\end{array}$ & $\mathrm{Y}$ & $Y$ & $\mathrm{Y}$ & $\begin{array}{l}? \\
\text { worn }\end{array}$ & $\mathrm{Y}$ & $\begin{array}{l}? \\
\text { worn }\end{array}$ & $Y$ & $Y$ \\
\hline Nostrils? & $\begin{array}{l}\mathrm{Y} \\
\text { arched }\end{array}$ & $\begin{array}{l}Y \\
\text { worn }\end{array}$ & $\begin{array}{l}Y \\
\text { arched }\end{array}$ & $\begin{array}{l}Y \\
\text { arched }\end{array}$ & $\begin{array}{l}Y \\
\text { partial }\end{array}$ & $\begin{array}{l}\mathrm{Y} \\
\text { arched }\end{array}$ & $\begin{array}{l}? \\
\text { worn }\end{array}$ & $\begin{array}{l}? \\
\text { worn }\end{array}$ & $\begin{array}{l}Y \\
\text { type? }\end{array}$ & $\begin{array}{l}\mathrm{Y} \\
\text { type? }\end{array}$ \\
\hline $\begin{array}{l}\text { Ridge from } \\
\text { nostrils to } \\
\text { nose } \\
\text { bridge? }\end{array}$ & $\mathrm{N}$ & $\begin{array}{l}\mathrm{N} \\
\text { worn }\end{array}$ & $\mathrm{N}$ & $\mathrm{N}$ & $\mathrm{N}$ & $\begin{array}{l}\mathrm{N} \\
\text { worn }\end{array}$ & $\begin{array}{l}? \\
\text { worn }\end{array}$ & $\begin{array}{l}\mathrm{N} \\
\text { worn }\end{array}$ & $\mathrm{N}$ & $\begin{array}{l}? \\
\text { worn }\end{array}$ \\
\hline $\begin{array}{l}\text { Heart } \\
\text { shaped } \\
\text { mouth? }\end{array}$ & $Y$ & $\mathrm{Y}$ & $\mathrm{Y}$ & $Y$ & $\begin{array}{l}Y \\
\text { incom } \\
\text {-plete }\end{array}$ & $Y$ & $Y$ & $\mathrm{~N}$ & $\begin{array}{l}\text { Y un- } \\
\text { conven } \\
\text { tional }\end{array}$ & $Y$ \\
\hline $\begin{array}{l}\text { Mid upper } \\
\text { tooth? }\end{array}$ & $\mathrm{N}$ & $\mathrm{Y}$ & $\mathrm{Y}$ & $\mathrm{Y}$ & $\mathrm{N}$ & $\begin{array}{l}Y \\
\text { worn }\end{array}$ & $\mathrm{N}$ & $\begin{array}{l}? \\
\text { worn }\end{array}$ & $?$ & $\mathrm{~N}$ \\
\hline $\begin{array}{l}\text { Corner } \\
\text { teeth? }\end{array}$ & $Y$ & $Y$ & $\mathrm{Y}$ & $Y$ & $\mathrm{~N}$ & $\begin{array}{l}\text { ? } \\
\text { worn }\end{array}$ & $Y$ & $\begin{array}{l}\text { ? } \\
\text { worn }\end{array}$ & $Y$ & $\mathrm{~N}$ \\
\hline $\begin{array}{l}\text { Internal } \\
\text { tongue? }\end{array}$ & $\mathrm{N}$ & $Y$ & $\mathrm{~N}$ & $\mathrm{~N}$ & $\mathrm{~N}$ & $\begin{array}{l}? \\
\text { worn }\end{array}$ & $\mathrm{N}$ & $\begin{array}{l}? \\
\text { worn }\end{array}$ & $\begin{array}{l}\text { Y un- } \\
\text { conven } \\
\text { tional }\end{array}$ & $\mathrm{N}$ \\
\hline $\begin{array}{l}\text { Tongue } \\
\text { against } \mathrm{cnr} \\
\text { tooth? }\end{array}$ & $\mathrm{N}$ & $\mathrm{N}$ & $\mathrm{N}$ & $\mathrm{N}$ & $\mathrm{N}$ & $\begin{array}{l}? \\
\text { worn }\end{array}$ & $\mathrm{N}$ & $\begin{array}{l}? \\
\text { worn }\end{array}$ & $Y$ & $\mathrm{~N}$ \\
\hline $\begin{array}{l}\text { Extended } \\
\text { tongue? }\end{array}$ & $\mathrm{N}$ & $\mathrm{N}$ & $\mathrm{N}$ & $\mathrm{N}$ & $\mathrm{N}$ & $\begin{array}{l}? \\
\text { worn }\end{array}$ & $\mathrm{N}$ & $\begin{array}{l}? \\
\text { worn }\end{array}$ & $\mathrm{N}$ & $\mathrm{N}$ \\
\hline $\begin{array}{l}\text { Forked } \\
\text { tongue? }\end{array}$ & $\mathrm{N}$ & $\mathrm{N}$ & $\mathrm{N}$ & $\mathrm{N}$ & $\mathrm{N}$ & $\begin{array}{l}? \\
\text { worn }\end{array}$ & $\mathrm{N}$ & $\begin{array}{l}? \\
\text { worn } \\
\end{array}$ & ? & $\mathrm{N}$ \\
\hline $\begin{array}{l}\text { Head } \\
\text { projections? }\end{array}$ & $\mathrm{N}$ & $\mathrm{N}$ & $\mathrm{N}$ & $\mathrm{N}$ & $\mathrm{N}$ & $\begin{array}{l}Y \\
\text { ears, } \\
\text { chin }\end{array}$ & $\begin{array}{l}Y \\
\text { ears, } \\
\text { chin }\end{array}$ & $\mathrm{N}$ & $\mathrm{N}$ & $\mathrm{N}$ \\
\hline $\begin{array}{l}\text { Indicative } \\
\text { neck? }\end{array}$ & $Y$ & $Y$ & $\mathrm{Y}$ & $Y$ & $Y$ & $\mathrm{~N}$ & $\mathrm{~N}$ & $Y$ & $Y$ & $Y$ \\
\hline $\begin{array}{l}\text { Extended } \\
\text { neck? }\end{array}$ & $\mathrm{N}$ & $\mathrm{N}$ & $\mathrm{N}$ & $\mathrm{N}$ & $\mathrm{N}$ & $Y$ & $\mathrm{Y}$ & $\mathrm{N}$ & $\mathrm{N}$ & $\mathrm{N}$ \\
\hline $\begin{array}{l}\text { Hunched } \\
\text { shoulder? }\end{array}$ & $\mathrm{N}$ & $\mathrm{N}$ & $\mathrm{N}$ & $\mathrm{N}$ & $\mathrm{N}$ & $Y$ & $Y$ & $\mathrm{~N}$ & $\mathrm{~N}$ & $\mathrm{~N}$ \\
\hline Forked ribs? & $\begin{array}{l}\text { Y: } 1 \\
\text { per side }\end{array}$ & $\mathrm{N}$ & $\begin{array}{l}\text { Y: } 1 \\
\text { per side }\end{array}$ & $\begin{array}{l}\text { Y: } 1 \\
\text { per side }\end{array}$ & $\begin{array}{l}\text { Y: } 1 \\
\text { per } \\
\text { side }\end{array}$ & $\mathrm{N}$ & $\mathrm{N}$ & $\mathrm{N}$ & $\begin{array}{l}\text { Y: } 1 \\
\text { per } \\
\text { side }\end{array}$ & $\begin{array}{l}\text { Y: } 1 \\
\text { per } \\
\text { side }\end{array}$ \\
\hline $\begin{array}{l}\text { Pattern } \\
\text { beneath } \\
\text { ribs? }\end{array}$ & $\mathrm{N}$ & $\mathrm{N}$ & $\begin{array}{l}Y \\
\text { wide } \\
\text { diamond }\end{array}$ & $\begin{array}{l}\mathrm{Y} \\
\text { diamond }\end{array}$ & $\mathrm{N}$ & $\mathrm{N}$ & $\mathrm{N}$ & $\mathrm{N}$ & $\begin{array}{l}Y \\
\text { diamond } \\
\text {, small }\end{array}$ & $\begin{array}{l}\mathrm{Y} \\
\text { tri- } \\
\text { angle }\end{array}$ \\
\hline Vagina? & $\mathrm{N}$ & $\mathrm{N}$ & $\mathrm{N}$ & $\mathrm{N}$ & $\mathrm{N}$ & $\mathrm{N}$ & $\mathrm{N}$ & $\mathrm{N}$ & $\mathrm{N}$ & $\mathrm{N}$ \\
\hline $\begin{array}{l}\text { Arms curve } \\
\text { out then in? }\end{array}$ & $Y$ & $Y$ & $Y$ & $Y$ & $Y$ & $Y$ & $\begin{array}{l}\mathrm{Y}(1) \\
\text { right } \\
\text { arm }\end{array}$ & $Y$ & $Y$ & $Y$ \\
\hline $\begin{array}{l}\text { Arms rest } \\
\text { on thighs? }\end{array}$ & $Y$ & $Y$ & $\mathrm{Y}$ & $Y$ & $Y$ & $Y$ & $\begin{array}{l}(1) \\
\text { right } \\
\text { arm }\end{array}$ & $Y$ & $Y$ & $Y$ \\
\hline $\begin{array}{l}\text { Hand to } \\
\text { chest or } \\
\text { mouth? }\end{array}$ & $\mathrm{N}$ & $\mathrm{N}$ & $\mathrm{N}$ & $\mathrm{N}$ & $\mathrm{N}$ & $\mathrm{N}$ & $\begin{array}{l}\text { C \& M: } \\
1 \text { finger }\end{array}$ & $\mathrm{N}$ & $\mathrm{N}$ & $\mathrm{N}$ \\
\hline $\begin{array}{l}\text { Hands } \\
\text { worked? }\end{array}$ & $\mathrm{N}$ & $\mathrm{N}$ & $\mathrm{N}$ & $\mathrm{N}$ & $\mathrm{N}$ & $Y$ & $Y(1)$ & $\mathrm{N}$ & $\mathrm{N}$ & $\mathrm{N}$ \\
\hline $\begin{array}{l}\text { Elbows } \\
\text { pointed and } \\
\text { /or lugged? }\end{array}$ & $P ; L$ & $P ; L$ & $P ; L$ & $P ; L$ & $P ; L$ & $P: 1$ & $P: 2 ; L: 1$ & $\mathrm{P} ; \mathrm{L}$ & $P ; L$ & $\mathrm{P} ; \mathrm{L}$ \\
\hline
\end{tabular}




\begin{tabular}{|c|c|c|c|c|c|c|c|c|c|c|}
\hline $\begin{array}{l}\text { Thighs: } \\
\text { rounded (0- } \\
\text { 4), straight } \\
(6-10) \text {, or } \\
\text { in-between } \\
\text { (5) }\end{array}$ & $\begin{array}{l}\mathrm{S} \\
9.5\end{array}$ & $\begin{array}{l}S \\
10.0\end{array}$ & $\begin{array}{l}S \\
10.0\end{array}$ & $\begin{array}{l}S \\
10.0\end{array}$ & $\begin{array}{l}S \\
10.0\end{array}$ & $\begin{array}{l}R \\
1.0\end{array}$ & $\begin{array}{l}R \\
2.0\end{array}$ & $\begin{array}{l}S \\
8.5\end{array}$ & $\begin{array}{l}\mathrm{S} \\
8.5\end{array}$ & $\begin{array}{l}S \\
8.5\end{array}$ \\
\hline $\begin{array}{l}\text { Knees: } \\
\text { rounded (0- } \\
4 \text { ), cornered } \\
(6-10) \text {, or } \\
\text { in-between } \\
\text { (5) }\end{array}$ & $\begin{array}{l}C \\
9.5\end{array}$ & $\begin{array}{l}C \\
9.0\end{array}$ & $\begin{array}{l}\mathrm{C} \\
9.0\end{array}$ & $\begin{array}{l}C \\
9.0\end{array}$ & $\begin{array}{l}C \\
9.5\end{array}$ & $\begin{array}{l} \\
\\
0.5\end{array}$ & $\begin{array}{l}R \\
1.0\end{array}$ & $\begin{array}{l}C \\
9.0\end{array}$ & $\begin{array}{l}\mathrm{C} \\
8.5\end{array}$ & $\begin{array}{l}C \\
9.0\end{array}$ \\
\hline $\begin{array}{l}\text { Leg } \\
\text { projections? }\end{array}$ & $\mathrm{N}$ & $\mathrm{N}$ & $\mathrm{N}$ & $N$ & $\mathrm{~N}$ & $\begin{array}{l}\text { Y lower } \\
\text { feet }\end{array}$ & $N$ & $\mathrm{~N}$ & $\begin{array}{l}\mathrm{Y} \\
\text { ankles }\end{array}$ & $\begin{array}{l}\mathrm{Y} \\
\text { ankles }\end{array}$ \\
\hline Leg knobs? & $\mathrm{N}$ & $\begin{array}{l}Y \\
\text { knees }\end{array}$ & $\begin{array}{l}\mathrm{Y} \\
\text { knees }\end{array}$ & $\mathrm{N}$ & $\begin{array}{l}Y \\
\text { knees }\end{array}$ & $\mathrm{N}$ & $\mathrm{N}$ & $\mathrm{N}$ & $\mathrm{N}$ & $\mathrm{N}$ \\
\hline Feet? & $\mathrm{N}$ & $\mathrm{N}$ & $\begin{array}{l}\text { Y faint } \\
\text { grooves }\end{array}$ & $\mathrm{N}$ & $\mathrm{N}$ & $\begin{array}{l}Y \\
3 \text { toes }\end{array}$ & $\mathrm{N}$ & $\mathrm{N}$ & $\mathrm{N}$ & $\mathrm{N}$ \\
\hline $\begin{array}{l}\text { Pounamu } \\
\text { variety? }\end{array}$ & 1 & KK & 1 & 1 & 1 & I\& KR & 1 & 1 & 1 & 1 \\
\hline $\begin{array}{l}\text { Pounamu } \\
\text { Source? }\end{array}$ & $\mathrm{CW}$ & CW & $\mathrm{CW}$ & $\mathrm{A}, \mathrm{CW}$ & $A, C W$ & $\mathrm{~A}, \mathrm{CW}$ & TK, W & $\mathrm{A}, \mathrm{CW}$ & $\mathrm{A}, \mathrm{CW}$ & $\begin{array}{l}\text { A, } \\
C W\end{array}$ \\
\hline $\begin{array}{l}\text { Heat } \\
\text { treatment? }\end{array}$ & $\mathrm{N}$ & $\mathrm{N}$ & $\mathrm{N}$ & $\mathrm{N}$ & $\mathrm{N}$ & $\mathrm{N}$ & $\mathrm{N}$ & $\mathrm{N}$ & $\mathrm{N}$ & $\mathrm{N}$ \\
\hline $\begin{array}{l}\text { Surface } \\
\text { reground? }\end{array}$ & $\mathrm{N}$ & $\mathrm{N}$ & $\mathrm{N}$ & $\mathrm{N}$ & $\mathrm{N}$ & $N$ & $\mathrm{~N}$ & $\mathrm{~N}$ & $\mathrm{~N}$ & $\mathrm{~N}$ \\
\hline Wear: 0-10 & 5.0 & 6.0 & 3.0 & 4.0 & 0.0 & 9.0 & 9.0 & 9.5 & 1.0 & 4.5 \\
\hline Other & & & 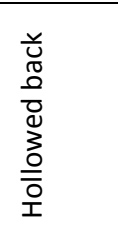 & & 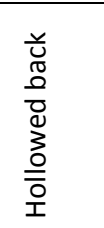 & & 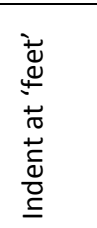 & 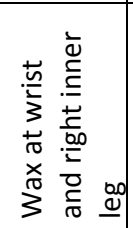 & 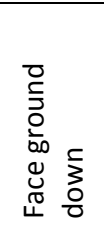 & \\
\hline
\end{tabular}




\begin{tabular}{|c|c|c|c|c|c|c|c|c|c|c|}
\hline Study no. & 2.11 & 2.12 & 2.13 & 2.14 & 2.15 & 2.16 & 2.17 & 2.18 & 2.19 & 2.20 \\
\hline $\begin{array}{l}\text { Collection } \\
\text { number }\end{array}$ & 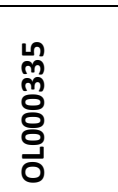 & 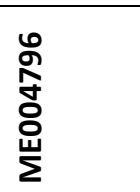 & 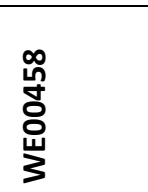 & $\begin{array}{l}\text { N } \\
\text { ڤે } \\
0 \\
0\end{array}$ & 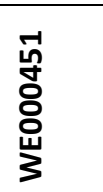 & 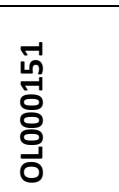 & 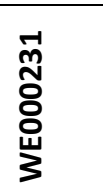 & 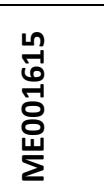 & 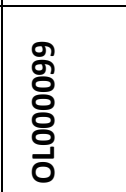 & $\begin{array}{l}\text { J } \\
0 \\
o \\
0\end{array}$ \\
\hline $\begin{array}{l}\text { Outline } \\
\text { shape }\end{array}$ & A & A & A & A & A & A & $\overline{A B}$ & $A B$ & $A B$ & $\overline{A B}$ \\
\hline $\begin{array}{l}\text { Type } \\
\text { (Webster) }\end{array}$ & $I$ & 1 & $\mathrm{I}$ & 1 & 1 & 1 & I & 1 & 1 & $\begin{array}{l}\text { I variant } \\
\end{array}$ \\
\hline Length $\mathrm{mm}$ & 62 & 108 & 134 & 144 & 96 & 130 & 65 & 69 & 110 & 87 \\
\hline Width $\mathrm{mm}$ & 30 & 58 & 67 & 67 & 55 & 83 & 39 & 46 & 77 & 50 \\
\hline Depth mm & 9 & 12 & 20 & 23 & 16 & 19 & 12 & 8 & $?$ & 13 \\
\hline $\begin{array}{l}\text { Width \% of } \\
\text { length }\end{array}$ & 49 & 54 & 48 & 47 & 57 & 64 & 59 & 67 & 66 & 58 \\
\hline $\begin{array}{l}\text { Head \% of } \\
\text { length }\end{array}$ & 47 & 47 & 47 & 50 & 47 & 49 & 41 & 42 & 50 & 50 \\
\hline $\begin{array}{l}\text { Body \% of } \\
\text { length }\end{array}$ & 28 & 28 & 24 & 25 & 25 & 22 & 30 & 27 & 25 & 24 \\
\hline $\begin{array}{l}\text { Legs \% of } \\
\text { length }\end{array}$ & 25 & 25 & 29 & 25 & 28 & 29 & 29 & 31 & 25 & 26 \\
\hline $\begin{array}{l}\text { Head tilt: } \\
\text { Left or Right }\end{array}$ & $R$ & $R$ & $R$ & $R$ & $\mathrm{~L}$ & $R$ & $R$ & $R$ & $\mathrm{~L}$ & $R$ \\
\hline $\begin{array}{l}\text { Degree of } \\
\text { head tilt }\end{array}$ & 45 & 45 & 45 & 45 & 45 & 45 & 60 & 60 & 40 & 45 \\
\hline $\begin{array}{l}\text { Extent head } \\
\text { pointed at } \\
\text { top: } 0-10\end{array}$ & 3.0 & 8.0 & 8.5 & 5.0 & 6.5 & 7.0 & 6.0 & 4.0 & 6.0 & 5.0 \\
\hline $\begin{array}{l}\text { Eyes large, } \\
\text { medium or } \\
\text { small? }\end{array}$ & $\mathrm{L}$ & $\mathrm{L}$ & $\mathrm{L}$ & $\mathrm{L}$ & $\mathrm{L}$ & $\mathrm{L}$ & $\mathrm{L}$ & $\mathrm{L}$ & $\mathrm{L}$ & $\mathrm{L}$ \\
\hline $\begin{array}{l}\text { Eye inlay? } \\
\text { (pāua, } \\
\text { sealing wax) }\end{array}$ & $z$ & $z$ & $z$ & 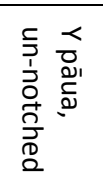 & $z$ & 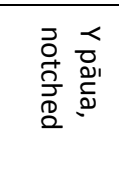 & $z$ & $z$ & 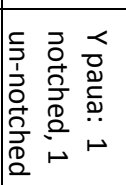 & $z$ \\
\hline $\begin{array}{l}\text { Secondary } \\
\text { eye rims? }\end{array}$ & $\mathrm{N}$ & $\mathrm{N}$ & $\mathrm{N}$ & $\mathrm{N}$ & $\mathrm{N}$ & $\mathrm{N}$ & $\mathrm{N}$ & $\mathrm{N}$ & $N$ & $\mathrm{Y}$ \\
\hline Brows? & $\mathrm{Y}$ & $Y(1)$ & $\mathrm{Y}$ & $\mathrm{Y}$ & $\mathrm{Y}$ & $\mathrm{Y}$ & $N$ & $\mathrm{Y}$ & $?$ & $\mathrm{Y}$ \\
\hline $\begin{array}{l}\text { Forehead } \\
\text { ridge? }\end{array}$ & $\mathrm{Y}$ & $\mathrm{Y}$ & $\mathrm{Y}$ & $\mathrm{Y}$ & $\mathrm{Y}$ & $\mathrm{Y}$ & $\mathrm{Y}$ & $?$ & $\mathrm{Y}$ & $\mathrm{Y}$ \\
\hline $\begin{array}{l}\text { Forking at } \\
\text { nose } \\
\text { bridge? }\end{array}$ & $\begin{array}{l}? \\
\text { worn }\end{array}$ & $\mathrm{Y}$ & $\mathrm{Y}$ & $\begin{array}{l}? \\
\text { worn }\end{array}$ & $\mathrm{Y}$ & $\mathrm{Y}$ & $\mathrm{N}$ & $\begin{array}{l}? \\
\text { worn }\end{array}$ & $\mathrm{Y}$ & $\mathrm{Y}$ \\
\hline Nostrils? & $\begin{array}{l}\text { ? } \\
\text { worn }\end{array}$ & $\begin{array}{l}Y \\
\text { uncon- } \\
\text { ventional }\end{array}$ & $\begin{array}{l}\mathrm{Y} \\
\text { uncon- } \\
\text { ventional }\end{array}$ & $\begin{array}{l}? \\
\text { worn }\end{array}$ & $\begin{array}{l}Y \\
\text { arched }\end{array}$ & $\begin{array}{l}\mathrm{Y} \\
\text { arched }\end{array}$ & $\begin{array}{l}\text { ? } \\
\text { worn }\end{array}$ & $\begin{array}{l}? \\
\text { worn }\end{array}$ & \begin{tabular}{|l|}
$?$ \\
worn
\end{tabular} & $\begin{array}{l}Y \\
\text { arched }\end{array}$ \\
\hline
\end{tabular}




\begin{tabular}{|c|c|c|c|c|c|c|c|c|c|c|}
\hline $\begin{array}{l}\text { Ridge from } \\
\text { nostrils to } \\
\text { nose } \\
\text { bridge? }\end{array}$ & $\begin{array}{l}? \\
\text { worn }\end{array}$ & $Y$ & $\mathrm{~N}$ & $\begin{array}{l}? \\
\text { worn }\end{array}$ & $\mathrm{N}$ & $\mathrm{N}$ & $\mathrm{N}$ & $\begin{array}{l}? \\
\text { worn }\end{array}$ & $\begin{array}{l}? \\
\text { worn }\end{array}$ & $\mathrm{N}$ \\
\hline $\begin{array}{l}\text { Heart } \\
\text { shaped } \\
\text { mouth? }\end{array}$ & $\begin{array}{l}\mathrm{Y} \\
\text { approx. }\end{array}$ & $Y$ & $\begin{array}{l}\mathrm{N} \\
\text { tear } \\
\text { drop }\end{array}$ & $Y$ & $Y$ & $Y$ & $Y$ & $\begin{array}{l}\text { ? } \\
\text { worn }\end{array}$ & $\mathrm{Y}$ & $Y$ \\
\hline $\begin{array}{l}\text { Mid upper } \\
\text { tooth? }\end{array}$ & $\begin{array}{l}\text { ? } \\
\text { worn }\end{array}$ & $Y$ & $Y$ & $Y$ & ? & $Y$ & $\begin{array}{l}\text { ? } \\
\text { worn }\end{array}$ & $\begin{array}{l}\text { ? } \\
\text { worn }\end{array}$ & $\mathrm{N}$ & $Y$ \\
\hline $\begin{array}{l}\text { Corner } \\
\text { teeth? }\end{array}$ & $\begin{array}{l}? \\
\text { worn }\end{array}$ & $Y$ & $Y$ & $Y$ & $Y$ & $Y$ & $\begin{array}{l}? \\
\text { worn }\end{array}$ & $\begin{array}{l}? \\
\text { worn }\end{array}$ & $\mathrm{Y}$ & $Y$ \\
\hline $\begin{array}{l}\text { Internal } \\
\text { Tongue? }\end{array}$ & $\begin{array}{l}? \\
\text { worn }\end{array}$ & $\mathrm{N}$ & $\mathrm{N}$ & $Y$ & $Y$ & $Y$ & $\begin{array}{l}? \\
\text { worn }\end{array}$ & $\begin{array}{l}? \\
\text { worn }\end{array}$ & $\mathrm{N}$ & $\mathrm{N}$ \\
\hline $\begin{array}{l}\text { Tongue } \\
\text { against cnr } \\
\text { tooth? }\end{array}$ & $\begin{array}{l}? \\
\text { worn }\end{array}$ & $N$ & $\mathrm{~N}$ & $Y$ & $Y$ & $Y$ & $\begin{array}{l}? \\
\text { worn }\end{array}$ & $\begin{array}{l}? \\
\text { worn }\end{array}$ & $\mathrm{N}$ & $\mathrm{N}$ \\
\hline $\begin{array}{l}\text { Extended } \\
\text { tongue? }\end{array}$ & $\begin{array}{l}? \\
\text { worn }\end{array}$ & $\mathrm{N}$ & $\mathrm{N}$ & $\mathrm{N}$ & $\mathrm{N}$ & $\mathrm{N}$ & $\mathrm{N}$ & $\begin{array}{l}? \\
\text { worn }\end{array}$ & $\mathrm{N}$ & $\mathrm{N}$ \\
\hline $\begin{array}{l}\text { Forked } \\
\text { tongue? }\end{array}$ & $\begin{array}{l}\text { ? } \\
\text { worn }\end{array}$ & $N$ & $\mathrm{~N}$ & $\mathrm{~N}$ & $\mathrm{~N}$ & $\mathrm{~N}$ & $\begin{array}{l}? \\
\text { worn }\end{array}$ & $\begin{array}{l}? \\
\text { worn }\end{array}$ & $\mathrm{N}$ & $\mathrm{N}$ \\
\hline $\begin{array}{l}\text { Head } \\
\text { projections? }\end{array}$ & $N$ & $N$ & $\mathrm{~N}$ & $\begin{array}{l}\mathrm{N} \\
\text { tab }\end{array}$ & $\mathrm{N}$ & $\mathrm{N}$ & $\mathrm{N}$ & $N$ & $\mathrm{~N}$ & $\mathrm{~N}$ \\
\hline $\begin{array}{l}\text { Indicative } \\
\text { neck? }\end{array}$ & $Y$ & $Y$ & $Y$ & $Y$ & $Y$ & $Y$ & $Y$ & $Y$ & $Y$ & $Y$ \\
\hline $\begin{array}{l}\text { Extended } \\
\text { neck? }\end{array}$ & $\mathrm{N}$ & $\mathrm{N}$ & $\mathrm{N}$ & $\mathrm{N}$ & $\mathrm{N}$ & $\mathrm{N}$ & $\mathrm{N}$ & $N$ & $\mathrm{~N}$ & $Y$ \\
\hline $\begin{array}{l}\text { Hunched } \\
\text { shoulder? }\end{array}$ & $\mathrm{N}$ & $\mathrm{N}$ & $\mathrm{N}$ & $\mathrm{N}$ & $\mathrm{N}$ & $\mathrm{N}$ & $\mathrm{N}$ & $\mathrm{N}$ & $\mathrm{N}$ & $\mathrm{N}$ \\
\hline Forked ribs? & $\mathrm{N}$ & $\begin{array}{l}\text { Y: } 3 \text { per } \\
\text { side }\end{array}$ & $\begin{array}{l}\text { Y: } 1 \text { per } \\
\text { side }\end{array}$ & $\begin{array}{l}\text { Y: } 4 \\
\text { per } \\
\text { side }\end{array}$ & $\mathrm{N}$ & $\mathrm{N}$ & $\begin{array}{l}\text { Y: } 1 \\
\text { per } \\
\text { side }\end{array}$ & $\mathrm{N}$ & $\begin{array}{l}\text { Y: } 2 \text { per } \\
\text { side }\end{array}$ & $\begin{array}{l}\text { Y: } 1 \text { per } \\
\text { side }\end{array}$ \\
\hline $\begin{array}{l}\text { Pattern } \\
\text { beneath } \\
\text { ribs? }\end{array}$ & $N$ & $\begin{array}{l}\mathrm{Y} \\
\text { triangle }\end{array}$ & $\mathrm{N}$ & $\mathrm{N}$ & $\mathrm{N}$ & $\mathrm{N}$ & $\mathrm{N}$ & $N$ & $\mathrm{~N}$ & $\begin{array}{l}\mathrm{N} \\
\text { faint } \\
\text { line }\end{array}$ \\
\hline Vagina? & $\mathrm{N}$ & $N$ & $Y$ & $Y$ & $\mathrm{~N}$ & $\mathrm{~N}$ & $\mathrm{~N}$ & $N$ & $Y$ & $\mathrm{~N}$ \\
\hline $\begin{array}{l}\text { Arms curve } \\
\text { out then in? }\end{array}$ & $Y$ & $\mathrm{Y}$ & $\mathrm{Y}$ & $\mathrm{Y}$ & $\mathrm{Y}$ & $Y$ & $\mathrm{~N}$ & $Y$ & $Y$ & $\mathrm{Y}$ \\
\hline $\begin{array}{l}\text { Arms rest } \\
\text { on thighs? }\end{array}$ & $Y$ & $Y$ & $Y$ & $Y$ & $Y$ & $Y$ & $Y$ & $\mathrm{Y}$ & $\mathrm{Y}$ & $Y$ \\
\hline $\begin{array}{l}\text { Hand to } \\
\text { chest or } \\
\text { mouth? }\end{array}$ & $\mathrm{N}$ & $\mathrm{N}$ & $\mathrm{N}$ & $N$ & $\mathrm{~N}$ & $\mathrm{~N}$ & $\mathrm{~N}$ & $\mathrm{~N}$ & $\mathrm{~N}$ & $\mathrm{~N}$ \\
\hline $\begin{array}{l}\text { Hands } \\
\text { worked? }\end{array}$ & $\mathrm{N}$ & $Y: 1$ & $\mathrm{~N}$ & $Y$ & $N$ & $\mathrm{~N}$ & $\mathrm{~N}$ & $\mathrm{~N}$ & $Y$ & $\mathrm{~N}$ \\
\hline $\begin{array}{l}\text { Elbows } \\
\text { pointed and } \\
\text { /or lugged? }\end{array}$ & $\mathrm{N}$ & $P ; L$ & $P ; L$ & $P ; L$ & $P ; L$ & $P ; L$ & $P$ & $P ; L$ & $P ; L$ & $P$ \\
\hline $\begin{array}{l}\text { Thighs: } \\
\text { rounded (0- } \\
4) \text {, straight } \\
\text { (6-10), or in- } \\
\text { between (5) }\end{array}$ & $\begin{array}{l}S \\
8.0\end{array}$ & $\begin{array}{l}S \\
7.0\end{array}$ & $\begin{array}{l}\mathrm{S} \\
9.5\end{array}$ & $\begin{array}{l} \\
9.5\end{array}$ & $\begin{array}{l}5 \\
8.0\end{array}$ & $\begin{array}{l}\mathrm{S} \\
9.5\end{array}$ & $\begin{array}{l}S \\
7.0\end{array}$ & $\begin{array}{l}S \\
8.0\end{array}$ & $\begin{array}{l}5 \\
8.0\end{array}$ & $\begin{array}{l}S \\
7.0\end{array}$ \\
\hline
\end{tabular}




\begin{tabular}{|c|c|c|c|c|c|c|c|c|c|c|}
\hline $\begin{array}{l}\text { Knees: } \\
\text { rounded (0- } \\
\text { 4), cornered } \\
(6-10) \text {, or in- } \\
\text { between (5) }\end{array}$ & $\begin{array}{l}\mathrm{C} \\
8.5\end{array}$ & $\begin{array}{l}\mathrm{C} \\
8.0\end{array}$ & $\begin{array}{l}\mathrm{C} \\
9.5\end{array}$ & $\begin{array}{l}\mathrm{C} \\
9.0\end{array}$ & $\begin{array}{l}\mathrm{C} \\
8.5\end{array}$ & $\begin{array}{l}\mathrm{C} \\
9.0\end{array}$ & \begin{tabular}{|l|}
1 \\
5.0
\end{tabular} & $\begin{array}{l}\mathrm{C} \\
8.0\end{array}$ & $\begin{array}{l}\mathrm{C} \\
8.5\end{array}$ & $\begin{array}{l}C \\
8.0\end{array}$ \\
\hline $\begin{array}{l}\text { Leg } \\
\text { projections? }\end{array}$ & $N$ & $\begin{array}{l}Y \\
\text { ankles }\end{array}$ & $\mathrm{N}$ & $\begin{array}{l}\mathrm{Y} \\
\text { ankles }\end{array}$ & $N$ & $N$ & \begin{tabular}{|l}
$\mathrm{Y}:$ \\
ankles
\end{tabular} & $\begin{array}{l}\text { Y: } \\
\text { ankles }\end{array}$ & $Y$ : feet & $\mathrm{N}$ \\
\hline Leg knobs? & $\mathrm{N}$ & $\mathrm{N}$ & $\begin{array}{l}Y \\
\text { knees }\end{array}$ & $\begin{array}{l}Y \\
\text { knees }\end{array}$ & $\mathrm{N}$ & $\mathrm{N}$ & $\mathrm{N}$ & $\begin{array}{l}\mathrm{Y}: \\
\text { knees }\end{array}$ & $\mathrm{N}$ & $\begin{array}{l}\text { Y: } \\
\text { ankle }\end{array}$ \\
\hline Feet? & $\mathrm{N}$ & $\mathrm{N}$ & $Y$ & $Y$ & $?$ & $\mathrm{~N}$ & $N$ & $\mathrm{~N}$ & $Y$ & $\mathrm{Y}$ \\
\hline $\begin{array}{l}\text { Pounamu } \\
\text { variety? }\end{array}$ & I & KR & $\begin{array}{l}\text { I } \\
\text { aged }\end{array}$ & KK & I \& KK & KK & $\begin{array}{l}\text { I } \\
\text { aged }\end{array}$ & KK & KK & Inc. \\
\hline $\begin{array}{l}\text { Pounamu } \\
\text { Source? }\end{array}$ & $\mathrm{A}, \mathrm{CW}$ & $?$ & $\mathrm{CW}$ & CW & A, CW & $\mathrm{CW}$ & CW & $\mathrm{CW}$ & $?$ & Inc. \\
\hline $\begin{array}{l}\text { Heat } \\
\text { treatment? }\end{array}$ & $\mathrm{N}$ & $\mathrm{N}$ & $\mathrm{N}$ & $\mathrm{N}$ & $N$ & $N$ & $N$ & $N$ & ? & $Y$ \\
\hline $\begin{array}{l}\text { Surface } \\
\text { reground? }\end{array}$ & $N$ & $N$ & $\mathrm{~N}$ & $N$ & $N$ & $N$ & $N$ & $N$ & $N$ & $N$ \\
\hline Wear: 0-10 & 9.0 & 5.0 & 6.0 & 8.0 & 6.0 & 3.0 & 8.0 & 9.5 & 6.0 & 1.0 \\
\hline Other & 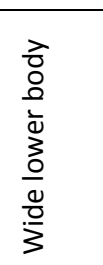 & 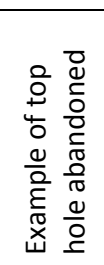 & 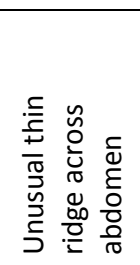 & & 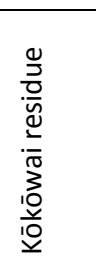 & & 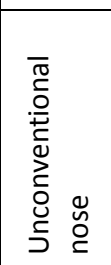 & 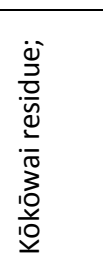 & $\begin{array}{l}\frac{0}{0} \\
\frac{0}{0} \\
\frac{0}{00} \\
\frac{0}{000} \\
0\end{array}$ & 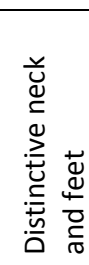 \\
\hline
\end{tabular}




\begin{tabular}{|c|c|c|c|c|c|c|c|c|c|c|}
\hline Study no. & 2.21 & 2.22 & 2.23 & 2.24 & 2.25 & 2.26 & 2.27 & 2.28 & 2.29 & 2.30 \\
\hline $\begin{array}{l}\text { Collection } \\
\text { number }\end{array}$ & 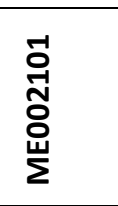 & 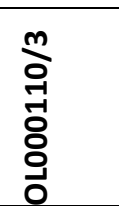 & 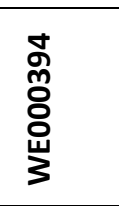 & 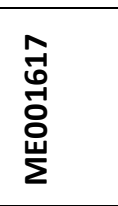 & $\begin{array}{l}\underset{N}{N} \\
\underset{\tilde{N}}{\tilde{\Sigma}} \\
\Sigma\end{array}$ & 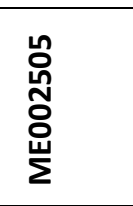 & 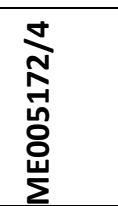 & 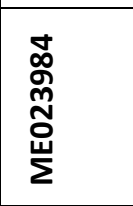 & 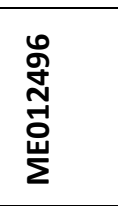 & 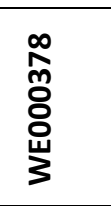 \\
\hline $\begin{array}{l}\text { Outline } \\
\text { shape }\end{array}$ & $A C$ & $A C$ & $A C$ & $B$ & $B$ & $B$ & B & B & $B$ & $B$ \\
\hline $\begin{array}{l}\text { Type } \\
\text { (Webster) }\end{array}$ & 1 & 1 & $1 / 11$ & 1 & I & 1 & II & I & 1 & II \\
\hline Length $\mathrm{mm}$ & 90 & 113 & 77 & 102 & 103 & 124 & 89 & 151 & 95 & 106 \\
\hline Width $\mathrm{mm}$ & 53 & 68 & 45 & 60 & 58 & 76 & 51 & 73 & 71 & 67 \\
\hline Depth $\mathrm{mm}$ & 14 & 14 & 9 & 18 & 14 & 15 & 10 & 15 & 17 & 14 \\
\hline $\begin{array}{l}\text { Width \% of } \\
\text { length }\end{array}$ & 59 & 60 & 57 & 59 & 56 & 61 & 57 & 53 & 71 & 64 \\
\hline $\begin{array}{l}\text { Head \% of } \\
\text { length }\end{array}$ & 49 & 48 & 51 & 48 & 49 & 43 & 39 & 48 & 41 & 45 \\
\hline $\begin{array}{l}\text { Body \% of } \\
\text { length }\end{array}$ & 23 & 26 & 22 & 27 & 26 & 27 & 31 & 26 & 27 & 28 \\
\hline $\begin{array}{l}\text { Legs } \% \text { of } \\
\text { length }\end{array}$ & 28 & 26 & 28 & 25 & 25 & 30 & 30 & 26 & 32 & 27 \\
\hline $\begin{array}{l}\text { Head tilt: } \\
\text { Left or Right }\end{array}$ & $\mathrm{L}$ & $R$ & $R$ & $\mathrm{~L}$ & $R$ & $R$ & $R$ & $R$ & $R$ & $\mathrm{~L}$ \\
\hline $\begin{array}{l}\text { Degree of } \\
\text { head tilt }\end{array}$ & 45 & 45 & 45 & 45 & 45 & 80 & 45 & 45 & 45 & 45 \\
\hline $\begin{array}{l}\text { Extent head } \\
\text { pointed at } \\
\text { top: } 0-10\end{array}$ & 9.0 & 5.0 & 5.0 & 4.0 & 6.0 & 6.0 & 8.0 & 8.0 & 6.0 & 6.0 \\
\hline $\begin{array}{l}\text { Eyes large, } \\
\text { medium or } \\
\text { small? }\end{array}$ & $\mathrm{L}$ & $\mathrm{L}$ & $\mathrm{s}$ & $\mathrm{L}$ & $\mathrm{L}$ & $\mathrm{L}$ & $S \& M$ & $\mathrm{~L}$ & $\mathrm{~L}$ & $\mathrm{~L}$ \\
\hline $\begin{array}{l}\text { Eye inlay? } \\
\text { (pāua, } \\
\text { sealing wax) }\end{array}$ & $z$ & 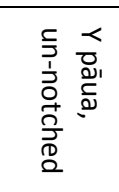 & $z$ & $\underset{\dot{\mathcal{x}}}{\mid}<$ & $z$ & 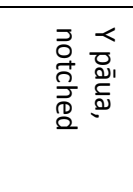 & $z$ & 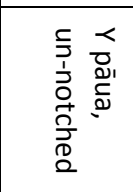 & $z$ & $z$ \\
\hline $\begin{array}{l}\text { Secondary } \\
\text { eye rims? }\end{array}$ & $\mathrm{N}$ & $\mathrm{N}$ & $\mathrm{N}$ & $\mathrm{N}$ & $\begin{array}{l}Y \\
\text { worn }\end{array}$ & $N$ & $\mathrm{~N}$ & $N$ & $\mathrm{~N}$ & $N$ \\
\hline Brows? & $\mathrm{Y}$ & $\mathrm{Y}$ & $\mathrm{Y}$ & $Y$ & $\mathrm{Y}$ & $\begin{array}{l}? \\
\text { worn } \\
\end{array}$ & $\mathrm{Y}$ & $\mathrm{Y}$ & $\mathrm{Y}$ & $Y(1)$ \\
\hline $\begin{array}{l}\text { Forehead } \\
\text { ridge? }\end{array}$ & $\mathrm{Y}$ & $\mathrm{Y}$ & $\mathrm{Y}$ & $\mathrm{Y}$ & $\mathrm{Y}$ & \begin{tabular}{|l}
$Y$ \\
\end{tabular} & $\mathrm{Y}$ & $\mathrm{Y}$ & $\mathrm{Y}$ & $\mathrm{N}$ worn \\
\hline $\begin{array}{l}\text { Forking at } \\
\text { nose bridge? }\end{array}$ & $\mathrm{Y}$ & $\mathrm{Y}$ & $\begin{array}{l}Y \\
\text { Worn }\end{array}$ & $\begin{array}{l}? \\
\text { worn }\end{array}$ & $\begin{array}{l}? \\
\text { worn }\end{array}$ & ? & Y worn & $\mathrm{Y}$ & ? & $\mathrm{Y}$ \\
\hline Nostrils? & $\begin{array}{l}\mathrm{Y} \\
\text { arched }\end{array}$ & $\begin{array}{l}\mathrm{Y} \\
\text { arched }\end{array}$ & $\begin{array}{l}\mathrm{Y} \\
\text { arched }\end{array}$ & $\begin{array}{l}\text { ? } \\
\text { worn }\end{array}$ & $\begin{array}{l}? \\
\text { worn }\end{array}$ & $\begin{array}{l}? \\
\text { worn }\end{array}$ & $\begin{array}{l}\mathrm{Y} \\
\text { arched }\end{array}$ & \begin{tabular}{|l|}
$\mathrm{Y}$ \\
uncon- \\
ventional
\end{tabular} & $\begin{array}{l}\mathrm{Y}: 1 \\
\text { worn } \\
\text { type? }\end{array}$ & $\begin{array}{l}\mathrm{Y} \\
\text { arched }\end{array}$ \\
\hline
\end{tabular}




\begin{tabular}{|c|c|c|c|c|c|c|c|c|c|c|}
\hline $\begin{array}{l}\text { Ridge from } \\
\text { nostrils to } \\
\text { nose bridge? }\end{array}$ & $Y$ & $?$ & $?$ & $\begin{array}{l}? \\
\text { worn }\end{array}$ & $\begin{array}{l}\text { ? } \\
\text { worn }\end{array}$ & $\mathrm{N}$ & $\begin{array}{l}? \\
\text { Worn }\end{array}$ & $\begin{array}{l}? \\
\text { worn }\end{array}$ & $\begin{array}{l}? \\
\text { worn }\end{array}$ & $\begin{array}{l}\text { ? } \\
\text { Worn }\end{array}$ \\
\hline $\begin{array}{l}\text { Heart } \\
\text { shaped } \\
\text { mouth? }\end{array}$ & $Y$ & $Y$ & $Y$ & $Y$ & $Y$ & $Y$ & $Y$ & $Y$ & $Y$ & $Y$ \\
\hline $\begin{array}{l}\text { Mid upper } \\
\text { tooth? }\end{array}$ & $\mathrm{Y}$ & $\mathrm{Y}$ & $\mathrm{N}$ & $Y$ & $Y$ & $N$ & $N$ & $Y$ & $Y$ & $Y$ \\
\hline $\begin{array}{l}\text { Corner } \\
\text { teeth? }\end{array}$ & $Y$ & $\mathrm{Y}$ & $Y$ & $Y$ & $\mathrm{Y}$ & $\begin{array}{l}Y \\
\text { worn }\end{array}$ & $\mathrm{N}$ & $Y$ & $\mathrm{Y}$ & $Y$ \\
\hline $\begin{array}{l}\text { Internal } \\
\text { Tongue? }\end{array}$ & $\mathrm{N}$ & $\mathrm{N}$ & $Y$ & $\begin{array}{l}? \\
\text { worn }\end{array}$ & $\mathrm{Y}$ & $N$ & $N$ & $Y$ & $\begin{array}{l}? \\
\text { worn }\end{array}$ & $N$ \\
\hline $\begin{array}{l}\text { Tongue } \\
\text { against cnr } \\
\text { tooth? }\end{array}$ & $\mathrm{N}$ & $\mathrm{N}$ & $Y$ & $\begin{array}{l}\text { ? } \\
\text { worn }\end{array}$ & $Y$ & $\mathrm{~N}$ & $\mathrm{~N}$ & $Y$ & $\begin{array}{l}\text { ? } \\
\text { worn }\end{array}$ & $\mathrm{N}$ \\
\hline $\begin{array}{l}\text { Extended } \\
\text { tongue? }\end{array}$ & $\mathrm{N}$ & $\mathrm{N}$ & $\mathrm{N}$ & $\mathrm{N}$ & $\mathrm{N}$ & $\mathrm{N}$ & $Y$ & $\mathrm{~N}$ & $\mathrm{~N}$ & $Y$ \\
\hline $\begin{array}{l}\text { Forked } \\
\text { tongue? }\end{array}$ & $\mathrm{N}$ & $N$ & $\mathrm{~N}$ & $\begin{array}{l}\text { ? } \\
\text { worn }\end{array}$ & $\mathrm{N}$ & $N$ & $Y$ & $\mathrm{~N}$ & $\begin{array}{l}\text { ? } \\
\text { worn }\end{array}$ & $Y$ \\
\hline $\begin{array}{l}\text { Head } \\
\text { projections? }\end{array}$ & $\mathrm{N}$ & $\mathrm{N}$ & $\begin{array}{l}\mathrm{N} \\
\text { knob at } \\
\text { top }\end{array}$ & $\mathrm{N}$ & $\mathrm{N}$ & $\mathrm{N}$ & $\mathrm{N}$ & $\mathrm{N}$ & $\mathrm{N}$ & $\begin{array}{l}\mathrm{Y}: \\
\text { at } \\
\text { cheeks }\end{array}$ \\
\hline $\begin{array}{l}\text { Indicative } \\
\text { neck? }\end{array}$ & $Y$ & $Y$ & $Y$ & $Y$ & $Y$ & $Y$ & $\mathrm{~N}$ & $Y$ & $Y$ & $\mathrm{~N}$ \\
\hline $\begin{array}{l}\text { Extended } \\
\text { neck? }\end{array}$ & $\mathrm{N}$ & $\mathrm{N}$ & $N$ & $\mathrm{~N}$ & $\mathrm{~N}$ & $\mathrm{~N}$ & $\mathrm{~N}$ & $\mathrm{~N}$ & $\mathrm{~N}$ & $Y$ \\
\hline $\begin{array}{l}\text { Hunched } \\
\text { shoulder? }\end{array}$ & $\mathrm{N}$ & $\mathrm{N}$ & $N$ & $\mathrm{~N}$ & $\mathrm{~N}$ & $\mathrm{~N}$ & $Y$ & $\mathrm{~N}$ & $\mathrm{~N}$ & $Y$ \\
\hline Forked ribs? & $\begin{array}{l}\text { Y: } 1 \text { per } \\
\text { side }\end{array}$ & $\begin{array}{l}\text { Y: } 1 \text { per } \\
\text { side }\end{array}$ & $\begin{array}{l}\text { Y: } 3 \text { per } \\
\text { side }\end{array}$ & $\mathrm{N}$ & $\begin{array}{l}\text { Y: } 1 \text { per } \\
\text { side }\end{array}$ & $\begin{array}{l}\text { Y: } 1 \text { per } \\
\text { side }\end{array}$ & $\mathrm{N}$ & $\begin{array}{l}\text { Y: } 1 \text { per } \\
\text { side }\end{array}$ & $\begin{array}{l}\text { Y: } 2 \text { per } \\
\text { side }\end{array}$ & $\mathrm{N}$ \\
\hline $\begin{array}{l}\text { Pattern } \\
\text { beneath } \\
\text { ribs? }\end{array}$ & $\mathrm{N}$ & $\mathrm{N}$ & $\mathrm{N}$ & $\mathrm{N}$ & $\begin{array}{l}\mathrm{Y}: \\
\text { groove, } \\
\text { forms a } \\
\text { triangle }\end{array}$ & $\mathrm{N}$ & $\mathrm{N}$ & $\mathrm{N}$ & $\mathrm{N}$ & $\mathrm{N}$ \\
\hline Vagina? & $\mathrm{N}$ & $N$ & $Y$ & $Y$ & $N$ & $N$ & $Y$ & $\mathrm{~N}$ & $\mathrm{Y}$ & $N$ \\
\hline $\begin{array}{l}\text { Arms curve } \\
\text { out then in? }\end{array}$ & $Y$ & $\mathrm{Y}$ & $Y$ & $Y$ & $\mathrm{Y}$ & $Y$ & $N$ & $Y$ & $\mathrm{Y}$ & $\mathrm{N}$ \\
\hline $\begin{array}{l}\text { Arms rest on } \\
\text { thighs? }\end{array}$ & $Y$ & $Y$ & $\mathrm{Y}$ & $\mathrm{Y}$ & $Y$ & $Y$ & $Y: 1$ & $\mathrm{Y}$ & $Y$ & $Y: 1$ \\
\hline $\begin{array}{l}\text { Hand to } \\
\text { chest or } \\
\text { mouth? }\end{array}$ & $\mathrm{N}$ & $\mathrm{N}$ & $\mathrm{N}$ & $\mathrm{N}$ & $\mathrm{N}$ & $\mathrm{N}$ & $C: 1$ & $\mathrm{~N}$ & $\mathrm{~N}$ & $\begin{array}{l}\mathrm{C}: 1 \\
M: 1 \\
\text { finger }\end{array}$ \\
\hline $\begin{array}{l}\text { Hands } \\
\text { worked? }\end{array}$ & $\begin{array}{l}\mathrm{Y} \\
\text { clawed }\end{array}$ & $\mathrm{N}$ & $Y$ & $\mathrm{~N}$ & $\mathrm{~N}$ & $\mathrm{~N}$ & $Y$ & $\mathrm{~N}$ & $Y$ & $Y$ \\
\hline $\begin{array}{l}\text { Elbows } \\
\text { pointed and } \\
\text { /or lugged? }\end{array}$ & $P ; L$ & $P ; L$ & $P ; L$ & $P ; L$ & $P ; L$ & $P ; L$ & $\mathrm{P}: 1$ & $P ; L$ & $\mathrm{P}: 2 ; \mathrm{L}: 1$ & $P: 1$ \\
\hline $\begin{array}{l}\text { Thighs: } \\
\text { rounded (0- } \\
\text { 4), straight } \\
\text { (6-10), or in- } \\
\text { between (5) }\end{array}$ & $\begin{array}{l}S \\
8.0\end{array}$ & $\begin{array}{l}S \\
9.0\end{array}$ & $\begin{array}{l}S \\
7.0\end{array}$ & $\begin{array}{l}S \\
8.0\end{array}$ & $\begin{array}{l} \\
8.5\end{array}$ & $\begin{array}{l}\mathrm{S} \\
9.5\end{array}$ & $\begin{array}{l}R \\
2.0\end{array}$ & $\begin{array}{l}S \\
6.0\end{array}$ & $\begin{array}{l}\mathrm{S} \\
8.0\end{array}$ & $\begin{array}{l}1 \\
5.0\end{array}$ \\
\hline
\end{tabular}




\begin{tabular}{|c|c|c|c|c|c|c|c|c|c|c|}
\hline $\begin{array}{l}\text { Knees: } \\
\text { rounded (0- } \\
\text { 4), cornered } \\
\text { (6-10), or in- } \\
\text { between (5) }\end{array}$ & $\begin{array}{l}C \\
8.0\end{array}$ & $\begin{array}{l}\mathrm{C} \\
8.5\end{array}$ & $\begin{array}{l}\mathrm{C} \\
7.0\end{array}$ & $\begin{array}{l}1 \\
5.0\end{array}$ & $\begin{array}{l}\mathrm{C} \\
7.0\end{array}$ & $\begin{array}{l}\mathrm{C} \\
9.0\end{array}$ & $\begin{array}{l}R \\
1.5\end{array}$ & $\begin{array}{l}R \\
3.0\end{array}$ & $\begin{array}{l}C \\
7.0\end{array}$ & $\begin{array}{l}R \\
1.0\end{array}$ \\
\hline $\begin{array}{l}\text { Leg } \\
\text { projections? }\end{array}$ & $\begin{array}{l}\text { Y: } \\
\text { ankles, } \\
\text { feet }\end{array}$ & $\mathrm{N}$ & $\begin{array}{l}\mathrm{Y:} \\
\text { ankles }\end{array}$ & $\mathrm{N}$ & $\begin{array}{l}? \\
\text { worn }\end{array}$ & $\begin{array}{l}\text { Y: } \\
\text { ankles }\end{array}$ & $\mathrm{N}$ & $\mathrm{N}$ & $\begin{array}{l}\text { Y: } \\
\text { ankles, } \\
\text { feet }\end{array}$ & $\mathrm{N}$ \\
\hline Leg knobs? & $\begin{array}{l}Y: \\
\text { knees }\end{array}$ & $\mathrm{N}$ & $\begin{array}{l}\mathrm{Y:} \\
\text { ankles }\end{array}$ & $\begin{array}{l}\text { Y: } \\
\text { knees }\end{array}$ & $\begin{array}{l}\mathrm{Y}: \\
\text { knees, } \\
\text { ankles }\end{array}$ & $\begin{array}{l}\text { Y: } \\
\text { knees }\end{array}$ & $\mathrm{N}$ & $\begin{array}{l}\mathrm{Y}: \\
\text { knees, } \\
\text { ankles }\end{array}$ & $\mathrm{N}$ & $\mathrm{N}$ \\
\hline Feet? & $\mathrm{Y}$ & $\mathrm{N}$ & $\mathrm{Y}$ & $\mathrm{N}$ & $\begin{array}{l}\mathrm{Y} \\
\text { worn }\end{array}$ & $\mathrm{Y}$ & $\mathrm{Y}$ & $\mathrm{Y}$ & $\mathrm{Y}$ & $Y$ \\
\hline $\begin{array}{l}\text { Pounamu } \\
\text { variety? }\end{array}$ & KR & KK & $\mathrm{I}$ & KK & 1 & 1 & 1 & KK \& I & $T$ & KK \\
\hline $\begin{array}{l}\text { Pounamu } \\
\text { Source? }\end{array}$ & CW & $\mathrm{CW}$ & $\mathrm{A}, \mathrm{CW}$ & CW & TK, W & $\mathrm{A}, \mathrm{CW}$ & TK, W & $\mathrm{A}, \mathrm{CW}$ & $P$ & $\mathrm{CW}$ \\
\hline $\begin{array}{l}\text { Heat } \\
\text { treatment? }\end{array}$ & $\mathrm{N}$ & $Y$ & $\mathrm{~N}$ & $\mathrm{~N}$ & $\mathrm{~N}$ & $\mathrm{~N}$ & $\mathrm{~N}$ & $\mathrm{~N}$ & $\mathrm{~N}$ & $\mathrm{~N}$ \\
\hline $\begin{array}{l}\text { Surface } \\
\text { reground? }\end{array}$ & $\mathrm{N}$ & $?$ & $\mathrm{~N}$ & $\mathrm{~N}$ & $\mathrm{~N}$ & $\mathrm{~N}$ & $\mathrm{~N}$ & $\mathrm{~N}$ & $\mathrm{~N}$ & $\mathrm{~N}$ \\
\hline Wear: 0-10 & 3.0 & 2.0 & 3.0 & 8.0 & 7.0 & 8.0 & 8.0 & 1.0 & 8.0 & 8.5 \\
\hline Other & 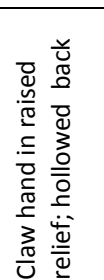 & 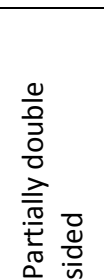 & & 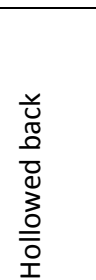 & 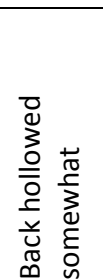 & & 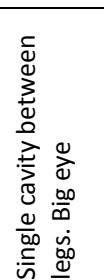 & 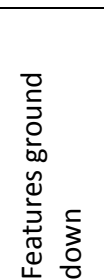 & 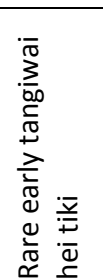 & 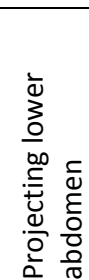 \\
\hline
\end{tabular}




\begin{tabular}{|c|c|c|c|c|c|c|c|c|c|c|}
\hline Study no. & 2.31 & 2.32 & 2.33 & 2.34 & 2.35 & 2.36 & 2.37 & 2.38 & 2.39 & 2.40 \\
\hline $\begin{array}{l}\text { Collection } \\
\text { number }\end{array}$ & $\begin{array}{l}\stackrel{0}{1} \\
\qquad \\
6 \\
-1 \\
\stackrel{4}{\Sigma}\end{array}$ & $\begin{array}{l}n \\
0 \\
0 \\
\varnothing \\
\varnothing\end{array}$ & 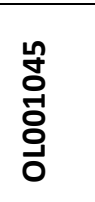 & 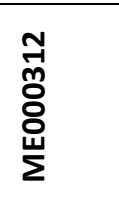 & 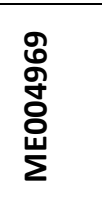 & 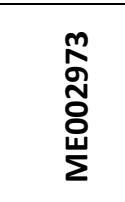 & 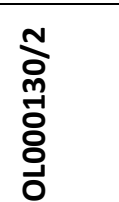 & 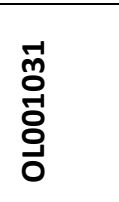 & 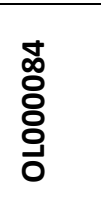 & $\begin{array}{l}\text { ஜ } \\
8 \\
\varnothing \\
\text { ठ }\end{array}$ \\
\hline $\begin{array}{l}\text { Outline } \\
\text { shape }\end{array}$ & $\mathrm{BC}$ & $\mathrm{C}$ & C & $\mathrm{C}$ & C & $\mathrm{C}$ & C & $\mathrm{C}$ & C & C \\
\hline $\begin{array}{l}\text { Type } \\
\text { (Webster) }\end{array}$ & I & I & I & II & I & II & II & I & 1 & I \\
\hline Length $\mathrm{mm}$ & 111 & 120 & 85 & 126 & 131 & 127 & 75 & 137 & 133 & 94 \\
\hline Width $\mathrm{mm}$ & 65 & 70 & 47 & 91 & 71 & 82 & 47 & 86 & 77 & 63 \\
\hline Depth mm & 19 & $?$ & 8 & 13 & 13 & 11 & 8.5 & 19 & 20 & 17 \\
\hline $\begin{array}{l}\text { Width \% of } \\
\text { length }\end{array}$ & 58 & 58 & 55 & 72 & 54 & 63 & 63 & 62 & 57 & 66 \\
\hline $\begin{array}{l}\text { Head \% of } \\
\text { length }\end{array}$ & 48 & 48 & 45 & 33 & 50 & 38 & 49 & 46 & 48 & 48 \\
\hline $\begin{array}{l}\text { Body \% of } \\
\text { length }\end{array}$ & 29 & 25 & 26 & 31 & 25 & 29 & 24 & 26 & 27 & 25 \\
\hline $\begin{array}{l}\text { Legs \% of } \\
\text { length }\end{array}$ & 23 & 27 & 29 & 36 & 25 & 33 & 27 & 28 & 24 & 27 \\
\hline $\begin{array}{l}\text { Head tilt: } \\
\text { Left or Right? }\end{array}$ & $R$ & $R$ & $R$ & $R$ & $\mathrm{R}$ & $\mathrm{R}$ & $\mathrm{R}$ & $\mathrm{R}$ & $R$ & $R$ \\
\hline $\begin{array}{l}\text { Degree of } \\
\text { head tilt }\end{array}$ & 45 & 45 & 45 & 65 & 45 & 50 & 35 & 45 & 45 & 50 \\
\hline $\begin{array}{l}\text { Extent head } \\
\text { pointed at } \\
\text { top: } 0-10\end{array}$ & 7.0 & 6.0 & 5.0 & 5.0 & 7.0 & 7.0 & 6.5 & 5.0 & 6.5 & 8.0 \\
\hline $\begin{array}{l}\text { Eyes large, } \\
\text { medium or } \\
\text { small? }\end{array}$ & $\mathrm{L}$ & $\mathrm{L}$ & $\mathrm{S}$ & $\mathrm{S}$ & $\mathrm{L}$ & $\mathrm{S}$ & $\mathrm{S}$ & $\mathrm{L}$ & $\mathrm{L}$ & $\mathrm{L}$ \\
\hline $\begin{array}{l}\text { Eye inlay? } \\
\text { (pāua, } \\
\text { sealing wax) }\end{array}$ & 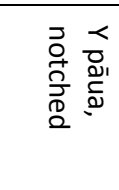 & 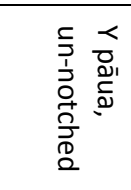 & $z$ & $z$ & $z$ & 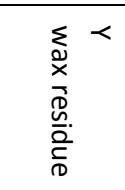 & $z$ & $z$ & 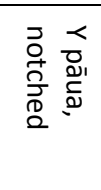 & $z$ \\
\hline $\begin{array}{l}\text { Secondary } \\
\text { eye rims? }\end{array}$ & $\mathrm{N}$ & $?$ & $\mathrm{~N}$ & $Y$ & $\mathrm{Y}$ & $\mathrm{N}$ & $\mathrm{N}$ & $Y$ & $\mathrm{~N}$ & $\mathrm{~N}$ \\
\hline Brows? & $Y$ & $Y$ & $Y$ & $?$ & $Y$ & $\begin{array}{l}\text { Y } \\
\text { worn }\end{array}$ & $Y$ & $Y$ & $Y$ & $Y$ \\
\hline $\begin{array}{l}\text { Forehead } \\
\text { ridge? }\end{array}$ & $Y$ & $Y$ & $\begin{array}{l}\mathrm{Y} \\
\text { worn }\end{array}$ & $\begin{array}{l}\text { Y } \\
\text { worn }\end{array}$ & $\mathrm{Y}$ & $\begin{array}{l}\text { Y } \\
\text { worn }\end{array}$ & $\mathrm{N}$ & $Y$ & $Y$ & $Y$ \\
\hline $\begin{array}{l}\text { Forking at } \\
\text { nose } \\
\text { bridge? }\end{array}$ & $\mathrm{Y}$ & $Y$ & $\begin{array}{l}Y \\
\text { worn }\end{array}$ & $Y$ & $\mathrm{Y}$ & $\begin{array}{l}\mathrm{Y} \\
\text { worn }\end{array}$ & $\mathrm{N}$ & $Y$ & $Y$ & $Y$ \\
\hline Nostrils? & $\begin{array}{l}\mathrm{Y} \\
\text { arched }\end{array}$ & $\begin{array}{l}\mathrm{Y} \\
\text { arched }\end{array}$ & $\begin{array}{l}\mathrm{Y} \\
\text { arched }\end{array}$ & $\begin{array}{l}? \\
\text { worn }\end{array}$ & $\begin{array}{l}Y \\
\text { uncon- } \\
\text { ventio } \\
\text { nal }\end{array}$ & $\begin{array}{l}Y \\
\text { type? }\end{array}$ & $\begin{array}{l}? \\
\text { worn }\end{array}$ & $\begin{array}{l}\mathrm{Y} \\
\text { arched }\end{array}$ & $\begin{array}{l}\mathrm{Y} \\
\text { arched }\end{array}$ & $\begin{array}{l}\mathrm{Y} \\
\text { arched }\end{array}$ \\
\hline
\end{tabular}




\begin{tabular}{|c|c|c|c|c|c|c|c|c|c|c|}
\hline $\begin{array}{l}\text { Ridge from } \\
\text { nostrils to } \\
\text { nose bridge? }\end{array}$ & $\mathrm{N}$ & $\mathrm{N}$ & $\begin{array}{l}? \\
\text { worn }\end{array}$ & ? & $Y$ & $\begin{array}{l}? \\
\text { worn }\end{array}$ & $\begin{array}{l}? \\
\text { worn }\end{array}$ & ? & ? & $\mathrm{N}$ \\
\hline $\begin{array}{l}\text { Heart } \\
\text { shaped } \\
\text { mouth? }\end{array}$ & $Y$ & $Y$ & $\mathrm{Y}$ & $Y$ & $Y$ & $Y$ & $Y$ & $Y$ & $Y$ & $Y$ \\
\hline $\begin{array}{l}\text { Mid upper } \\
\text { tooth? }\end{array}$ & $?$ & $Y$ & $\mathrm{Y}$ & $\mathrm{N}$ & $\mathrm{Y}$ & $\mathrm{N}$ & $Y$ & $Y$ & $?$ & $\mathrm{Y}$ \\
\hline $\begin{array}{l}\text { Corner } \\
\text { teeth? }\end{array}$ & $Y$ & $Y$ & $Y$ & $Y$ & $Y$ & $\mathrm{~N}$ & $Y$ & $Y$ & $Y$ & $\mathrm{Y}$ \\
\hline $\begin{array}{l}\text { Internal } \\
\text { tongue? }\end{array}$ & $Y$ & $\mathrm{~N}$ & $\mathrm{~N}$ & $\mathrm{~N}$ & $\begin{array}{l}? \\
\text { worn }\end{array}$ & $\mathrm{N}$ & $\mathrm{N}$ & $Y$ & $Y$ & $\mathrm{Y}$ \\
\hline $\begin{array}{l}\text { Tongue } \\
\text { against } \\
\text { corner } \\
\text { tooth? }\end{array}$ & $Y$ & $\mathrm{~N}$ & $\mathrm{~N}$ & $\mathrm{~N}$ & $\begin{array}{l}\text { ? } \\
\text { worn }\end{array}$ & $\mathrm{N}$ & $\mathrm{N}$ & $Y$ & $Y$ & $Y$ \\
\hline $\begin{array}{l}\text { Extended } \\
\text { tongue? }\end{array}$ & $\mathrm{N}$ & $Y$ & $\mathrm{~N}$ & $\mathrm{~N}$ & $\mathrm{~N}$ & $\mathrm{~N}$ & $Y$ & $\mathrm{~N}$ & $\mathrm{~N}$ & $\mathrm{~N}$ \\
\hline $\begin{array}{l}\text { Forked } \\
\text { tongue? }\end{array}$ & $\mathrm{N}$ & $\begin{array}{l}\text { ? } \\
\text { worn }\end{array}$ & $N$ & $N$ & $\begin{array}{l}\text { ? } \\
\text { worn }\end{array}$ & $\mathrm{N}$ & $\begin{array}{l}\text { ? } \\
\text { worn }\end{array}$ & $N$ & $\mathrm{~N}$ & $Y$ \\
\hline $\begin{array}{l}\text { Head } \\
\text { projections? }\end{array}$ & $\mathrm{N}$ & $\mathrm{N}$ & $\mathrm{N}$ & $\begin{array}{l}\text { Y: } \\
\text { ear, } \\
\text { chin }\end{array}$ & $\mathrm{N}$ & $\begin{array}{l}\text { Y: } \\
\text { ear, chin }\end{array}$ & $\begin{array}{l}\text { Y: } \\
\text { ears, } \\
\text { chin }\end{array}$ & $\mathrm{N}$ & $\mathrm{N}$ & $\mathrm{N}$ \\
\hline $\begin{array}{l}\text { Indicative } \\
\text { neck? }\end{array}$ & $\mathrm{Y}$ & $Y$ & $\mathrm{Y}$ & $\mathrm{N}$ & $\mathrm{Y}$ & $\mathrm{N}$ & $\mathrm{N}$ & $\mathrm{Y}$ & $Y$ & $\mathrm{Y}$ \\
\hline $\begin{array}{l}\text { Extended } \\
\text { neck? }\end{array}$ & $\mathrm{N}$ & $\mathrm{N}$ & $\mathrm{N}$ & $Y$ & $\mathrm{~N}$ & $Y$ & $Y$ & $\mathrm{~N}$ & $\mathrm{~N}$ & $\mathrm{~N}$ \\
\hline $\begin{array}{l}\text { Hunched } \\
\text { shoulder? }\end{array}$ & $\mathrm{N}$ & $\mathrm{N}$ & $\mathrm{N}$ & $\mathrm{Y}$ & $\mathrm{N}$ & $\mathrm{Y}$ & $\mathrm{Y}$ & $\mathrm{N}$ & $\mathrm{N}$ & $\mathrm{N}$ \\
\hline Forked ribs? & $\begin{array}{l}\text { Y: } 2 \text { per } \\
\text { side }\end{array}$ & $\begin{array}{l}\text { Y: } 1 \text { per } \\
\text { side }\end{array}$ & $\mathrm{N}$ & $\mathrm{N}$ & $\begin{array}{l}\text { Y: } 4 \\
\text { per } \\
\text { side }\end{array}$ & $\mathrm{N}$ & $\mathrm{N}$ & $\begin{array}{l}Y: 2 \\
\text { per side }\end{array}$ & $\begin{array}{l}? \\
\text { worn }\end{array}$ & $\mathrm{N}$ \\
\hline $\begin{array}{l}\text { Pattern } \\
\text { beneath } \\
\text { ribs? }\end{array}$ & $\mathrm{N}$ & $\mathrm{N}$ & $\mathrm{N}$ & $\mathrm{N}$ & $\mathrm{N}$ & $\mathrm{N}$ & $\mathrm{N}$ & $\begin{array}{l}\mathrm{Y}: \\
\text { diamond }\end{array}$ & $\mathrm{N}$ & $\mathrm{N}$ \\
\hline Vagina? & $\mathrm{N}$ & $Y$ & $Y$ & $N$ & $Y$ & $Y$ & $Y$ & $Y$ & $\mathrm{~N}$ & $\mathrm{~N}$ \\
\hline $\begin{array}{l}\text { Arms curve } \\
\text { out then in? }\end{array}$ & $\mathrm{Y}$ & $Y$ & $Y$ & $\mathrm{~N}$ & $Y$ & $\mathrm{~N}$ & $Y: 1$ & $Y$ & $Y$ & $\mathrm{Y}$ \\
\hline $\begin{array}{l}\text { Arms rest } \\
\text { on thighs? }\end{array}$ & $Y$ & $Y$ & $Y$ & $Y: 1$ & $Y$ & $Y: 1$ & $Y: 1$ & $Y$ & $Y$ & $Y$ \\
\hline $\begin{array}{l}\text { Hand to } \\
\text { chest or } \\
\text { mouth? }\end{array}$ & $\mathrm{N}$ & $\mathrm{N}$ & $\mathrm{N}$ & C: 1 & $\mathrm{~N}$ & $\mathrm{C}: 1$ & C: 1 & $\mathrm{~N}$ & $\mathrm{~N}$ & $\mathrm{~N}$ \\
\hline $\begin{array}{l}\text { Hands } \\
\text { worked? }\end{array}$ & $\mathrm{N}$ & $\mathrm{N}$ & $\mathrm{Y}$ & $\begin{array}{l}Y \\
\text { worn }\end{array}$ & $Y$ & $Y$ & $Y$ & $Y$ & $\mathrm{~N}$ & $\mathrm{~N}$ \\
\hline $\begin{array}{l}\text { Elbows } \\
\text { pointed and } \\
\text { /or lugged? }\end{array}$ & $P ; L$ & $P ; L$ & $P ; L$ & $P: 1 ; L: 1$ & $P ; L$ & P:1; L:1 & $P$ & $P ; L$ & $\mathrm{P} ; \mathrm{L}$ & $P ; L$ \\
\hline $\begin{array}{l}\text { Thighs: } \\
\text { rounded (0- } \\
\text { 4), straight } \\
\text { (6-10), or in- } \\
\text { between (5) }\end{array}$ & $\begin{array}{l}S \\
9.0\end{array}$ & $\begin{array}{l}S \\
9.0\end{array}$ & $\begin{array}{l}\mathrm{S} \\
9.0\end{array}$ & $\begin{array}{l}\mathrm{R} \\
1.0\end{array}$ & $\begin{array}{l}S \\
8.0\end{array}$ & $\begin{array}{l}R \\
1.0\end{array}$ & $\begin{array}{l}1 \\
5.0\end{array}$ & $\begin{array}{l}\mathrm{S} \\
9.0\end{array}$ & $\begin{array}{l}\mathrm{S} \\
8.5\end{array}$ & $\begin{array}{l}S \\
8.0\end{array}$ \\
\hline
\end{tabular}




\begin{tabular}{|c|c|c|c|c|c|c|c|c|c|c|}
\hline $\begin{array}{l}\text { Knees: } \\
\text { rounded (0- } \\
4) \text {, cornered } \\
(6-10) \text {, or in- } \\
\text { between (5) }\end{array}$ & $\begin{array}{l}C \\
7.0\end{array}$ & $\begin{array}{l}\mathrm{C} \\
8.5\end{array}$ & $\begin{array}{l}\mathrm{C} \\
7.5\end{array}$ & $\begin{array}{l}1 \\
0.5\end{array}$ & $\begin{array}{l}C \\
6.0\end{array}$ & $\begin{array}{l} \\
\\
0.5\end{array}$ & $\begin{array}{l}\mathrm{R} \\
1.0\end{array}$ & $\begin{array}{l}\mathrm{C} \\
9.0\end{array}$ & $\begin{array}{l}\mathrm{C} \\
7.5\end{array}$ & $\begin{array}{l}C \\
8.0\end{array}$ \\
\hline $\begin{array}{l}\text { Leg } \\
\text { projections? }\end{array}$ & $\mathrm{N}$ & $\begin{array}{l}\text { Y: } \\
\text { ankles }\end{array}$ & $\begin{array}{l}\mathrm{Y}: \\
\text { ankles }\end{array}$ & $\mathrm{N}$ & $\begin{array}{l}\text { Y: } \\
\text { feet }\end{array}$ & $\mathrm{N}$ & $\mathrm{N}$ & $\begin{array}{l}\text { Y: } \\
\text { ankles, } \\
\text { feet }\end{array}$ & $\mathrm{N}$ & $\mathrm{N}$ \\
\hline Leg knobs? & $\mathrm{N}$ & $\begin{array}{l}\text { Y: } \\
\text { knees }\end{array}$ & $\mathrm{N}$ & $\mathrm{N}$ & $\begin{array}{l}\text { Y: } \\
\text { knees }\end{array}$ & $N$ & $\mathrm{~N}$ & $\begin{array}{l}\mathrm{Y}: \\
\text { knees, } \\
\text { ankles }\end{array}$ & $N$ & $N$ \\
\hline Feet? & $Y$ & $Y$ & $Y$ & $Y$ & $Y$ & $Y$ & $Y$ & $Y$ & $\begin{array}{l}\text { Y: } 1 \\
\text { groove }\end{array}$ & $N$ \\
\hline $\begin{array}{l}\text { Pounamu } \\
\text { variety? }\end{array}$ & KK & KR \& KK & 1 & 1 & KK & 1 & KK & 1 & KK & 1 \\
\hline $\begin{array}{l}\text { Pounamu } \\
\text { Source? }\end{array}$ & $\mathrm{CW}$ & ? & ? & Inc. & $\mathrm{CW}$ & W & $\mathrm{CW}$ & $\mathrm{A}, \mathrm{CW}$ & ? & $\mathrm{CW}$ \\
\hline $\begin{array}{l}\text { Heat } \\
\text { treatment? }\end{array}$ & $N$ & ? & $\mathrm{N}$ & $Y$ & $\mathrm{~N}$ & $\mathrm{~N}$ & $\mathrm{~N}$ & $\mathrm{~N}$ & ? & $Y$ \\
\hline $\begin{array}{l}\text { Surface } \\
\text { reground? }\end{array}$ & $\mathrm{N}$ & $N$ ? & $\mathrm{N}$ & $Y$ & $N$ & $\mathrm{~N}$ & $N$ & $N$ & ? & $Y$ \\
\hline Wear: 0-10 & 2.0 & 3.0 & 4.0 & 4.0 & 3.0 & 5.5 & 7.5 & 0.0 & 5.0 & 6.0 \\
\hline Other & 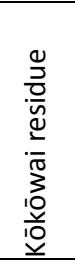 & 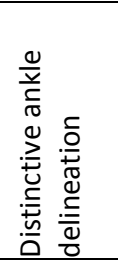 & 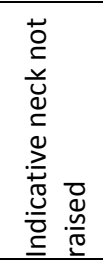 & 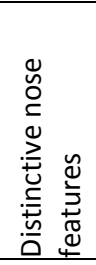 & 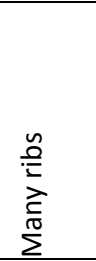 & 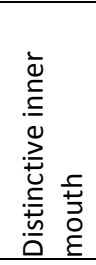 & & & & 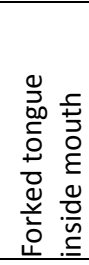 \\
\hline
\end{tabular}




\begin{tabular}{|c|c|c|c|c|c|c|c|c|c|c|}
\hline Study no. & 2.41 & 2.42 & 2.43 & 2.44 & 2.45 & 2.46 & 2.47 & 2.48 & 2.49 & 2.50 \\
\hline $\begin{array}{l}\text { Collection } \\
\text { number }\end{array}$ & 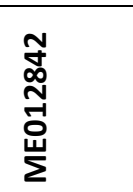 & $\begin{array}{l}m \\
\stackrel{m}{0} \\
\stackrel{0}{1} \\
\stackrel{\tilde{L}}{\Sigma}\end{array}$ & 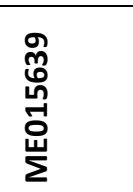 & 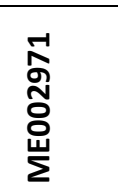 & $\begin{array}{l}\infty \\
0 \\
0 \\
0 \\
0\end{array}$ & 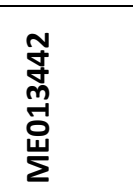 & 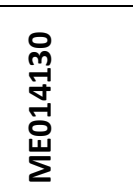 & $\begin{array}{l}\text { o̊ } \\
\text { ठे } \\
\text { ठ઼ }\end{array}$ & $\begin{array}{l}\text { ळ } \\
\text { ठे } \\
\text { ठ઼ }\end{array}$ & 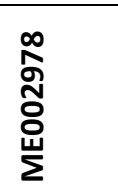 \\
\hline $\begin{array}{l}\text { Outline } \\
\text { shape }\end{array}$ & C & C & C & C & $C D$ & $C D$ & $\mathrm{D}$ & $\mathrm{D}$ & $\mathrm{D}$ & D \\
\hline $\begin{array}{l}\text { Type } \\
\text { (Webster) }\end{array}$ & 1 & $1 / I I$ & II & II & I & $1 / I I$ & 1 & 1 & 1 & 1 \\
\hline Length $\mathrm{mm}$ & 123 & 63 & 109 & 170 & 88 & 82 & 100 & 104 & 80 & 107 \\
\hline Width $\mathrm{mm}$ & 79 & 50 & 75 & 101 & 60 & 55 & 59 & 68 & 59 & 60 \\
\hline Depth $\mathrm{mm}$ & 20 & 7 & 11 & 16 & 13 & 9 & 14 & 10 & 11 & 10 \\
\hline $\begin{array}{l}\text { Width \% of } \\
\text { length }\end{array}$ & 64 & 78 & 70 & 59 & 68 & 67 & 60 & 64 & 73 & 57 \\
\hline $\begin{array}{l}\text { Head \% of } \\
\text { length }\end{array}$ & 51 & 44 & 43 & 40 & 46 & 45 & 48 & 50 & 45 & 49 \\
\hline $\begin{array}{l}\text { Body \% of } \\
\text { length }\end{array}$ & 22 & 24 & 26 & 30 & 28 & 26 & 27 & 23 & 24 & 22 \\
\hline $\begin{array}{l}\text { Legs } \% \text { of } \\
\text { length }\end{array}$ & 27 & 32 & 31 & 30 & 26 & 29 & 25 & 27 & 31 & 29 \\
\hline $\begin{array}{l}\text { Head tilt: } \\
\text { Left or Right }\end{array}$ & $\mathrm{L}$ & $\mathrm{L}$ & $R$ & $R$ & $R$ & $\mathrm{~L}$ & $R$ & $R$ & $R$ & $R$ \\
\hline $\begin{array}{l}\text { Degree of } \\
\text { head tilt }\end{array}$ & 45 & 60 & 55 & 45 & 45 & 60 & 45 & 45 & 45 & 45 \\
\hline $\begin{array}{l}\text { Extent head } \\
\text { pointed at } \\
\text { top: } 0-10\end{array}$ & 7.0 & 6.0 & 6.0 & 5.0 & 5.0 & 7.0 & 8.0 & 6.0 & 7.0 & 3.0 \\
\hline $\begin{array}{l}\text { Eyes large, } \\
\text { medium or } \\
\text { small? }\end{array}$ & $\mathrm{L}$ & $\mathrm{S}$ & $\mathrm{S}$ & $\mathrm{S}$ & $\mathrm{L}$ & $\mathrm{L}$ & $\mathrm{L}$ & $\mathrm{L}$ & $\mathrm{L}$ & $L$ \\
\hline $\begin{array}{l}\text { Eye inlay? } \\
\text { (pāua, } \\
\text { sealing wax) }\end{array}$ & 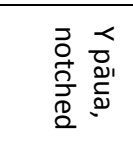 & $z$ & 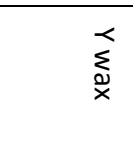 & $\underset{\substack{x \\
x}}{r}$ & $z$ & $z$ & $z$ & $z$ & $z$ & $\sum_{\substack{x \\
x}}^{<}$ \\
\hline $\begin{array}{l}\text { Secondary } \\
\text { eye rims? }\end{array}$ & $Y$ & $\mathrm{~N}$ & $\mathrm{~N}$ & $N$ & $\mathrm{Y}$ & $\mathrm{N}$ & $N$ & $\mathrm{~N}$ & $\mathrm{~N}$ & $\mathrm{~N}$ \\
\hline Brows? & $Y$ & $\mathrm{~N}$ & $Y$ & $\mathrm{Y}$ & $Y$ & $\mathrm{Y}$ & $Y$ & $Y$ & $Y$ & $\begin{array}{l}\mathrm{Y} \\
\text { worn }\end{array}$ \\
\hline $\begin{array}{l}\text { Forehead } \\
\text { ridge? }\end{array}$ & $\mathrm{Y}$ & $\mathrm{N}$ & $\mathrm{N}$ & $Y$ & $\mathrm{Y}$ & $\mathrm{N}$ & $\mathrm{Y}$ & $Y$ & $\mathrm{Y}$ & $\begin{array}{l}\mathrm{Y} \\
\text { worn }\end{array}$ \\
\hline $\begin{array}{l}\text { Forking at } \\
\text { nose bridge? }\end{array}$ & $Y$ & $\mathrm{~N}$ & $\mathrm{Y}$ & $\mathrm{Y}$ & $Y$ & $\mathrm{~N}$ & $\mathrm{Y}$ & $Y$ & $Y$ & ? \\
\hline Nostrils? & $\begin{array}{l}Y \\
\text { type? }\end{array}$ & $\begin{array}{l}Y \\
\text { arched }\end{array}$ & $\begin{array}{l}? \\
\text { worn } \\
\end{array}$ & $\begin{array}{l}\mathrm{Y} \\
\text { arched }\end{array}$ & $\begin{array}{l}? \\
\text { worn } \\
\end{array}$ & $\begin{array}{l}? \\
\text { worn }\end{array}$ & \begin{tabular}{|l|}
$\mathrm{Y}$ \\
arched \\
\end{tabular} & $\begin{array}{l}Y \\
\text { arched }\end{array}$ & $\begin{array}{l}? \\
\text { worn }\end{array}$ & $\begin{array}{l}\text { ? } \\
\text { worn }\end{array}$ \\
\hline $\begin{array}{l}\text { Ridge from } \\
\text { nostrils to } \\
\text { nose bridge? }\end{array}$ & $?$ & $\begin{array}{l}? \\
\text { worn }\end{array}$ & $\begin{array}{l}? \\
\text { worn }\end{array}$ & ? & $\begin{array}{l}? \\
\text { worn }\end{array}$ & $\begin{array}{l}? \\
\text { worn }\end{array}$ & $\mathrm{Y}$ & $\mathrm{N}$ & $?$ & $\begin{array}{l}? \\
\text { worn }\end{array}$ \\
\hline
\end{tabular}




\begin{tabular}{|c|c|c|c|c|c|c|c|c|c|c|}
\hline $\begin{array}{l}\text { Heart } \\
\text { shaped } \\
\text { mouth? }\end{array}$ & $\mathrm{Y}$ & $Y$ & $Y$ & $Y$ & $Y$ & $Y$ & $Y$ & $Y$ & $Y$ & $\mathrm{Y}$ \\
\hline $\begin{array}{l}\text { Mid upper } \\
\text { tooth? }\end{array}$ & $Y$ & $\mathrm{~N}$ & $\mathrm{~N}$ & $Y$ & $N$ & $\mathrm{~N}$ & $Y$ & $\begin{array}{l}? \\
\text { worn }\end{array}$ & $\mathrm{Y}$ & \begin{tabular}{|l|}
$?$ \\
worn
\end{tabular} \\
\hline $\begin{array}{l}\text { Corner } \\
\text { teeth? }\end{array}$ & $Y$ & $\mathrm{~N}$ & $\mathrm{~N}$ & $Y$ & $\mathrm{Y}$ & $\mathrm{N}$ & $Y$ & $\mathrm{Y}$ & $Y$ & $\mathrm{Y}$ \\
\hline $\begin{array}{l}\text { Internal } \\
\text { Tongue? }\end{array}$ & $\begin{array}{l}? \\
\text { worn }\end{array}$ & $N$ & $\mathrm{~N}$ & $\mathrm{~N}$ & $N$ & $N$ & $N$ & $\begin{array}{l}? \\
\text { worn }\end{array}$ & $\mathrm{N}$ & \begin{tabular}{|l}
$?$ \\
worn
\end{tabular} \\
\hline $\begin{array}{l}\text { Tongue } \\
\text { against cnr } \\
\text { tooth? }\end{array}$ & $\begin{array}{l}? \\
\text { worn }\end{array}$ & $\mathrm{N}$ & $\mathrm{N}$ & $\mathrm{N}$ & $\mathrm{N}$ & $\mathrm{N}$ & $\mathrm{N}$ & $\begin{array}{l}? \\
\text { worn }\end{array}$ & $\mathrm{N}$ & $\begin{array}{l}? \\
\text { worn }\end{array}$ \\
\hline $\begin{array}{l}\text { Extended } \\
\text { tongue? }\end{array}$ & $\mathrm{N}$ & $\mathrm{N}$ & $Y$ & $\mathrm{Y}$ & $Y$ & $Y$ & $\mathrm{~N}$ & $\mathrm{~N}$ & $\mathrm{~N}$ & \begin{tabular}{|l|}
$?$ \\
worn
\end{tabular} \\
\hline $\begin{array}{l}\text { Forked } \\
\text { tongue? }\end{array}$ & $\begin{array}{l}\text { ? } \\
\text { worn }\end{array}$ & $\mathrm{N}$ & $\begin{array}{l}\text { ? } \\
\text { worn }\end{array}$ & $\mathrm{Y}$ & $Y$ & $\begin{array}{l}\text { ? } \\
\text { worn }\end{array}$ & $\mathrm{N}$ & $\begin{array}{l}\text { ? } \\
\text { worn }\end{array}$ & $\mathrm{N}$ & \begin{tabular}{|l|}
$?$ \\
worn
\end{tabular} \\
\hline $\begin{array}{l}\text { Head } \\
\text { projections? }\end{array}$ & $\mathrm{N}$ & $\begin{array}{l}\mathrm{Y}: \\
\text { chin }\end{array}$ & $\begin{array}{l}Y: \\
\text { ears, } \\
\text { chin }\end{array}$ & $\begin{array}{l}Y: \\
\text { ears, } \\
\text { chin }\end{array}$ & $\mathrm{N}$ & $\begin{array}{l}\text { Y: } \\
\text { ear, chin }\end{array}$ & $\mathrm{N}$ & $\mathrm{N}$ & $\mathrm{N}$ & $\mathrm{N}$ \\
\hline $\begin{array}{l}\text { Indicative } \\
\text { neck? }\end{array}$ & $\mathrm{Y}$ & $\mathrm{N}$ & $\mathrm{N}$ & $\mathrm{N}$ & $Y$ & $\mathrm{~N}$ & $Y$ & $Y$ & $Y$ & $\mathrm{Y}$ \\
\hline $\begin{array}{l}\text { Extended } \\
\text { neck? }\end{array}$ & $\mathrm{N}$ & $Y$ & $Y$ & $Y$ & $\mathrm{~N}$ & $Y$ & $\mathrm{~N}$ & $\mathrm{~N}$ & $\mathrm{~N}$ & $N$ \\
\hline $\begin{array}{l}\text { Hunched } \\
\text { shoulder? }\end{array}$ & $\mathrm{N}$ & $\mathrm{N}$ & $Y$ & $Y$ & $\mathrm{~N}$ & $\mathrm{~N}$ & $\mathrm{~N}$ & $\mathrm{~N}$ & $N$ & $N$ \\
\hline Forked ribs? & $\begin{array}{l}\text { Y: } 2 \text { per } \\
\text { side }\end{array}$ & $\begin{array}{l}\text { Y: } 1 \\
\text { per } \\
\text { side } \\
\text { (groov } \\
\text { es) }\end{array}$ & $\mathrm{N}$ & $\mathrm{N}$ & $\mathrm{N}$ & $\mathrm{N}$ & $\begin{array}{l}\text { Y: } 1 \text { per } \\
\text { side }\end{array}$ & $\begin{array}{l}\text { Y: } 2 \text { per } \\
\text { side }\end{array}$ & $\mathrm{N}$ & $\begin{array}{l}\text { Y: } 1 \text { per } \\
\text { side }\end{array}$ \\
\hline $\begin{array}{l}\text { Pattern } \\
\text { beneath } \\
\text { ribs? }\end{array}$ & $\mathrm{N}$ & $\mathrm{N}$ & $\mathrm{N}$ & $\mathrm{N}$ & $\mathrm{N}$ & $\mathrm{N}$ & $\mathrm{N}$ & $\mathrm{N}$ & $\mathrm{N}$ & $N$ \\
\hline Vagina? & $Y$ & $\mathrm{~N}$ & $\mathrm{Y}$ & $Y$ & $Y$ & $\mathrm{~N}$ & $\mathrm{~N}$ & $Y$ & $\mathrm{~N}$ & $N$ \\
\hline $\begin{array}{l}\text { Arms curve } \\
\text { out then in? }\end{array}$ & $Y$ & $Y$ & $\mathrm{~N}$ & $N$ & $Y$ & $Y$ & $Y$ & $Y$ & $Y$ & $\mathrm{Y}$ \\
\hline $\begin{array}{l}\text { Arms rest on } \\
\text { thighs? }\end{array}$ & $Y$ & $Y$ & $Y: 1$ & $Y: 1$ & $Y$ & $\mathrm{Y}$ & $Y$ & $Y$ & $\mathrm{Y}$ & $\mathrm{Y}$ \\
\hline $\begin{array}{l}\text { Hand to } \\
\text { chest or } \\
\text { mouth? }\end{array}$ & $\mathrm{N}$ & $\mathrm{N}$ & C: 1 & C: 1 & $N$ & $\mathrm{~N}$ & $\mathrm{~N}$ & $\mathrm{~N}$ & $\mathrm{~N}$ & $N$ \\
\hline $\begin{array}{l}\text { Hands } \\
\text { worked? }\end{array}$ & $\mathrm{Y}$ & ? & $Y$ & $Y$ & $Y$ & $Y$ & $\mathrm{~N}$ & $Y: 1$ & $\mathrm{~N}$ & $N$ \\
\hline $\begin{array}{l}\text { Elbows } \\
\text { pointed and } \\
\text { /or lugged? }\end{array}$ & $P ; L$ & $P$ & $P: 1 ; L: 1$ & $P: 1 ; L: 2$ & $P$ & $P ; L$ & $P ; L$ & $P ; L$ & $P ; L$ & $P ; L$ \\
\hline $\begin{array}{l}\text { Thighs: } \\
\text { rounded (0- } \\
\text { 4), straight } \\
\text { (6-10), or in- } \\
\text { between (5) }\end{array}$ & $\begin{array}{l}\mathrm{S} \\
9.0\end{array}$ & $\begin{array}{l}S \\
7.0\end{array}$ & $\begin{array}{l}S \\
7.0\end{array}$ & $\begin{array}{l}\mathrm{R} \\
0.0\end{array}$ & $\begin{array}{l}S \\
8.0\end{array}$ & $\begin{array}{l} \\
9.5\end{array}$ & $\begin{array}{l}\mathrm{S} \\
9.0\end{array}$ & $\begin{array}{l}\mathrm{S} \\
10.0\end{array}$ & $\begin{array}{l}S \\
9.0\end{array}$ & $\begin{array}{l}S \\
9.5\end{array}$ \\
\hline
\end{tabular}




\begin{tabular}{|c|c|c|c|c|c|c|c|c|c|c|}
\hline $\begin{array}{l}\text { Knees: } \\
\text { rounded (0- } \\
4) \text {, cornered } \\
(6-10) \text {, or in- } \\
\text { between (5) }\end{array}$ & $\begin{array}{l}C \\
8.0\end{array}$ & $\begin{array}{l}R \\
1.0\end{array}$ & $\begin{array}{l}R \\
1.0\end{array}$ & $\begin{array}{l}R \\
1.0\end{array}$ & $\begin{array}{l}C \\
7.5\end{array}$ & $\begin{array}{l}\mathrm{C} \\
9.0\end{array}$ & $\begin{array}{l}\mathrm{C} \\
8.0\end{array}$ & $\begin{array}{l}\mathrm{C} \\
9.5\end{array}$ & $\begin{array}{l}C \\
8.0\end{array}$ & $\begin{array}{l}\mathrm{C} \\
8.5\end{array}$ \\
\hline $\begin{array}{l}\text { Leg } \\
\text { projections? }\end{array}$ & $\mathrm{N}$ & $\mathrm{N}$ & $\mathrm{N}$ & $\mathrm{N}$ & $\mathrm{N}$ & $\begin{array}{l}\mathrm{Y}: \\
\text { ankles }\end{array}$ & $N$ & ? & $\mathrm{N}$ & $N$ \\
\hline Leg knobs? & $\mathrm{N}$ & $N$ & $\mathrm{~N}$ & $\begin{array}{l}\mathrm{Y}: \\
\text { ankles }\end{array}$ & $\begin{array}{l}\mathrm{Y}: \\
\text { knees }\end{array}$ & Y: knees & $N$ & Y: knees & $\mathrm{N}$ & $N$ \\
\hline Feet? & $Y$ & $Y$ & $Y$ & $Y$ & $\bar{Y}$ & $Y$ & $\mathrm{~N}$ & $Y$ & $\mathrm{~N}$ & $\begin{array}{l}Y \\
\text { groove }\end{array}$ \\
\hline $\begin{array}{l}\text { Pounamu } \\
\text { variety? }\end{array}$ & 1 & KK & 1 & 1 & KR & 1 & 1 & 1 & 1 & 1 \\
\hline $\begin{array}{l}\text { Pounamu } \\
\text { Source? }\end{array}$ & $\mathrm{A}, \mathrm{CW}$ & CW & $\mathrm{A}, \mathrm{CW}$ & A, CW & $\mathrm{CW}$ & CW & $\mathrm{CW}$ & CW & Inc. & $\mathrm{A}, \mathrm{CW}$ \\
\hline $\begin{array}{l}\text { Heat } \\
\text { treatment? }\end{array}$ & $\mathrm{N}$ & $\mathrm{N}$ & $\mathrm{N}$ & $\mathrm{N}$ & $N$ & $N$ & $\mathrm{~N}$ & $\mathrm{~N}$ & $Y$ & $N$ \\
\hline $\begin{array}{l}\text { Surface } \\
\text { reground? }\end{array}$ & $\mathrm{N}$ & $\mathrm{N}$ & $\mathrm{N}$ & $\mathrm{N}$ & $N$ & $\mathrm{~N}$ & $\mathrm{~N}$ & $\mathrm{~N}$ & $Y$ & $N$ \\
\hline Wear: 0-10 & 5.0 & 8.0 & 6.0 & 0.0 & 8.0 & 7.0 & 5.0 & 3.0 & 8.0 & 8.5 \\
\hline Other & 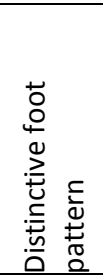 & & & 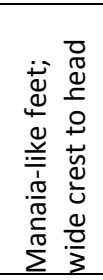 & 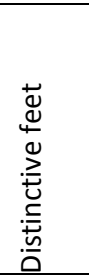 & & & 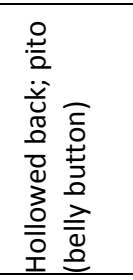 & & 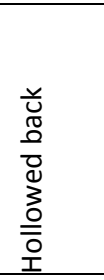 \\
\hline
\end{tabular}




\section{References}

\section{Bibliography (books, articles and papers):}

Anderson, A., 1998. The Welcome of Strangers: An ethnohistory of southern Maori A.D.16501850: University of Otago Press.

Anderson, A., 2008. A Migration History. In Te Maire Tau and Atholl Anderson (eds), Ngāi Tahu: A Migration History: The Carrington Text. Wellington: Bridget Williams Books in association with Te Rūnanga O Ngāi Tahu, pp.20-37.

Archey, G., 1933. Evolution Of Certain Maori Carving Patterns. Journal of the Polynesian Society, 42:171-190.

Archey, G., 1936. Maori Carving-Patterns. Journal of the Polynesian Society, 45:49-62.

Barrow, T., 1961. Two hei tiki-matau Amulets. Journal of the Polynesian Society, 70:353.

Barrow, T., 1962. An Experiment in Working Nephrite. Journal of the Polynesian Society, $71: 254$.

Barrow, T., 1964. The Decorative Arts of the New Zealand Maori. Wellington and Auckland: Reed.

Beattie, H., 1994. Traditional Lifeways Of The Southern Maori: the Otago University Museum ethnological project, 1920. A. Anderson (ed.), Dunedin: University of Otago Press in association with Otago Museum.

Beck, R.J., with Maika Mason, 2002. Mana Pounamu: New Zealand Jade. Birkenhead, Auckland: Reed Publishing (NZ) Ltd.

Beck, R.J., with Maika Mason, 2010. Pounamu: the jade of New Zealand. North Shore, Auckland: Penguin Group (NZ).

Best, E., 1912. The Stone Implements of the Maori. Wellington: Dominion Museum Bulletin, No. 4, 1912.

Best, E., 1914. Ceremonial Performances Pertaining To Birth, As Performed By The Maori Of New Zealand In Past Times. The Journal of the Royal Anthropological Institute, 154:127-131.

Best, E., 1924. The Maori As He Was. Wellington: Government Printer.

Brown, D., 2003. Tai Tokerau Whakairo Rākau: Northland Māori Wood Carving. Birkenhead, Auckland: Reed Publishing (NZ) Ltd. 
Chapman, F.R., 1891. On the Working of Greenstone or Nephrite by the Maoris.

Transactions of the New Zealand Institute, 24:479-539.

Day, K., 2001. Māori Wood Carving of the Taranaki Region. Birkenhead, Auckland: Reed Publishing (NZ) Ltd.

Davidson, J., 1984. The Prehistory of New Zealand. Auckland: Longman Paul Limited.

Davidson, J., 1996. Maori Prehistory. In Starzecka (ed.), 1996. pp.8-25.

Edge-Partington, J., 1996. In B.L. Miller (ed.), Ethnographical album of the Pacific islands. Bangkok: SDI Publications. $2^{\text {nd }}$ edn.

Furey, L., 1996. Oruarangi: The archaeology and material culture of a Hauraki pa. Bulletin Of The Auckland Institute And Museum, No. 17, 1996.

Gell, A., 1998. Art And Agency: An Anthropological Theory. Oxford: Clarendon Press.

Grey, George, 1854. Ko Nga Mahinga A Nga Tupuna Maori. London: George Willis.

Grey, George, 1855a. Polynesian Mythology And Ancient Traditional History Of The New Zealand Race. Albemarle Street, London: John Murray. $1^{\text {st }}$ edn.

Grey, George, 1885b. Polynesian Mythology And Ancient Traditional History Of The New Zealand Race. Auckland: H. Brett, Evening Star Office. $2^{\text {nd }}$ edn.

Golson, J., 1959. Culture Change in Prehistoric New Zealand. In J.D. Freeman and W.R. Geddes (eds), Anthropology in the South Seas. New Plymouth: Avery, 29-74.

Groube, L.M., 1967. A Note On The Hei-Tiki. Journal of the Polynesian Society, 76:453-458. Groube, L.M., 1969. From Archaic To Classic Maori. Auckland Student Geographer, 6:1-11. Hakiwai, A., 1996. Maori Society Today. In Starzecka (ed.), 1996. pp.50-68.

Hawkesworth, J., 1775. An Account of the Voyages undertaken by the order of His Present Majesty, for making Discoveries in the Southern Hemisphere, and successively performed by Commodore Byron, Captain Wallis, Captain Carteret, and Captain Cook, in the Dolphin, the 
Swallow, and the Endeavour: Drawn from the Journals which were kept by the several Commanders, and from the Papers of Joseph Banks, Esq. Vol.2, Dublin: James Williams. Heaphy, C., 1904. A Visit to the Greenstone Country. Part II. In New Zealand Illustrated Magazine. 1 November 1904, Auckland: p.97.

Hiroa, Te Rangi, 1950. The Coming of the Maori. Wellington: Whitcombe \& Tombs. $2^{\text {nd }}$ edn. Irwin, G., 2004. Kohika, The Archaeology Of A Late Maori Lake Village In The Ngati Awa Rohe Bay Of Plenty New Zealand. Auckland: Auckland University Press.

Jacob, C., R. Walter and C. Jennings, 2010. Review Of The Archaeology Of Foveaux Strait, New Zealand. Journal of the Polynesian Society, 119:25-59.

Kaeppler, A.L., 1978. "Artificial Curiosities": being An Exposition of Native Manufacturers Collected on the Three Pacific Voyages of Captain James Cook, R.N. Honolulu, Hawaii: Bishop Museum Press.

Kaeppler, A.L., 2011. Holophusicon The Leverian Museum. An Eighteenth Century English Institution of Science, Curiosity, and Art. Altenstadt, Germany: ZKF Publishers.

Kidwell, C.S., and Velie, A., 2005. Native American Studies. United Kingdom: Edinburgh University Press.

Ling Roth, H., 1891. Crozet's Voyage to Tasmania, New Zealand and the Ladrone Islands, and the Philippines in the Years 1771-1772. Oxford Street, London: Truslove \& Shirley.

Lockerbie, Leslie, 1959. From Moa-Hunter to Classic Maori in Southern New Zealand. In J.D. Freeman and W.R. Geddes (eds), Anthropology in the South Seas. New Plymouth: Avery, 9093.

Makereti, 1986. The old-time Maori. Auckland: New Women's Press.

Mallon, S., 2010. Against Tradition. In T. Wesley-Smith (ed.), The Contemporary Pacific. Honolulu: University of Hawai'i Press, 22 (2):362-381. 
Mataira, K., 1983. Negative and Positive Influences in the Development of Oceanic Art. In S. Mead and B. Kernot (eds), Art and Artists of Oceania. Palmerston North: The Dunmore Press, 80-87.

Mead, S.M., 1984. Nga Timatanga Me Nga Paringa O Te Mana Maori The Ebb and Flow of Mana Maori and the Changing Context of Maori Art. In S.M. Mead (ed.), Te Maori: Maori Art from New Zealand Collections. Auckland: Heinemann Publishers (NZ) Ltd, 20-36.

Mead, H.M., 2003. Tikanga Māori Living by Māori Values. Wellington: Huia Publishers. Milligan, R.R.D., 1958. Ranginui, Captive Chief of Doubtless Bay, 1769. Journal of the Polynesian Society, 67:194, Plates 1 \& 2.

Neich, R., 1997. Pounamu: Maori Jade Of New Zealand. Auckland: David Bateman Ltd. Oldman, W.O., et al, 2004. The Oldman Collection of Maori Artifacts. New Edition of Polynesian Society Memoir 14.

Orbell, M., 1995. The Illustrated Encyclopedia Of Maori Myth and Legend. Christchurch: Canterbury University Press.

Orchiston, D.W., 1972a. Maori Neck and Ear ornaments of the 1770's: a Study in Protohistoric Ethno-Archaeology. Journal of the Royal Society of New Zealand, 2 (1):91-107.

Orchiston, D.W., 1972b. Maori greenstone pendants in the Australian Museum, Sydney. In Records of the Australian Museum, 28:pp.161-213.

Phillips, W.J., 1966. Maori Life and Custom. Wellington: Reed.

Polack, J.S., 1838. New Zealand: Being a Narrative of Travels and Adventures During a Residence in that Country Between the Years 1831 and 1837. Vol.1. New Burlington Street, London: Richard Bentley.

Prickett, N., 1999. Nga Tohu Tawhito: Early Maori Ornaments. Albany, Auckland: David Bateman Ltd.

Reed, A.W., 2004. Reed Book of Māori Mythology. Auckland: Reed Publishing (NZ) Ltd. 
Robley, H.G., 1915. Pounamu, Notes on New Zealand Greenstone. London: T.J.S. Guildford \& Co. Ltd.

Salmond, A., 1991. Two worlds: first meetings between Maori and Europeans, $1642-1772$. Auckland: Viking.

Salmond, A., 1997. Between worlds: early exchanges between Maori and Europeans, 1773 1815. Auckland: Penguin Books (NZ) Ltd.

Savage, John, 1807. Some Account of New Zealand. London: Union Printing Office.

Simmons, D.R., 1965. Perspectives in Maori Carving. In Landfall, 19 (2):pp.143-148.

Simmons, D.R., 1966a. The Sources Of Sir George Grey's Nga Mahi A Nga Tupuna. Journal of the Polynesian Society, 75 (2):177-188.

Simmons, D.R., 1966b. Appendix Other Tiki In Otago Museum. In Skinner, H.D., 1966, The Maori Hei-Tiki. Otago Museum Trust Board. $2^{\text {nd }}$ edn. Dunedin: pp.16-29.

Skinner, H.D., 1916. Evolution In Maori Art. - Pendants. Journal of the Royal Anthropological Institute, 46:309-321.

Skinner, H.D., 1932. Maori Amulets In Stone, Bone, And Shell. Journal of the Polynesian Society, 41:202-211.

Skinner, H.D., 1933. The Making of Mere-pounamu and Hei-tiki. Journal of the Polynesian Society, 42:31.

Skinner, H.D., 1935. Maori Amulets in Stone, Bone, and Shell. Journal of the Polynesian Society, 44:19-22.

Skinner, H.D., 1940. The Maori Hei-Tiki. Dunedin: Coulls Somerville Wilkie Ltd. $1^{\text {st }}$ edn. Skinner, H.D., 1959. Murdering Beach Collecting and Excavating, The First Phase: 1850 1950. Journal of the Polynesian Society, 68:219-238.

Skinner, H.D., with D.R. Simmons, 1966. The Maori Hei-Tiki. Dunedin: Otago Museum Trust Board. $2^{\text {nd }}$ edn. 
Skinner, H.D., 1974. Comparatively Speaking: Studies in Pacific Material Culture 1921 1972. Dunedin: University of Otago Press.

Smith, L.T., 1999. Decolonizing Methodologies: Research and Indigenous Peoples. London: Zed Books.

Starzecka, D.C. (ed.), 1996. Maori Art And Culture. London: British Museum Press.

Tamarapa, A., 2002. Anaru Rondon in conversation with Awhina Tamarapa. In H. Smith (ed.), Taiāwhio Conversations With Contemporary Māori Artists. Wellington: Te Papa Press, pp.154-165.

Te Awekotuku, N., 1996. Maori: People and Culture. In Starzecka (ed.), 1996. pp.26-49.

Thacker, M., 1960. Excavations at Pa Bay, Banks Peninsula. New Zealand Archaeological Association Newsletter, 4 (1):8-12.

Trotter, M., and B. McCulloch, 1971. Prehistoric Rock Art Of New Zealand. Wellington: A.H. \& A.W. Reed Ltd.

Webster, K.A., 1948. The Armytage collection of Maori jade. London: Cable Press.

Wilkes, C., 1845. Narrative Of The United States Exploring Expedition. During The Years 1838, 1839, 1840, 1841, 1842. Vol.1, London: Wiley and Putnam.

Wood, P., 2012. Oceanic art and 'curiosity'. In E. Barker (ed.), Art \& Visual Culture 16001850. London: Tate Publishing in association with The Open University, plate 7.25.

Thesis:

Groube, L.M., 1964. Settlement Patterns in Prehistoric New Zealand. Unpublished M.A. thesis, Anthropology, University of Auckland.

Jahnke, R.H.G., 2006. He Tataitanga Ahua Toi, the house that Riwai built / a continuum of Maori art. Ph.D. thesis, Palmerston North: Massey University.

Price, L.K., 1994. H.D. Skinner as teacher: defining the paradigms in his teaching at the University of Otago 1919-1952. Unpublished M.A. thesis, Anthropology, University of Otago. 
Wards, I., 2009. The Collecting of H.D. Skinner: A Cook Islands case study. Unpublished M.A. thesis, University of Otago.

Watt, R.J. 1990. The Fake Maori Artefacts Of James Edward Little And James Frank Robieson. Unpublished Ph.D. thesis, Victoria University of Wellington.

\section{Websites:}

Barnes, Helen Moewaka, 2000. Kaupapa maori: explaining the ordinary. University of Auckland. [Accessed 2014]. Available from:

http://www.kaupapamaori.com/assets//explaining the ordinary.pdf

Bonica, Dante, 2009. Pounamu Tools. Dante Bonica, an expert in stone tools, demonstrates the effectiveness of pounamu tools. Kura Pounamu Treasured stone of Aotearoa New Zealand. [Accessed 5 December 2013]. Available from:

http://collections.tepapa.govt.nz/exhibitions/pounamu/PounamuTools.html

Heaphy, C., 1 November 1904. A Visit to the Greenstone Country. Part II. New Zealand Illustrated Magazine. Auckland: 97. [Accessed 5 December 2013]. Available from:

http://paperspast.natlib.govt.nz/cgi-bin/paperspast?a=d\&d=NZI19041101.2.5\&l=mi\&e=------10--1----0--

Innes, R.A., 2004. American Indian Studies Research is Ethical Research: A Critique of Linda Smith's Decolonizing Methodologies. The Graduate School: The University of North Carolina at Chapel Hill. [Accessed 5 December 2013]. Available from:

http://gradschool.unc.edu/studentlife/diversity/newdirections/2004/panels/innes.html

Museum of New Zealand Te Papa Tongarewa, 2009. Kura Pounamu Treasured Stone of Aotearoa New Zealand. [Accessed 5 December 2013]. Available from:

http://collections.tepapa.govt.nz/exhibitions/pounamu/PounamuWall.aspx

Ratner, Carl, 2000. Agency and Culture. Journal for The Theory of Social Behaviour, 30:413434. [Accessed 2014]. Available from:

http://lchc.ucsd.edu/mca/Paper/00 01/agency.htm 
Robson, John, 2013. John Davall Burr ( 1746-1783). Captain Cook Society. [Accessed 5 December 2013]. Available from:

http://www.captaincooksociety.com/home/detail/1059/john-davall-burr-1746-1783

Royal, Te Ahukaramu Charles, 2012. Hawaiki - The significance of Hawaiki. Te Ara - the Encyclopedia of New Zealand, updated 22-Sep-12. [Accessed 5 December 2013]. Available from: http://www.teara.govt.nz/en/hawaiki/page-1

Schwäbisches Tagblatt, 8 August 2013. Ein Poupou für das Raritätenkabinett. [Accessed 2014]. Available from: http://www.uni-tuebingen.de/museum-schloss/schatzAugust.pdf

Science in the News, 1998. Maori carving should come home, says professor. The Royal Society of New Zealand, posted 4-May-98. [Accessed 5 December 2013]. Available from: http://www.royalsociety.org.nz/1998/05/04/maori-carving-should-come-home-saysprofessor/

The British Museum. Tiki belonging to Captain Cook. Trustees of the British Museum. [Accessed 5 December 2013]. Available from:

http://www.britishmuseum.org/explore/highlights/highlight objects/loan in/t/tiki belongi $\underline{\text { ng to captain cook.aspx }}$

\section{Unpublished sources:}

Belcher, P., 2005. Hei Tiki. Eastern Institute of Technology, Hawkes Bay

Te Papa collection accession record, 1912. Acquisition - Donation; Lord St Oswald.

\section{Personal correspondence:}

Anderson, Atholl, Personal Correspondence, 26 June 2013

Beck, Russell, Personal Correspondence, 20 October 2013

Davidson, Janet, Personal Correspondence, 26 May 2013

Rondon, Ānaru, Personal Correspondence, 20 September 2013 